PRISM THERMAL-HYDRAULIC (FORCED AND NATURAL CONVECTION) COMPLETE IN-VESSEL-MODEL PERFORMANCE TESTS:

PHASE I AND PHASE II

by

J. J. Oras and K. E. Kasza

\author{
Materials and Components Technology Division \\ Argonne National Laboratory \\ 9700 South Cass Avenue \\ Argonne, Illinois 60439
}

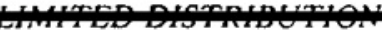

This 1 ULPRISM-TM series provides the documentation of results for thentiv

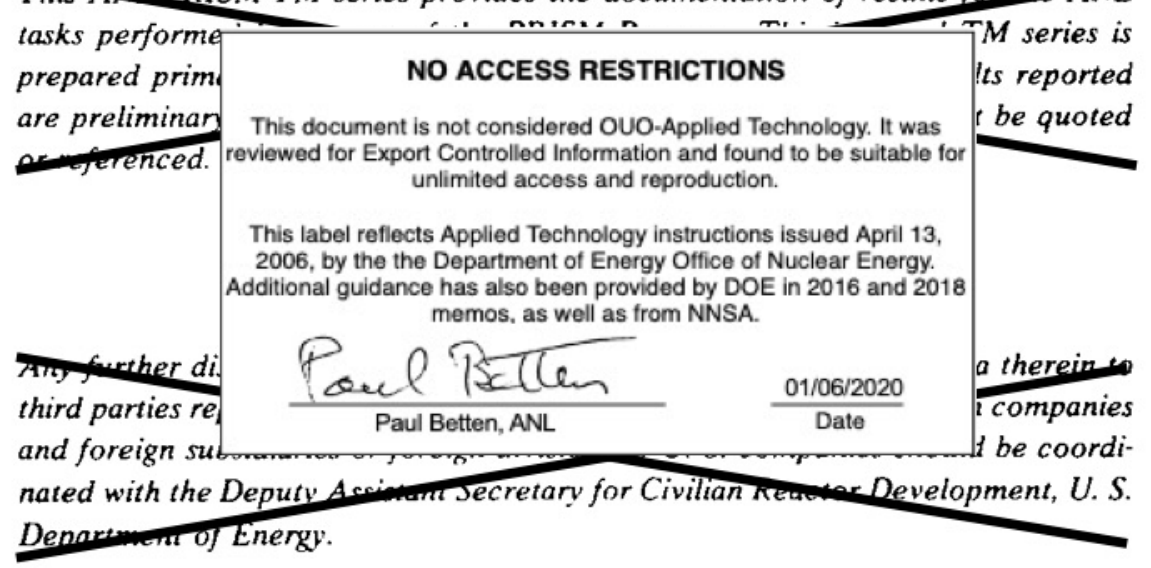




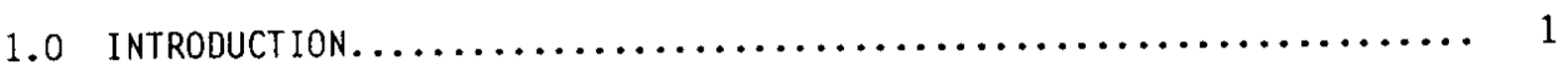

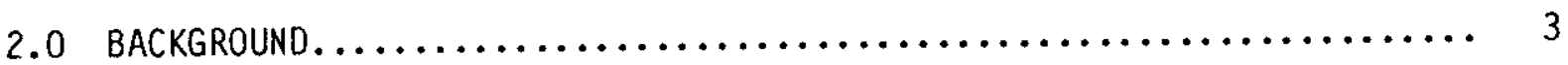

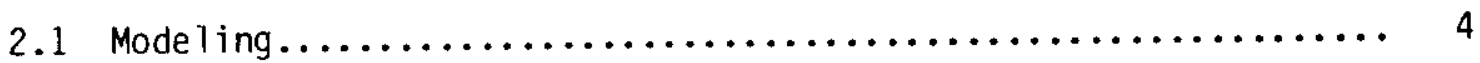

2.1 .1 General Similarity......................... 5

2.1 .2 PRISM Similarity................................ 6

2.2 Model Description. ............................ 9

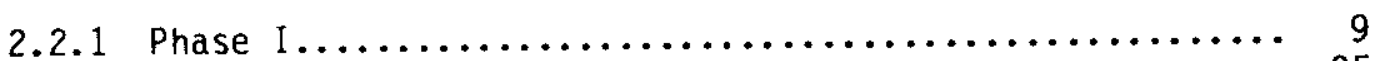

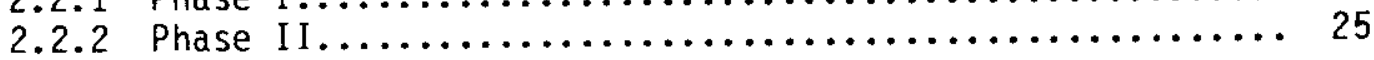

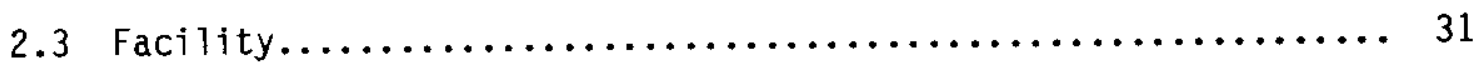

2.3 .1 Description of MCTF...................... 31

2.3.1.1 Steady-State Mode................... 34

2.3.1.2 Transient Computer-Controlled Mode.......... 34

2.3.2 Advanced Reactor Test Center................. 37

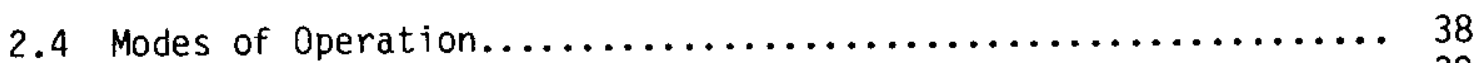

2.5 Prototype Transients of Interest.................... 39

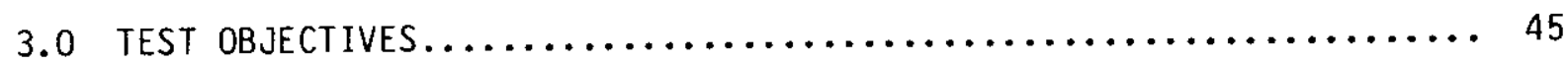

3.1 Phase I (Initial Scoping Tests) $\ldots \ldots \ldots \ldots \ldots \ldots \ldots \ldots \ldots \ldots \ldots$

3.1 .1 Flow Distribution........................ 45

3.1 .2 Cold Plenum Stratification................... 46

3.1.3 Constant Flow Thermal Transients (MCTF Interface)...... 46

3.1.4 Natural Convection (Core Heaters) ............... 47

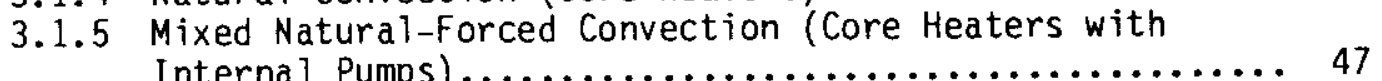

3.1.6 Prototypic Transient A-4 (Plant Unloading at $3 \%$ Per

3.2 Phase II ...................................... 48

3.2.1 Simulated Prototypic Transients................ 48

3.2.1.1 Reduction of Power From 100 to $25 \%$ (A-4)..... 52

3.2.1.2 Reactor Trip From Fu11 Power with Maximum

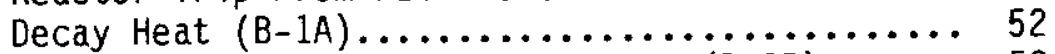

3.2.1.3 Loss of Power to One Primary Pump (B-3B)..... 52

3.2.1.4 Loss of Feedwater to A11 Modules Supplying One Turbine, with Scram After Steam Generator Dryout $(B-5 B) \ldots \ldots \ldots \ldots \ldots \ldots \ldots$ 


\section{TABLE OF CONTENTS (Contd.)}

Page

3.2.1.5 Loss of Feedwater to A17 Modules Supplying One Turbine, with Thirty-Second-Delayed

Scram $(B-5 B) \ldots \ldots \ldots \ldots \ldots \ldots \ldots \ldots \ldots \ldots, 58$

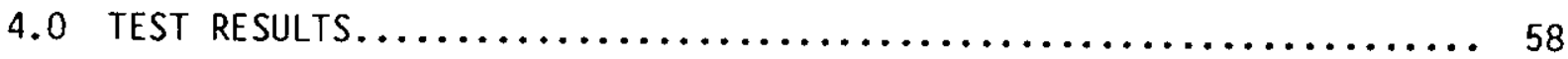

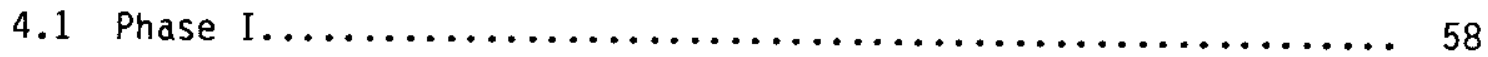

4.1.1 Flow Distribution............................ 58

4.1 .2 Cold Plenum Stratification......................... 67

4.1.3 Constant Flow Thermal Transients..................... 68

4.1 .4 Natural Convection........................... 83

4.1.5 Mixed Natural-Forced Convection..................... 97

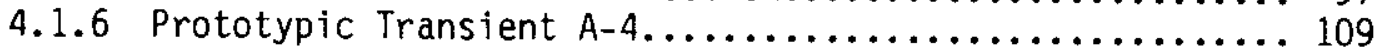

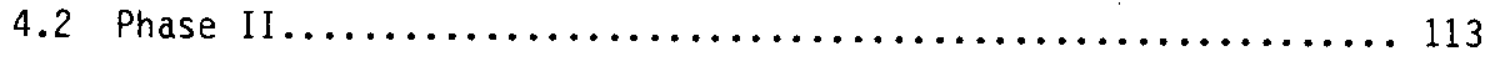

4.2.1 Simulated Prototypic Transients...................... 113

4.2.1.1 Reduction of Power From 100 to $25 \%$ (A-4)...... 118

4.2.1.2 Reactor Trip From Full Power with Maximum

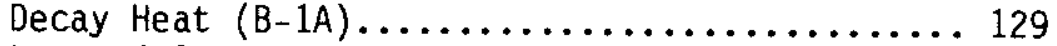

4.2.1.3 Loss of Power to One Primary Pump $(B-3 B) \ldots \ldots .139$

4.2.1.4 Loss of Feedwater to All Modules Supplying

One Turbine, with Scram After Steam

Generator Dryout $(B-5 B) \ldots \ldots \ldots \ldots \ldots \ldots \ldots \ldots \ldots \ldots \ldots \ldots \ldots$

4.2.1.5 Loss of Feedwater to All Modules Supplying

One Turbine, with Thirty-Second Delayed

Scram $(B-5 B) \ldots \ldots \ldots \ldots \ldots \ldots \ldots \ldots \ldots \ldots \ldots \ldots \ldots \ldots \ldots$

5.0 SUMMARY AND CONCLUSION.................................. 174

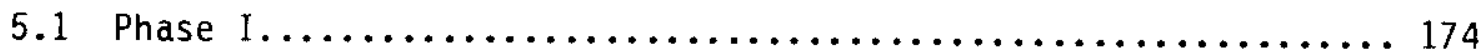

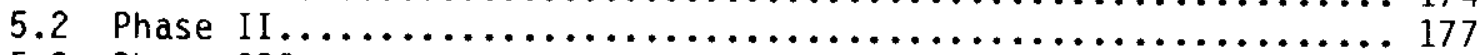

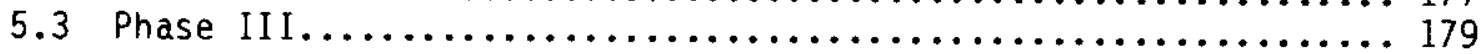

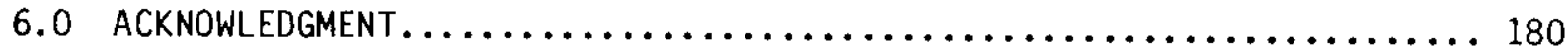

7.0 References........................................... 180 
1. ANL/MCTF Therma1-Hydraulic Model of GE/PRISM Advanced

Reactor Concept.................................. 11

2. PRISM Model Elevation with Dimensions of Key Features $\ldots \ldots \ldots \ldots 13$

3. Completed ANL Plastic Model of PRISM................... 14

4. View of Lower Half of Containment Vessel with $60 \mathrm{~kW}$ Core Heater Mounted in Place............................... 15

5. PRISM Model on Test Stand Inserted in Lower Portion of Containment vessel................................... 17

6. PRISM Model Housed in Containment Vessel Positioned on the Test Stand of the ANL Advanced Reactor Test Center............. 18

7. Closeup of a Pump Inlet and Ducted Pump Propeller............. 19

8. Closeup of Upper Plenum Floor Showing Pump Outlet Plenum........ 20

9. Kidney-Shaped IHX Outlets with Instrumentation............. 21

10. View of One of Two Pump Exit Plenums and the Pumps that

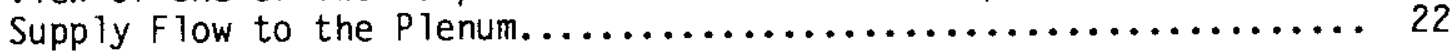

11. Locations of PRISM Thermocouples in ANL Model of PRISM......... 23

12. Locations of PRISM Thermocouples in ANL Model of PRISM......... 24

13. PRISM Model Pressure Taps/Dye Injection Ports............... 26

14. UIS Model Mounted on Thermocouple Sting................. 27

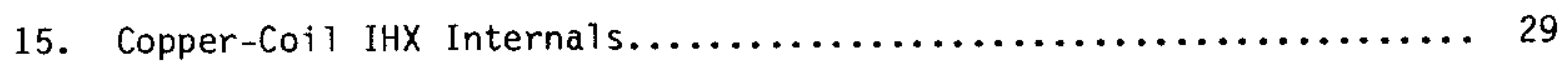

16. Complete IXH Model with Copper Coil Internals.............. 30

17. View of IHX Inlet on Outer Radial Wall $\ldots \ldots \ldots \ldots \ldots \ldots \ldots \ldots \ldots \ldots$

18. View of IHX Inlet on Inner Radial Wall $\ldots \ldots \ldots \ldots \ldots \ldots \ldots \ldots \ldots$

19. ANL Mixing Components Test Facility, $2000 \mathrm{gpm}$ Therma 1Hydraulic Transient Simulation Water Loop.................. 35

20. Simplified Schematic Diagram of the MCTF ................ 36 


\section{LIST OF FIGURES (Contd.)}

Page

21. PRISM Prototype Reactor Power for a Reactor Trip from Full

Power with Maximum Decay Heat $(B-1 A) \ldots \ldots \ldots \ldots \ldots \ldots \ldots \ldots \ldots . \ldots . \ldots$

22. PRISM Prototype Sodium Flowrates for a Reactor Trip from Full

Power with Maximum Decay Heat $(B-1 A) \ldots \ldots \ldots \ldots \ldots \ldots \ldots \ldots \ldots . \ldots 1$

23. PRISM Prototype Primary Sodium Temperatures for a Reactor

Trip from Full Power with Maximum Decay Heat (B-1A) ........... 42

24. Reactor Power During A-4 Plant Unloading at $3 \%$ Per Minute

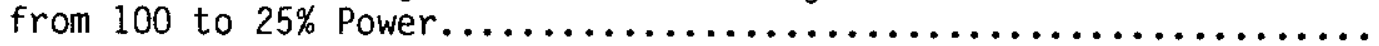

25. Sodium Flowrates During A-4 Plant Unloading at $3 \%$ Per

Minute from 100 to $25 \%$ Power........................... 50

26. Primary Sodium Temperatures During A-4 Plant Unloading at

$3 \%$ Per Minute from 100 to $25 \%$ Power.......................... 51

27. Intermediate Sodium Temperatures During A-4 Plant Unloading at $3 \%$ Per Minute from 100 to $25 \%$ Power...................... 53

28. Reactor Power Following B-1A Reactor Trip from Full Power with

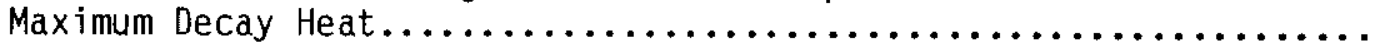

29. Sodium Flowrates Following B-1A Reactor Trip from Full Power

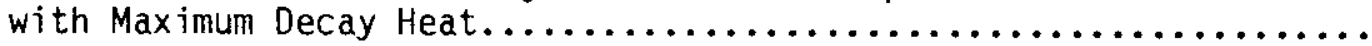

30. Primary Sodium Temperatures Following B-1A Reactor Trip from

Ful1 Power with Maximum Decay Heat.

31. Intermediate Sodium Temperatures Following Reactor Trip from

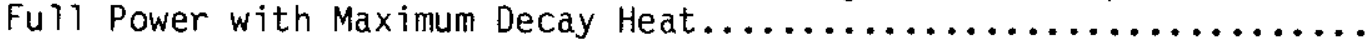

32. Reactor Power Following B-5B Loss of Feedwater to All Modules Supplying One Turbine, with Scram After Steam Generator

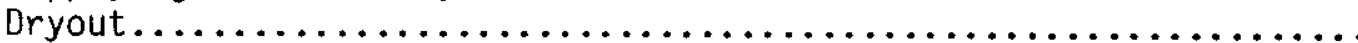

33. Sodium Flowrates Following B-5B Loss of Feedwater to All Modules Supplying One Turbine, with Scram After Steam

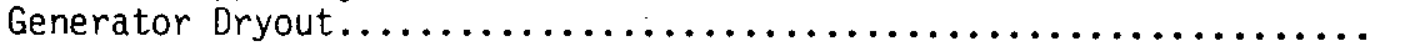

34. Primary Sodium Temperatures Following B-5B Loss of Feedwater to All Modules Supplying One Turbine, with Scram After Steam

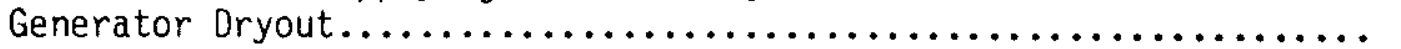

35. Intermediate Sodium Temperatures Following B-5B Loss of Feedwater to All Modules Supplying One Turbine, with Scram After Steam Generator Bryout. 


\section{LIST OF FIGURES (Contd.)}

Page

36. Reactor Power Following B-5B Loss of Feedwater to All Modules

Supplying One Turbine, with 30 -Second Delayed Scram............ 63

37. Sodium Flowrates Following B-5B Loss of Feedwater to A11

Modules Supplying One Turbine, with 30-Second Delayed Scram....... 64

38. Primary Sodium Temperatures Following B-5B Loss of Feedwater to All Modules Supplying One Turbine, with 30-Second Delayed

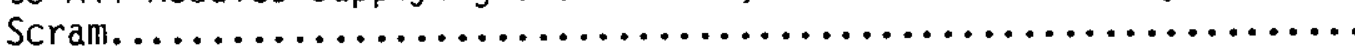

39. Intermediate Sodium Temperature Following B-58 Loss of

Feedwater to All Modules Supplying One Turbine, with 30-Second

Delayed Scram.................................... 66

40a. Flowrate and Temperature of Fluid Entering PRISM Core from the MCTF During the Start of JU1901.................... 70

40b. Flowrate and Temperature of Fluid Entering PRISM Core from the MCTF for JU1901............................... 71

41. Development of Thermal Stratification in PRISM Model Cold Plenum During a Constant-Flow Therma 1-Upramp Transient for Ju1901.

42. Development of Thermal Stratification in PRISM Model Cold Plenum During a Constant-Flow Thermal-Upramp Transient for JU2001.

43. Development of Thermal Stratification in PRISM Model Cold Plenum During a Constant-Flow Therma 1-Upramp Transient

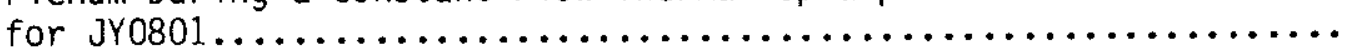

44. Development of Thermal Stratification in PRISM Model Cold Plenum During a Constant-Flow Therma 1-Upramp Transient

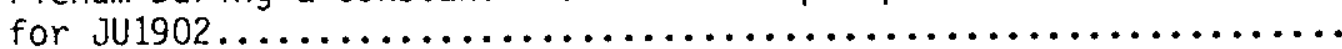

45. PRISM Model Temperature Behavior in Annular Overflow Gap When No Overflow Occurs for a Thermal Upramp that Caused

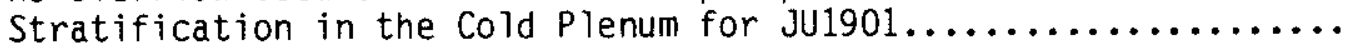

46. PRISM Model Upper Plenum Temperature Response to a Therma1Upramp Transient for JU1901......................... 80

47. Variation of PRISM Model Flow Radial Temperature in the Upper Plenum at the Approximate Elevation of the IHX Inlets for JU1901... 
48. Vertical Variation of PRISM Model Flow Temperature on the Outside of the Radial Shield for a Thermal-Upramp

Transient for JU1901.

49. PRISM Model Temperature Responses at the Inlets and Outlets of Various Subregions for a Therma 1-Upramp Transient for

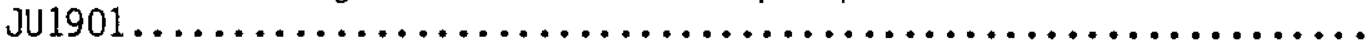

50. PRISM Model Temperature Responses at the Inlets and Outlets of Various Subregions for a Thermal-Upramp Transient for

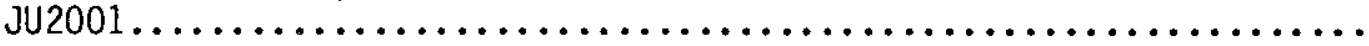

51. PRISM Model Temperature Responses at the Inlets and Outlets of Various Subregions for a Thermal-Upramp Transient for

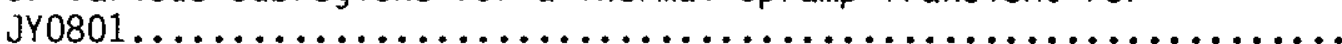

52. PRISM Model Temperature Responses at the Inlets and Outlets of Various Subregions for a Thermal-Upramp Transient for

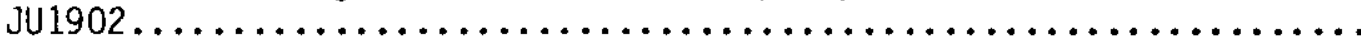

53. Development of Thermal Stratification in PRISM Model Cold Plenum During a Natural-Convection Transient for JY2301.......... 90

54. Development of Thermal Stratification in PRISM Model Cold Plenum During a Natural-Convection Transient for JY1501...........

55. Development of Thermal Stratification in PRISM Model Cold Plenum During a Natural-Convection Transient for JY2401........... 92

56. Development of Thermal Stratification in PRISM Model Cold Plenum During a Natural-Convection Transient for JY1601......... 93

57. PRISM Model Upper Plenum Temperature Response to a Natura 1-

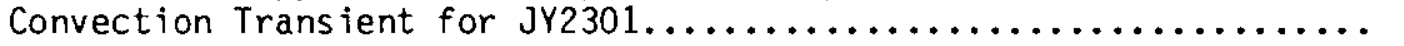

58. PRISM Model Temperature Responses at the Inlets and Outlets of Various Subregions for a Natural Convection Transient for

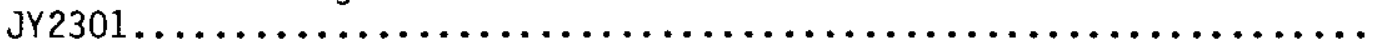

59. Development of Thermal Stratification in PRISM Model Cold Plenum During a Mixed Natural-Forced-Convection Transient

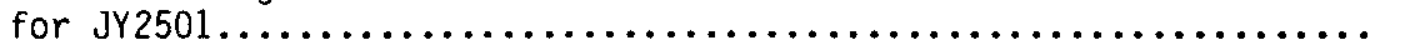

60. Development of Thermal Stratification in PRISM Model Cold Plenum During a Mixed Natural-Forced-Convection Transient for JY2901. 


\section{LIST OF FIGURES (Contd.)}

61. Development of Thermal Stratification in PRISM Model Cold Plenum During a Mixed Natural-Forced-Convection Transient for JY2801.

62. PRISM Mode1 Upper Plenum Temperature Responses to a Mixed Natural-Forced-Convection Transient for JY2501................. 103

63. PRISM Mode1 Upper Plenum Temperature Response (Off Centerline) to a Mixed Natural-Forced-Convection Transient for JY2901......... 105

64. PRISM Model Upper Plenum Temperature Response (Off Centerline) to a Mixed Natural-Forced-Convection Transient for JY2801......... 106

65. PRISM Model Upper Plenum Temperature Response (Off Centerline) to a Mixed Natural-Forced-Convection Transient for JY2501......... 107

66. PRISM Model Temperature Responses at the Inlets and Outlets of Various Subregions for a Mixed Natural-Forced-Convection

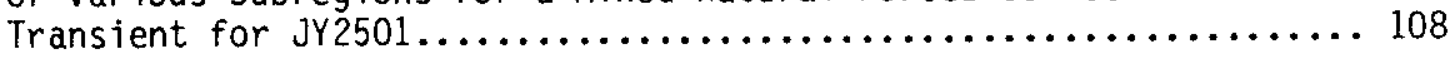

67. Flowrate and Temperature of Fluid Entering PRISM Core from

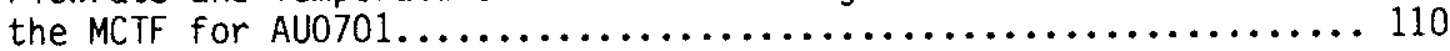

68. PRISM Model Cold Plenum Temperature Response to a 100 to $25 \%$ Power Reduction Transient for AU0701...................... 111

69. PRISM Model Upper Plenum Temperature Response (Off Centerline) to a 100 to $25 \%$ Power Reduction Transient, as a Function of

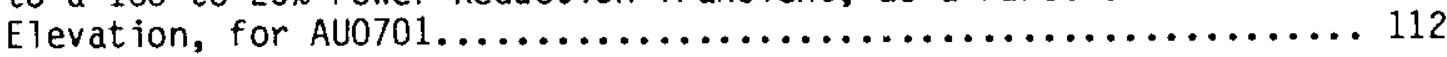

70. PRISM Model Upper Plenum Temperature Response to a 100 to $25 \%$ Power Reduction Transient, as a Function of Radial Location,

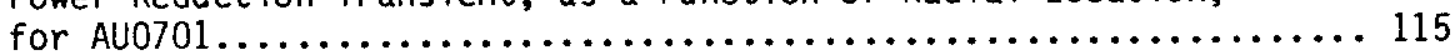

71. PRISM Model Temperature Responses at the Inlets and Exits of Various Subregions for the 100 to 25\% Power Reduction

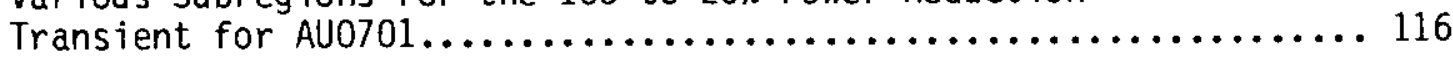

72. Flowrate and Temperature of Fluid Entering PRISM Core from

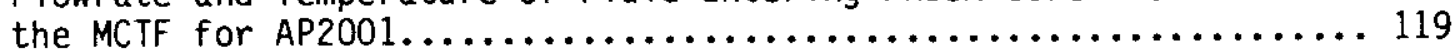

73. PRISM Model Lower Plenum Temperature Response to a 100 to $25 \%$

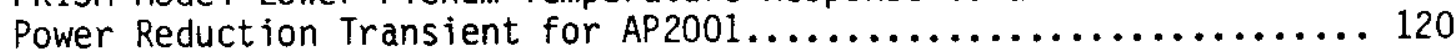

74. PRISM Model Upper Plenum Temperature Response (Off Centerline) to a 100 to $25 \%$ Power Reduction Transient, as a Function of

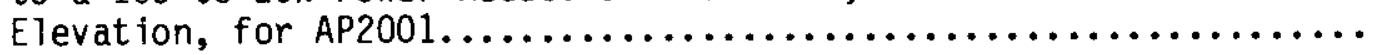


75. PRISM Mode 1 Upper Plenum Temperature Response to a 100 to $25 \%$ Power Reduction Transient, as a Function of Radial Location,

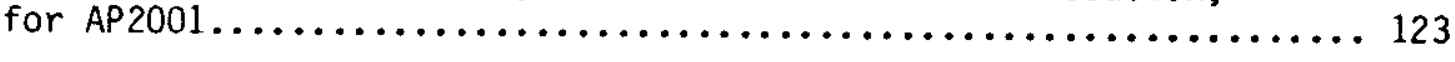

76. PRISM Model Upper Plenum Temperature Response to a 100 to $25 \%$ Power Reduction Transient, as a Function of Elevation,

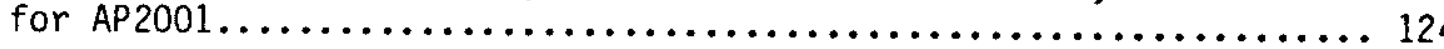

77. PRISM Model Upper Plenum Temperature Response at Midelevation in the Overflow Gap for AP2001.

78. PRISM Model Temperature Responses at the Inlets and Exits of Various Subregions for the 100 to 25\% Power Reduction

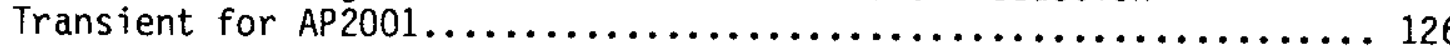

79. PRISM Model Temperature Responses at the Inlet and out let of the IHX Heat Sinks, Together with the Flowrate, for AP 2001

80. PRISM Model IHX Heat Sink Capacity, as a Function of Time,

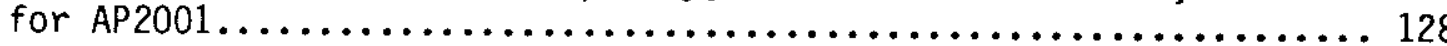

81. Flowrate and Temperature of Fluid Entering PRISM Core from the MCTF for MY2001 During Initial Portion of the Transient....... 131

82. Responses of Thermocouples in the Lower Plenum at Various Elevations Inside the Radial-Shield Liner for MY2001............ 132

83. Responses of Thermocouples in the Upper Plenum at Various Elevations for MY2001................................. 133

84. PRISM Model IHX Heat Sink Capacity as a Function of Time

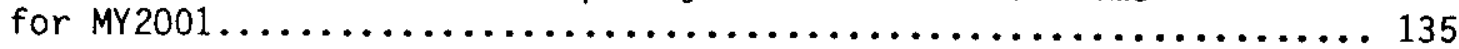

85. PRISM Model Temperature Response at the Inlet and Outlet of the IHX Heat Sinks, Together with Flowrate for MY2001........ 136

86. Temperature Response of the PRISM Model Upper Plenum at Midelevation in the Overflow Gap for MY2001.

87. Vertical Variation of PRISM Model Flow Temperature on the Outside of the Radial Shield for MY2001.................... 138

88. PRISM Model Temperature Responses at the Inlets and Outlets of Various Subregions for MY2001....................... 140

89. Flow and Temperature of Fluid Entering PRISM from the MCTF for JU0301 During Initial Portion of Transient. 


\section{LIST OF FIGURES (Contd.)}

90. Responses of Thermocouples in the Lower Plenum at Various Elevations Inside the Radial-Shield Liner for Jy0301............ 143

91. Responses of Thermocouples in the Upper Plenum at Various

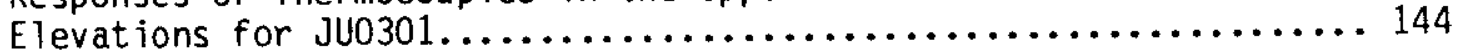

92. Heat Sink Capacity of PRISM Model IHX as a Function of

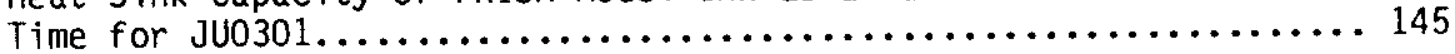

93. Temperature Response of the PRISM Model at the Inlet and Outlet of the IHX Heat Sinks, Together with Flowrate

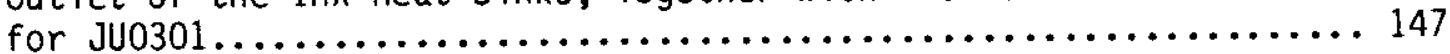

94. Temperature Responses of the PRISM Model Upper Plenum at Midelevation in the Overflow Gap for Ju0301................. 148

95. Vertical Variation of PRISM Mode1 Flow Temperature on the Outside of the Radial Shield for JU0301......................... 149

96. PRISM Model Temperature Responses at the Inlets and Outlets

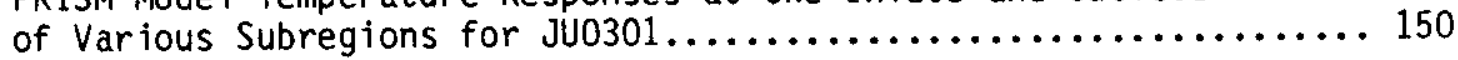

97. Flowrate and Temperature of Fluid Entering PRISM Core from the MCTF for JU0901 During Initial Portion of Transient.......... 153

98. Thermocouple Responses in the Lower Plenum at Various Elevations Inside the Radial-Shield Liner for Ju0901............ 154

99. Thermocouple Responses in the Upper Plenum at Various

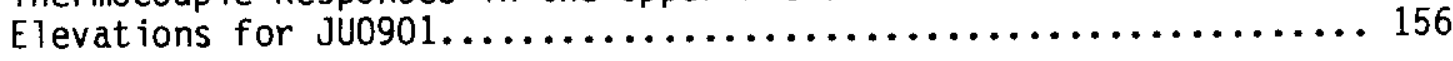

100. PRISM Mode 1 IHX Heat Sink Capacity as a Function of Time

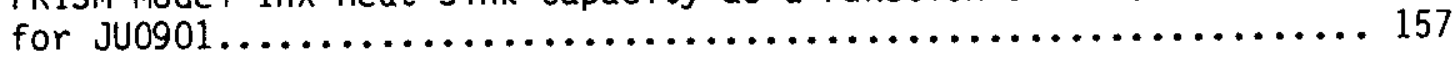

101. PRISM Model Temperature Response at the Inlet and Outlet of the IHX Heat Sinks Together with Flowrate for JU0901.......... 158

102. PRISM Mode1 Upper Plenum Temperature Response at

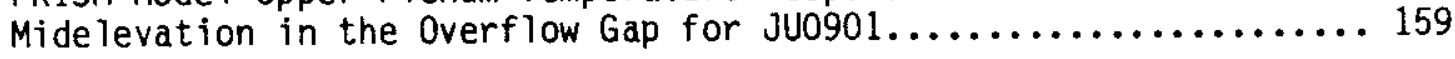

103. Vertical Variation of PRISM Model Flow Temperature on the Outside of the Radial Shield for Ju0901........................ 161

104. PRISM Model Temperature Responses at the Inlets and Outlets of Various Subregions for JU0901. 


\section{LIST OF FIGURES (Contd.)}

Page

105. Flowrate and Temperature of Fluid Entering PRISM Core from the MCTF for MY2801 During Initial Portion of Transient........... 164

106. Thermocouple Responses in the Lower Plenum at Various Elevations Inside the Radial-Shield Liner for MY2801............ 165

107. Thermocouple Responses in the Upper Plenum at Various Elevations for MY2801............................... 167

108. PRISM Mode 1 IHX Heat Sink Capacity as a Function of Time for MY2801

109. PRISM Mode 1 Temperature Response at the Inlet and Outlet of the IHX Heat Sinks Together with Flowrate for MY2801............. 169

110. PRISM Model Upper Plenum Temperature Response at Midelevation in the Overflow Gap for MY2801......................... 170

111. Vertical Variation of PRISM Model Flow Temperature on the Outside of the Radial Shield for MY2801.................... 171

112. PRISM Model Temperature Responses at the Inlets and Outlets of Various Subregions for MY 2801 
I. PRISM Model Operating Conditions and Similarity Parameters for Fu 11 Power and Flow.................................... 8

II. PRISM Model Core Temperature Rise....................... 9

III. Dimensions of PRISM Circular-Cross-Section Features............ 12

IV. Nondimensional Parameters for the Constant Flow Therma 1 Transients............................................ 69

V. Nond imensional Parameters for the Natural-Convection Transients........................................... 89

VI. Nondimensional Parameters for the Mixed Natural-ForcedConvection Transients.................................. 98

VII. PRISM Phase II Tests: Transient Type, Simulated Core Temperature Difference, and Heat Sink Capacity of IHX's.......... 114 


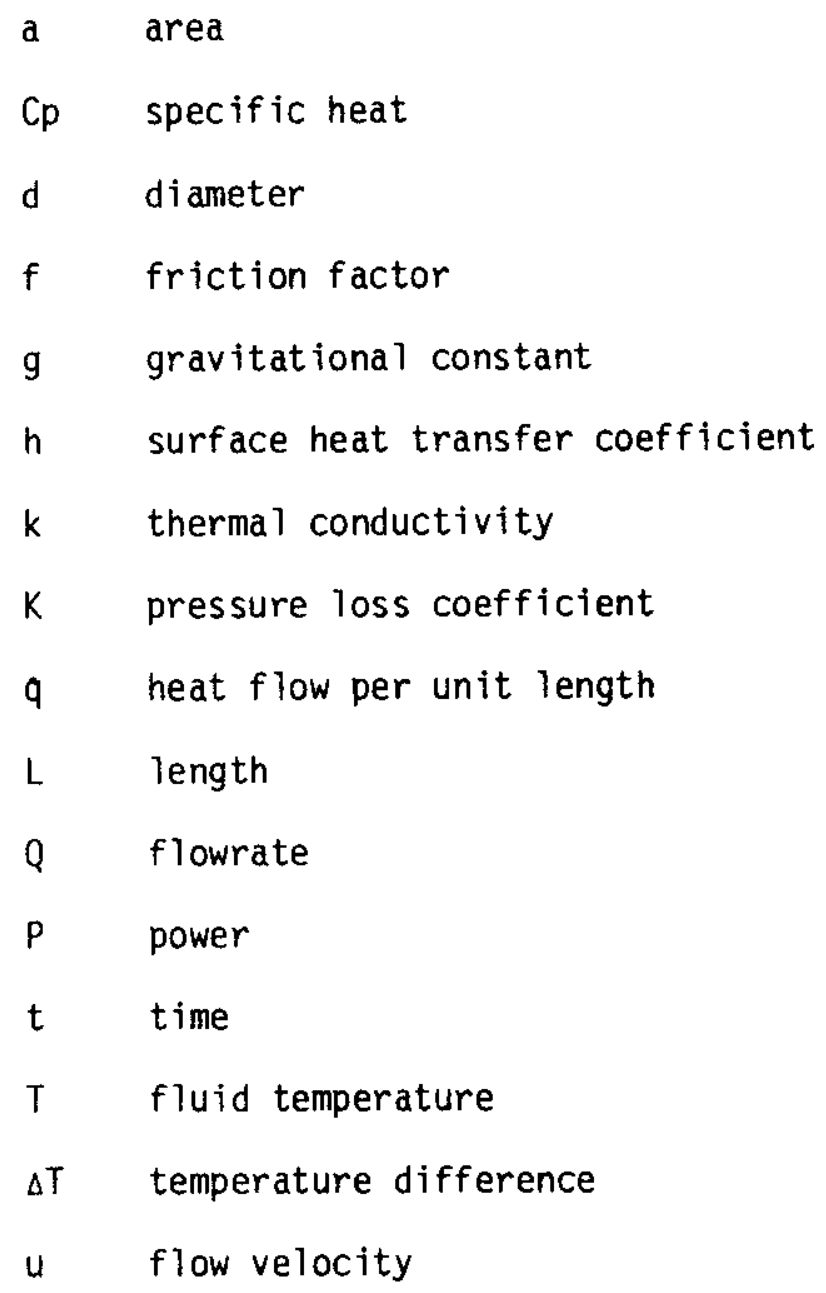


NOMENCLATURE (Contd.)

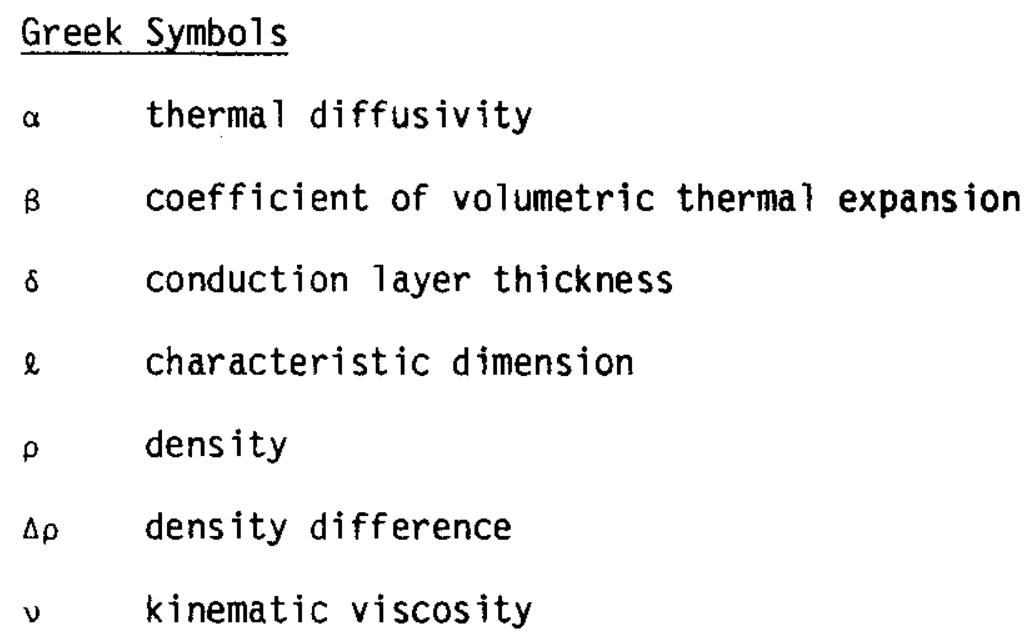

\section{Subscripts}

c denotes cold fluid conditions

core denotes value in core barrel

gap denotes value in radial gap between radial shield and containment vessel

$\mathrm{h}$ denotes value associated with heat transferred

$\mathrm{H} \quad$ denotes hot fluid conditions

i denotes different components

M denotes model value

- denotes characteristic value

P denotes prototype value

$R$ denotes ratio of model to prototype

s denotes a solid 
PRISM THERMAL-HYDRAULIC (FORCED AND NATURAL CONVECTION)

COMPLETE IN-VESSEL-MODEL PERFORMANCE TESTS:

PHASE I AND PHASE II

by

J. J. Oras and K. E. Kasza

ABSTRACT

In FY 1985, the U.S. DOE directed the Argonne National Laboratory (ANL) Flow and Mixing Processes Program to utilize its Mixing Components Test Facility (MCTF) to support the needs of the new Advanced Concepts Reactor Program for development of inherently safe, cost-competitive reactors. In cooperation with GE, a test program was developed to support PRISM, one of the advanced-concepts liquid metal reactor designs. The broadly stated objective of this program is to use the ANL/MCTF for transient and steady-state thermal-hydraulic tests, conducted in a scaled water model of the PRISM/RV and all major in-vessel components, to explore important high- and low-flow naturalconvection operation scenarios for assessing factors that influence thermal-hydraulic performance, reactor coolability, and structural thermal distributions. This paper describes the ANL PRISM model and the results obtained from both Phase I and Phase II of the thermal-hydraulic test program.

A transparent plastic (polycarbonate and cast acrylic), 1/5.24-scale model of the GE/PRISM advanced reactor was constructed at ANL. This model can be altered to reflect the evolving design. A11 major in-vessel components are represented in this model, which fits in a two-piece cylindrical containment vessel with large windows for laser flow visualization. The reactor core is simulated by a $60-\mathrm{kW}$ electrical-resistance immersion heater with computer-interfaceable SCR power control. Computer-controlled forced flow is provided in two ways: for low-flow conditions, four in-vessel pumps (propellers driven by 1/4-hp dc motors with SCR controllers) are used; and for highflow conditions, the MCTF water loop is used. Computer control of the immersion heater, in-vessel pumps, and the MCTF allows transient simulations. The two IHXs are designed to contain heat sinks, and the cold wall of the containment vessel simulates cooling by the RVACS. This model is the most complete thermalhydraulic water model built to date for a U.S. DOE LMR program.

A complete geometric model was built because the thermalhydrautic performance of one subregion of the prototype under a variety of conditions will depend upon the conditions that 
prevail elsewhere in the reactor. Therefore, any similarity analysis of the model design should consider the whole RV. A one-dimensional similarity analysis, applicable to such a complete system, has been followed in developing the PRISM model.

Phase I tests facilitated the shakedown process and the development of many complex control features and subsystems which have been incorporated in the PRISM model. The Phase I tests also highlighted specific thermal-hydraulic phenomena of potential interest to designers. The tests were conducted in the following general categories: isothermal flow distribution, hot plenum free-surface behavior, constant-flow therma? transients, natural-convection flows, and mixed forced-natural-convection flows. Phase II tests consisted of simulations of five prototypic transients which were chosen by GE because their severity and frequency of occurrence could pose potential design concerns such as stress problems caused by rapid temperature changes and inadequate heat rejection due to inadequate flow. A stratified hot/cold interface formation in the cold plenum, backflow in a shut down pump, and unanticipated naturalconvection currents in the overflow gap are some of the phenomena that were discovered during these tests. These phenomena will be highlighted because of their possible importance to the designer. 


\subsection{INTRODUCTION}

The DOE/LMR program has embarked upon a new initiative to develop an innovative advanced-concept reactor. DOE has awarded development contracts to GE (PRISM), AI (SAFR) and ANL (IFR) for development of inherently safe, costcompetitive reactors. Al1 reactor concepts are of the pool type with the IHXs and primary pumps immersed in sodium within the reactor vessel (RV). Hence, in order to establish the reliability and inherent safety of a reactor concept, it is very important to know the thermal-hydraulics that are associated with the interplay and feedback between these components and the plenums, the core, other in-vessel structures, and the heat transfer from the RV walls to the ambient. The new designs must be able to ride out, with minimal operator intervention, such events as a loss of normal heat sink with reactor scram or a loss of coolant pumping power and normal heat sink with failure to scram by relying on passive means for heat rejection from the RV. As a consequence, knowledge of the temperature and flow distributions during these low-flow, transient and steady-state, mixed-and natural-circulation flow conditions is essential to the validation of the core coolability and component and structural performance under conditions of possibly detrimental thermal distributions and to the provision of information to aid in the development and validation of the COMMIX thermal-hydraulic computer code. Additionally, the influence of individual IHX, pump, and internals design and placement on general thermal-hydraulic performance and reliability of the system as we 17 as the individual components must be assessed.

In FY 1985 the U.S. DOE directed the ANL Flow and Mixing Processes Program to utilize its Mixing Components Test Facility (MCTF) to support the needs of the new Advanced Concepts Reactor Program for development of inherently safe, cost-competitive reactors. In cooperation with GE, a test program was developed to support PRISM, one of the advanced-concepts reactor designs. The broadly stated objective of this program is to

conduct, in the ANL/MCTF, transient and steady-state thermal-hydraulic scaled water model tests of the PRISM/RV and a 11 major in-vesse 1 components for important high- and low-flow natural-convection operation scenarios for assessing factors that influence: 
Therma 1-hydraulic performance

Reactor coolability

Structural thermal distributions.

A single RV test model was used because the flow and thermal behavior in a given subregion are the result of complex interactions with and feedbacks from the rest of the RV. With separate subregion models, it would be very difficult to properly simulate inlet and outlet conditions for these models. Simulations of PRISM in-vessel thermal-hydraulics, under key postulated reactor operation scenarios, are required to provide GE/PRISM designers with performance information that is vital to the assessment of the workability of the various design features that are being incorporated into the ir innovative, inherently safe reactor and of the workability of the system as a whole. The model being tested will be altered to incorporate new features that are compatible with the evolving PRISM design.

The ANL/MCTF, as a result of its pioneering studies [1-18] over the last seven years on thermal-buoyancy effects in reactor components (i.e. IHXs, SGs, piping, and plenums), has developed unique, broad experience relative to the understanding and study of transient thermal-buoyancy effects in reactor components. These studies focused on such things as

- Pipe flow stratification that produces pipe stress and influences energy transport between components

- Steam generator and heat exchanger flow channeling and instabilities that cause tube bunde and tube sheet thermal stress

- Stratification of pipe flow/plenum interface recirculation zone, which causes nozzle stresses

- Large scale periodic eddies that strongly influence thermal-plume behavior and plenum mixing

- Therma 1-buoyancy-force-induced laminarization of stratified shear layers, a mechanism that mitigates thermal striping and reduces plenum mixing

- Therma]-buoyancy-force suppression or enhancement of heat transfer under low flow, which influence the overall heat transfer of the heat exchanger 
- Buoyancy-induced recirculation zones in baffled tube bundles and other components, which reduce heat transfer and produce radial temperature variation and "cold" spots.

In the pool reactors currently under development, many of the above phenomena can potentially occur within the RV and interact in a complex manner because of the proximity of components and the multiple flow paths between the various subregions of the RV. ANL is studying these phenomena in the PRISM reactor. The following sections describe the ANL program that is being conducted in support of PRISM and report results from phenomena-scoping tests (i.e., Phase I tests) and tests on simulated prototypic transients (i.e., Phase II tests).

\subsection{BACKGROUND}

In general, with its PRISM in-vessel scaled model thermal-hydraulic tests, ANL is addressing such matters as

i) Characterization of hot, intermediate, and cold plenum mixing, thermal distributions, and location of stratified interfaces with time for the various reactor steady and transient events

ii) Influence of stratified interface locations on (a) flow and thermal ramps into and out of IHXs, pumps, and the core, and at other critical liquid/solid-structural interfaces (i.e., redan), (b) availability of in-vessel heat sinks associated with structure and sodium, and (c) reactor vessel heat-rejection capability to ambient air by means of the GE/RVACS

iii) Influence of flow path resistance (both the level and possible disparity between paths comprised of IHX, pump, and core) between hot and cold plenums on (a) general reactor coolability, (b) start-up time constant for natural-circulation flow, and (c) potential for multiple flow-path-created flow instabilities or reverse-flow siphoning or blockage (produced, for example, by thermal distributions in the IHXs prior to transition to the natural-convection circulation mode which setup flow-opposing thermal density heads) 
iv) Influence of upper internals structure (UIS) design on upper plenum mixing and thermal distributions

v) The question, can a core/upper-hot-plenum recirculation loop be formed which may short circuit the preferred flow paths (through IHXs and pumps) between upper and lower plenums and thereby reduce heat sink availability and/or core hot spots?

vi) Influence of proximity and grouping of outlets and inlets of IHXs, pumps, and core on (a) potential for flow shunting (unequal flow split between the flow paths connecting the hot and cold plenums) and (b) on mixing in the plenums

vii) Characterization of the potential for cover-gas/sodium interface flow disturbances and gas entrainment at high flow

viii) Simulation of a "cold" RV wall (the result of air cooling in the prototype, RVACS) to allow assessment of the influence of walldriven, in-vessel, natural-convection currents on (a) plenum stratified-interface behavior, (b) heat rejection to ambient, and (c) temperature distribution in annular overflow gap.

ix) The use of select sets of experimental data to assist in further validating the COMMIX code which is currently being used to guide design of the PRISM prototype.

The PRISM test model in which these studies are being conducted was completed at ANL in April 1986. The testing of this model (i.e., Phase I tests which consist of shakedown and phenomena-scoping testing) and its alteration (which included installation of operational IHX's) to reflect the evolving PRISM design (i.e., Phase II tests which consist of simulations of five prototypic transients) continued in FY 1987 . Testing continues in FY 1988 (Phase III) and whereas the nature of the Phase III activity is described in Sec. 5.0, this section gives details of the modeling laws that were utilized, the model description, the test facility, the possible modes of model operation, and the transients of interest for Phase I and Phase II.

\subsection{Modeling}

The pertinent similarity parameters that were used in modeling the PRISM prototype are highlighted and their values for the ANL model are presented. 
ANL has built a thermal-hydraulic water model of the complete RV and all the essential internal features of the PRISM prototype. A complete geometric model has been built because the thermal-hydraulic performance of one subregion of the prototype under a variety of conditions will depend upon the conditions that prevail elsewhere in the reactor. Therefore, any similarity analysis of the model design should consider the whole RV. A one-dimensional similarity analysis applicable to such a complete system has been followed in developing the PRISM model [19].

\subsubsection{General Similarity}

A nondimensionalization of the governing one-dimensional conservation equations for a flow yields the following modeling similarity parameters:

Richardson No.; $\quad R_{i} \equiv \frac{g B \Delta T_{0} l_{0}}{u_{0}^{2}}=\frac{\text { Buoyancy }}{\text { Inertia Force }}$

Friction No.;

$$
F_{i} \equiv\left(\frac{f \ell}{d}+k\right)_{i}=\frac{\text { Friction }}{\text { Inertia Force }}
$$

Modified Stanton No.; $\quad S t_{i} \equiv\left(\frac{4 h e_{0}}{\rho C_{p} u_{0} d}\right)_{i}=\frac{\text { Wall Convection }}{\text { Axial Convection }}$

Time Ratio;

$$
T_{i}^{\star} \equiv\left(\frac{\alpha_{s}}{\delta^{2}} \frac{l_{0}}{u_{0}}\right)_{i}=\frac{\text { Transport Time }}{\text { Conduction Time }}
$$

Biot No.;

$$
B_{i} \equiv\left(\frac{h \delta}{k_{s}}\right)_{i}=\frac{\text { Wal1 Convection }}{\text { Conduction }}
$$

Heat Source No.; $\quad Q_{s i} \equiv\left(\frac{\dot{q}_{s}{ }_{0}}{\rho_{s} C_{p s}{ }_{0}{ }_{0} \Delta T_{0}}\right)_{i}=\frac{\text { Heat Source }}{\text { Axial Energy Change }}$

In addition to these parameters, geometric similarity is also required between the model and the prototype.

It is obvious from an examination of these parametric groups that a Reynolds number, Re, does not appear in the equations. Because the analysis is one-dimensional, Re, which normally appears because of the boundary layer 
type shear zones, enters only implicitly through the boundary conditions. By the same token, the Prandt 1 number, Pr, enters through the surface heat transfer coefficient, $h$.

The steady-state solutions of the conservation equations provide for $\Delta T_{0}$, the scaling temperature differential, and, $u_{0}$, the scaling velocity. These are given by

$$
\begin{aligned}
& \Delta T_{0}=\frac{\dot{q}_{0} l_{0}}{\rho C_{p} u_{0}}\left(\frac{a_{s o}}{a_{0}}\right) \\
& u_{0}=\frac{\left(\frac{\dot{q}_{0} l_{0}}{\rho C_{p}}\right) l_{h}\left(\frac{a_{s o}}{a_{0}}\right)^{1 / 3}}{\frac{1}{2 g} \sum_{i}\left(F_{i} / A_{i}^{2}\right)}
\end{aligned}
$$

\subsubsection{PRISM Similarity}

Complete similarity between model and prototype is achieved by matching all the above parametric groups of the model, $M$, to those of the prototype, $P$. The resultant ratios are defined by the subscript " $R$ ". It is generally accepted that, for complex thermal-hydraulic models, complete similarity cannot be achieved.

Furthermore it is often the case that different materials are utilized in fabrication of the model (e.g., glass or plastic in the model versus steel in the prototype). From the governing equations, it can also be shown that the following geometrical parameters should be satisfied for complete similarity:

$$
\begin{aligned}
& A_{i R}=\frac{\left(a_{i} / a_{0}\right)_{M}}{\left(a_{i} / a_{0}\right)_{P}}=1 \quad \text { (kinematic similarity from continuity) } \\
& t_{R}=e_{R}^{3} /(\text { volumetric flow })_{R} \\
& \left(\sum_{i} L_{i} / A_{i}\right)_{R}=1
\end{aligned}
$$




$$
\begin{aligned}
& L_{i_{R}}=L_{h R}=1 \quad \text { (for dynamic similarity from the momentum equation) } \\
& \left(\sum_{i} F_{j} / A_{j}^{2}\right)_{R}=1
\end{aligned}
$$

The last condition is satisfied by flow resistance orificing of the PRISM test section components to ensure proper pressure drops around the flow circuits of the model. Because the friction and form contributions to $F_{j}$ are very complex, model and prototype similarity could not be achieved exactly over the entire flow range but was achieved at a point corresponding to $10 \%$ of prototype flow. Resistance orificing has been used in the model core and the IHXs.

It can be shown that once $R_{i R}=1$ is satisfied (i.e., that Richardson number similarity exists between model and prototype), the correct similarity in $U_{O R}$, the reference velocity, is established. Hence, maintaining $R_{i R} \equiv 1$ was a key constraint in designing the PRISM model and in conducting the tests.

The $\Delta T_{O R}$, the reference temperature ratio between model and prototype to satisfy $R_{i R}=1$, is thus given by

$$
\Delta T_{O R}=\frac{\Delta T_{O M}}{\Delta T_{O P}}=\dot{q}_{O R}\left(\frac{1}{\rho C_{P}}\right){ }_{R} \frac{\ell_{O R}}{u_{O R}} \frac{\delta_{O R}}{d_{O R}} .
$$

This condition was used to establish power requirements for the electrical heater in the PRISM model.

For the PRISM model, similarity in the following parameters was not maintained:

$$
\begin{aligned}
& S t_{i R} \neq 1 \\
& T_{i R}^{\star} \neq 1 \\
& B_{i R} \neq 1 \\
& Q_{S O R} \neq 1 .
\end{aligned}
$$


However, once the model is fully specified (i.e., scale, materials, temperature, power, flow) the model/prototype parameter ratios can be evaluated to check on distortions between model and prototype.

It is generally agreed that full similarity in $S t_{i R}$ and $B_{i R}$ is difficult to attain in complex thermal-hydraulic-model testing. Because these two parameters signify the temperature drops at and in the wa11s, in an attempt to simulate buoyancy around the PRISM flow circuits, their full satisfaction is not of first order importance. The simulation of this buoyancy is achieved by maintaining $R_{i R} \equiv 1$ and the pressure ratio $\left(\sum_{i} F_{i} / A_{j}^{2}\right)_{R} \equiv 1$ in the PRISM model tests.

A computer program was written to explore the model/prototype similarity, and the tradeoffs for various model designs and sets of facility control parameters. For example, PRISM size scale ranging from $1 / 5$ to $1 / 25$, with variations of the mode 1 core test section power of $1000,500,100,50$, and $10 \mathrm{~kW}$, was explored. The computer code was also used to calculate such quantities as velocity, core temperature rise, pressure drop, and flowrate in the model for these different parameters as well as the similarity parameter ratios.

The collective consideration of the resulting information and the MCTFimposed operating conditions led to fixing the PRISM model design as highlighted by the parameters given in Table I.

Table I. PRISM Model Operating Conditions and Similarity Parameters for Full Power and Flow

$$
\begin{aligned}
\text { Scale } & =5.24 \\
P & =275 \mathrm{~kW} \\
Q & =128 \mathrm{gpm} \\
\Delta T & =14.7^{\circ} \mathrm{F} \\
U_{R} & =0.086 \\
\Delta \rho_{R} & =0.0085 \\
Q_{R} & =0.00313 \\
R_{R} & =0.046 \\
P_{R} & =7.41 \\
t_{R} & =2.22 \\
S T_{R} & =1.69
\end{aligned}
$$


The actual prototype/mode 1 geometric scaling ratio is 5.24 . Prototype full flow and power are represented in the model by $128 \mathrm{gpm}$ and $275 \mathrm{~kW}$, respectively. Also, an event in the model takes 2.22 times longer to occur than in the prototype. Table II shows the model core temperature rise over its operational range for various combinations of flow/power ratio. Under conditions of $f l o w /$ power match, the model core temperature rise is $14.73^{\circ} \mathrm{F}$.

Table II. PRISM Model Core Temperature Rise

\begin{tabular}{rrrrrrrr}
\hline & \multicolumn{7}{c}{ Power, \% } \\
\cline { 2 - 8 } F10w, \% & \multicolumn{1}{c}{100} & 60 & 40 & 20 & 10 & 5 & 3 \\
\hline 100 & 14.73 & 8.84 & 5.89 & 2.95 & 1.47 & 0.74 & 0.44 \\
60 & 24.55 & 14.73 & 9.82 & 4.91 & 2.46 & 1.23 & 0.74 \\
40 & 36.83 & 22.10 & 14.73 & 7.37 & 3.68 & 1.84 & 1.10 \\
20 & 13.66 & 44.19 & 29.46 & 14.73 & 7.37 & 3.68 & 2.21 \\
10 & 147.31 & 88.39 & $\underline{58.92}$ & 29.46 & 14.73 & 7.37 & 4.42 \\
5 & 294.62 & 176.77 & 117.85 & $\underline{58.92}$ & 29.46 & 14.73 & 8.84 \\
3 & 491.04 & 294.62 & 196.42 & 98.21 & 49.10 & 24.55 & 14.73 \\
\hline
\end{tabular}

The areas below the solid lines in the columns are operationally forbidden because of excessive temperature rises which can result in boiling and/or softening of the plastic model.

The $10 \%$ power and flow condition (i.e., $27.5 \mathrm{~kW}$ and $12.8 \mathrm{gpm}$ ) is the operational dividing point between the externally driven and the internally driven test section mode of operation (see Sections 2.4 and 2.5 for greater detail).

\subsection{Model Description}

\subsubsection{Phase I}

A $1 / 5.24$ scale mode 1 of the PRISM advanced reactor design, based on the GE 1985 reference design, was constructed of transparent plastic 
(polycarbonate and cast acrylic). All major in-vessel components are represented except the active IHX heat sinks. The model fits in a two-piece cylindrical containment vessel (41-3/4 in. 10, 9-1/2 ft tal1) with large windows that are used for laser flow visualization. The vessel is described in more detai1 in Section 2.3. The reactor core is simulated by a $60 \mathrm{~kW}$ electrical-resistance immersion heater with computer-interfaceable SCR power control. Computer-controlled forced flow is provided in two ways: for lowflow conditions, four in-vesse 1 pumps (propellers driven by 1/4-hp dc motors with SCR controllers) are used; for high-flow conditions, the MCTF water loop is used. Computer control of the immersion heater and pumps allows transient simulations. The modes of operation used to simulate various transients are described in Section 2.4. The two IHXs are designed to contain heat sinks (installed in the Phase II testing), and the cold wall of the containment vessel simulates RVACS cooling.

A schematic representation of the model, showing the modeled in-vessel components, is presented in Fig. 1. Water flows up vertically in the 17-1/2in.-ID core barrel over the immersion heater elements, through the core resistance simulator, and into the upper plenum. From the upper plenum it flows into the two IHX inlets and proceeds downward where it empties via two exit pipes per IHX into the annular region between the radial shield and the containment vessel wa17. It continues downward through this region unt il it turns radially inward just below the radial shield, where it is drawn upwards through the radial shield into four pump inlets. The flow leaves the pump exit plena in the downward direction by means of eight core inlet pipes (four pipes per pump exit plenum) to return either to the core or, by way of two exit manifolds, to the MCTF, depending on the mode of operation (see Section 2.4 for discussion on modes of operation). Included in the model is a $1 / 4$ in. annular overflow gap for the study of transients involving RVACS cooling. Perforated plates provide the proper pressure drops through the IHXs (i.e., perforated plates are located at both the inlets and exits), and the core (an 18-in.-tall cylinder with 30 equally spaced, circular perforated plates, which fit in the core barre1). The pressure drop similarity is based on Euler number matching between prototype and model at 10\% flow. At the exit of each of the four pumps, three rows of circular holes are drilled around the 


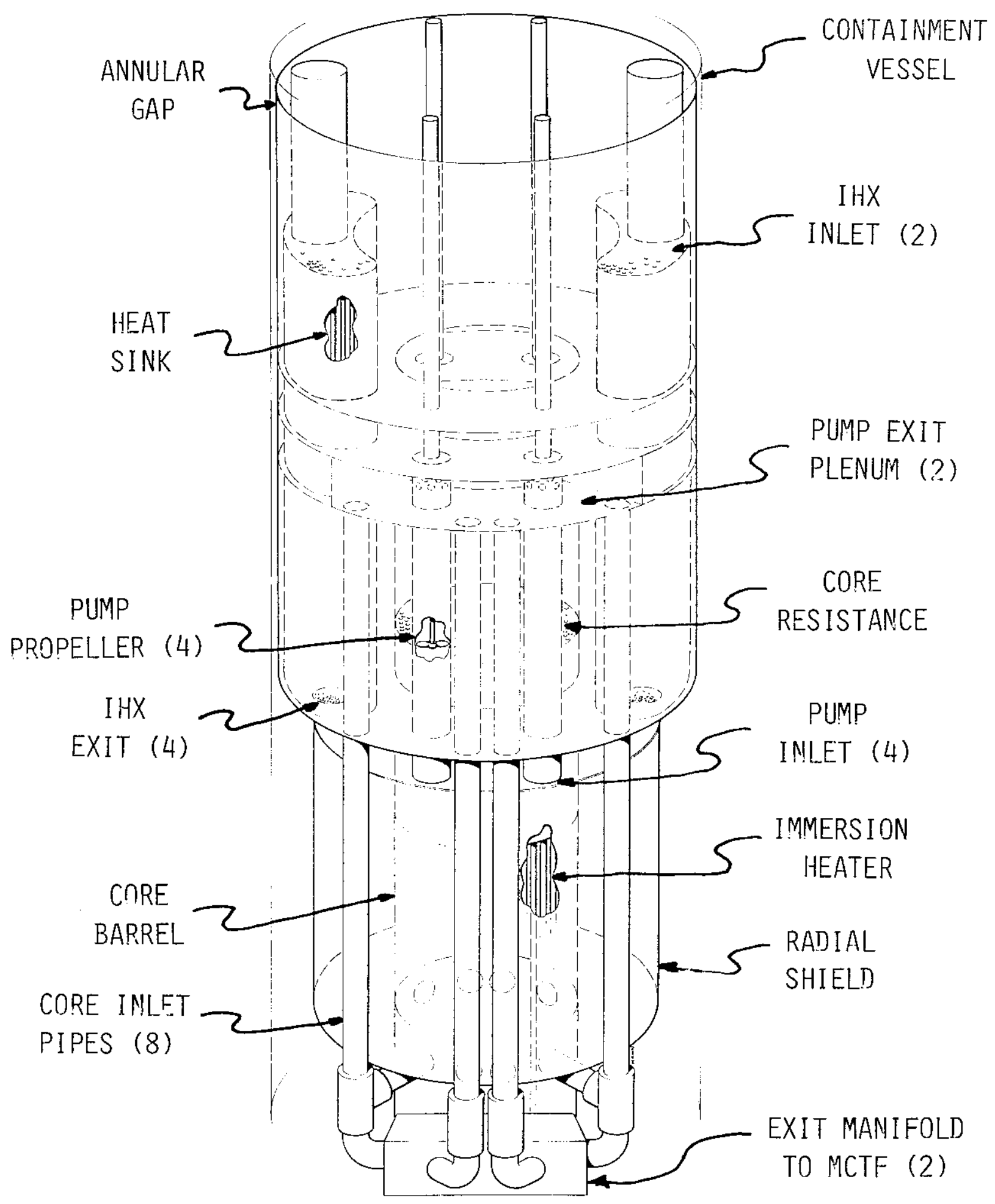

Fig. 1. ANL/MCTF Therma1-Hydraulic Model of GE/PRISM Advanced Reactor Concept 
circumference, similar to the prototype. The dimensions of critical components are indicated in Fig. 2 and Table III.

Table III. Dimensions of PRISM Circular Cross Section Features

\begin{tabular}{lc} 
Feature & Dimension (in.) \\
\hline & \\
Core Barrel (ID) & 17.5 \\
Containment Vesse1 (ID) & 41.7 \\
Plenum Wal1 (OD) & 41.2 \\
Annular Overflow Gap & 0.25 \\
Radial Shield Wal1 (OD) & 34.0 \\
Pump Housing Pipes (ID) & 3.5 \\
Core Inlet Pipes (ID) & 2.25 \\
IHX Outlet Pipes (ID) & 3.5 \\
IHX Secondary Flow Pipes (OD) & 5.5 \\
IHX Centerline Circle Diameter & 33.3 \\
Pump Housing Centerline Circle Diameter & 29.8 \\
Core Inlet Pipe Centerline Circle Diameter & 38.0 \\
\hline
\end{tabular}

The completed plastic model is shown in Fig. 3, prior to insertion as a single unit into the containment vessel. Two kidney-shaped intermediate heat exchangers can be seen (without cooling coils in place) in the top half of the model, one in the forefront and the other in the rear. The radial shield and the core inlet pipes are visible in the lower half of the model. Near the bottom, in the core barrel, an inner tube serves as flow diverter. This inner tube, when inflated, blocks off flow from the ejght core inlet pipes and thus allows the flow to be routed back to the MCTF. Near the bottom, outside the core barrel, flexible metal ducting connects the core inlet pipes to the return manifolds which route the flow back to the MCTF. Almost halfway up the model, on both sides, propellers mounted on 1/2-in. shafts are visible. The shafts extend to the top of the model where they are coupled to dc motors (located outside of the vessel) when the model is in the containment vessel and the top cover is in place.

A view of the 60 -in.-long lower section of the two-section containment vessel is shown in Fig. 4. The $60 \mathrm{~kW}$ immersion heater is seen through the windows, protruding from the center of the floor of the pressure vessel. Large bolts in the foreground show the attachment of the vessel to the steel 


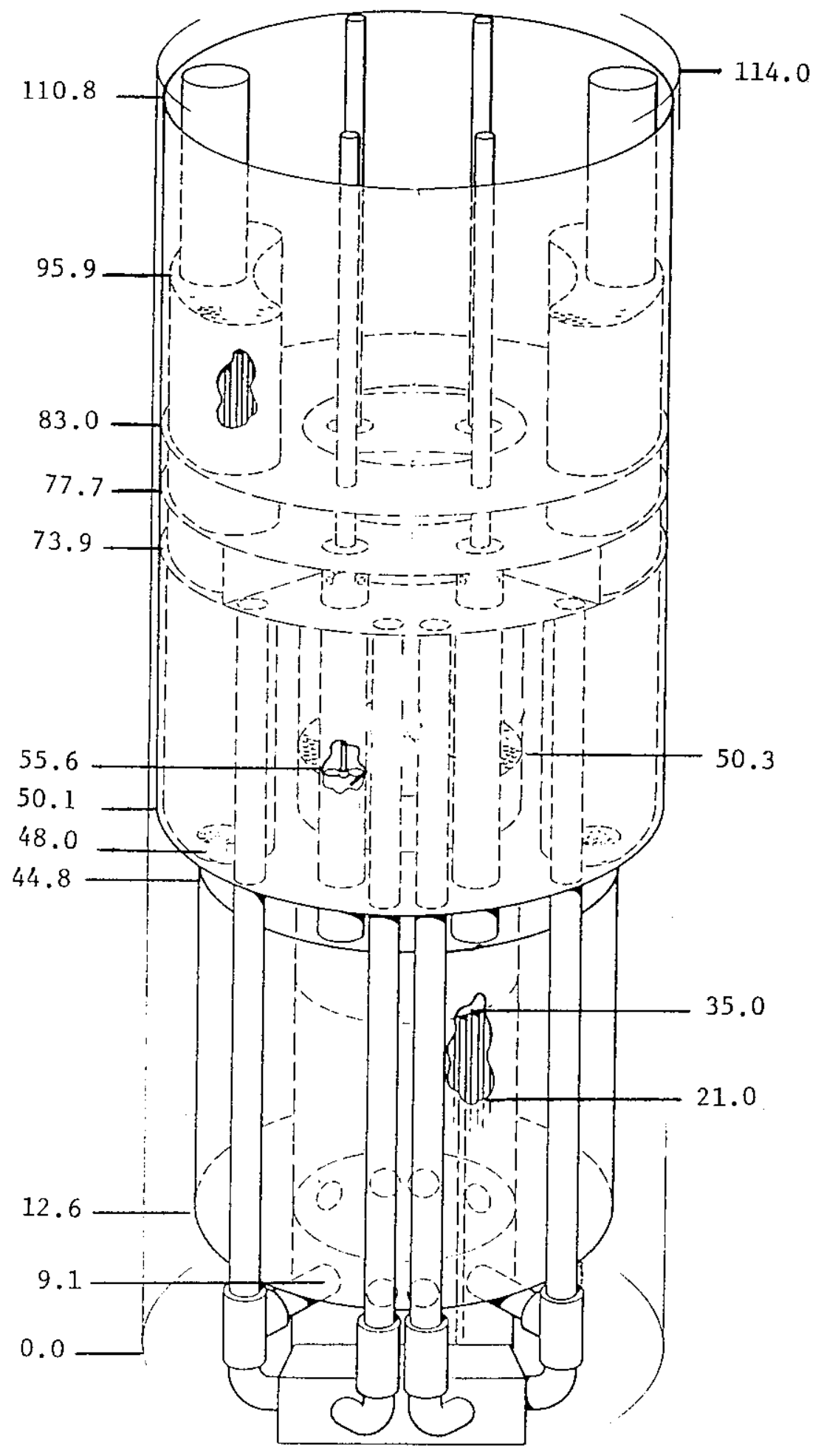

All Dimensions in Inches

Fig. 2. PRISM Model Elevation Dimensions of Key Features 


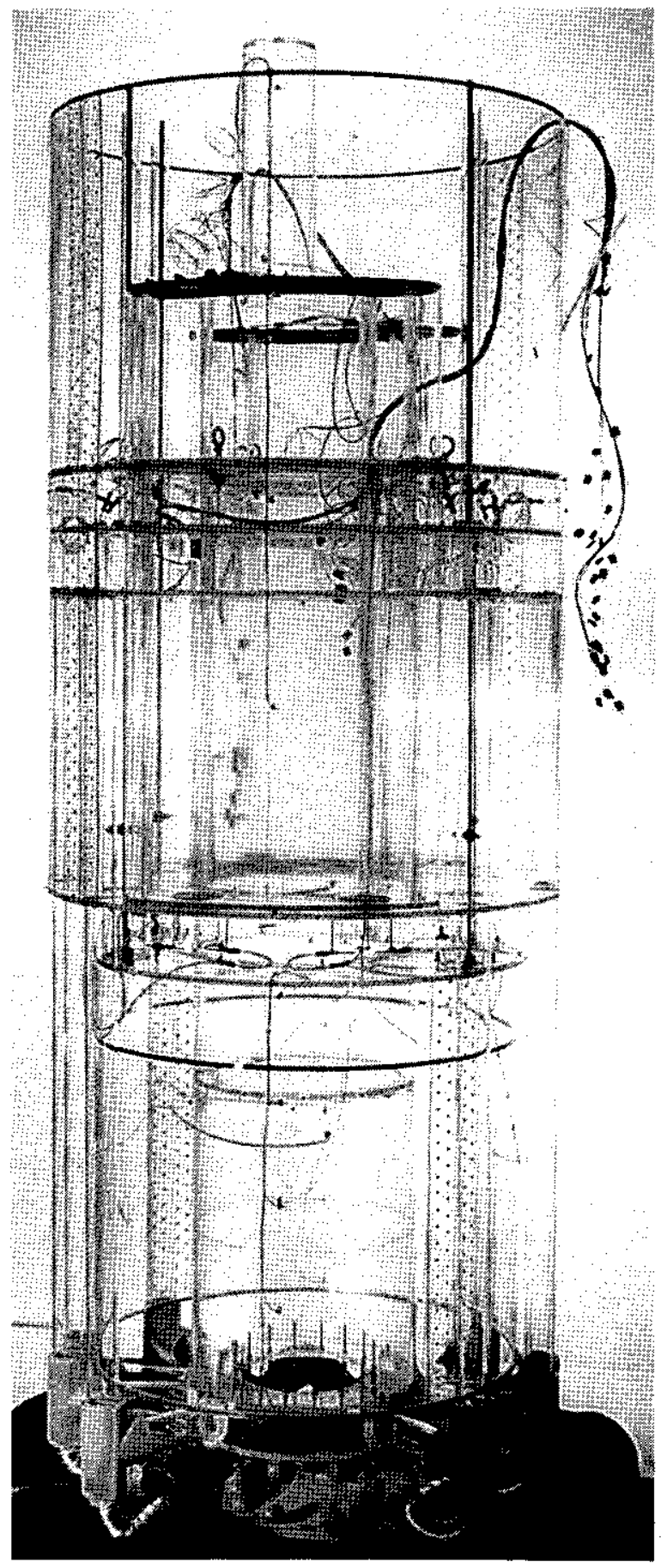

Fig. 3. Completed ANL Plastic Model of PRISM 


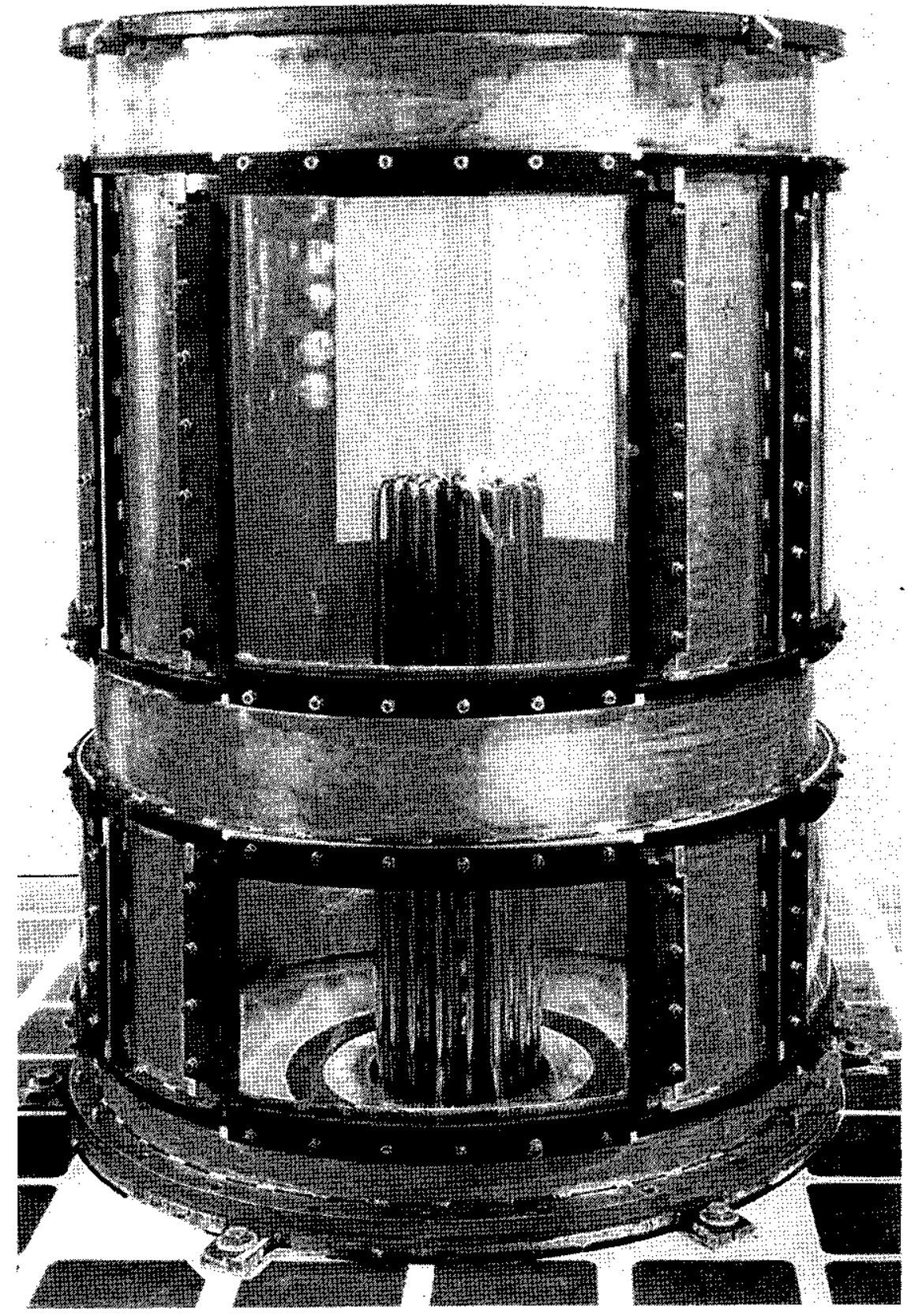

Fig. 4. View of Lower Haif of Containment Vessel with $60 \mathrm{~kW}$ Core Heater Mounted in Place 
support stand. Figure 5 shows the PRISM model sitting in the lower section of the vesse1. The PRISM model, with the upper half of the containment vessel in place, is shown in Fig. 6, together with a view of the MCTF facility at the right (described in Section 2.3). The left portion of the picture is the Argonne Advanced Reactor Test Center (described in Section 2.3).

Various subregions of the model are shown in Figs. 7-10. Figure 7 shows a pump inlet, near the center of the picture, with the propeller near the top center. A view looking at an angle down on the upper plenum floor is shown in Fig. 8. Kidney-shaped IHXs are located on both sides. In addition, in the lower center of the photograph, a pump exit plenum (common to two perforated pump outlet pipes) is visible together with the entrances to four core supply pipes. The circular holes around the circumference of each pump exit are clearly visible. Thermocouple locations are also clearly visible. Figure 9 is a bottom view showing the two exits from a kidney-shaped intermediate heat exchanger. Instrumentation, both thermocouple and pressure taps (or dye injectors), are clearly visible. Figure 10 is another view of the pump exit plenum (seen in the upper right) and the propellers of two pumps (seen in the lower right).

Thermocouples are positioned at the entrance and exit of each subregion of the model. Thermocouples mounted on vertical stings are used to measure vertical temperature gradients that are encountered in thermal stratification. Thermocouples mounted on horizontal stings are used to measure radial or circumferential temperature gradients in key regions such as near the welds of the IHXs to the reactor outlet plenum floor. The various thermocouple locations on the model are shown in Figs. 11 and 12, together with their designations. Thermocouples are also mounted on four movable stings (rods with thermocouples mounted on them): two in the hot upper plenum, off center (one on a radius through the center of an IHX, the other on a radius midway between $I H X S$ ) ; one on the centerline protruding down the core barrel to the top of the core heater; and one in the lower cold plenum near the radial shield. The stings in the outlet plenum are mounted on the cover, whereas the sting in the lower plenum is mounted on the floor of the containment vesse1. Strings of thermocouples are used in this text to denote thermocouples mounted in a straight line (i.e., horizontal or vertical) on an object such as the floor of a plenum or the radial shield liner. 


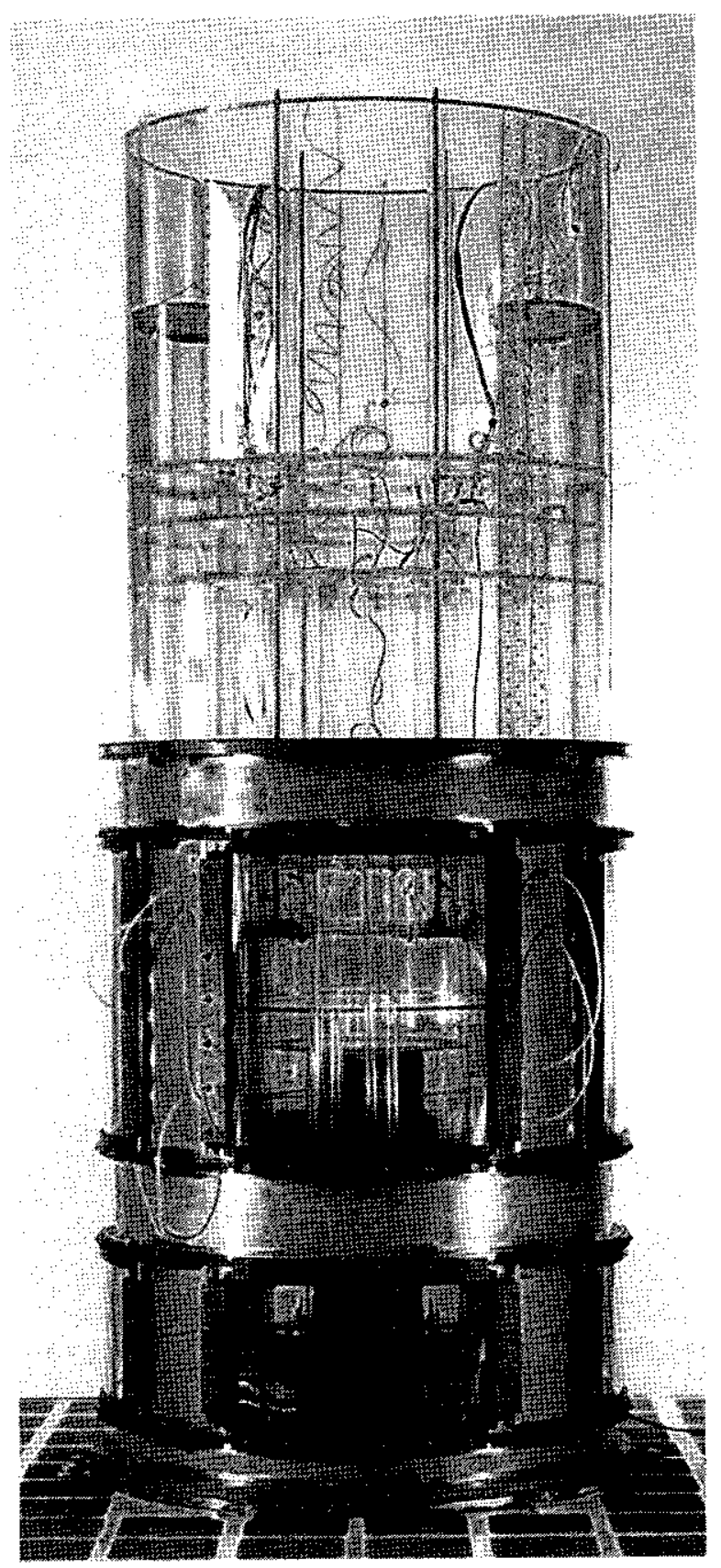

Fig. 5. PRISM Model on Test Stand Inserted in Lower Portion of Containment Vessel 


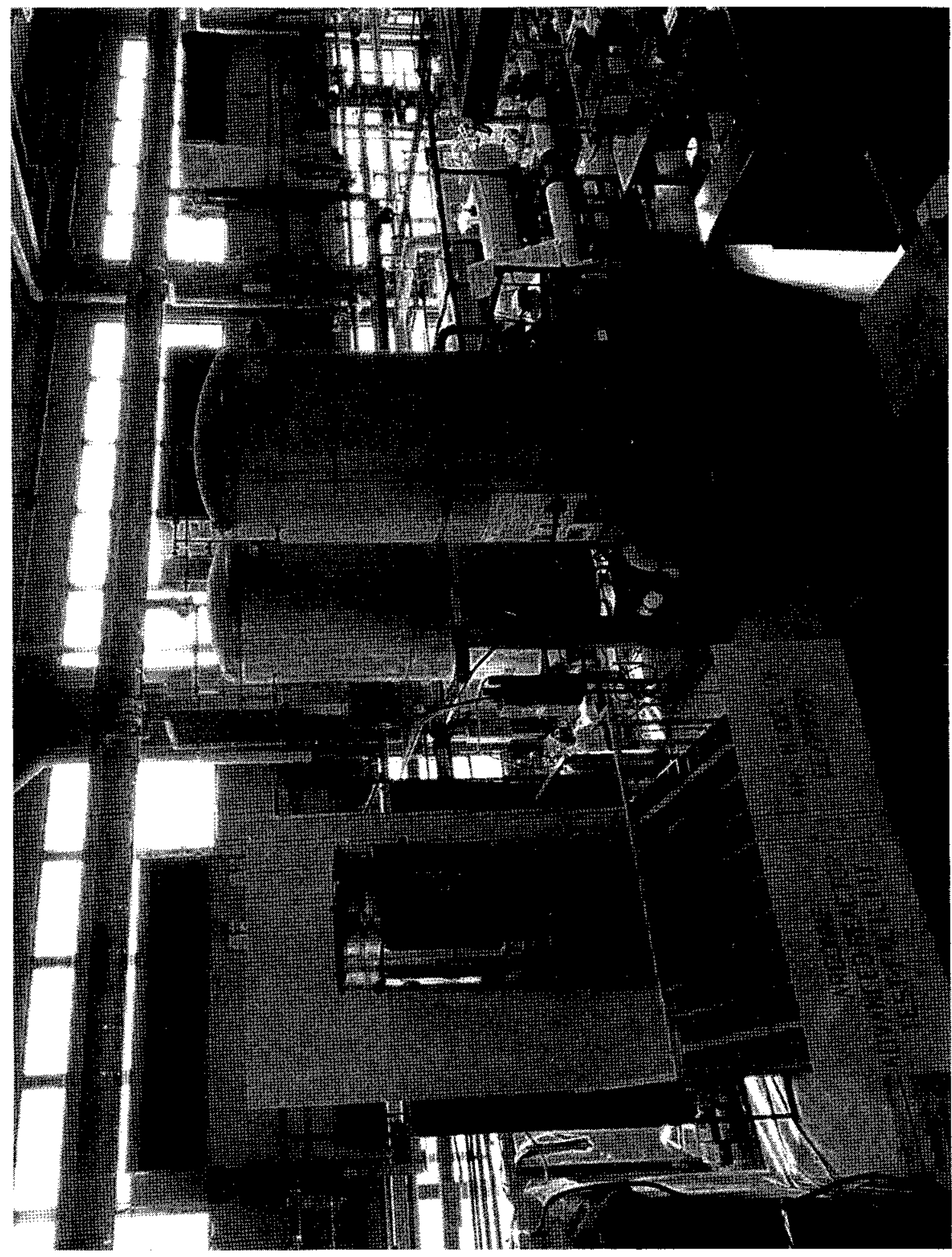

年

งิ ช

岂

$+$

空

E⿺

ro

$+$

乌

$=\stackrel{\alpha}{\alpha}$

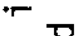

명

¿

오궁

을

을

돈

政

음 生

$0^{\circ}$

무 


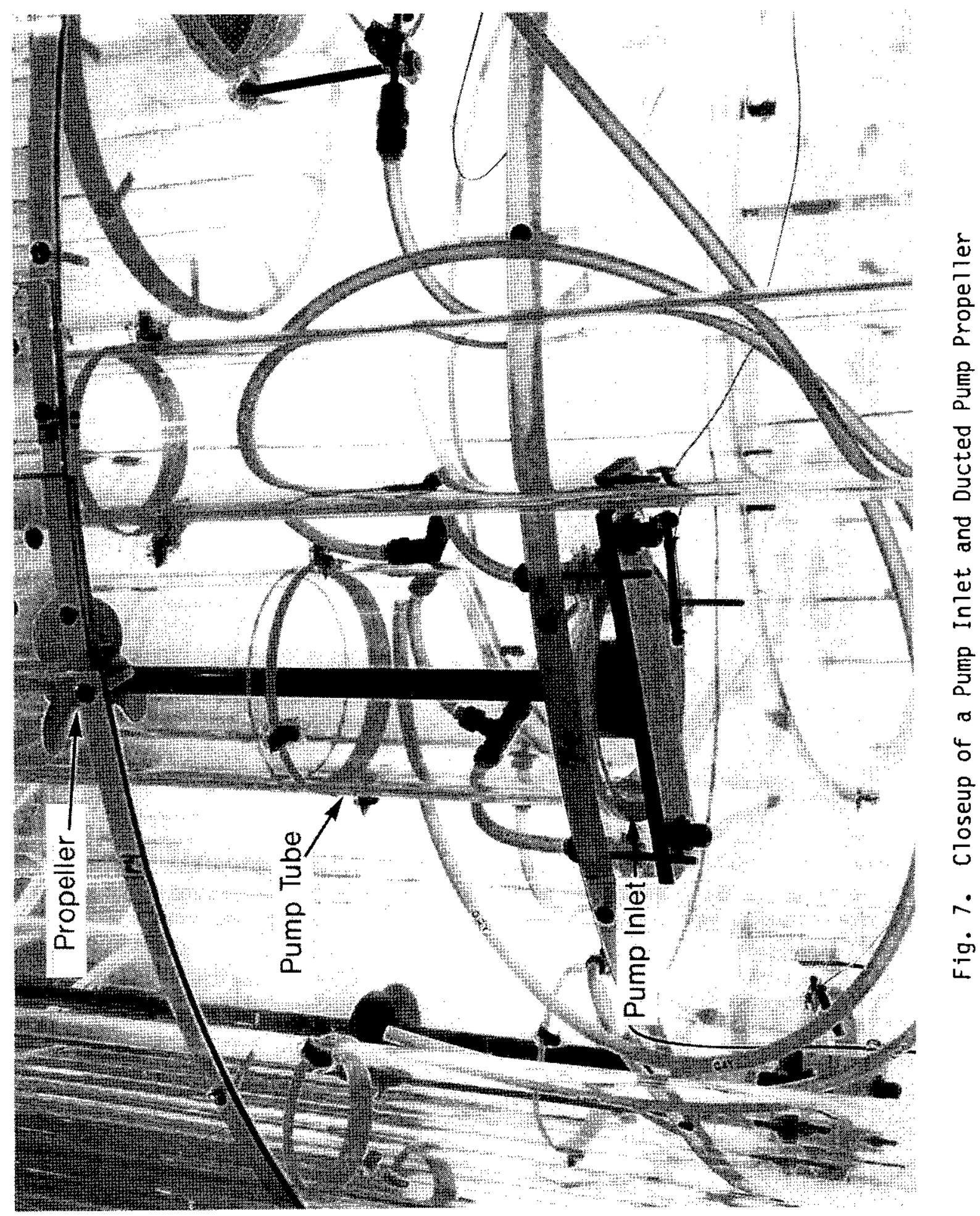




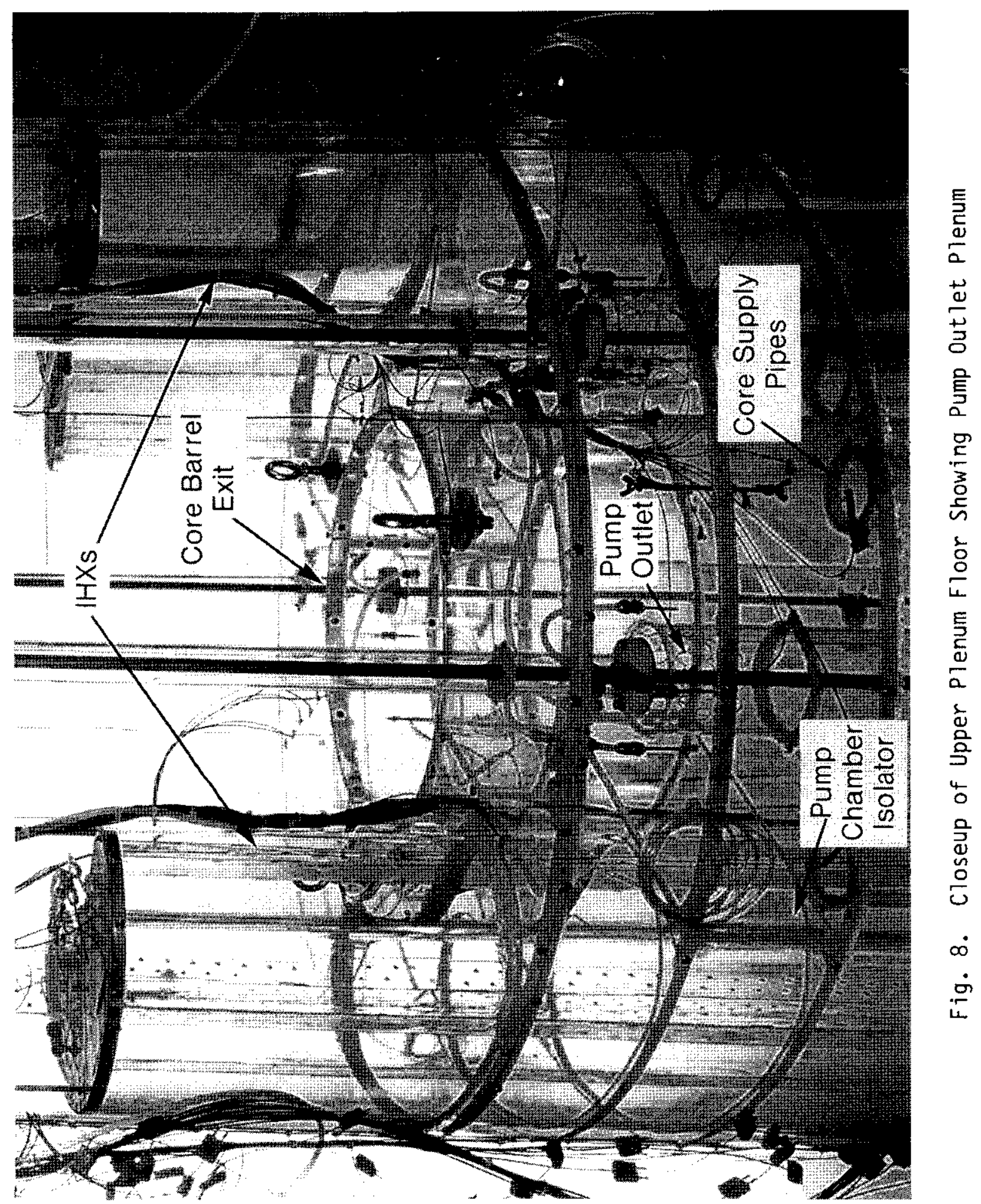




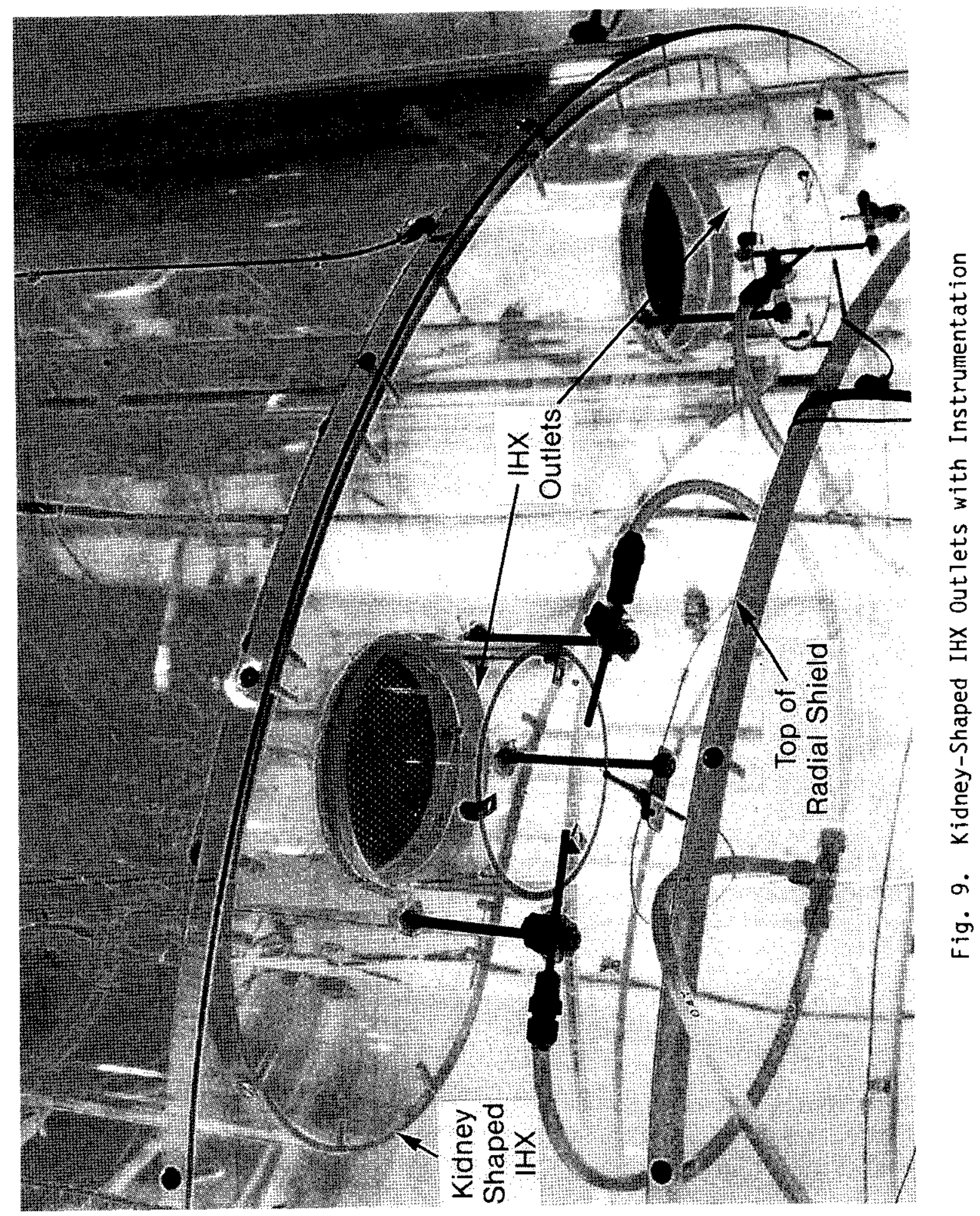




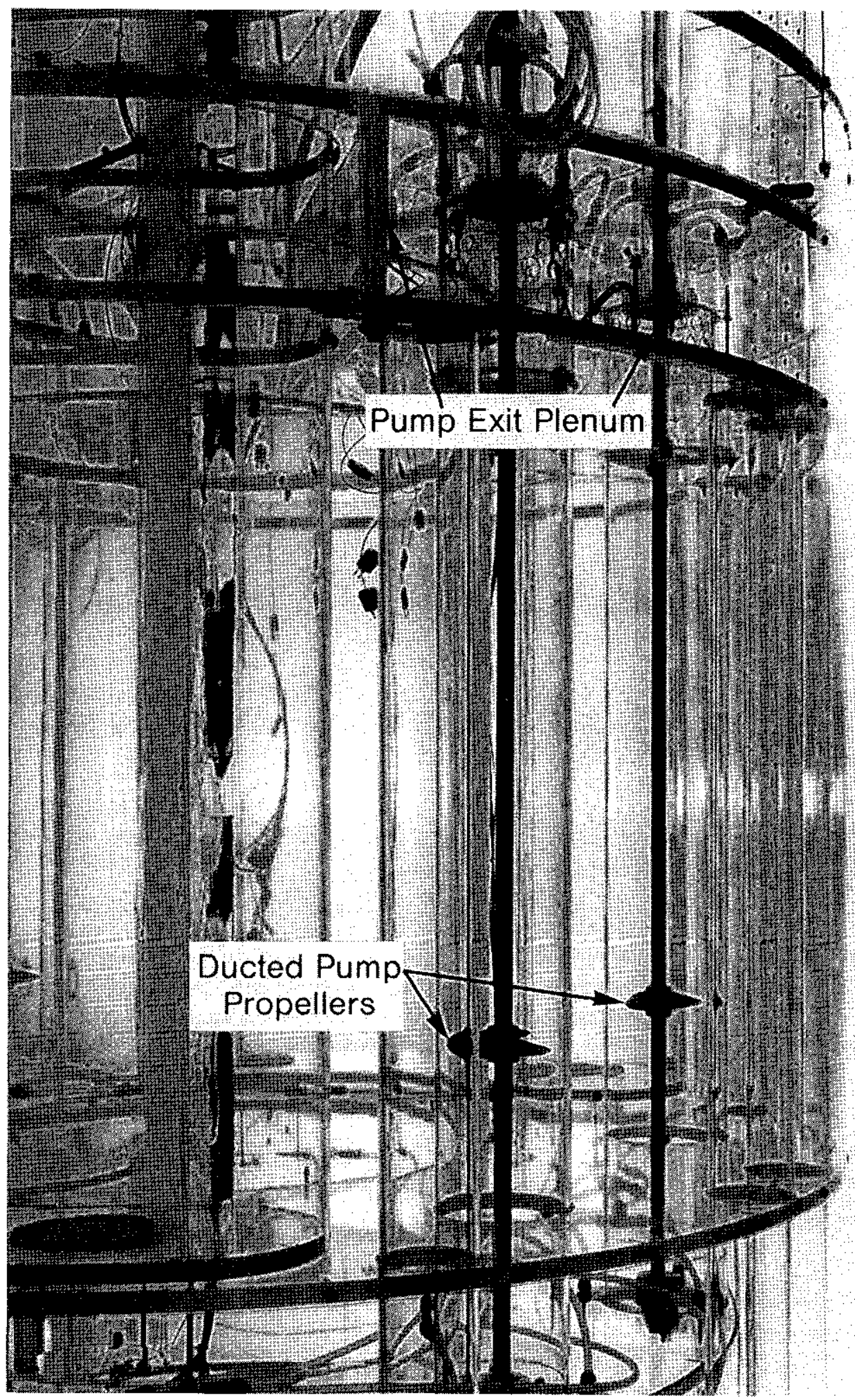

Fig. 10. View of One of Two Pump Exit Plenums and the Pumps that Supply Flow to the Plenum 
$N$

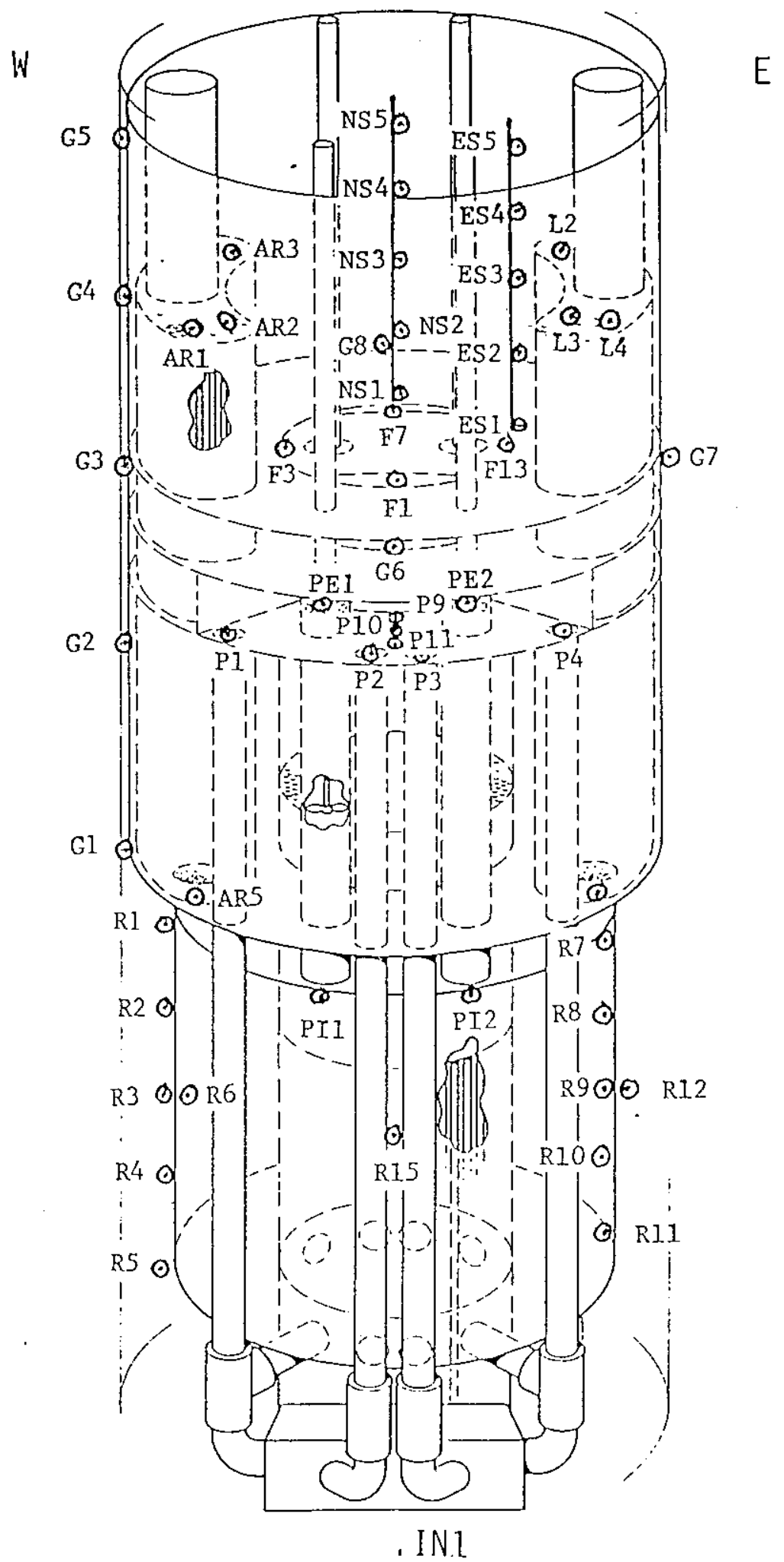

Fig. 11. Locations of PRISM Thermocouples in ANI. Model of PRISM 
S

E

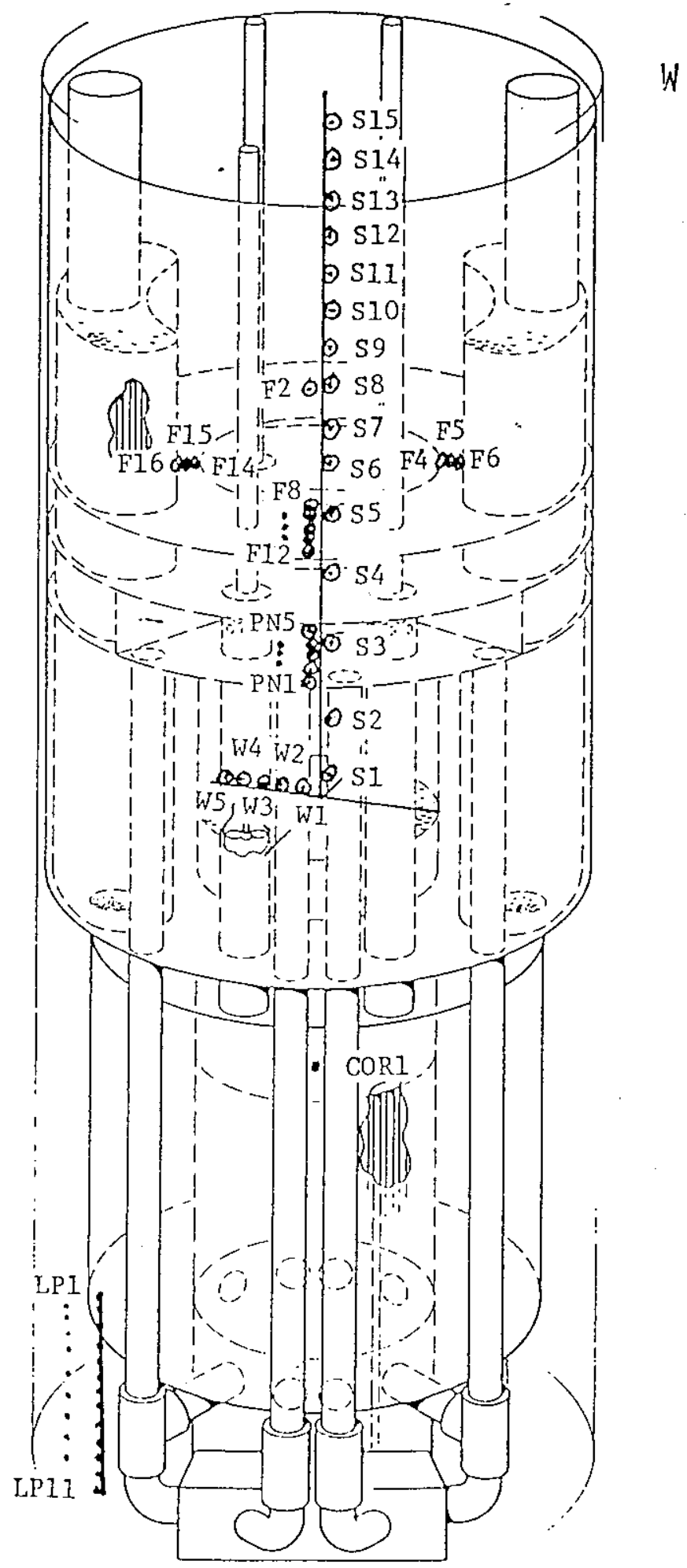

Fig. 12. Locations of PRISM Thermocouples in ANL Model of PRISM. 
The core barrel sting has radial arms at its lower extremity with a series of thermocouples mounted on it to measure the uniformity of the core flow temperature. The sting can be rotated to map out the entire core.

Pressure taps are located at the entrance and exit of key subregions (see Fig. 13). These pressure taps can be used to inject dye to make time-offlight measurements and thus, to determine velocities in key regions. Additional dye injectors on the rotatable vertical sting on the core centerline (one on each of the four horizontal radial legs, at varying distances from the centerline) are used to trace communication between discrete core locations and the IHX inlets.

\subsubsection{Phase II}

During the four- or five-month period after Phase I testing, evolving PRISM design changes were evaluated with respect to their relative importance to the ANL model. When a design change was thought to have a possible impact on the thermal-hydraulic tests, it was included in the model after consultation with GE. The following changes were incorporated in the ANL PRISM thermal-hydraulic model for Phase II tests: increased simulated core resistance, a UIS, heat sinks in the two IHXS, and modification of the inlets to the IHXs. Each of these changes will be described in more detail in the remainder of this section.

Phase I testing indicated that the core pressure drop was too low and needed to be increased by approximately 50\%. For this reason, 15 additional circular perforated plates were added; thus, a total of 45 circular perforated plates simulated the core resistance. Modeling required Euler number similarily, and the increased core resistance satisfied this criterion.

The UIS was constructed of a 12-in. 0D, 54-3/4-in.-long, cast acrylic plastic tube with a 2-1/2-in.-wide vertical slot, as shown in Fig. 14 . The slot simulates the opening in the UIS for refueling. The slot is divided into thirds by two ribs of plastic to maintain the rigidity of the UIS model. Circular discs, with 2-1/2-in.-wide radial slots, are attached to both ends of the plastic slotted tube. A plug in the center of each of the end discs is used to center the UIS model when mounted. The UIS is mounted on the center thermocouple sting, which hangs from the centerline of the containment vessel cover of the PRISM thermal-hydraulic model. Mounting the UIS on the center 


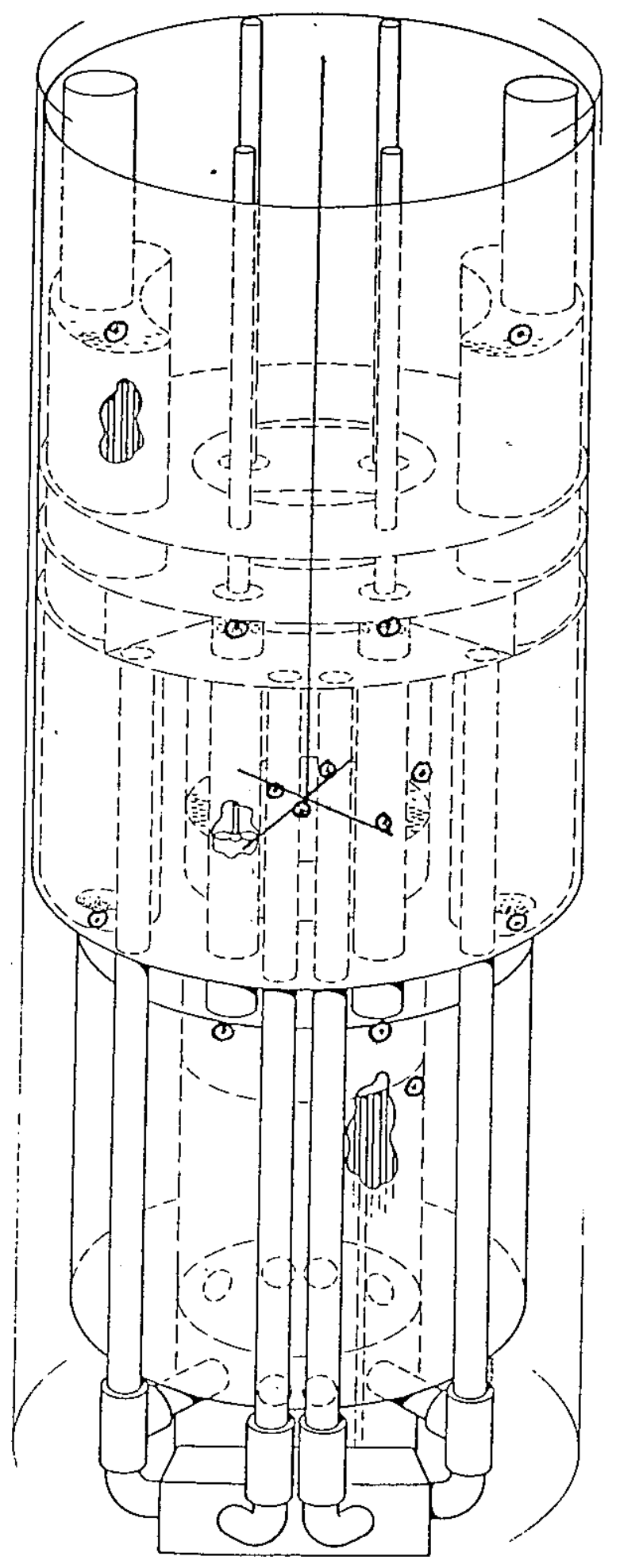

Fig. 13. PRISM Model Pressure Taps/Dye Injection Ports 


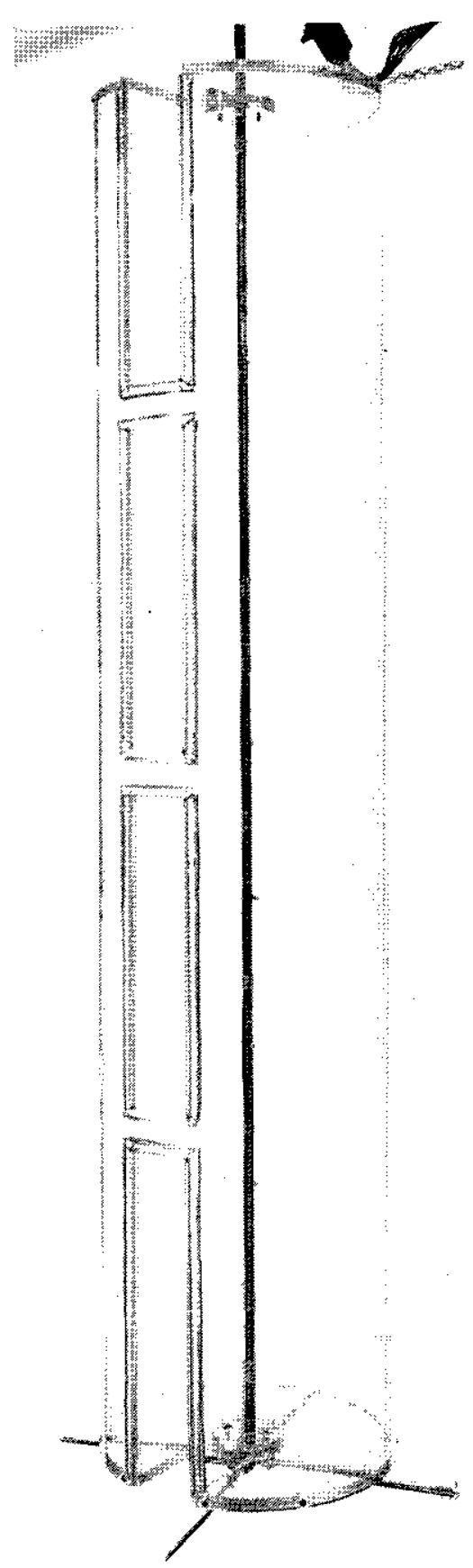

Fig. 14. UIS Model Mounted on Thermocouple Sting 
thermocouple sting allows repositioning of the UIS, both vertically with respect to the core, and rotationally, so that the slot and dye injectors can be rotated to any desired location above the core.

Copper coil heat exchanger internals were designed to reject approximately 10-15\% of simulated prototype full power (i.e., 27.5-40.8 kW) by means of bullding cooling water (i.e., canal water). Approximately $118 \mathrm{ft}$ of soft copper tubing ( $3 / 8 \mathrm{in} .00,0.305 \mathrm{in}$. ID) was coiled in a rectangular pattern to form a filat sheet which was then curved to the contour of the kidney-shaped heat exchanger. Four such plates were bound together to form the internals for each of the IHXs, as shown in Fig. 15. Baffling was accomplished by placing stainless steel wool at alternating locations between the four coiled sheets (as seen along the edge of the internals in Fig. 15) to promote crossflow over the copper tubing, and by placing a stainless stee perforated plate near the bottom of the internals to prevent the flow from streaming directly into the two small circular exits of each IHX (as seen in the lower portion of Fig. 15). One of the internals is shown in the plastic, kidney-shaped IHX in Fig. 16. Three rubber deflectors are shown near the far curved wall of the IHX; these are used to divert the flow back toward the center of the internals. Any open space between the near curved wall and the internals was filled in to prevent flow channeling, which would lessen the effectiveness of the internals. The inlets of each of the four plates of each IHX were fed from a common inlet manifold and, similarly, the outlets were connected to a common outlet manifold. The total flowrate of the secondary side of both IHXs was measured by a turbine flowmeter, and this flowrate, together with the temperatures of the inlet and outlet manifolds, was monitored by the Data Acquisition System (DAS), thus enabling the calculation of the heat sink capacity during a simulation of a prototypic transient.

Finally, the GE IHX inlet design was changed from flow entering vertically through the top of each IHX to flow entering radially inward near the top of each IHX. With this design change, a concern developed about possible choking of the flow that was going through the gap between the outer IHX wall and the liner. For this reason, the gap was enlarged. In order to conveniently accommodate these changes, a window was cut out in the upper portion of the IHX outer wal1 (i.e., 12-1/4 in. from the top of the IHX or 1 in. above the hot plenum floor) to increase the gap between the liner and 


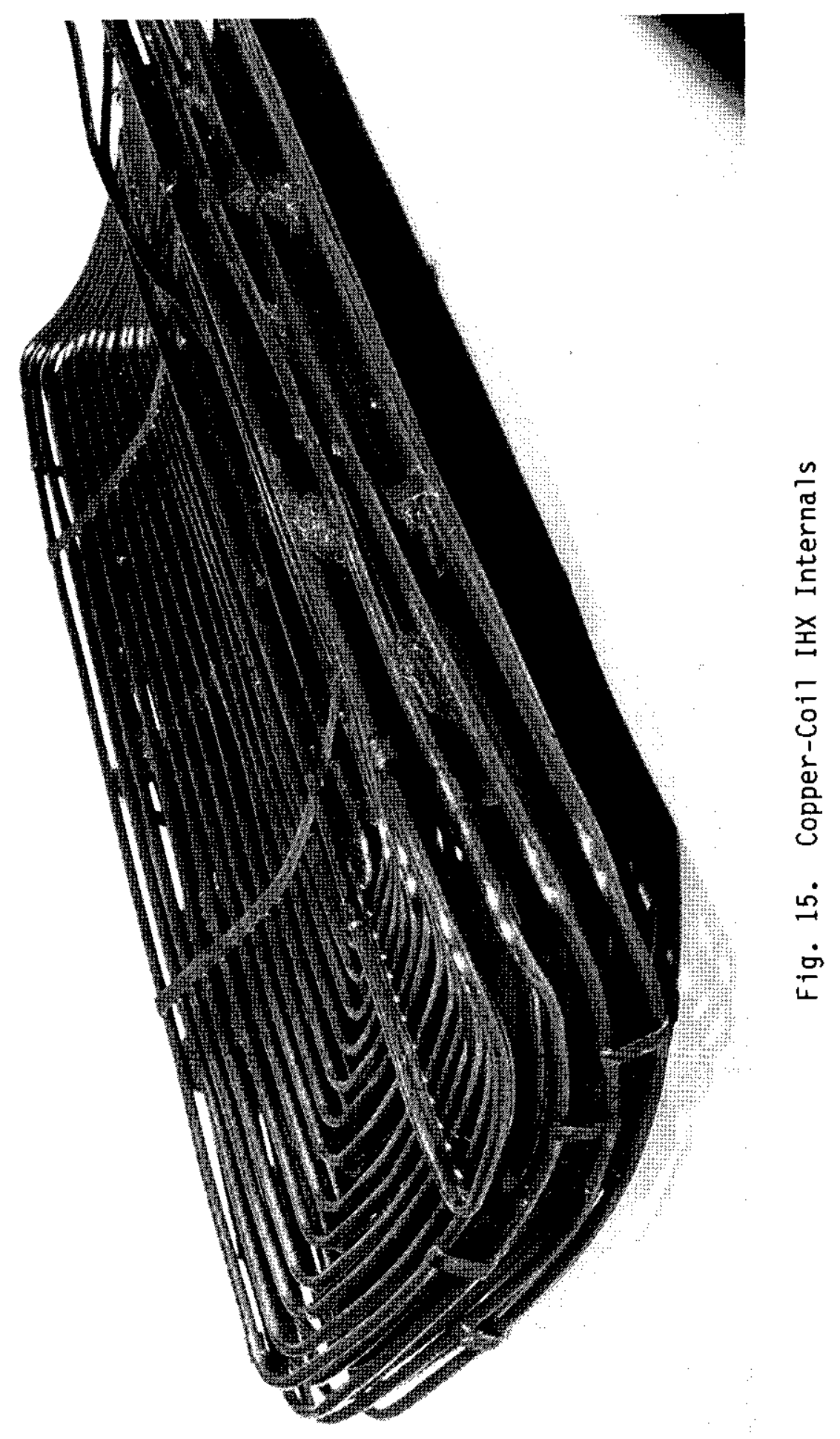




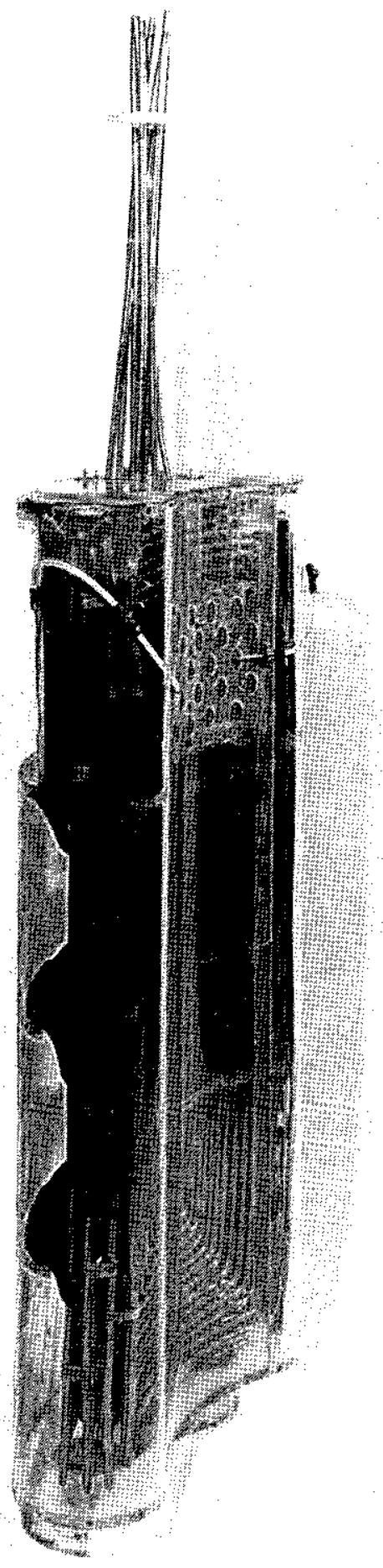

Fig. 16. Complete IXH Model with Copper Coil Internals 
the outer IHX wall from $1 / 2$ in. to $1-1 / 2$ in. In this model design, core flow has equal access to this gap from both, the sides and top of the IHX. The cut out window and the associated ledge that is used to move the outer radial wall inward is shown in Fig. 17. In order to have a more even split of pressure drop across the IHX (i.e., half at the IHX inlet and half at the outlets), as requested by GE, 63\%-open-area, stainless stee1, perforated plates (0.156-in.ID holes and 20 gauge) were necessary in the 3-1/2-in.-ID IHX exits. Thus, four circular discs were made, one for each outlet, to replace the higher resistance discs that were used in Phase I. A 23\%-open-area, stainless stee1, perforated plate $(0.0625-\mathrm{in.-ID}$ holes and 22 gauge) continued to be used for the IHX inlets. A flow area of $60.25 \mathrm{sq}$. in. was necessary to give the required pressure drop of 0.000221 psi at $10 \%$ of simulated full flow. In order to obtain a uniform flow distribution within the area of the inlet, a uniform staggered pattern of 1-in.-ID holes in 5 rows was drilled around the circumference of each IHX, over which the 23\%-open-area perforated plate was attached to provide the proper resistance. The vertical distance between 1 in.-ID hole centers was 1-1/4 in., and the horizontal distance between hole centers was 2-1/4 in. The same hole pattern was used on both the inner and outer radial surfaces of the IHX inlet. The inner surface had 25 holes (5 rows of 5 holes), as shown in Fig. 18, whereas the outer suface had 52 holes ( 3 rows of 10 and 2 rows of 11 holes), as shown in Fig. 17. These holes are located within a region between $1 \mathrm{in}$. and 6-1/4 in. above the hot plenum floor. To avoid possible weakening of the model, the holes were not drilled in the seams between the half cylinders that formed the sides of the IHXs and the intervening curved plastic sheet. Thus, the inlet of the ANL model is somewhat smaller than prototypic, but it retains the most important therma1hydraulic characteristics of the inlet. The perforated plate was mounted over these holes to provide the proper resistance. Because of the gap modification, the vertical cylinder, which is mounted on the IHX solid top, and through which the inlets and outlets of the copper coil internals exit the IHX, is centered on the solid top (see Fig. 16), not on the IHX.

\subsection{Facility}

\subsubsection{Description of MCTF}

The tests were performed in the ANL Material and Components Technology Division's MCTF which is interfaced with the Advanced Reactor Test Center. 


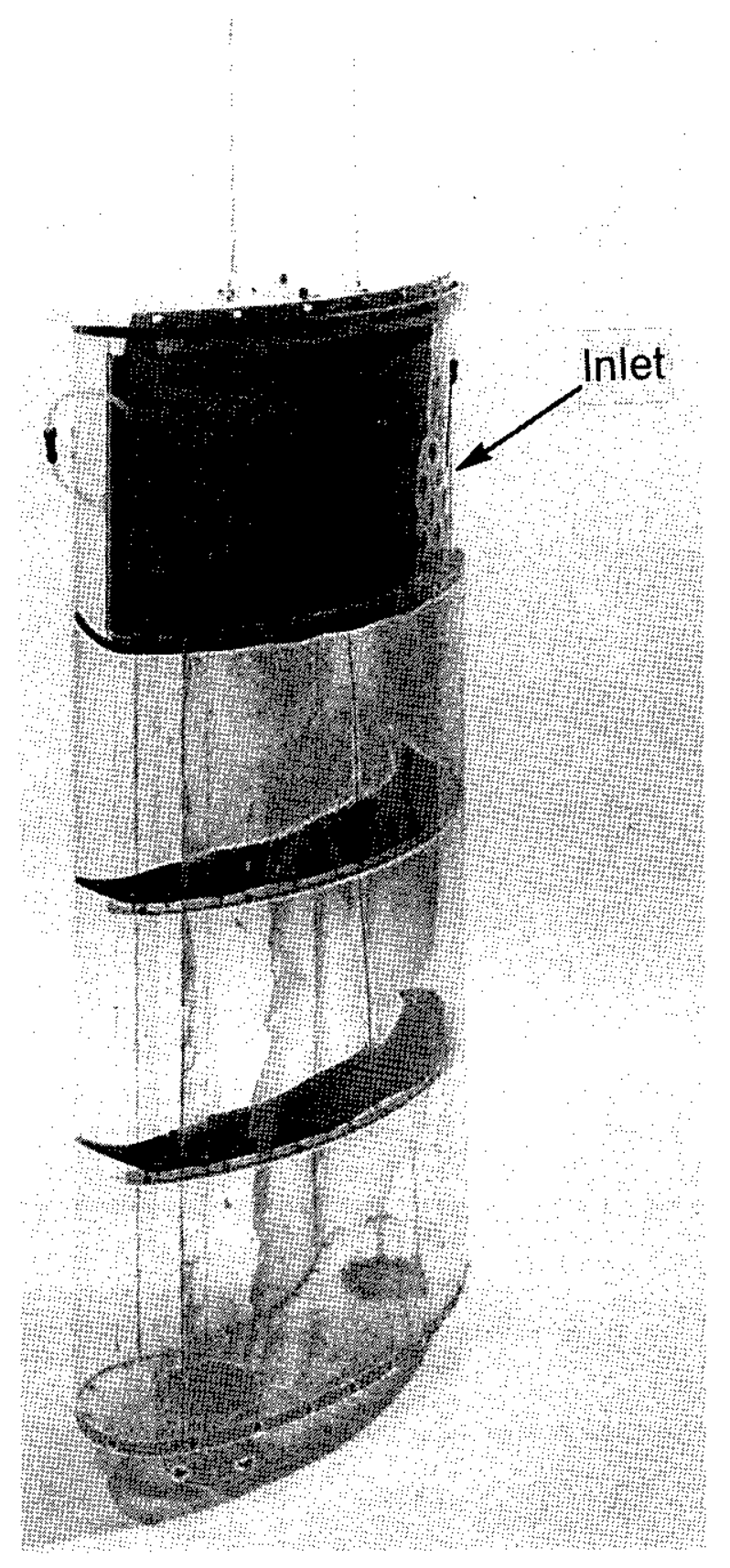

Fig. 17. View of IHX Inlet on Outer Radial Wall 


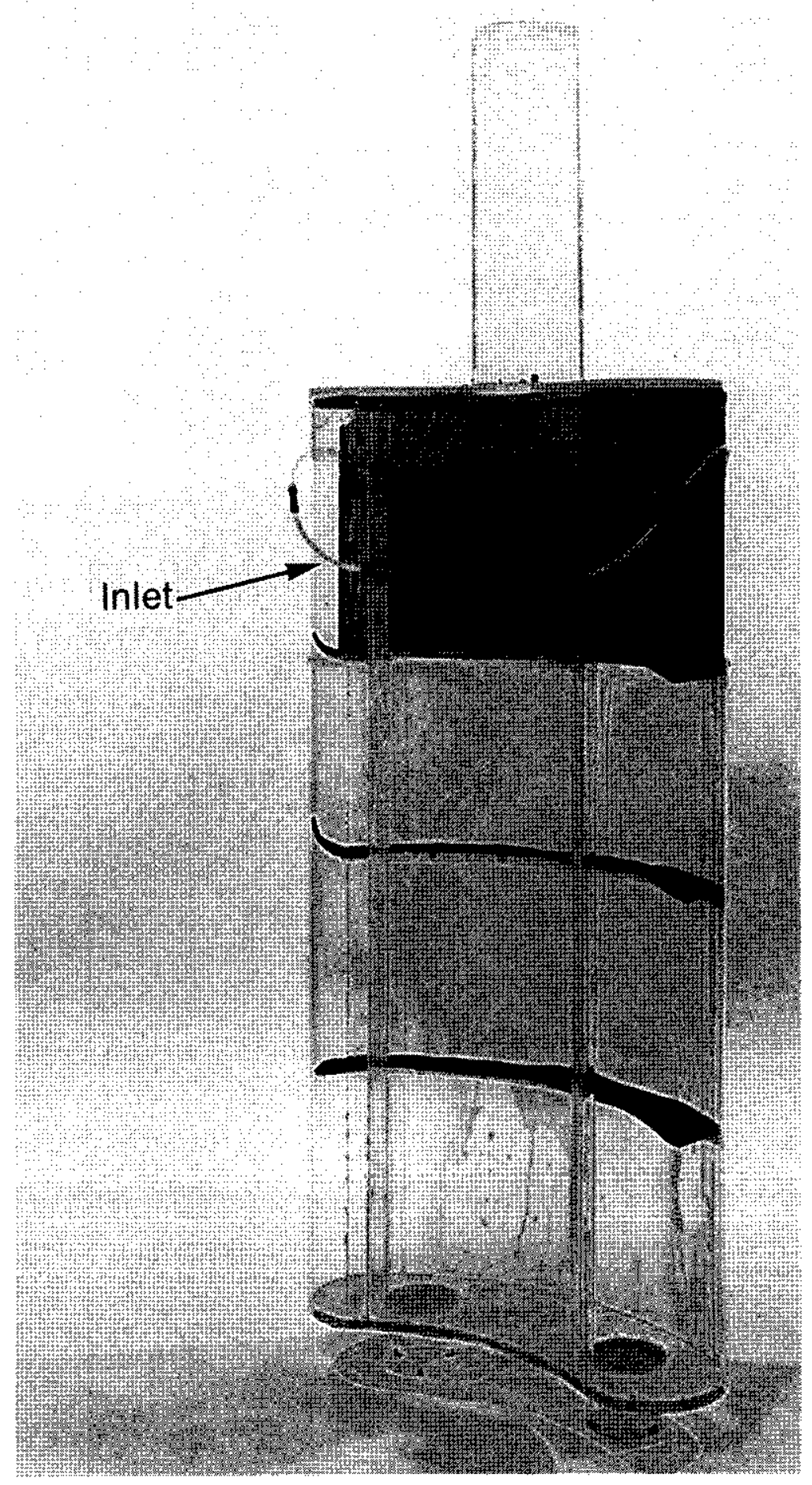

Fig. 18. View of IHX Inlet on Inner Radial Wall 
The MCTF is a low-pressure ( 0 to $100 \mathrm{psig}$ ), low-temperature (40 to $240^{\circ} \mathrm{F}$ ), closed-system, circulating-water loop. Figure 19 is a photograph of the facility. A simplified schematic diagram of the loop is shown in Fig. 20. The flow from a $2200-\mathrm{gpm}\left(454-\mathrm{m}^{3} / \mathrm{hr}\right)$ pump is split into two streams: one stream goes to a controllable steam-heated heat exchanger; the other goes to a controllable water-cooled heat exchanger. The hot, $Q_{H}$, and cold, $Q_{C}$ streams at temperatures $T_{H}$ and $T_{C}$ go to separate 3000 -gal $\left(11.356-\mathrm{m}^{3}\right)$ reservoir tanks, from which flows at the two respective temperatures and desired flowrates can be supplied. The supply-line flowrates are measured with turbine flowmeters. The return leg to the pump contains an ASME orifice plate flowmeter that can be used as a check on system flow.

The test facility can operate in two modes: steady-state and transient computer-controlled.

\subsubsection{Steady-State Mode}

In this mode of operation, fluid streams, at individually selected constant flowrates and constant temperature, can be delivered to a test section. The streams can be set at the supply tank temperatures, $T_{H}$ and $T_{C}$, or the flow from the two tanks can be combined by means of valves to achieve intermediate temperatures.

\subsubsection{Transient Computer-Controlled Mode}

The transient streams are created by combining, at a given instant, the appropriate relative amounts of $Q_{H}$ and $Q_{C}$ to obtain the desired instantaneous flowrate and temperature. Control valves and turbine flowmeters in lines $A$ and $B$ are interfaced with the MCTF minicomputer system. A control 10op between the valve and the flowmeter, in conjunction with computer-stored functions that describe the desired transient flow and temperature, allows transient simulation. The two transient-controlled streams are combined at flow-mixer point $C$, and the resulting thermal-hydraulic transient is supplied to the test section.

In the MCTF, a high-speed minicomputer data-acquisition system accumulates real-time data and provides after-the-fact analysis. The system can currently accept up to 192 data channels. Signal conditioning in the form 


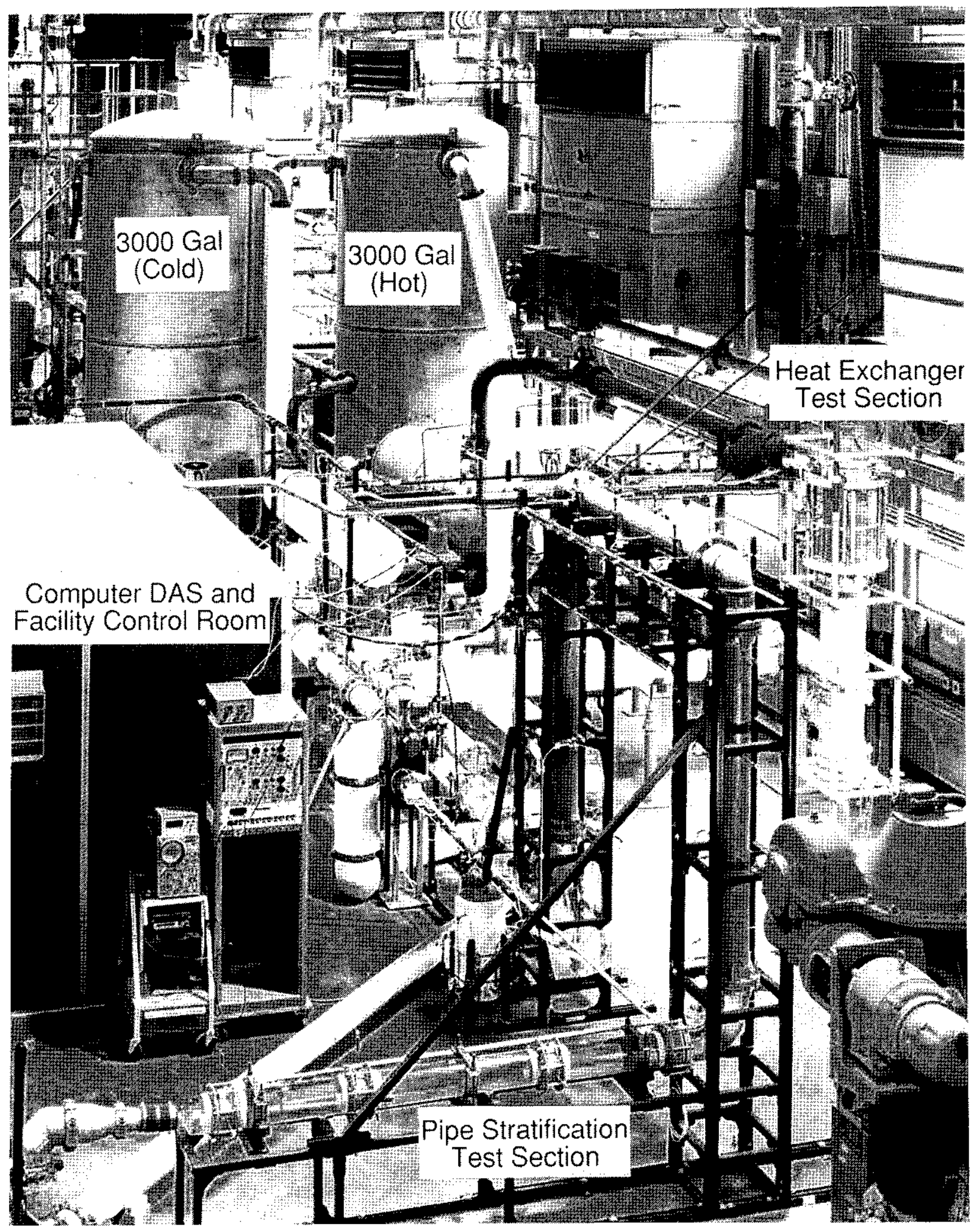

Fig. 19. ANL Mixing Components Test Facility, 2000 gpm Thermal-Hydraulic Transient Simulation Water Loop 


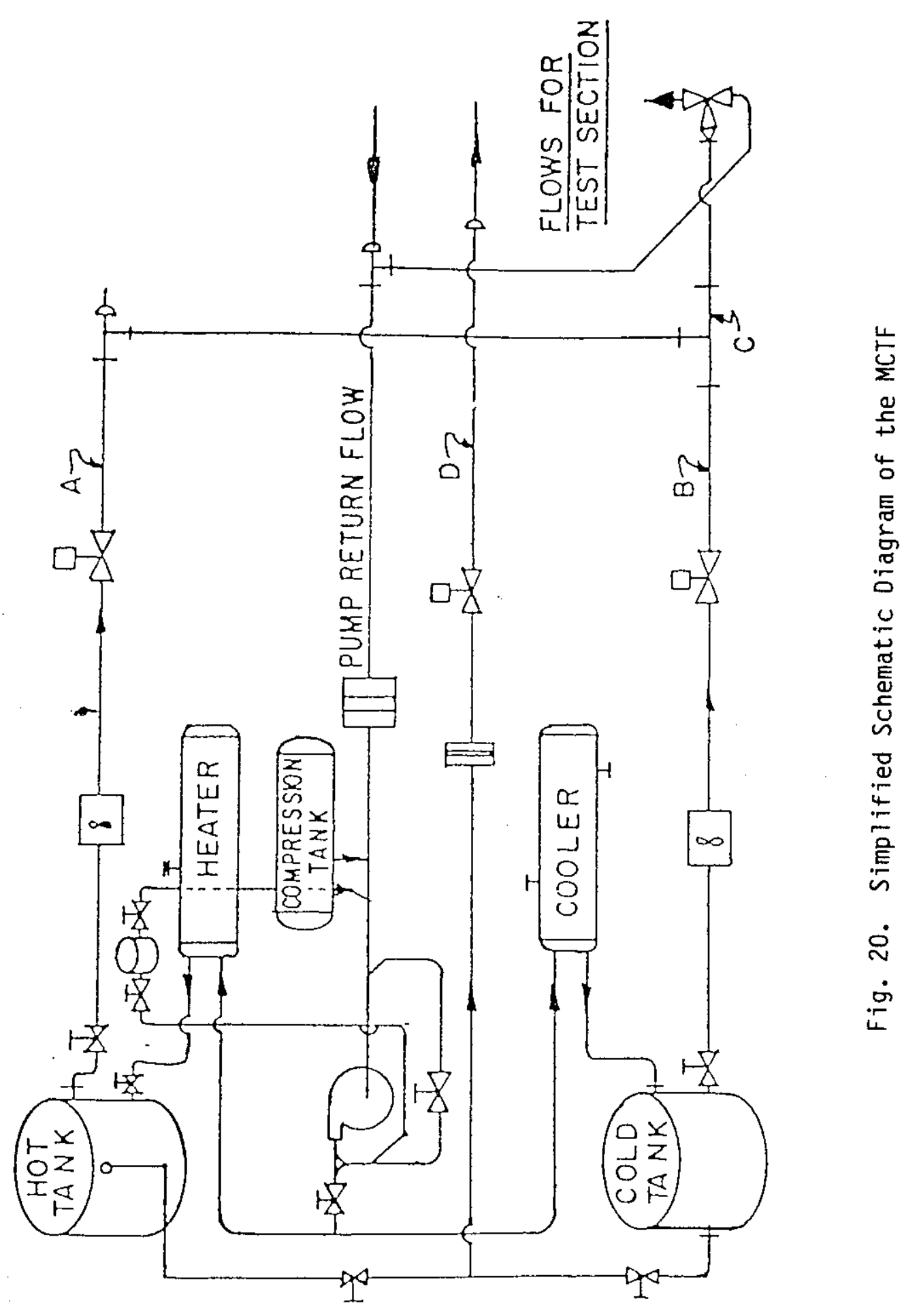


of amplifiers and filtering is used. The channels are scanned and digitized via an $A / D$ converter. Scan times between consecutive readings for a given channel, when 192 channels are used, can be as sma 11 as $20 \mathrm{~ms}$. The data are stored on hard-disk memory as well as on magnetic tape. MCTF computer software allows engineering-units conversion, analysis of data, and plotting of results, either at the experimental facility or on main computer at Argonne.

Additional capabilities associated with the facility include the ability to measure velocity distributions by means of laser doppler anemometry, hot wire/film anemometry, or a laser flow visualization technique developed at ANL. A high speed (12,000 pictures per second) video camera/image digitizer for computerized image processing of flow field studies, together with a $4 \mathrm{~W}$ argon-ion laser, is used in the laser flow visualization technique. In addition, the facility can measure temperature and pressure via fast-response thermocouples and pressure transducers, respectively. Software has been developed to control the loop and to acquire, reduce, and analyze the data.

\subsubsection{Advanced Reactor Test Center}

The Advanced Reactor Test Center was developed at ANL to test various advanced reactor designs under thermal-hydraulic conditions that are provided by the MCTF, as described in the previous subsection. The Test center consists of a containment vessel, immersion heater, dc pump drive motors, a large steel stand, and associated plumbing. The heater and pumps are computer-programmable and are operable from the facility computer. Various plastic models of different advanced reactor designs can be inserted in the containment vessel for testing.

The containment vesse 1 is a two-section, 42-in.-00 cylinder made of 1/8-in. stainless steel; one $54 \mathrm{in.}$ long, the other, $60 \mathrm{in.}$ long. Each section is flanged at both ends to permit flexibility in stacking and orientation. Large windows, made of 1-in.-thick polycarbonate, provide access for flow visualization. Three windows are positioned vertically; two in the 60-in.-long section, for viewing critical subregions of the model. The pattern of window placement is repeated in each quadrant of the vessel, for a total of 12 windows. The vessel top cover is made of 1 -in.-thick 
polycarbonate (for viewing) whereas the bottom is made of 1-in.-thick stainless steel. The containment vessel, Advanced Reactor Test Center, and MCTF are shown in Fig. 6. The plastic PRISM model is inserted or removed from the vessel as a complete unit by means of three eye bolts (see Fig. 3).

The containment vesse 1 sits on an 8-ft-square, 36.5-in.-high steel stand. The stand allows access for viewing around the vessel and room under it for mounting the immersion core heater and plumbing to the MCTF loop. The $60 \mathrm{~kW}$ immersion heater is mounted vertically through the center of the vessel bottom. In the open system mode of operation, flow from the MCTF proceeds vertically upward, channeled by the core barrel that is over the heating elements. The active heat element zone occupies a 10-in.-dia, 14-in.-high volume, positioned so its thermal center models the PRISM prototype. The return flow line from the vessel to the MCTF has two pneumatic valves in paraliel, located under the stand, for isolating the vessel from the MCTF loop when the vessel is used as a closed system.

Four 1/4-hp dc motors, mounted on the vessel cover, turn four 3-in.diameter propellers, located in the PRISM mode1, to simulate internal pump flow at low flow ( $0-10 \%$ of full flow). The pumps (i.e., dc motors) and the immersion heater have controllers that are under computer command.

\subsection{Modes of Operation}

The PRISM thermal-hydraulic model can be operated in three distinct modes: externally driven forced flow, internally driven forced flow, and internally driven natural-convection flow. Various combinations of these modes are also possible.

In the externally driven forced flow mode, high to intermediate flowrates are supplied to the PRISM core from the MCTF under computer control. The flow passing through the model is returned to the MCTF via the two exit manifolds that are located in the cold plenum (see Fig. 1). This is accomplished by inflating the inner-tube flow diverter that is located in the core inlet pipe region, and opening the two MCTF return pneumatic valves. This allows the flow collected in the two manifolds to exit the model. In this mode, the flowrate and the temperature of the flow supplied to the core are controlled by the MCTF thermal-hydraulic system and minicomputer as a function of time. 
In the second mode (internally driven forced flow), the PRISM model is isolated from the MCTF by closing the two MCTF return pneumatic valves outside the model and deflating the flow diverter inner tube to allow flow through the eight pipes that supply the core. In this mode, low-level forced flow and transition to natural circulation are provided by four internal pumps (i.e., four propellers driven by dc motors), a core immersion heater as the heat source, and two IHX heat sinks (for Phase II). Both the flowrate provided by the dc-driven pumps and the power supplied by the immersion heater are controlled in this mode by the MCTF minicomputer as a function of time.

In the last mode, internally driven natural convection, the situation is the same as in the second mode except that no internal pumps are operating. The natural convection is driven by the temperature differences caused by the core heater, the intermediate heat exchangers, and the RVACS simulated by the cold RV wall. For complex test scenarios, a given transient can be composed of all three modes of operation. The next subsection gives an example of how a prototype reactor transient is simulated.

\subsection{Prototype Transients of Interest}

GE identified for ANL the following seven prototype transients, whose severity was judged by GE to be of potential concern to the designers:

1. Plant unloading at $3 \%$ per min from 100 to $25 \%$ power (A-4)

2. Reactor trip from ful1 power with maximum decay heat (B-1A)

3. Loss-of-flow without scram or SAS activation at EOEC

4. Loss of heat sink without scram or SASS activation at EOEC

5. Loss of power to one primary pump (B-3B)

6. Loss of feedwater to all modules supplying one turbine, with scram after steam generator dryout (B-5B), and

7. Loss of feedwater to all modules supplying one turbine, with 30-5delayed scram (B-5B).

ANL evaluated the transient descriptions that were provided by GE. Based on the highest priority needs of GE and the capability of the ANL facility, transients $1,2,5,6$, and 7 were simulated as part of the Phase II testing of PRISM.

Transient 2, B-1A, is used as an example of how the Advanced Reactor Test Center simulates a transient. Figures 21 through 23 define the GE prototype 

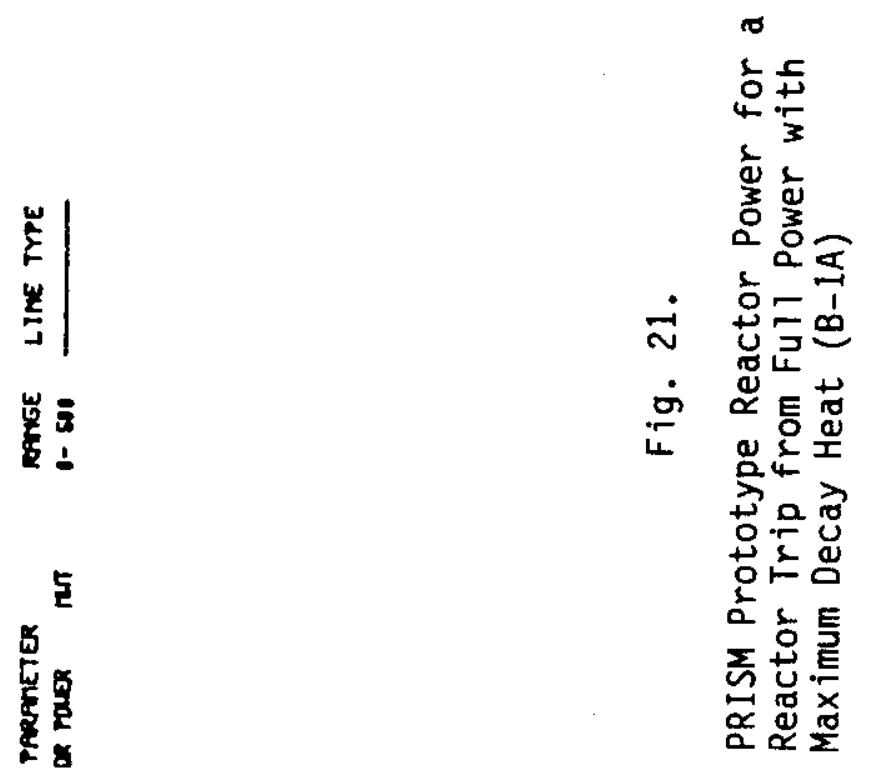

है

ì

赵

?.

$\stackrel{\infty}{\rightarrow}$

히

z

$\uparrow$

ชำ

+

$\pm$

$\frac{5}{\Sigma}$

เ

$\stackrel{\infty}{\rightarrow}$

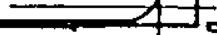

dәfomeded yoez lof paqej!puI se abuey 


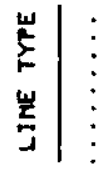

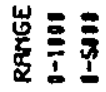

害

空

tón

a 3

+.

To

雾这

낮

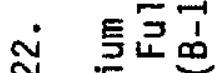

$\approx$ ह

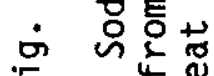

ㄴ.

구을

용

용

党目

$\sum \underset{\mathrm{g}}{\mathrm{E}}$

$\underset{\alpha}{x}$

舟定

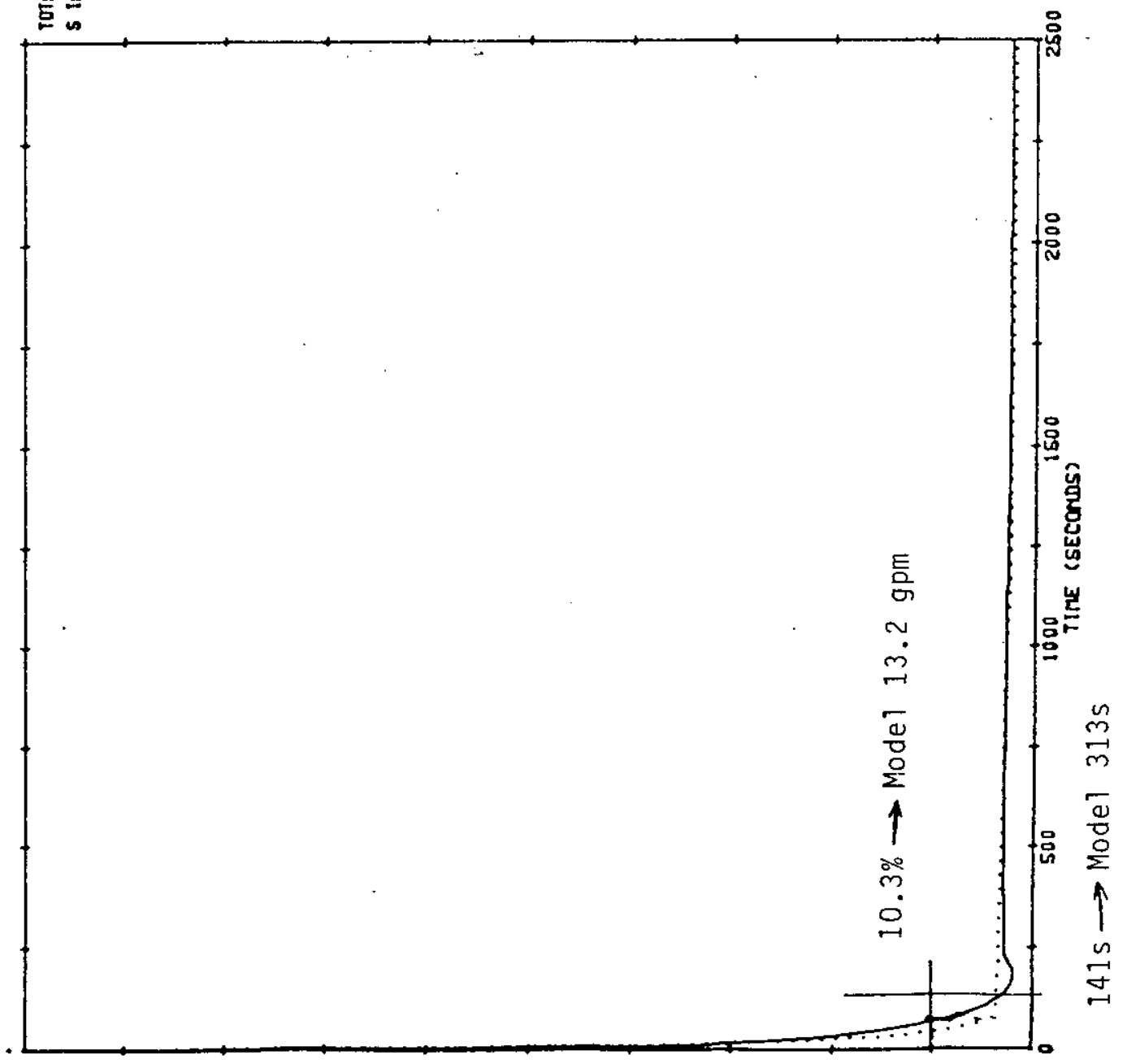

lafomened yoez lof pazes!puI se zбuey 


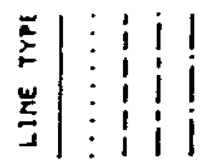

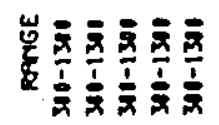
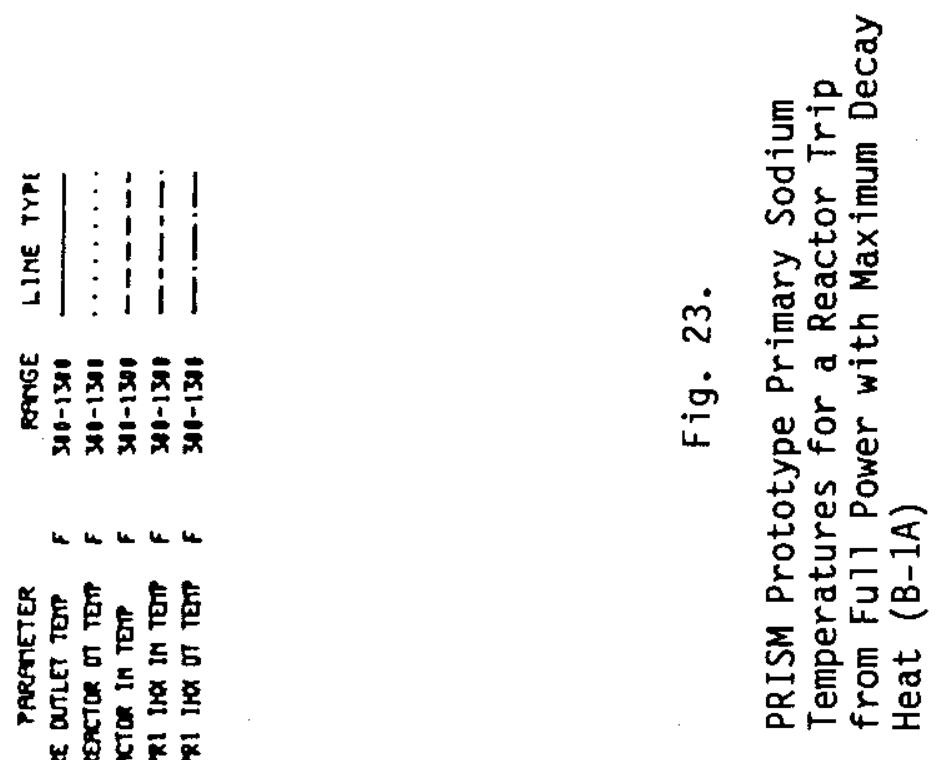

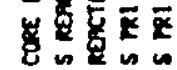

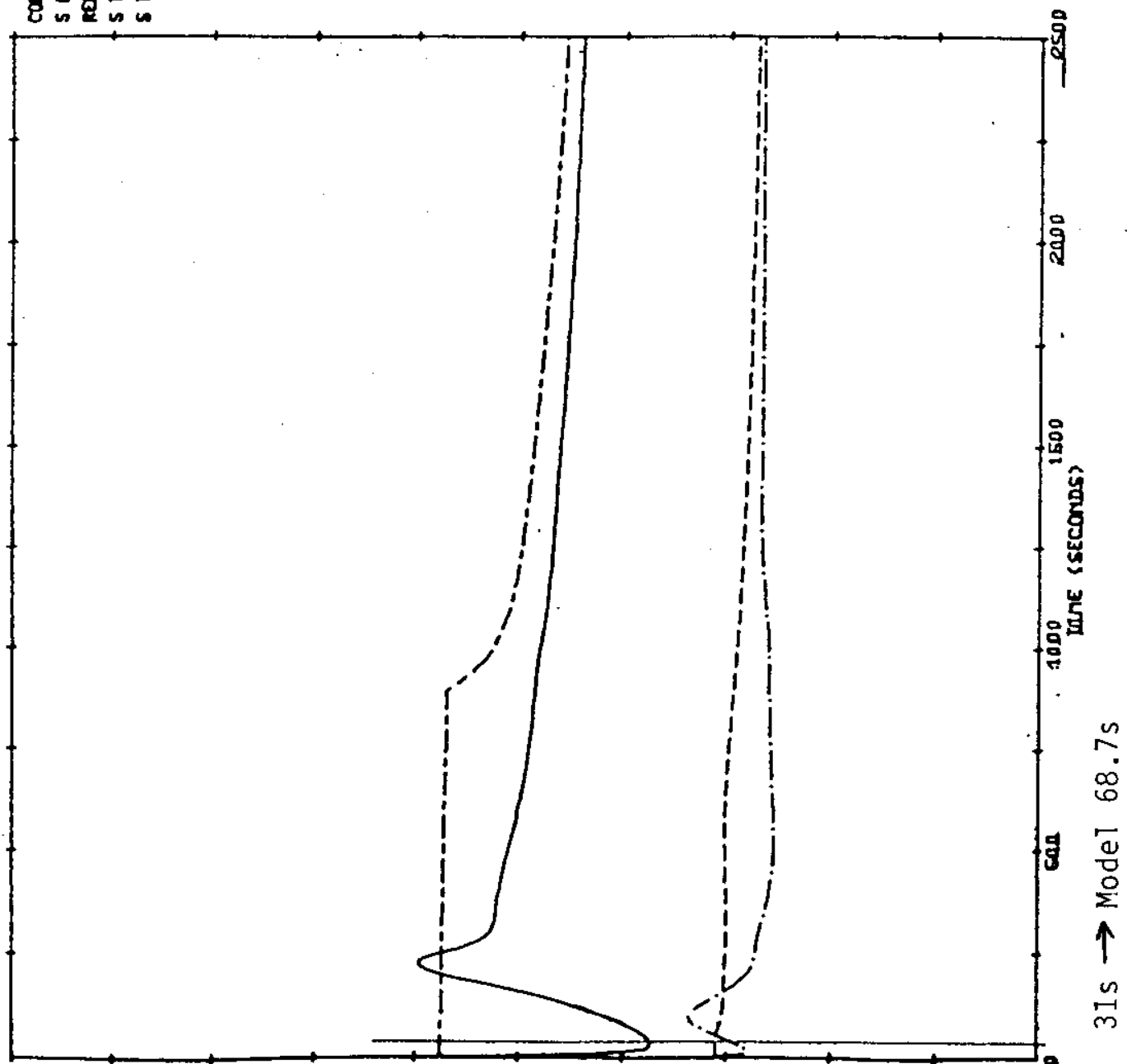

dəzameded yoez dof pazeotpuI se әбиey 
transient $B-1 A$. The modeling described in Section 2.1 requires that the ratio of model to prototype Richardson numbers be unity. This criterion can be satisfied for every instant during a transient in which the model is isolated from the MCTF (i.e., natural-convection and mixed natural-forced-convection flows). For these types of transients, the flow-driving forces are supplied internally, and most importantly, the thermal-driving temperature difference exists in the model (i.e., core and IHX inlet/outlet temperatures). When the model is interfaced to the MCTF (necessitated by the fact that $100 \%$ power could not be supplied by the immersion heater), the thermal driving force is absent, unless it is fictitiously introduced prior to initiation of the transient. Cold water, introduced in the flow path downstream of the IHXs before transient initiation, can provide this thermal driving force. Through Richardson number similarity, the $100 \%$ flowrate and core temperature difference were determined to be $128 \mathrm{gpm}$ and $13^{\circ} \mathrm{F}$, respectively which results in $100 \%$ effective model power of $275 \mathrm{~kW}$. The hot and cold MCTF 3000-gal reservoirs were filled with water at $100^{\circ}$ and $80^{\circ} \mathrm{F}$, respectively, to obtain a transient flow from the MCTF which would vary in temperature from $100^{\circ}$ to $87^{\circ} \mathrm{F}$ (i.e., corresponding to the core temperature difference of the mode1). The choice of reservoir temperatures directly affected the heat sink capability of the IHX's and therefore, compromise was necessary. Neither the immersion heater nor the IHX heat sinks are large enough to handle the 100\%-power conditions. Thus, the IHXs cannot maintain the cold water at $87^{\circ} \mathrm{F}$. Since the goal of PRISM testing is to study buoyancy-driven and buoyancy-moderated flows, the high flows (i.e., 100\% flows) are necessary only to set up the flow patterns in the flow circuit, even though at these high flowrates Richardson number similarity is not satisfied identically. At these high flows the Richardson number is very small in both the model and prototype, indicating that thermal buoyancy is negligible, and that the previous simplifications can be supported. In the GE prototypic transient, a heat sink capacity of approximately $11.7 \%$ of full power existed from approximately $t=47 \mathrm{~s}$ to $t=302 \mathrm{~s}$. Since there is currently no capability to vary the heat sink capacity during the transient simulation, the value of $11.7 \%$ of full power was judged to be an acceptable compromise, being valid for a considerable portion of the transient near the time when flow and temperature in the reactor were still varying dramatically. The prototypic temperature transient (shown in 
Fig. 23) was nondimensionalized with respect to the core temperature rise, and the model transient followed this nondimensionalized temperature transient, when the model core temperature rise was taken into consideration (i.e., $13^{\circ} \mathrm{F}$ obtained through Richardson number similarity at 100\% flow and power). Indicated on Figs. $21-23$ is the prototype time of $141 \mathrm{~s}$, at which time, in the model simulation (i.e., $313 \mathrm{~s}$ ), the mode of operation changes from an interface with the MCTF to a completely closed system. Also indicated is the prototype time of $31 \mathrm{~s}$, at which time, in the model simulation (i.e., $68.7 \mathrm{~s}$ ), the immersion heater is turned on at a power level of $18.9 \mathrm{~kW}$. A test was run in the following manner: The heat sink capability was set up with $87^{\circ} \mathrm{F}$ water from the MCTF flowing through the model at a flowrate of $26.7 \mathrm{gpm}$, corresponding to the same flow condition in the prototype at which $11.7 \%$ heat sink capacity existed. The flowrate of the cooling water in the model's IHXs was adjusted to obtain this heat sink capacity (i.e., $32.2 \mathrm{~kW}$ ). This setting was not changed during the test. Initial1y, $100^{\circ} \mathrm{F}$ water from the MCTF was circulated through the test section at $128 \mathrm{gpm}$ for at least $15 \mathrm{~min}$. At $t=0$ the flowrate and temperature of the water from the MCTF decreased at a prescribed rate (i.e., follow the nondimensionalized equivalents of Figs. 22 and 23 respectively) that was controlled by the minicomputer until, at $t=68.7 \mathrm{~s}$, the immersion heater was turned on while the flow was still being provided from the MCTF at a constant temperature of $87^{\circ} \mathrm{F}$. The heat generation at this time was $18.9 \mathrm{~kW}$ (corresponding to $4.4 \%$ of ful1 model power). The minicomputer then controlled the heat generation of the immersion heater and the constant temperature flow from the MCTF unt il $t=313$ seconds, which corresponds to $10.3 \%$ of simulated prototype flow (model time is 2.22 times longer than prototype time due to modeling laws discussed in Section 2.1). At this time, the inner-tube flow diverter was deflated, the manifold return valves to the MCTF were shut, and the pump motors were turned on (i.e., switch from external to internal or closed-system mode of operation). At this time the flowrate of $13.2 \mathrm{gpm}$ was being dictated by the minicomputer. The power and flowrate were then further decreased, as prescribed by the prototype conditions (i.e., the nondimensionalized equivalents of Figs. 21 and 22 , respectively), since the simulation was under computer control. Computer software, developed for the MCTF, was modified to control the immersion heater, internal pumps and the MCTF flow control valves. During the preceding 
simulation of the B-1A transient, the minicomputer directly controlled flowrate and temperature before $t=68.7 \mathrm{~s}$; after $t=68.7 \mathrm{~s}$, it controlled core power and flowrate.

\subsection{TEST OBJECTIVES}

\subsection{Phase I (Initial Scoping Tests)}

During the initial phase of PRISM model testing at ANL, five types of phenomena-scoping tests were conducted. These tests served two purposes. First, they were less complex than tests associated with the full simulations of prototype transients and thus facilitated the shakedown process and the development of the many complex control features and subsystems which have been incorporated into the PRISM model. Second, these tests isolated and highlighted specific states of reactor prototype operation and the resulting thermal-hydraulic phenomena so that the absence or presence of the phenomena that are of general of interest to designers (identified in Section 2.0) can be rapidly identified as to whether or not they are potentially design issues. These types of tests also aid in identifying which parameters control a specific phenomenon. The five categories of phenomena-scoping tests are: isothermal flow distribution, hot plenum free surface behavior, constant-flow thermal transients, natural-convection flows, and mixed-forced naturalconvection flows. At the request of GE, the prototype transient A-4 (i.e., plant unloading at $3 \%$ per min from 100 to $25 \%$ power, see Section 2.5 ) was simulated at the close of Phase I testing (i.e., just before PRISM was removed from the containment vessel).

\subsubsection{Flow Distribution}

Isothermal flow tests were conducted to observe the flow distribution in the PRISM model as a function of flowrate. The model was interfaced to the MCTF facility. Information such as the effectiveness of mixing in certain subregions or the presence of semi-stagnant or stagnant flow regions was evaluated by observing dye that was injected into key regions. The presence of semi-stagnant or stagnant flow regions at high or intermediate flow can result in "hot" or "cold" spots under nonisothermal flow conditions; during the transition to natural circulation, even larger flow field temperature 
differences can occur and create large thermal-buoyancy forces. Hence it is important to know how these stagnant flow regions affect structural thermal stress and the actual flow levels that are attained when the flow is reduced.

Another flow distribution concern relates to the hot plenum free surface. Significant surface disturbances would indicate to the designer a need for some kind of suppressor plate. Also, there is a concern that the cover gas wi11 be entrained into the sodium and ingested in the IHXs. Tests were conducted at values of free surface Froude number of $20-30 \%$ of those in the prototype.

\subsubsection{Cold Plenum Stratification}

Testing was conducted in which thermal upramps were superimposed on a constant flowrate that was provided by the MCTF facility. The objective of the testing was to observe the effect of the thermal transient on the flow and thermal distributions in the cold plenum of the model. In particular, the flow distribution tests described in Section 3.1.1 indicated that the cold plenum flow turned radially inward just below the radial shield, after moving vertically downward from the IHX exits, and then moved vertically upward through the radial shield. In doing so, it left a volume of stagnant water near the cold plenum floor. The test described in this section was conducted to observe the effect of thermal buoyancy, caused by temperature differences between the stagnant region and the main flow circuit, on this stagnant water. Thermal stratification is important in this region because of the potential for inducing structural thermal stresses in the core inlet pipes, nozzles, and critical weld regions. Furthermore, there is a potential for the sodium to freeze, because this isolated flow region is in contact with the vessel wall which is rejecting heat due to the RVACS.

\subsubsection{Constant Flow Thermal Transients (MCTF Interface)}

The objectives of this series of thermal-upramp transient tests with constant flow were to check the ability of the facility to simulate the initial portion of a complex transient; to provide the designer with initial information about the effects of varying combinations of constant flow levels and thermal-upramp transients on the tendency for thermal stratification; and 
to observe the extent of stagnant region "hot" and "cold" spots in the model, which may be of concern to the designers because of the thermal stresses caused by potentially severe temperature gradients. The initial portion of a complex transient (see example in Section 2.5) is driven by flow from the MCTF with both temperature and flowrate prescribed as a function of time. The thermal-upramp transient tests constituted the first step in a checkout of the ability of the MCTF/Advanced Reactor Test Center to simulate complex reactor transients. The designer can also use the information generated by these tests to evaluate the PRISM model design at various flow levels and during slow transients, which may be approximated as a series of constant flowrate steps, each of which experiences a thermal upramp and is characterized by a given value of Richardson number. Finally, the location and extent of possible stagnant "hot" or "cold" regions highlights for the designer the regions where structural thermal stresses must be carefully evaluated.

\subsubsection{Natural Convection (Core Heaters)}

The objectives of this series of tests were to check additional capabilities of the facility to simulate another portion of a complex transient, and to provide the designer with initial information about the effects of various power levels on natural-convection flow behavior within various subregions and around the flow circuits. The final portion of a complex transient (see example in Section 2.5) can be a natural-convection flow, in which the Advanced Reactor Test Center is isolated from the MCTF and the internal pumps of the model are not operated. Only the core electrical heater is on (in Phase I testing, no IHX heat sinks were utilized). Thus, this series of tests checks out the controllability of the immersion heater by the minicomputer. Information generated, such as the magnitude of the natural-convection flow and temperature distributions for various Richardson numbers, are useful to the designer who is evaluating the suitability of the PRISM design with respect to the natural-convection flow circulation mode.

\subsubsection{Mixed Natural-Forced Convection (Core Heaters with Internal Pumps)}

The objectives of this series of tests were to check additional features of the facility for their capability to simulate another portion of a complex transient and to provide the designers with information about the effect of 
low forced flowrates on the natural-convection patterns at various power levels. For these tests, the four internal pumps and the immersion heater were controlled by the minicomputer. This capability, together with those checked out in the other scoping tests described above, enabled the simulation of complex transients such as those described in Section 2.5.

\subsubsection{Prototypic Transient A-4 (Plant Unloading at 3\% Per Minute From 100 to $25 \%$ Power)}

The objective of simulating prototypic transient A-4 at this time was to provide GE designers with early preliminary information on how PRISM reacts to a typical prototypic transient. This transient was simulated again in Phase II testing after evolving design changes were incorporated into the model. The transient A-4 consisted of a thermal downramp superimposed on a constant flowrate provided by the MCTF facility (i.e., the inverse of the tests described in Section 3.1.3). Details of the prototypic transient supplied by GE are shown in Figs. 24-26 for power, flow, and temperature from the core, respectively.

\subsection{Phase II}

\subsubsection{Simulated Prototypic Transients}

The objective of this series of tests was to simulate five prototypic transients which, because of their severity and frequency of occurrence, could pose potential design concerns such as stress problems caused by rapid temperature changes and inadequate heat rejection due to inadequate flow, etc. The simulation of these transients required the use of all of the capabilities checked in Phase I testing. The five prototypic transients simulated were:

1. Reduction of power from 100 to $25 \%(A-4)$.

2. Reactor trip from full power with maximum decay heat $(B-1 A)$.

3. Loss of power to one primary pump $(B-3 B)$.

4. Loss of feedwater to all modules supplying one turbine, with scram after steam generator dryout $(B-5 B)$, and

5. Loss of feedwater to a 11 modules supplying one turbine, with 30-sdelay scram $(B-5 B)$. 


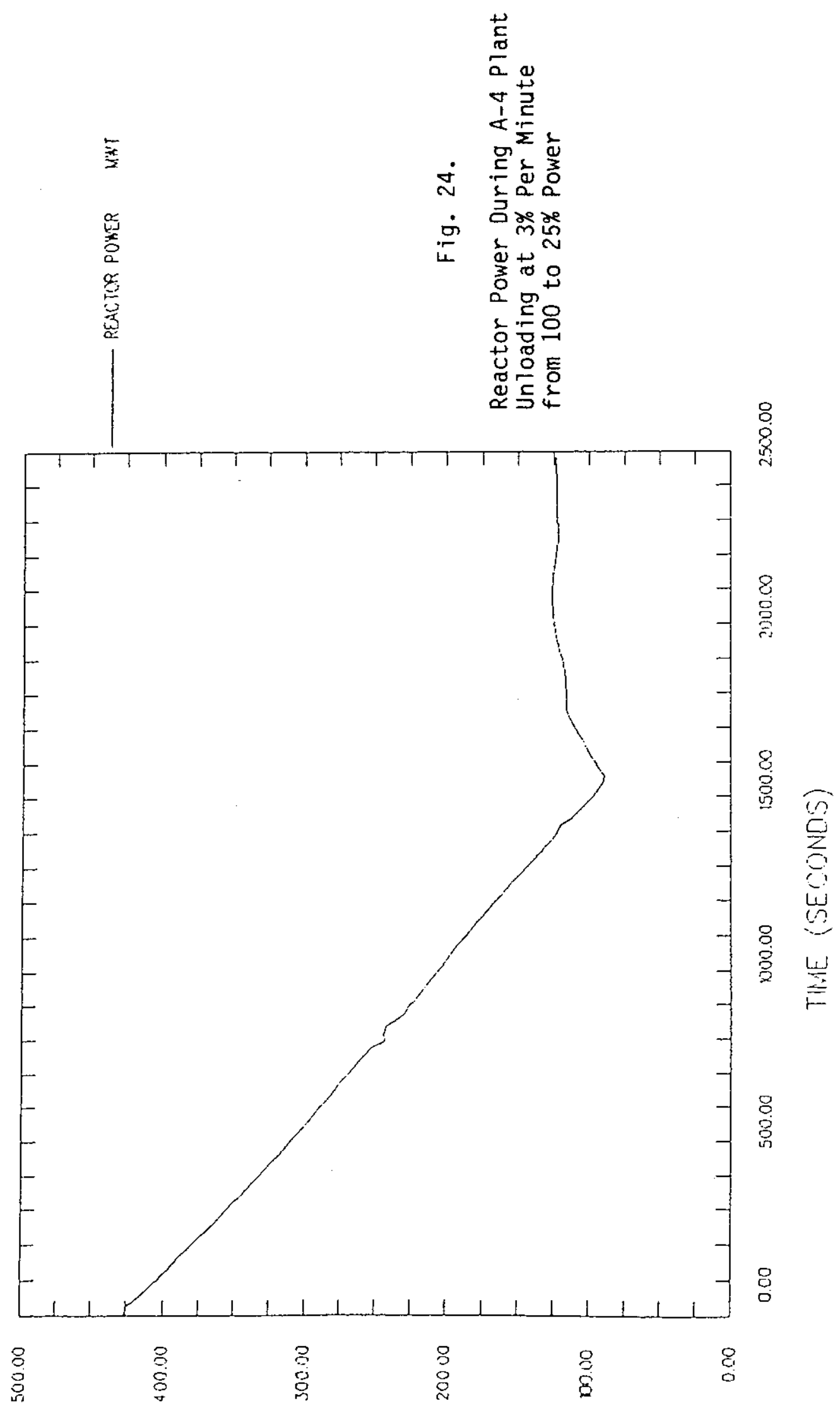




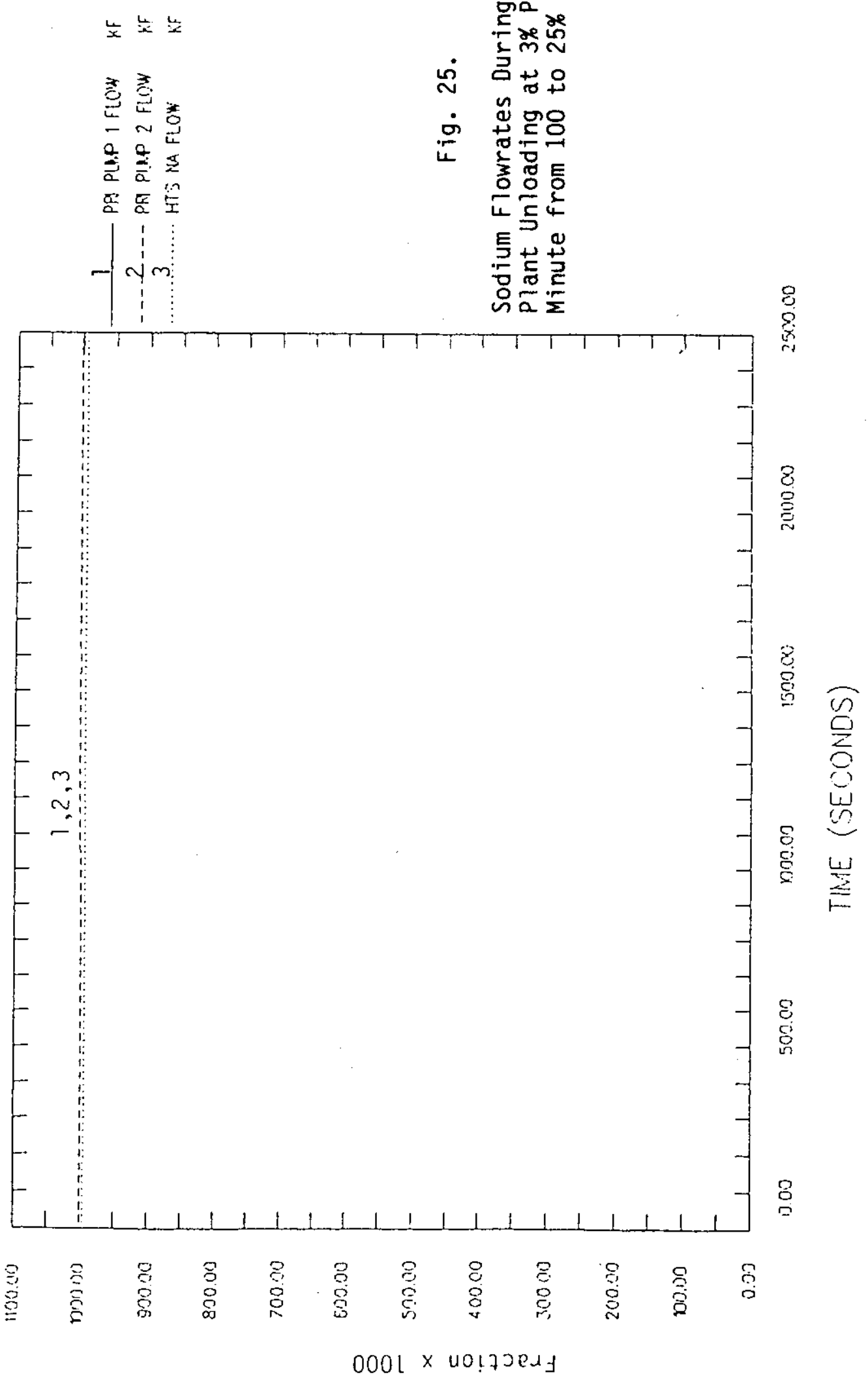




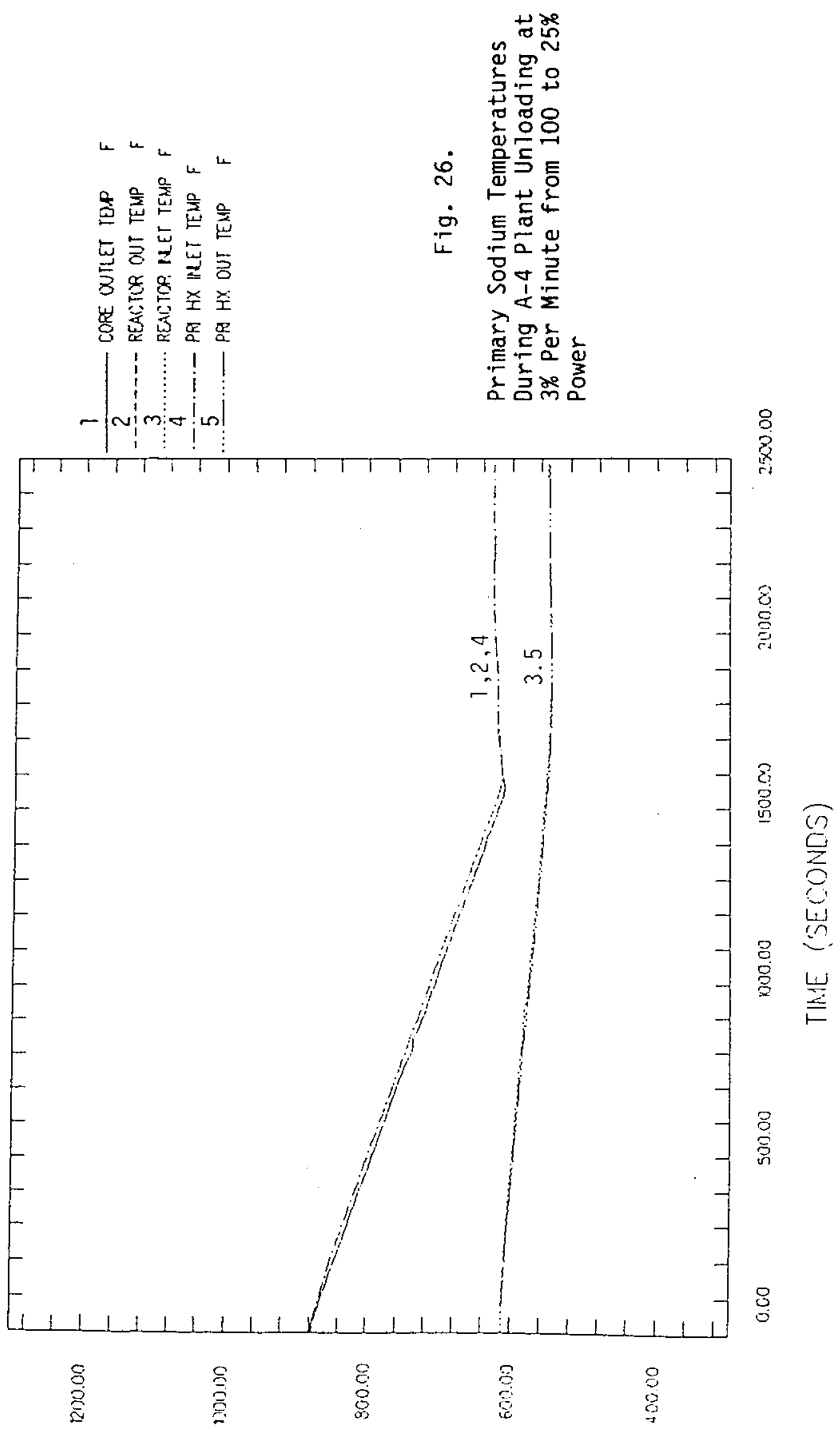


Details of each of the prototypic transients were provided by GE in the form of graphs $[20,21]$. For small values of time, the details were provided by $G E$ in tabular form [22].

\subsubsection{Reduction of Power From 100 to $25 \%$ (A-4)}

The objective of repeating the simulation of transient A-4 during Phase II was to provide GE designers with updated information on how PRISM reacts to the operating conditions described in Section 3.1.6 when the UIS and heat sinks in the IHXs were added for a more representative simulation. of the postulated transients, this event is expected to occur most often. The details of the prototype transient A-4, as presented in Section 3.1 .6 for Phase I, are shown in Figs. 24-26 for power, flow, and temperature from the core, respectively. The intermediate sodium temperatures in the IHXs, which are used to determine the heat sink capacity of the ANL PRISM model for the Phase II tests, are shown in Fig. 27.

\subsubsection{Reactor Trip From Full Power With Maximum Decay Heat (B-1A)}

of the postulated transients, this event, which involves a trip of a single reactor module, which initiates the tripping of the primary and intermediate sodium pumps a half second later, is expected to be the most severe. The sodium pumps coast down to pony motor flow, while the turbine continues to operate at reduced load compared with the remaining operating modules. The details of the prototypic transient B-1A are presented in Figs. 28-31 for power, flow, and temperature from the core and intermediate heat exchangers.

\subsubsection{Loss of Power to One Primary Pump (B-3B)}

In this transient the voltage applied to one of the four primary pumps decays to zero, while the other primary pumps remain at full voltage until the reactor scram occurs. Sodium flow in the affected pump decreases rapidly to zero and then reverses as the unaffected pumps run out on the ir head/flow curves. The details of the scram used in the ANL simulation are those discussed in Section 3.2.1.2. 


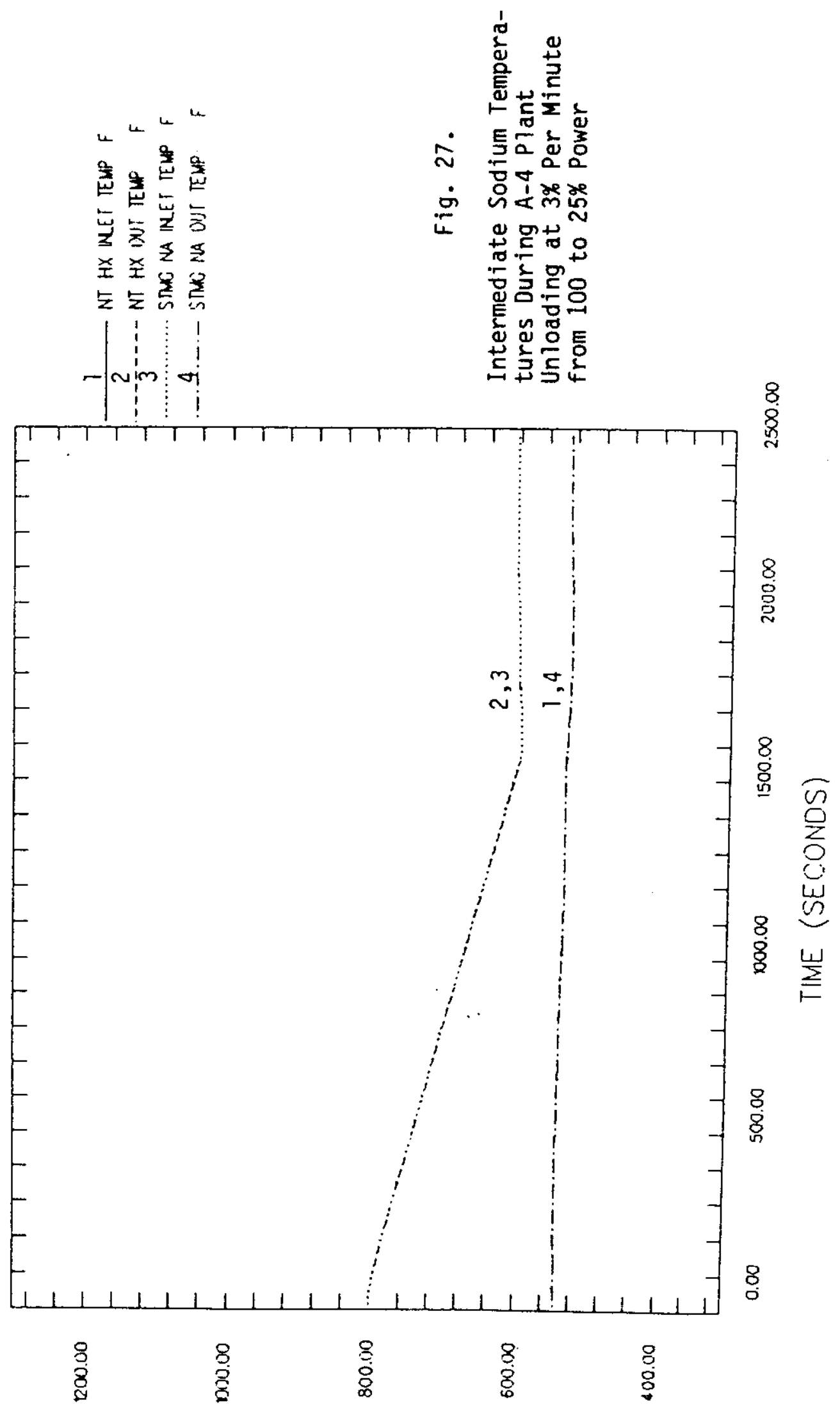




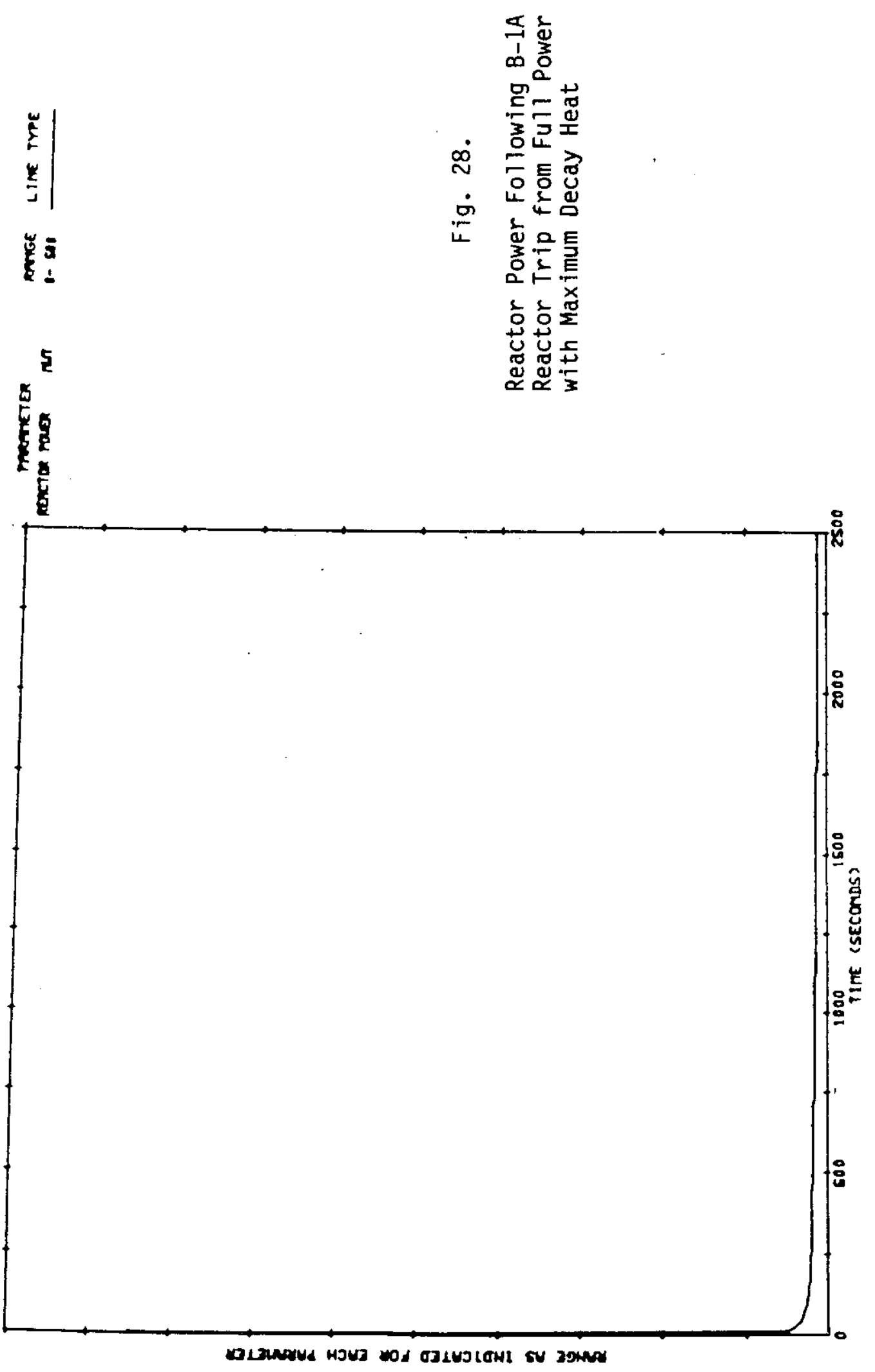



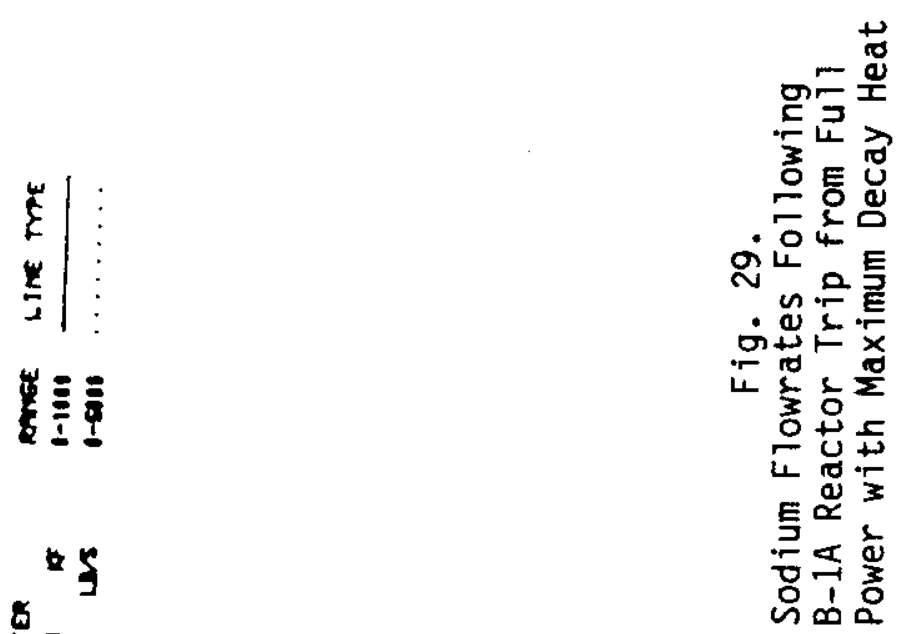

5

鿷

45

뭉ㅇㅇ

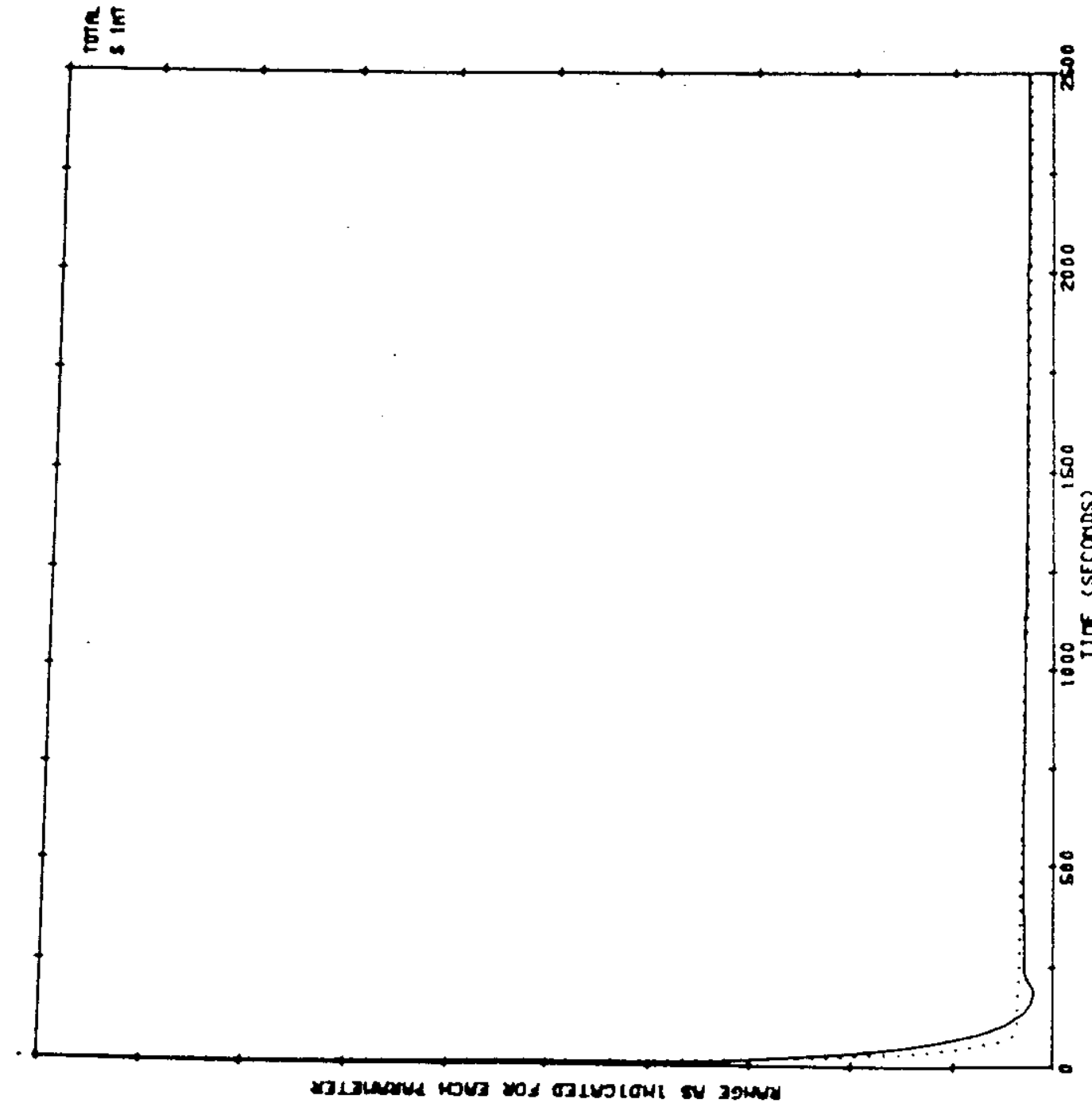



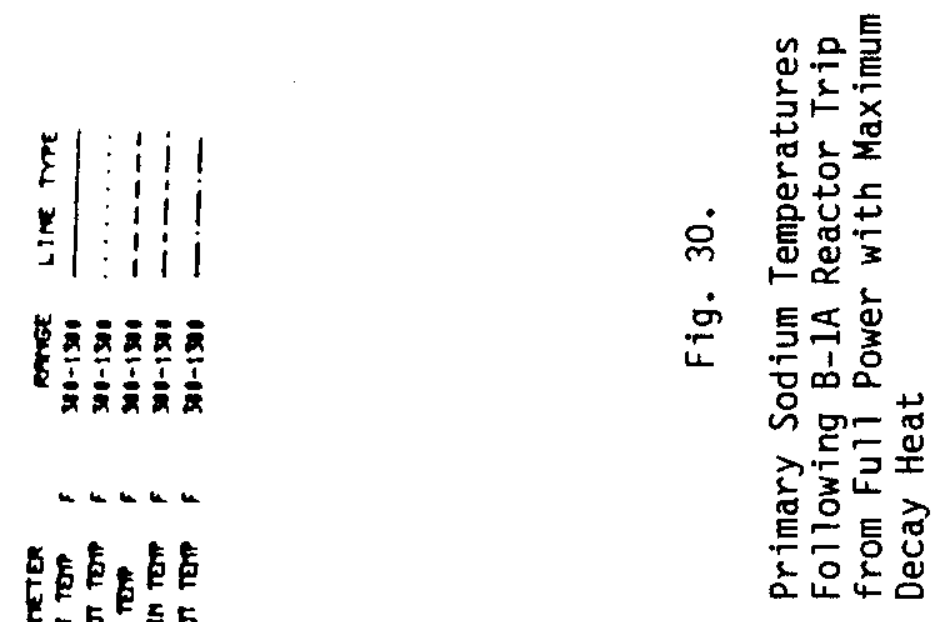

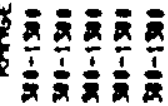

$55=5$

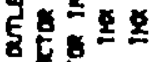

$8 \mathrm{Ez}$

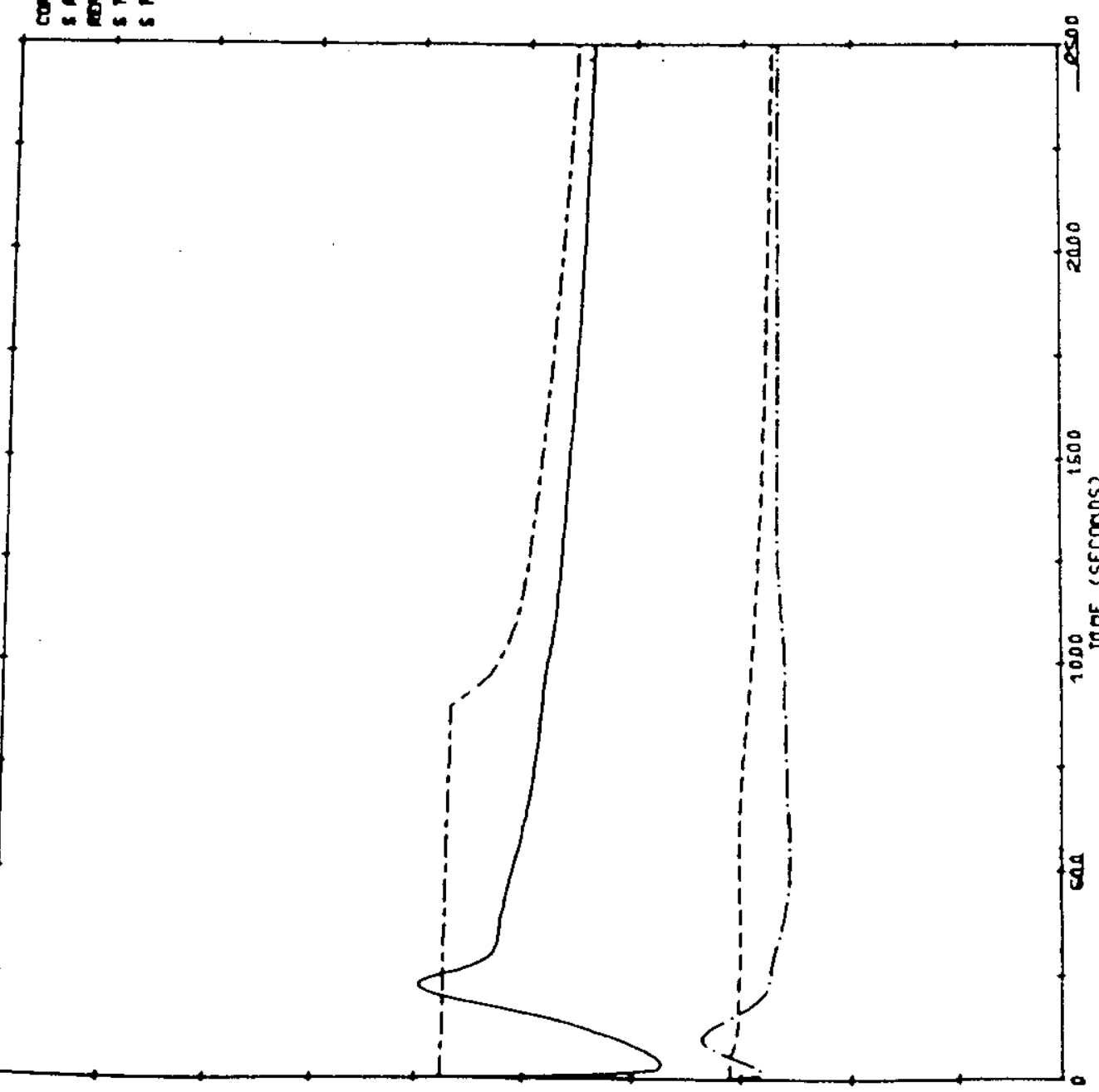

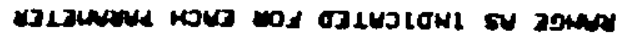




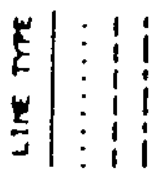

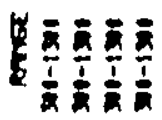

ancu

들

5655

S 5 E

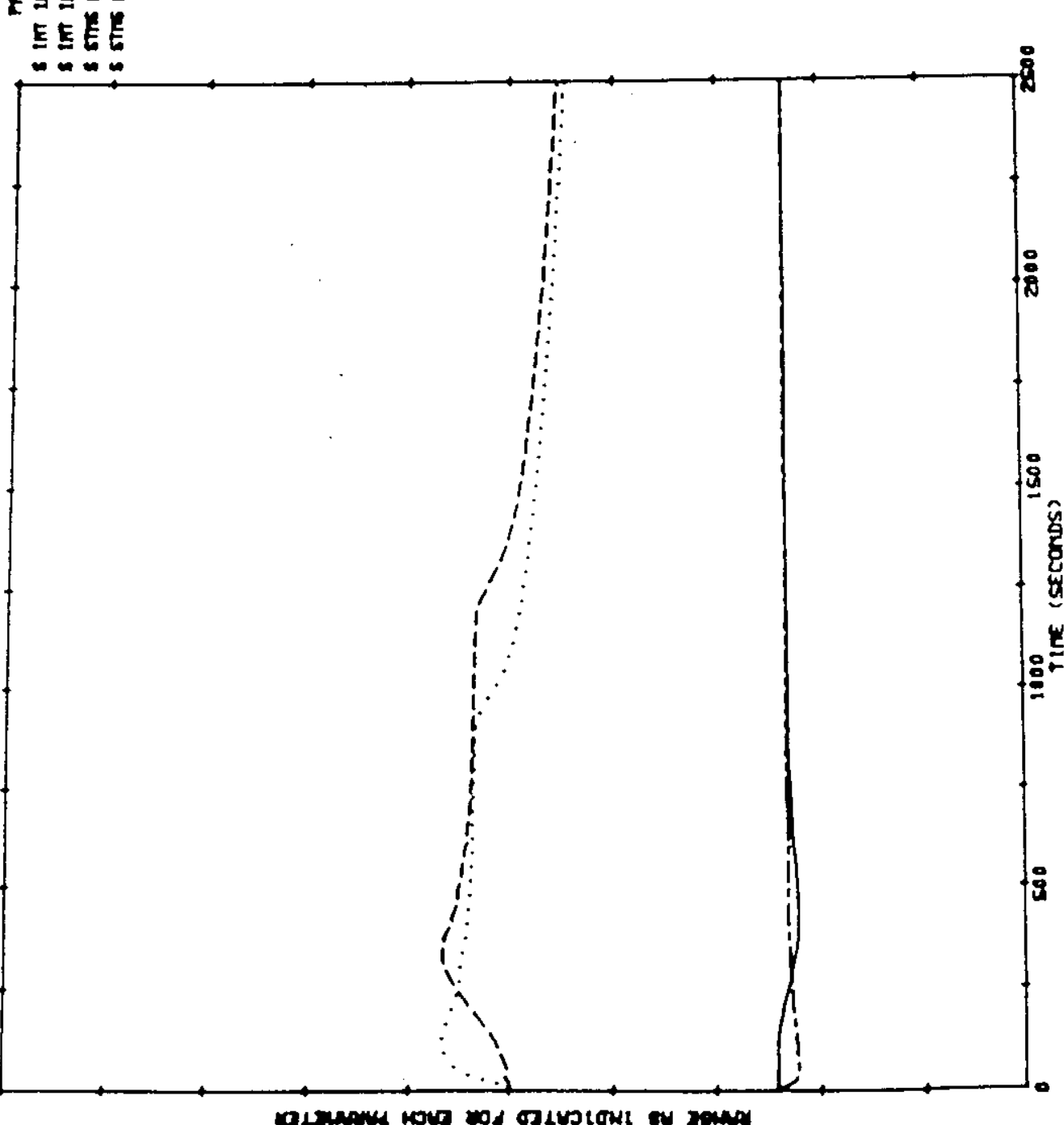

원을

点

政

这铰

- $\quad$ 늠

-

\pm 定:

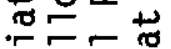

E

\& $\mathscr{d}$ 它

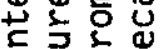

吉起告
.

한

뭉우옹 


\subsubsection{Loss of Feedwater to All Modules Supplying One Turbine, with Scram After Steam Generator Dryout (B-5B)}

This transient, a reactor scram, is initiated by high primary IHX outlet temperature after steam generator dryout. This event, the first of two for prototypic transient B-5B (the second event is presented in the following Section), shows the plant response with a dryout before the reactor shutdown. The details of this transient are presented in Figs, 32-35 for power, flow, and temperature from the core and intermediate heat exchangers.

\subsubsection{Loss of Feedwater to All Modules Supplying One Turbine, With Thirty- Second-Delayed Scram $(B-5 B)$}

This transient, a reactor scram, is based on a steam drum low-level trip $30 \mathrm{~s}$ after the loss of feedwater flow. This event, the second of two for prototypic transient $8-58$, demonstrates that shutdown cooling can be accomplished, for some time, with water that is in the steam drum and recirculation line. The details of this transient are presented in Figs. 3639 for power, flow, and temperature from the core and intermediate heat exchangers.

\subsection{TEST RESULTS}

\subsection{Phase I}

Corresponding to the subsections of the previous section on test objectives, the following subsections describe the results from the scoping tests conducted on the PRISM thermal-hydraulic model.

\subsubsection{Flow Distribution}

A series of five isothermal tests was conducted at flowrates corresponding to $5,10,15,50$, and $100 \%$ of simulated prototype flow (as determined by similarity modeling described in Section 2.1). Dye was injected into key regions and flow patterns were observed.

Dye injected at the dye injection ports located on the thermocouple sting in the core barrel just downstream from the core resistance simulator did not remain a filament under the above flow conditions. This finding indicates that the core barrel is a well-mixed region. The dye proceeded from the 


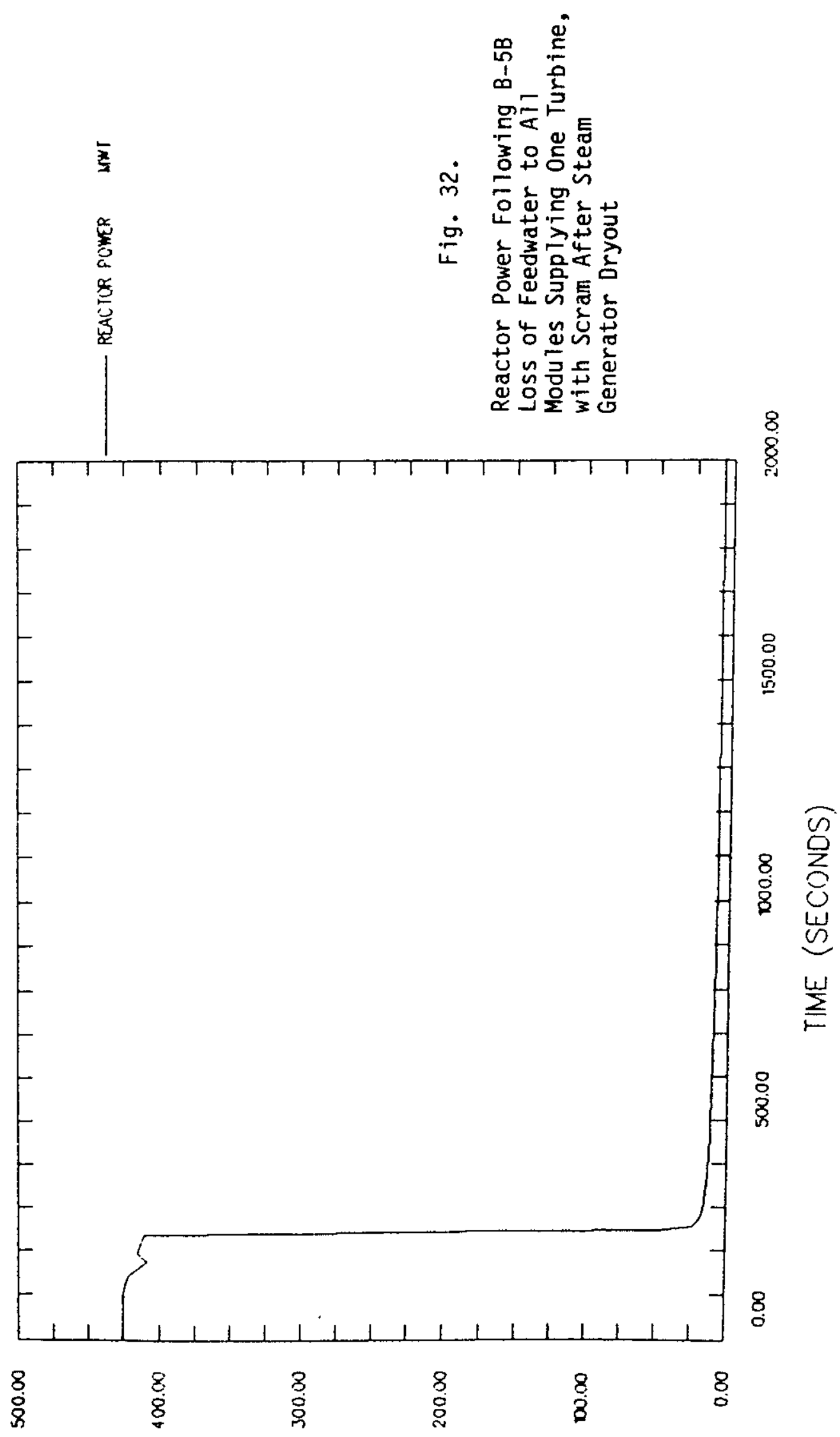




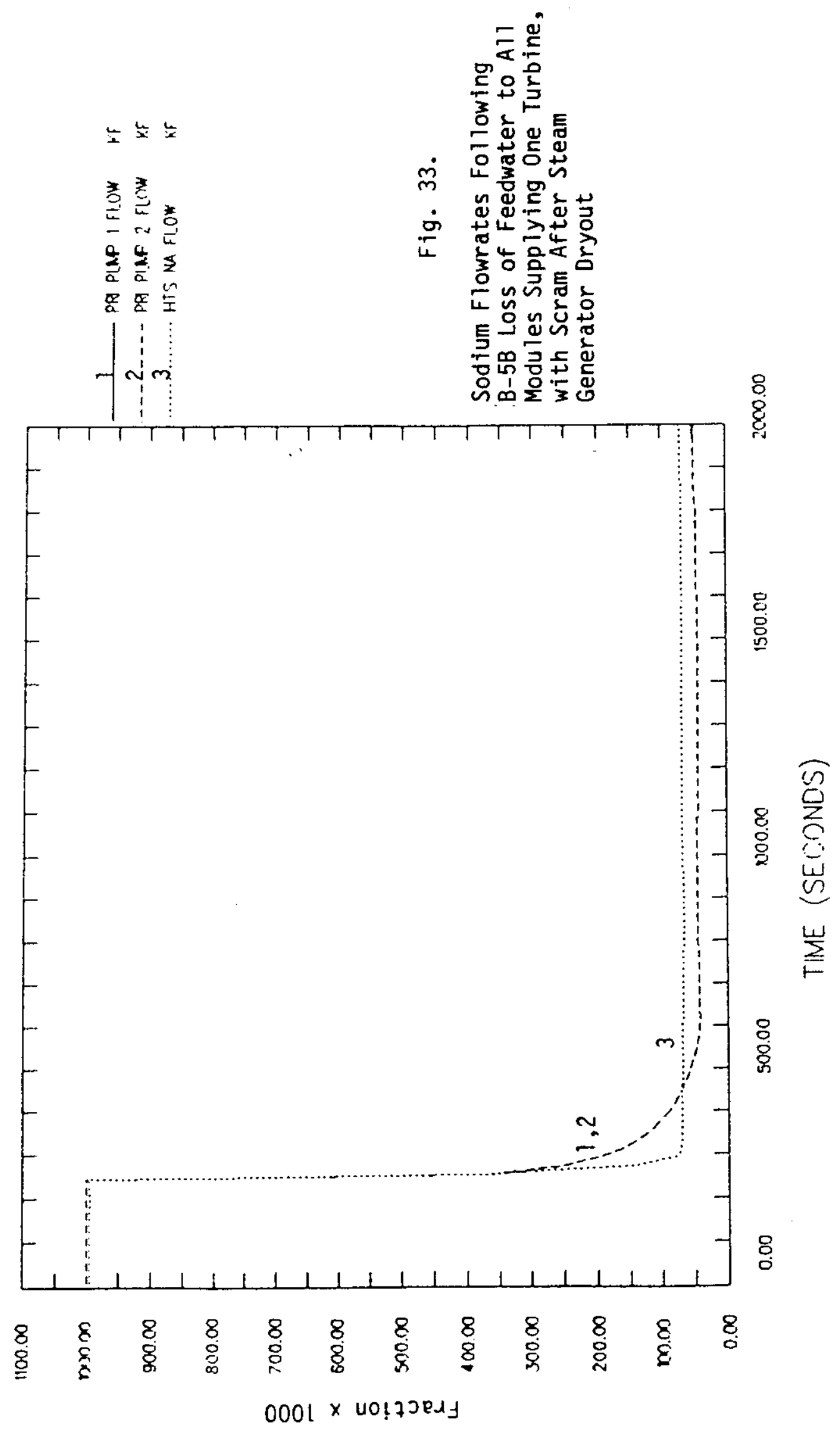




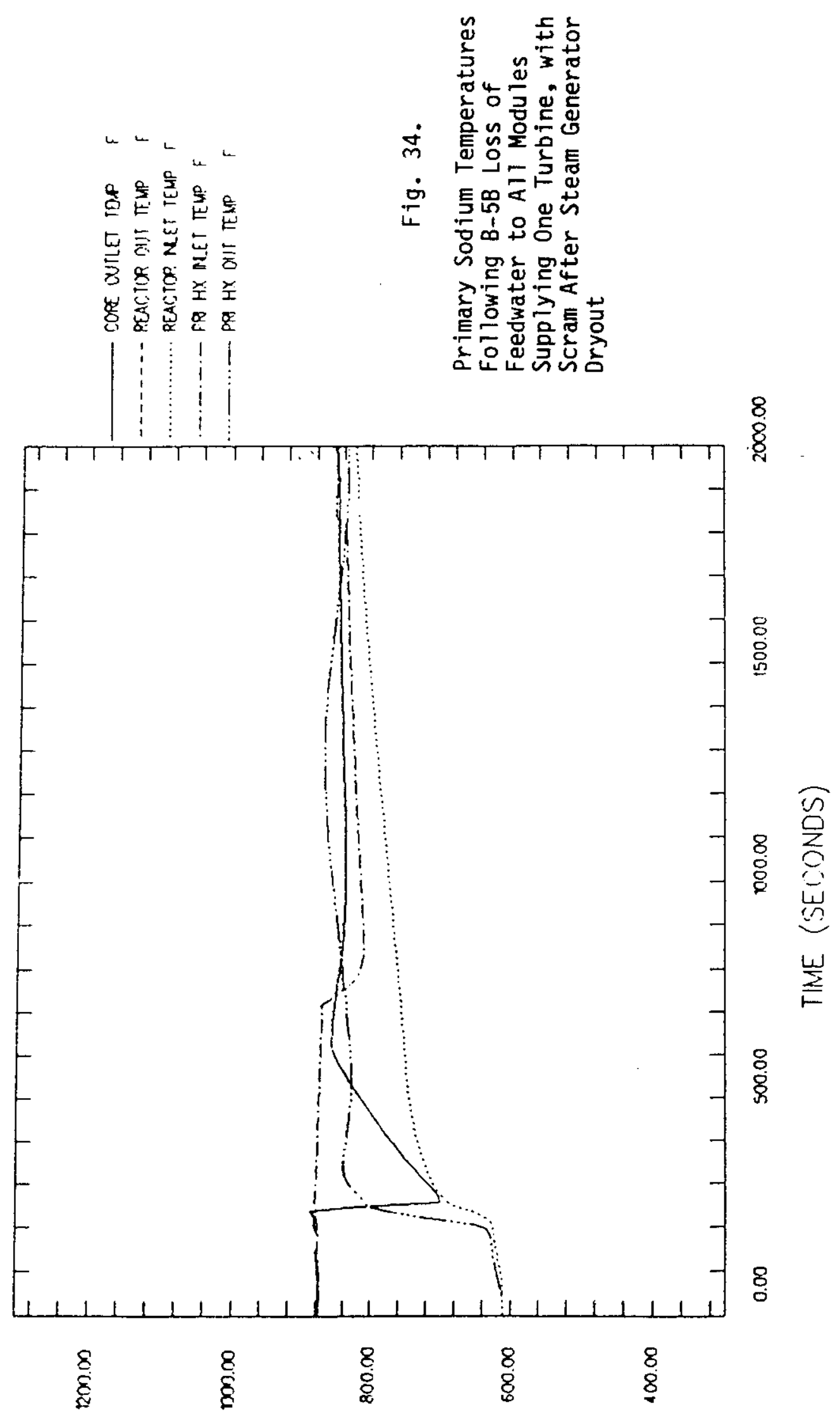




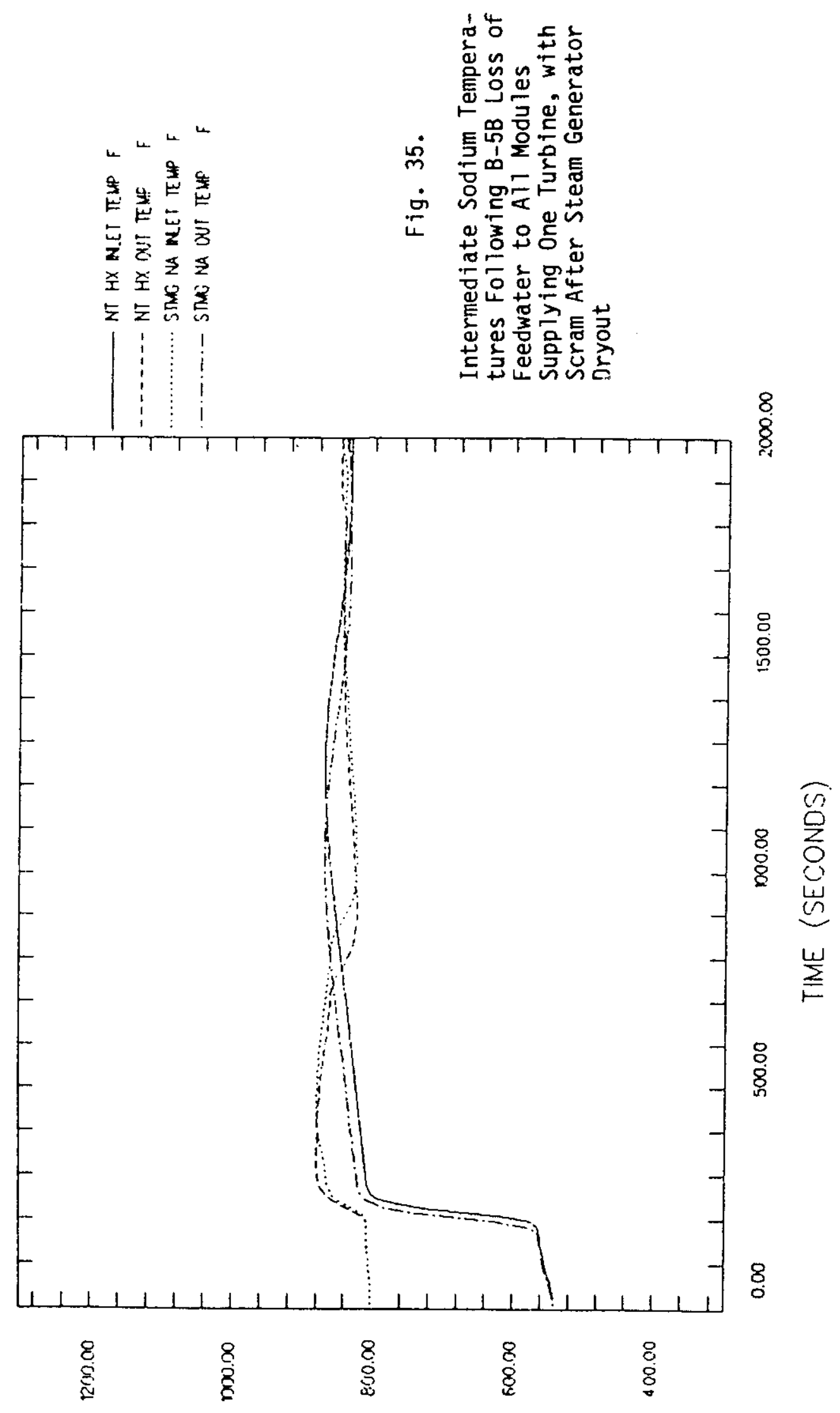




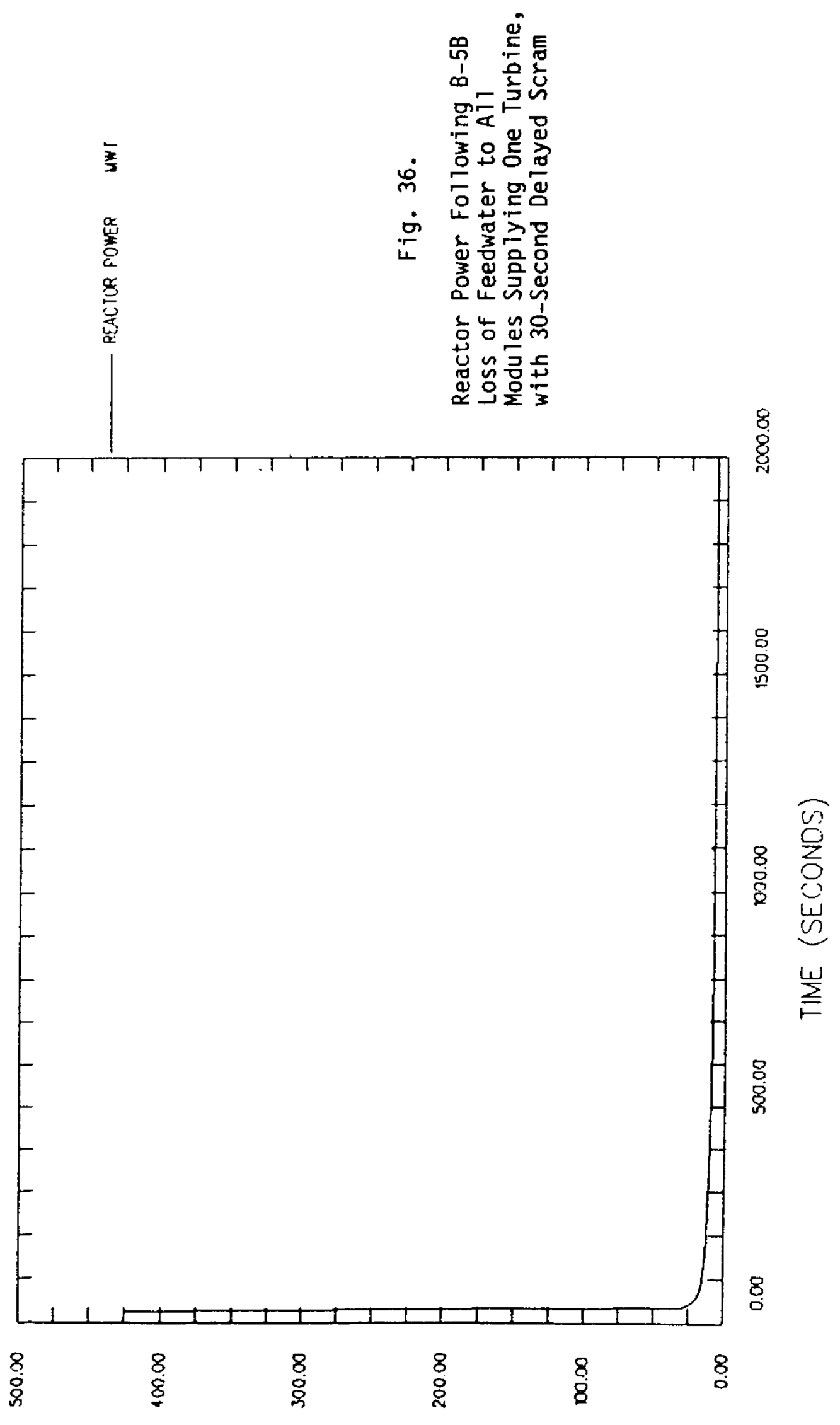




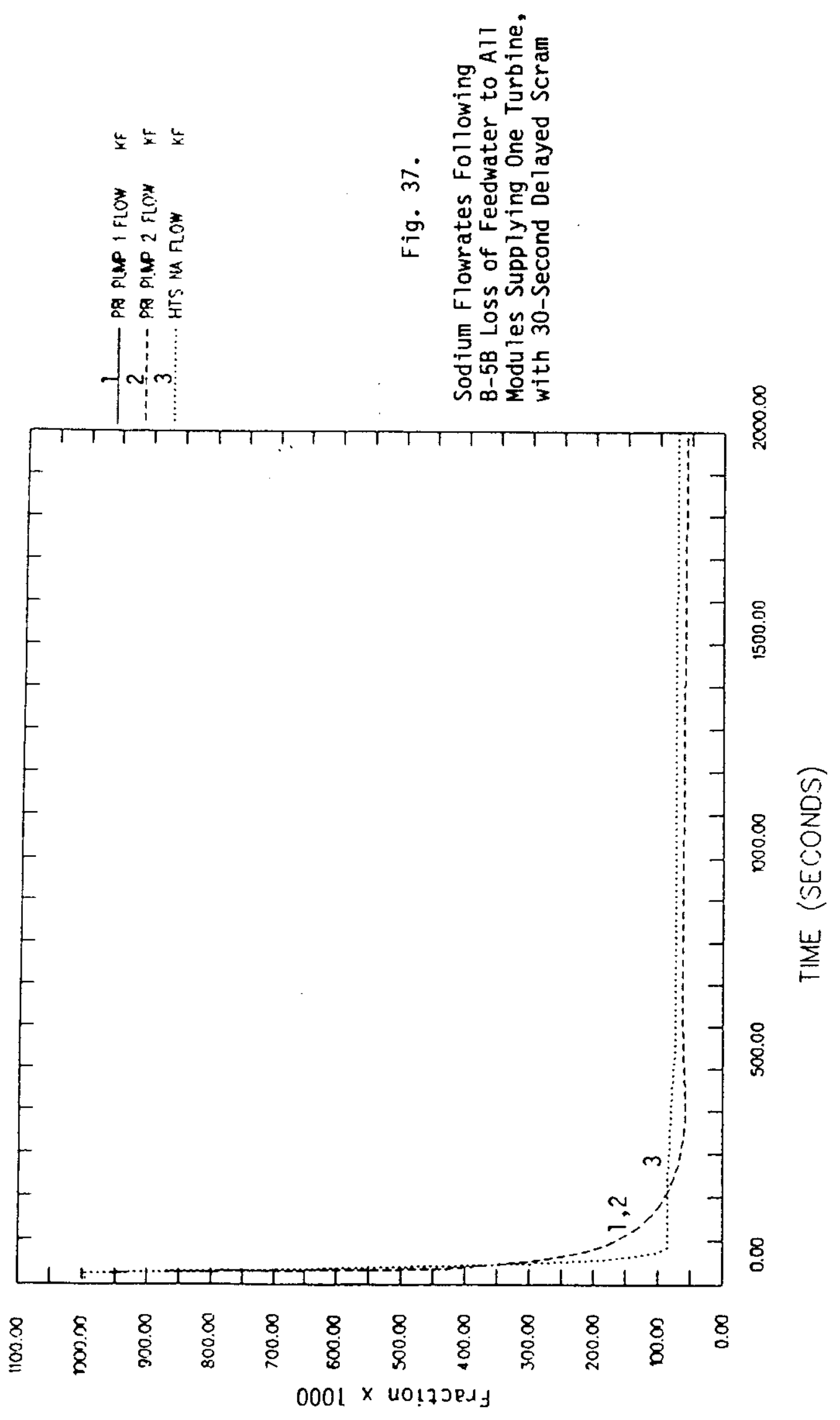




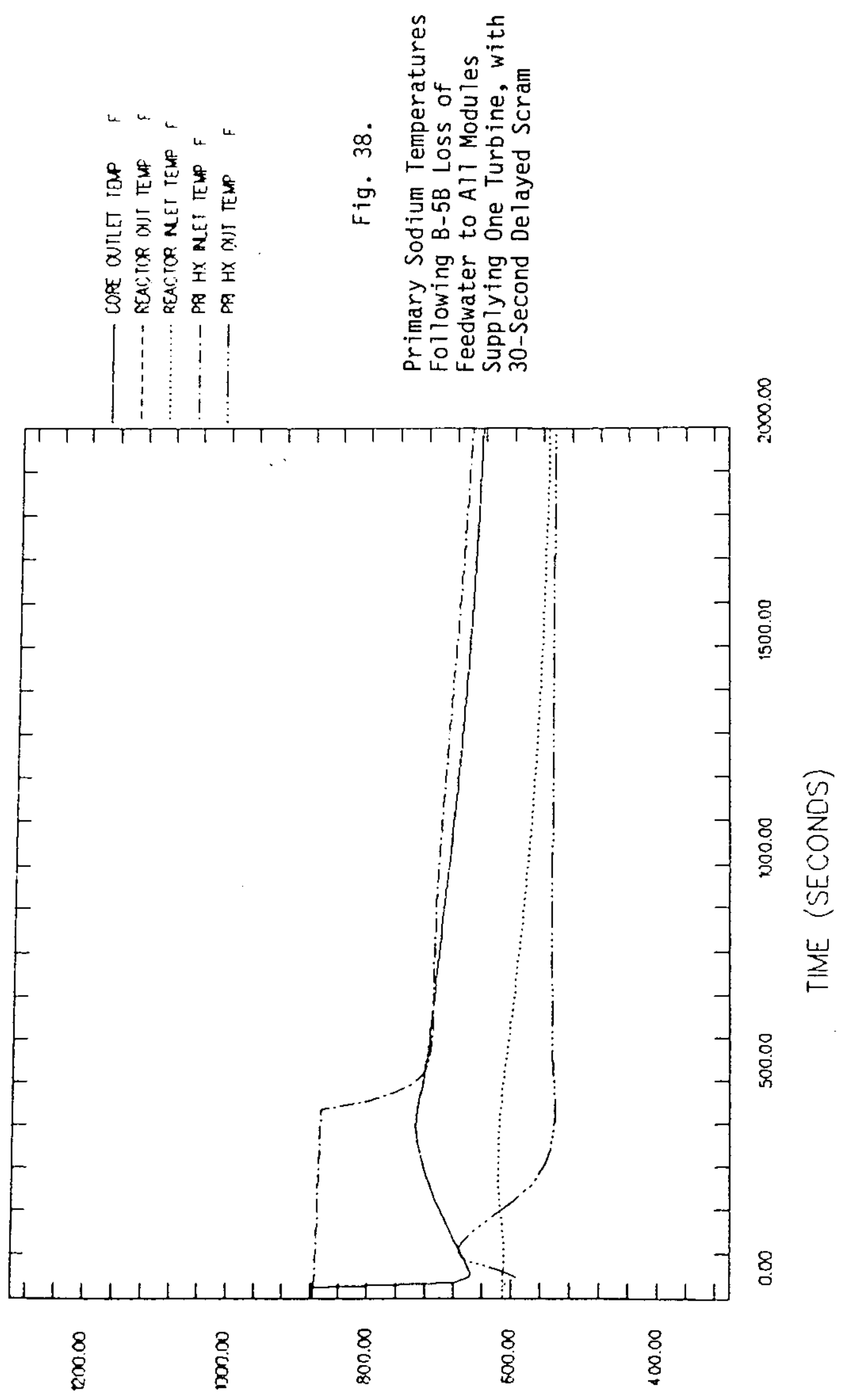




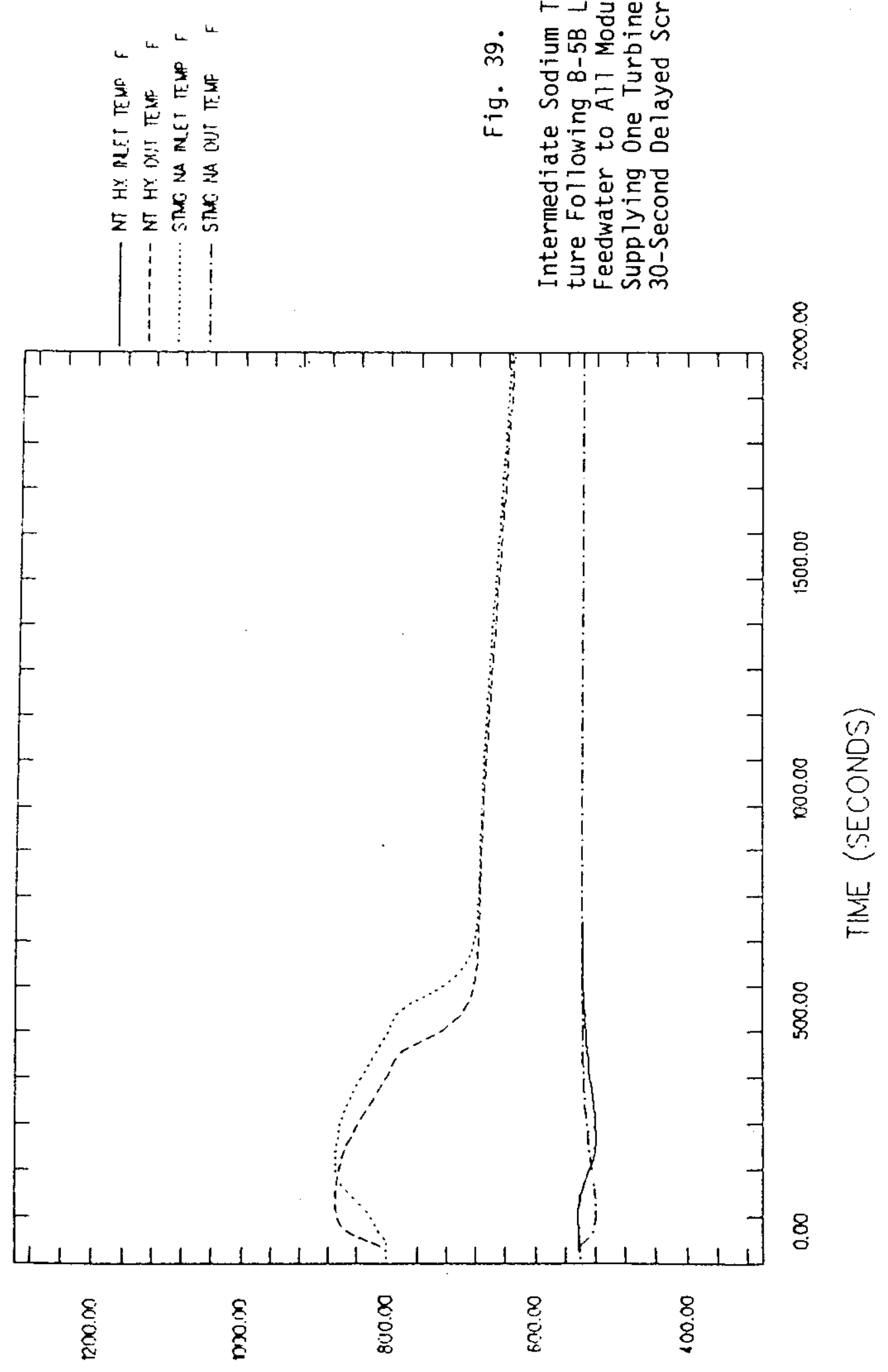


injection port up the core barrel to the IHX inlet on the same side of the model where it was injected into the core barrel. (Phase II tests, discussed later, show that, with a UIS, the core flow is much more complex.) The path of the dye is important when the location of fission product detectors in the upper plenum is being determined. Additional dye was injected at both exits of one IHX. The failure of the dye to remain a filament indicates good mixing. In fact, the two jets merged some distance below the exits. The dye continued down towards the bottom of the radial-shield liner. However, the jets from both IHXs never merged in the annular region outside of the radial shield. At the high flowrates, the flow moving downward around the radialshield liner, originating from the IHX exits, penetrated to the floor of the lower plenum. However, at about $10 \%$ of simulated prototype full flow and below, the annular flow turned in radially about 1-1/2 in. below the bottom edge of the radial shield and then proceeded up through the radial shield. A large volume of fluid below the radial shield remained stagnant. Thus, at certain flowrates, even under isothermal conditions, a large volume of fluid in the lower plenum does not participate in the mixing.

A series of constant flow, isothermal tests was conducted to measure the pressure drop across the simulated core as a function of flowrate. The resulting pressure drops across the core were 0.7 in. of $\mathrm{H}_{2} \mathrm{O}$ at $38 \mathrm{gpm}$, $0.4 \mathrm{in}$. of $\mathrm{H}_{2} \mathrm{O}$ at $26 \mathrm{gpm}, 0.15 \mathrm{in}$. of $\mathrm{H}_{2} \mathrm{O}$ at $13 \mathrm{gpm}$ (this value was used for similarity between model and prototype), and $0.05 \mathrm{in}$. of $\mathrm{H}_{2} \mathrm{O}$ at $6 \mathrm{gpm}$.

Finally, the free surface in the upper plenum was observed at the various flow levels. Even at $100 \%$ of simulated prototype flow (corresponding to $20 \%$ of the prototype Froude number at full flow), the surface remained quiescent. This is not conclusive for the prototype since $100 \%$ of prototype Froude number was unattainable in the present tests, i.e., the flowrate could not safely be raised to increase the Froude number which is the ratio of inertia to gravity forces.

\subsubsection{Cold Plenum Stratification}

Because of the poor flow behavior in the cold plenum under isothermal conditions, a test was conducted in which $65^{\circ} \mathrm{F}$ water in the PRISM model was initially stagnant, and at $t=0$ (i.e., the start of the test) $100^{\circ} \mathrm{F}$ water was 
forced through the model at $21 \mathrm{gpm}$ (nominally 15\% of simulated prototype full flow) by the MCTF (i.e., external mode of operation). Initially, a hot/cold interface formed in the upper plenum which moved lower as a function of time until it reached the IHX inlets. Hot water then flowed through the IHXs into the annular region between the radial-shield liner and the RV wal1. Dye injected at one of the IHX exits showed that the hot fluid exiting the IHX accumulated in the IHX exit region. Some of the accumulated fluid rose into the overflow gap and replaced the initially cold water there while the majority of the hot flow slowly moved downward towards the bottom of the radial-shield liner in a stratified fashion. After about 15 minutes, a hot/cold (distinct) interface formed immediately below the radial-shield liner. Incoming hot water flowed down the annular gap between the radial shield and the RV wall from the IHX exits to just below the radial-shield liner, and then proceeded up the radial shield to the pump inlets. The hot/cold interface, illuminated by the dye, was very distinct. Thus, the annular flow between the radial shield and the RV wall did not penetrate to the lower plenum floor. The stagnant cold plenum lower region was further aggravated by the thermal-buoyancy forces. This is contrary to the observation in the preceding section in which this annular flow did penetrate to the floor for an isothermal flow at the same flowrate. Buoyancy forces caused by the temperature difference between the hot incoming flow and the cold stagnant water near the floor of the lower plenum were strong enough to counteract the inertia forces of the jet, turn it radially inward, and leave a large volume of water which did not participate in mixing. Thus, large temperature gradients existed in a region with many welds (i.e., core inlet tubes) which could fail because of excessive thermal stresses. The observation that the dyed hot water rose into the cold water in the overflow gap, even though there was no overflow, is important to the designer who is estimating the amount of heat that is rejected through the pressure vessel wall (i.e., RVACS cooling). A more detailed series of tests was conducted to further explore the preceding phenomena. These tests are discussed in the following section.

\subsubsection{Constant Flow Thermal Transients}

A series of four tests was conducted in which a constant flow driven by the MCTF was forced through the PRISM model with a step change (upramp) in 
temperature. The tests were run with 5, 15, 30, and $60 \%$ of simulated prototype full flow, with a nominal step change in temperature of $16.7^{\circ} \mathrm{C}$ for all tests. The Richardson and Reynolds numbers (based on core barrel ID) for these tests ranged from 21 to 3021 and 1434 to 16392 , respectively, as shown in Table IV. The results of test JU1901, with 15\% of simulated prototype full flow, will be highlighted, and comparisons will be made with the remaining tests. The flow provided by the MCTF and its temperature when entering the model core are shown in Figs. 40a and b for JU1901 as a function of time. The flowrate and temperature of the flow at the core inlet remained constant from $40 \mathrm{~s}$ until the end of the test (i.e., $5500 \mathrm{~s}$ ). The variations of flow and temperature between 0 and $40 \mathrm{~s}$ (see Fig. 40a) are due to the opening and closing of MCTF control valves, the effect of which is small considering the flowrate and the total length of the test.

Table IV. Nondimensional Parameters for the Constant Flow Thermal Transients Test Flow $(\%) \quad$ Flowrate $\left(M^{3} / h r\right) \quad \Delta T\left({ }^{\circ} \mathrm{C}\right) \quad \operatorname{Re}^{\mathrm{a}} \quad \mathrm{Ri}^{\mathrm{a}} \quad \mathrm{Re}^{\mathrm{b}} \quad \mathrm{Ri}^{\mathrm{b}}$

\begin{tabular}{rrrrrrrr}
\hline JU2001 & 5 & 1.4 & 12.2 & 1434 & 3021 & 331 & 4914 \\
JU1901 & 15 & 4.3 & 17.0 & 4285 & 366 & 990 & 596 \\
JY0801 & 30 & 8.1 & 15.0 & 8352 & 90 & 1930 & 147 \\
JU1902 & 60 & 16.7 & 15.4 & 16392 & 21 & 3787 & 35 \\
\hline
\end{tabular}

a Based on core barrel ID.

based on radial-gap diameter outside the radial shield.

The responses of 8 of the 11 thermocouples mounted on a vertical sting (see Fig. 12) on the cold plenum floor about 2 in. inside the radial-shield liner are shown in Fig. 41. LP1 is located approximately 2 in. above the bottom edge of the radial-shield liner $(-14-5 / 8$ in. above the cold plenum floor) and LP11 is located 2-1/8 in. above the floor of the cold plenum. These thermocouples were placed in this region because of the observed stagnant region discussed in the previous sections. There is a time delay of $500 \mathrm{~s}$ before hot fluid reaches the thermocouple sting (same order as the 15 min observed in the previous section before a distinct interface formed). Dye was also injected at the exits of an IHX in test JU1901, and the thermally stratified dyed interface was measured 11-1/4 in. above the cold plenum 


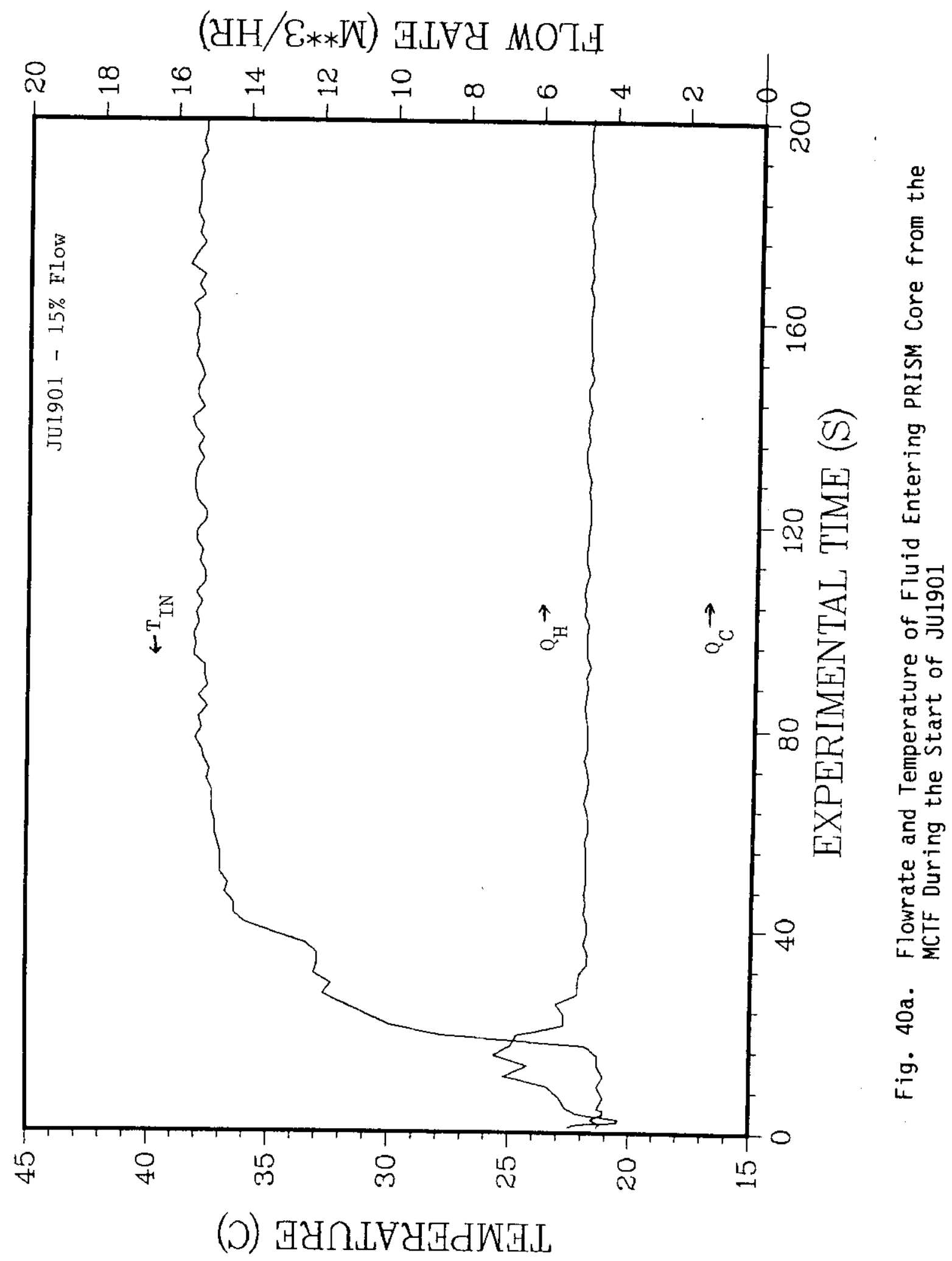




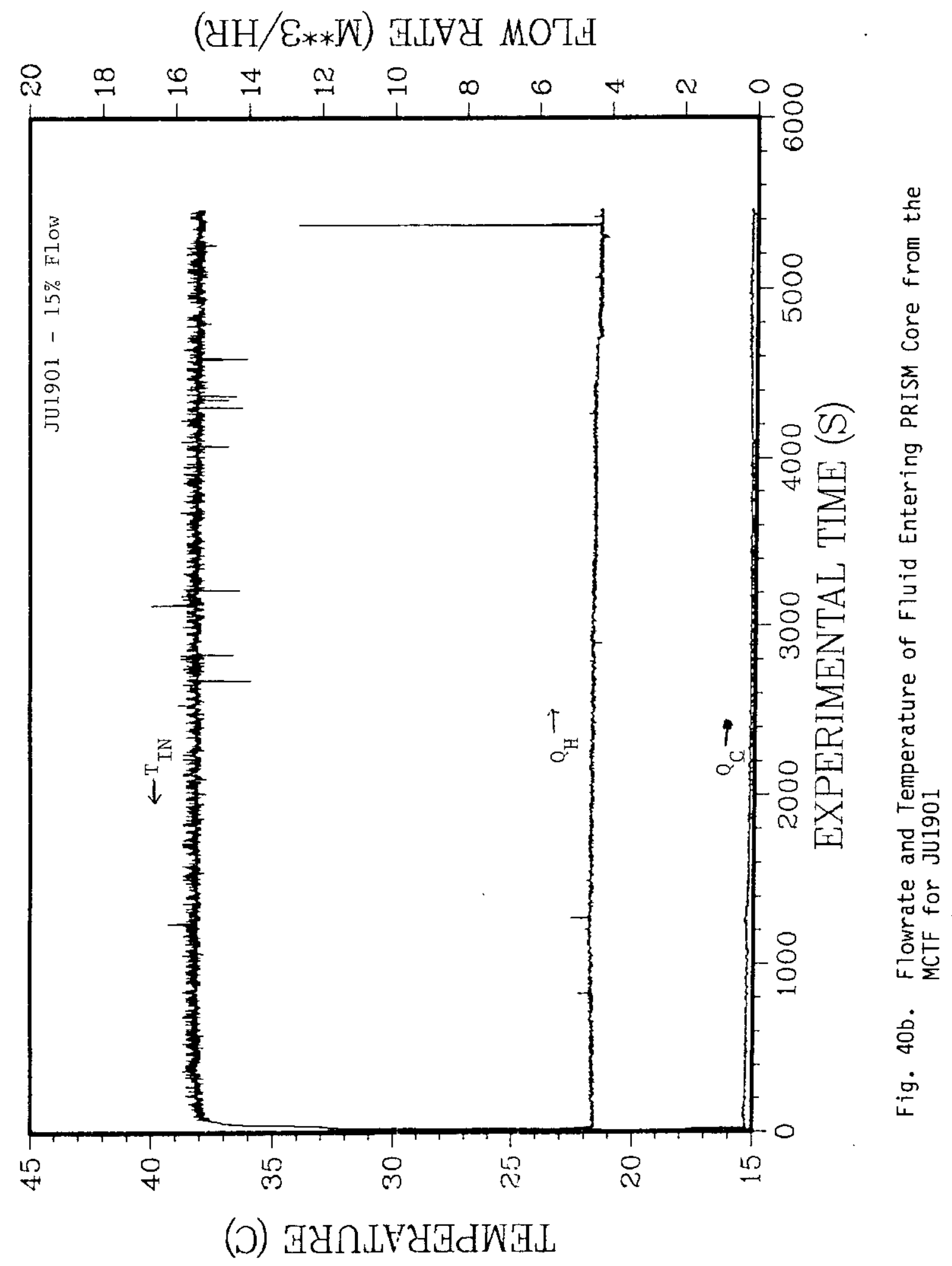




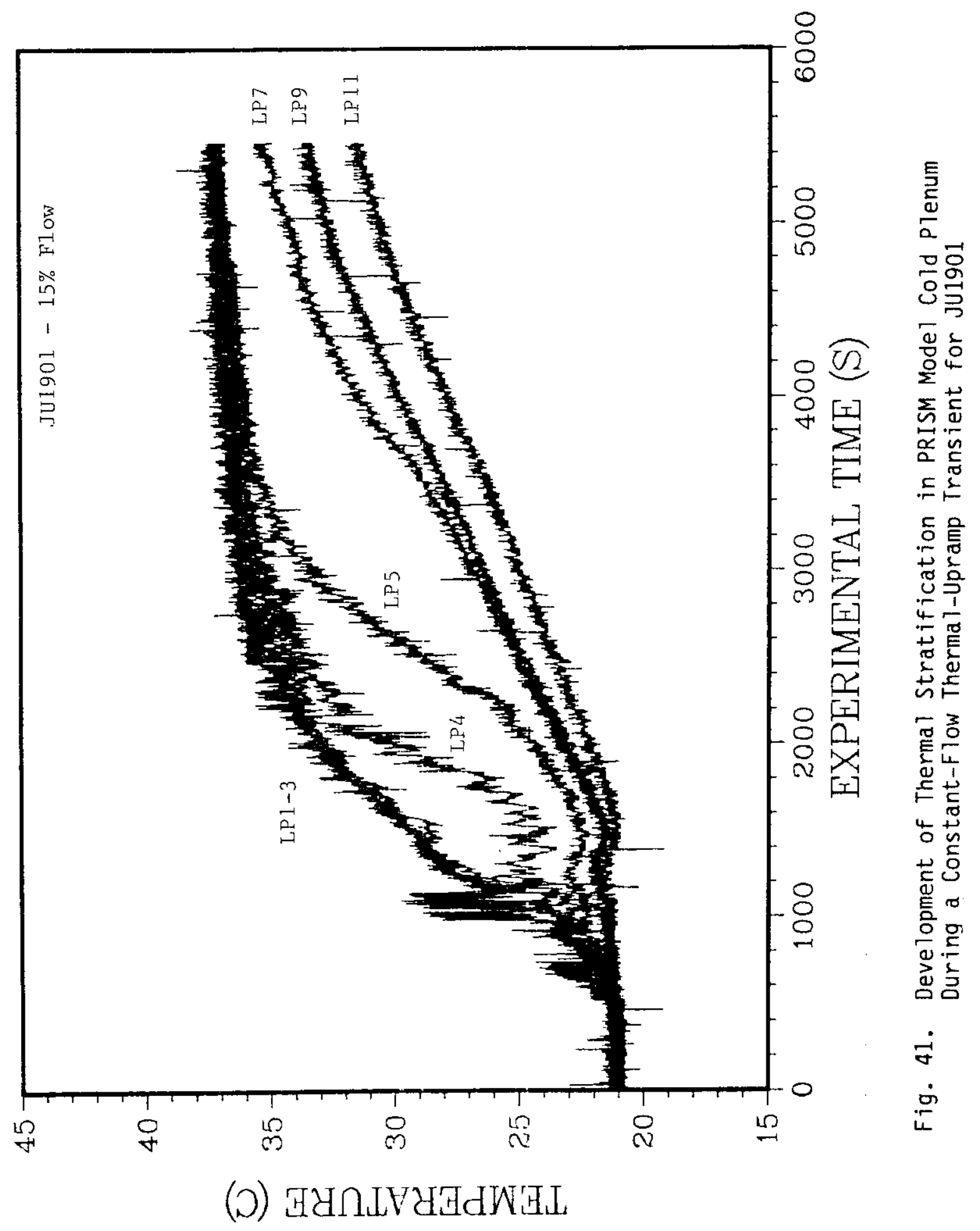


floor. The bottom edge of the radial-shield liner is $12.6 \mathrm{in}$. above the plenum floor. The interface slowly undulated $\pm 1 / 2$ in. and appeared billowy (like a cloud). The cold stagnant region below the stratified interface is clearly indicated in Fig. 41 and begins forming at $t=500 \mathrm{~s}$. Thermocouples LP1-3 are above the interface, and LP7, LP9, and LP11 are below it. LP4 is very close to the stratified interface elevation. The response of thermocouple LP11 is very linear after $2000 \mathrm{~s}$, an indication that it is in a region where heat is transferred dominantiy by conduction, not convection (i.e., it is in a stagnant region). The Richardson number (based on the radial-gap diameter outside the radial shield) was 596 for JU1901, an indication that the buoyancy forces are much larger than the inertia force, which accounts for the stratified lower plenum.

The corresponding thermocouple responses for the remaining tests (i.e., JU1902, JU2001, and JY0801) are presented in Figs. 42-44. The following general observations were noted:

1. Thermal stratification occurred in the lower plenum in a 11 four tests. Richardson numbers (based on the radial-gap diameter outside the radial shield) varied between 35 and 4914, an indication that the thermal buoyancy forces are large compared to the inertia forces. Additional tests are necessary to determine the lower threshold value of the Richardson number below which there is no stratification in the lower plenum.

2. The delay time before the stagnant region begins to form varied as the flowrate, i.e., the lower the flowrate, the longer the delay time. This is related to the fill time during which the incoming hot fluid displaces cold fluid in the upper regions of the model.

3. In all tests, the stagnant region initially formed below LP3, which is $12-1 / 8 \mathrm{in}$. above the floor of the lower plenum.

4. The thermocouple responses for JU2001 (i.e., $5 \%$ flow) were a 11 linear, indicating that the dominant mode of heat transfer in the lower plenum at this low flowrate was conduction.

5. As the flowrate increased from one test to another, temperature fluctuations for a particular thermocouple grew larger in amplitude, an indication that the flow was changing from laminar to turbulent. The calculated Reynolds number (based on the radial gap outside the 


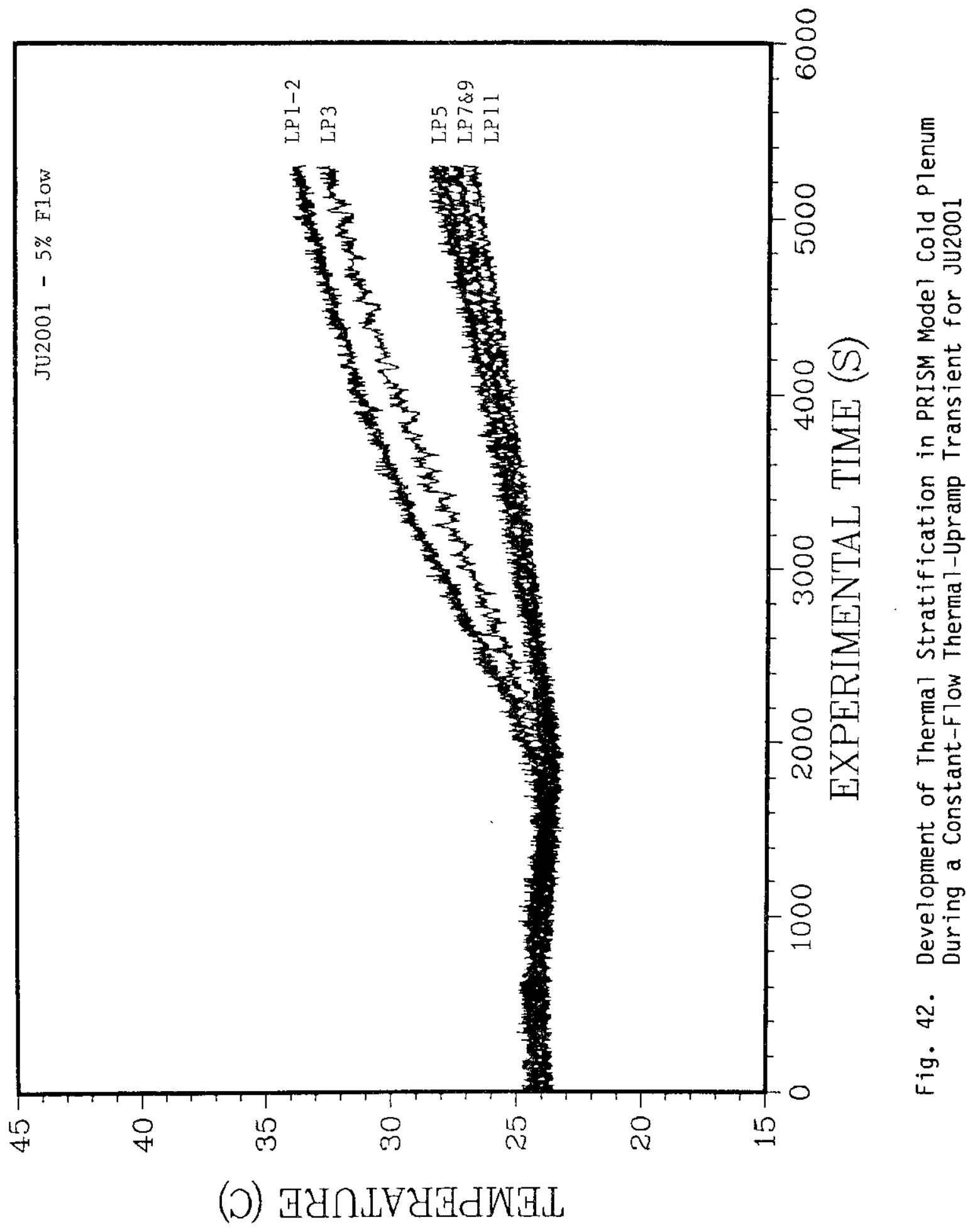




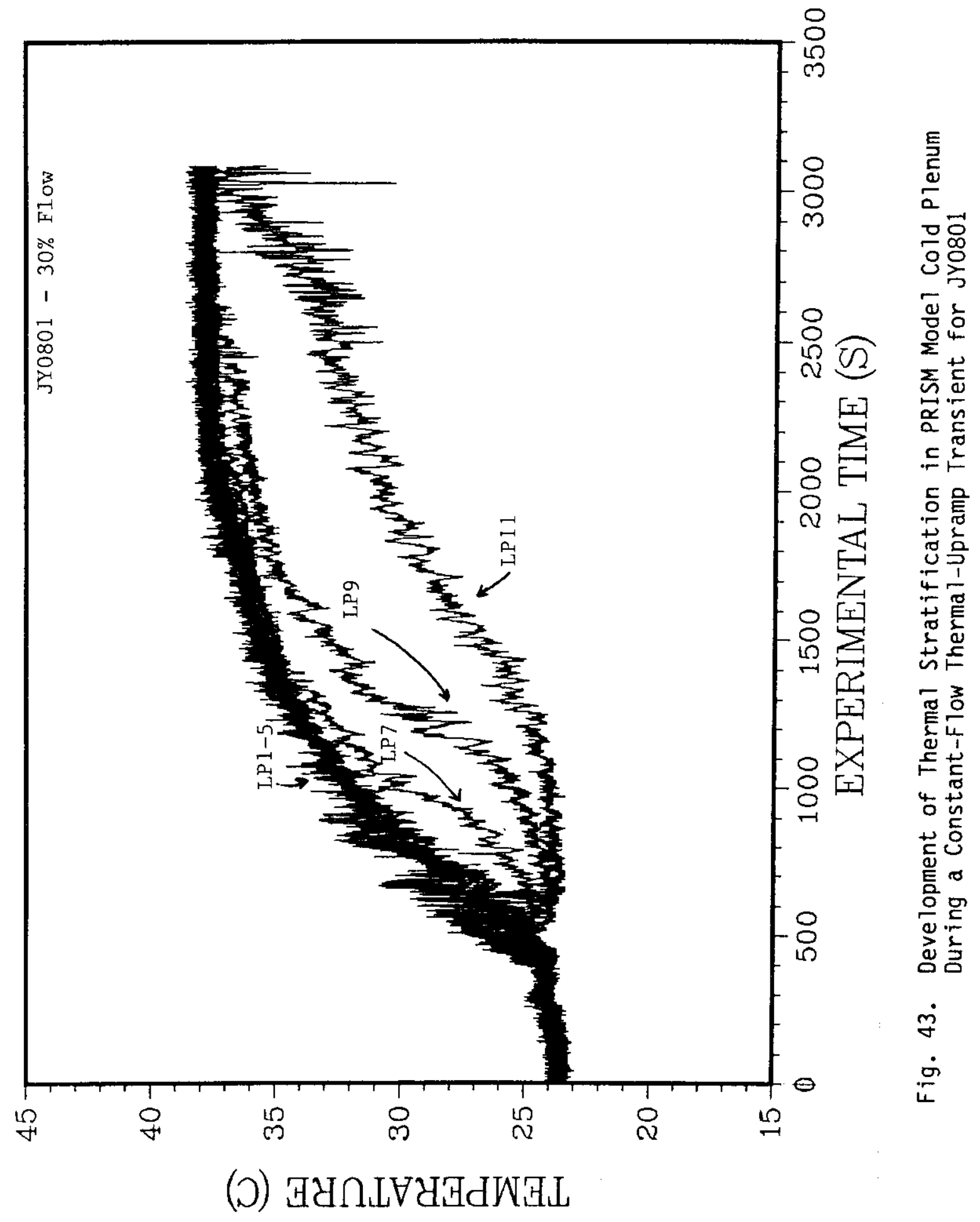




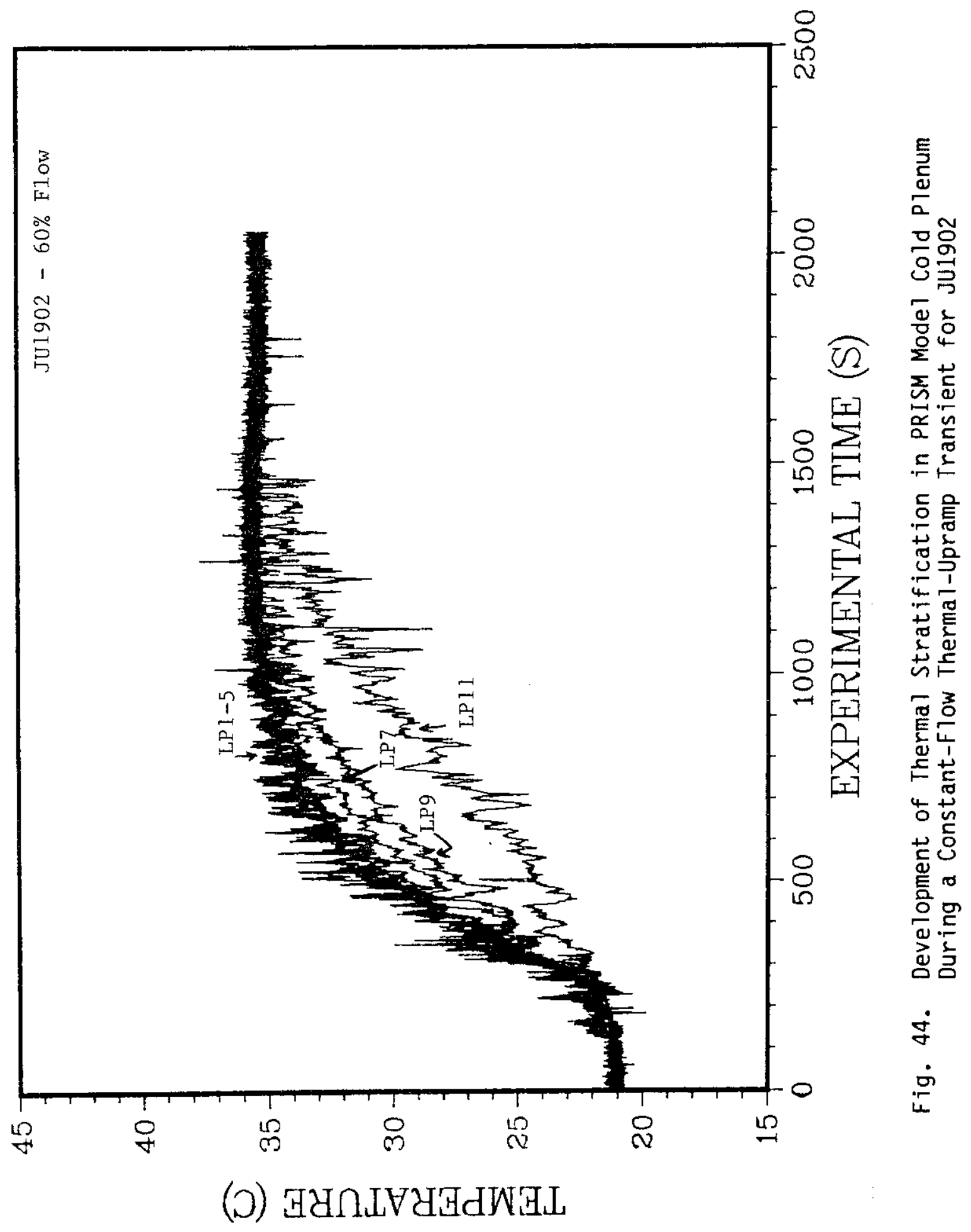


radial shield) for these tests confirmed this (see Table 1). Reynolds numbers (based on the radial-gap diameter outside the radial shield) were 331 and 990 for JU2001 and JU1901, respectively. Thus, these flows were laminar since the Reynolds numbers were well below 2000. The Reynolds numbers for the remaining two tests, JY0801 and JU1902, were 1920 and 3787, respectively. The flow in Jy0801 was in transition from laminar to turbulent, whereas the flow in JU1902 was turbulent. This is in accord with the observed behavior of the thermocouple responses in these tests.

6. The persistance time of the cold stagnant region varied inversely with flowrate for the same temperature difference because the larger the flowrate, the smaller the thermal-buoyancy forces and hence, increased mixing occurred across the stratified interface and washed away the stagnant region.

The hot/cold stratified interface was also observed by means of dye injection in the tests with 5, 30, and 60\% of simulated prototype full flow. The difference noted was that, for the $60 \%$ flow test, the interface was not as distinct (i.e., some turbulent mixing) and moved down toward the plenum floor more rapidiy, whereas for the $5 \%$ flow test, the interface was extremely distinct and motionless (i.e., appeared as a fine line). For the 5\% flow test, multiple interfaces formed, separated by approximately 1 in., i.e., sharp density differences were observed as distinct lines even without the use of dye. All stratified interfaces initially formed at approximately the same elevation as that observed in test $J U 1901$ (i.e., between approximate1y 10-1/2 and 11-1/4 in. above the plenum floor). The distinctness of the interface is an indication of the transition from turbulent to laminar flow and the influence of thermal-buoyancy suppression of mixing at the interface as the flowrates were decreased. The stratified stagnant region in the lower plenum existed in an area with many pipe welds, etc. The temperature gradients resulting from stratification cause thermal stresses, which need to be evaluated by the designer.

The response of thermocouple G3, located at midelevation in the overflow gap surrounding the hot plenum, is shown in Fig. 45 for Ju1901. The hot fluid exiting the IHX, driven upward by natural-convection currents reached the midpoint of the overflow gap during the same time period as the hot/cold 


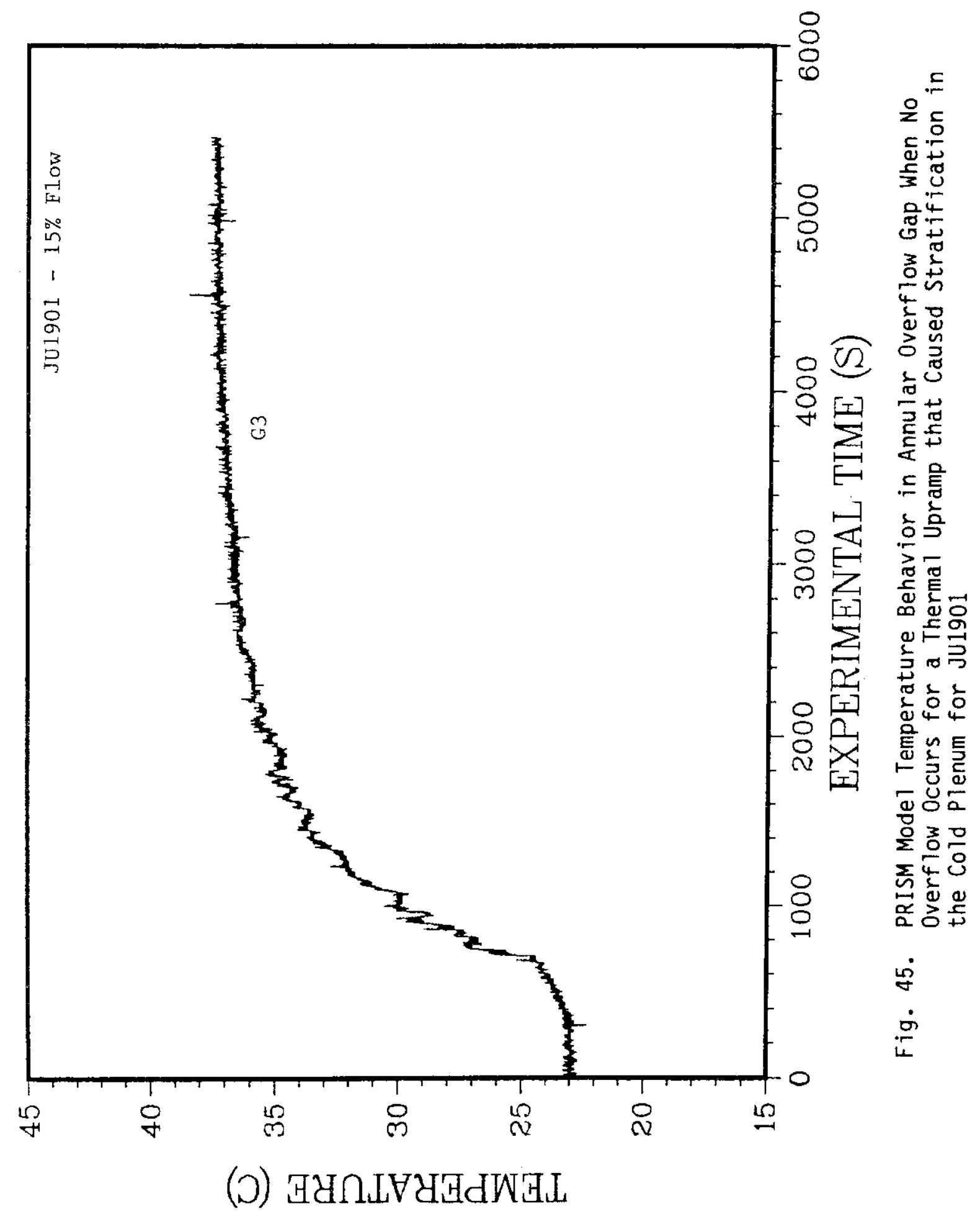


interface was forming in the lower plenum. Even the time delay was of the same order of magnitude. The response of thermocouple 63 was nonlinear, an indication of heat transfer by convection as well as conduction. The preceding observation is valid for all four tests with the only difference being the magnitude of the time delay, which is a function of flowrate, i.e., the higher the flowrate the shorter the time delay. This is important to the designer who is estimating RVAC capacity and vessel heat losses, especially if it was previously assumed that heat transfer in this annular stagnant gap was only by conduction.

A vertical sting of thermocouples in the upper plenum, located off the centerline, on a radius midway between two IHXS (about 5-3/4 in. from the liner, see Fig. 11), is shown in Fig. 46 for JU1901. NS1 is near the upper plenum floor, whereas NS4 is near the free surface. The responses for thermocouples NS1 through NS4 fall on top of one another except between $t=1100$ and $1900 \mathrm{~s}$ where there is an indication of a small degree of stratification in the upper plenum. This behavior is seen in the data for all four tests. There is essentially no stratification in the upper plenum in any of these four tests. The Richardson numbers (based on the core barrel diameter) range between 21 and 3021 (see Table IV). Thus, the thermalbuoyancy forces are large compared to the inertia forces, but, unlike the cold lower plenum, they act in the same direction and thus do not promote stratification. The cold fluid initially in the upper plenum mixes with the core flow and is washed out of the upper plenum.

The responses of thermocouples 58 (on the sting on the centerline of the model, Fig. 12) and NS3 (on the sting off the centerline, on a radius midway between IHXS, Fig. 11) located near the elevation of the IHX inlets are shown in Fig. 47 for JU1901. The temperature in the upper plenum at this elevation was, for the most part, symmetrical except between $t=900$ and $2500 \mathrm{~s}$ when the temperature at the centerline (in the hot jet flowing upwards from the core) is $1^{\circ} \mathrm{F}$ warmer than that off center between the IHXs. This behavior was also seen in the data for all four tests.

Responses for a vertical string of thermocouples mounted on the outer surface of the radial-shield liner (see Fig. 11) are presented in Figure 48. $R 1$ is at the highest elevation, whereas $R 5$ is at the lowest. The responses 


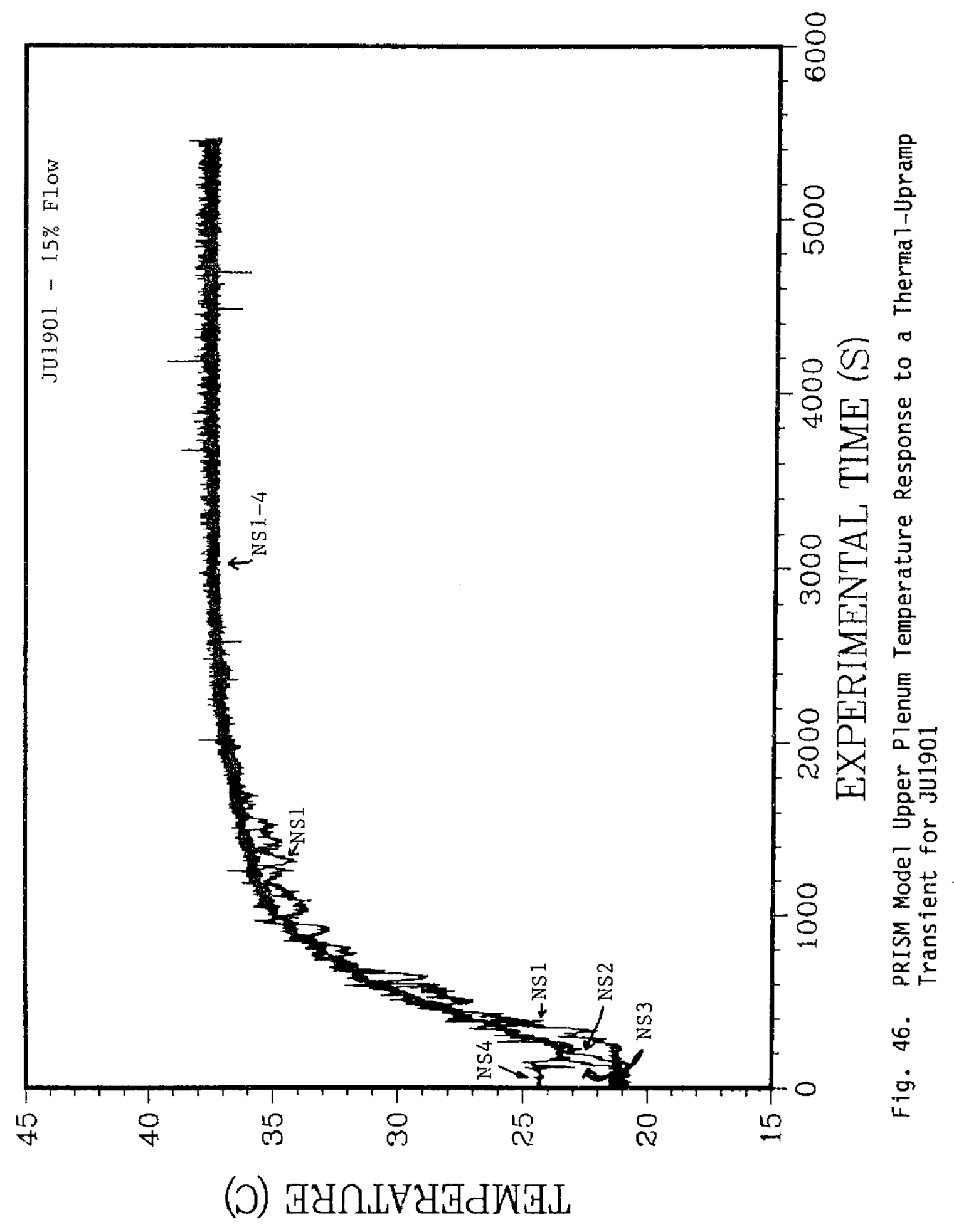




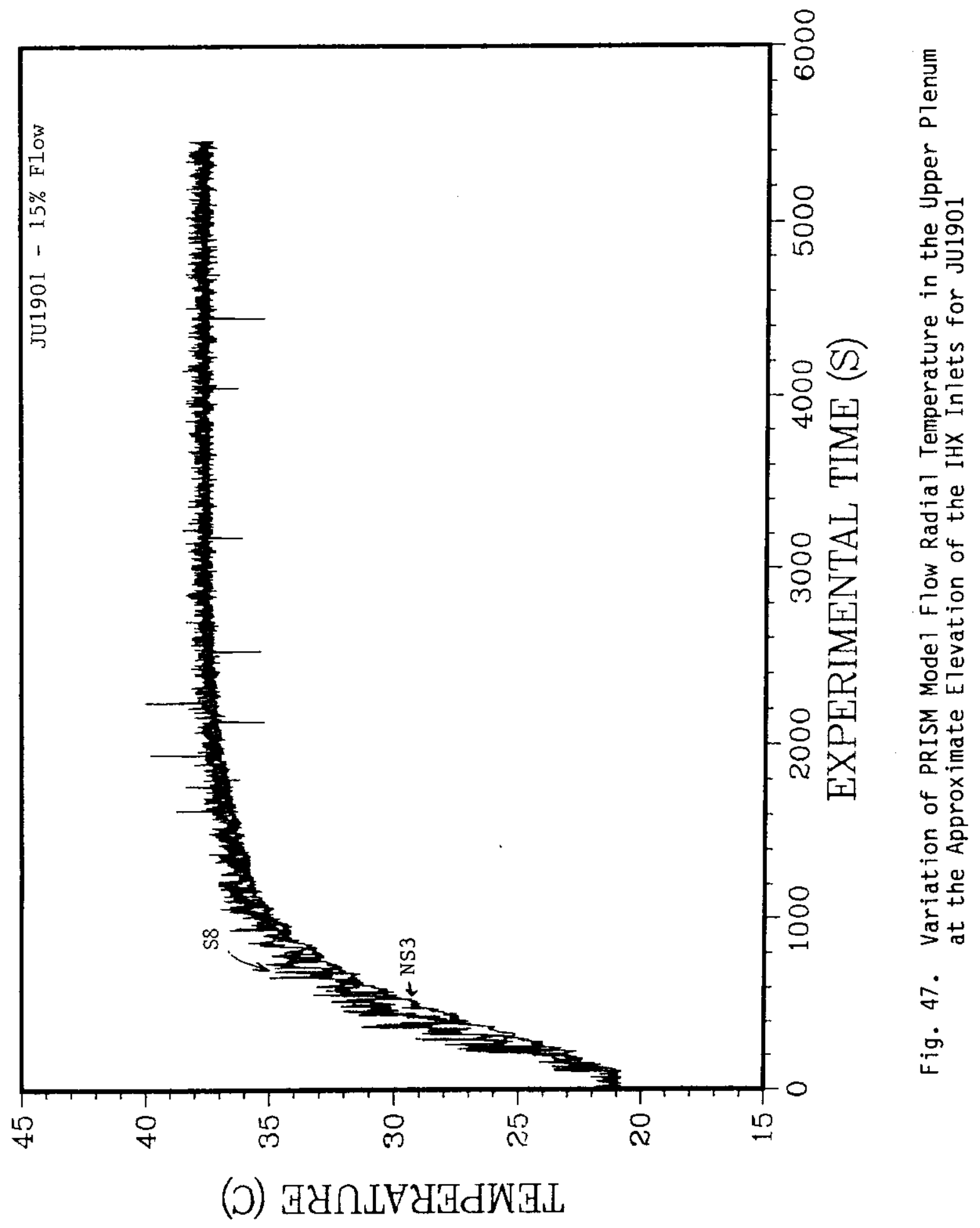




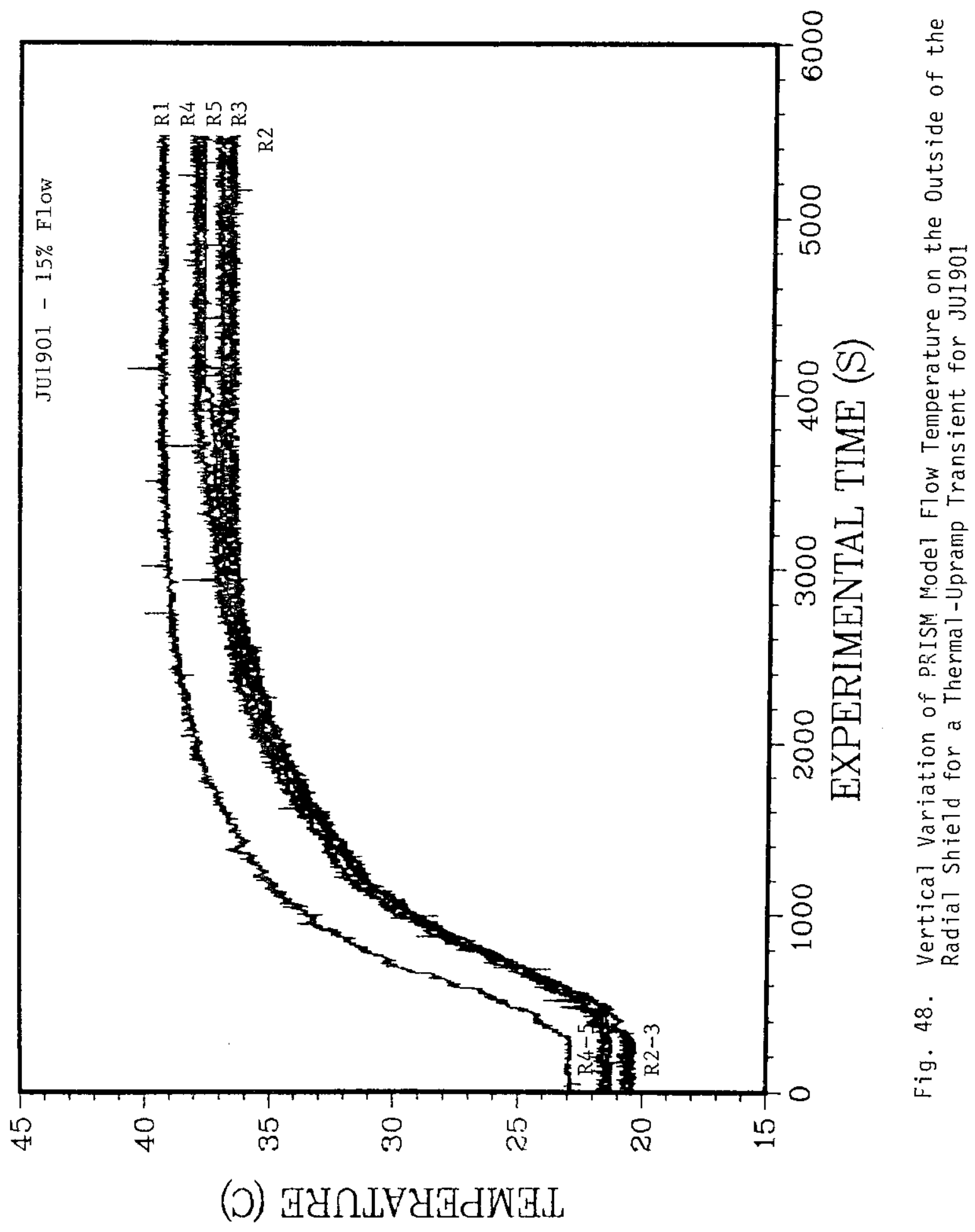


generally fall on top of one another if the initial thermocouple offsets are factored in. This behavior is evident in all four tests.

The responses of the thermocouples at the entrances and exits of critical flow circuit subregions (see Figs. 11 and 12) are presented in Fig. 49 for JU1901. Generally, the warm front was seen to traverse the flow circuit in sequence [i.e., core exit (S5), IHX inlet (LI), IHX exit (L6), outside radial shield (R5), pump inlet (PI1), pump exit (PE4), and core return pipe (P3)]. The corresponding thermocouple responses for the remaining tests (i.e., JU1902, JU2001, and JY0801) are presented in Figs. 50-52. The thermal front traversed the flow circuit faster as the flowrate was increased. The initially cold fluid was thus replaced with hot fluid more quickly at higher flow-rates. In addition, S13, located in the upper plenum, had larger temperature fluctuations for JU1901, JY0801, and JU1902, and Reynolds numbers (based on the core barrel IDs) of 4285, 8352, and 16392, respectively, than for JU2001 which had a Reynolds number of 1434. Thus, the flow of JU2001 was laminar (i.e., below a value of 2000), whereas the flows in the remaining three tests were al1 turbulent. The observed larger temperature fluctuations are indicative of increased turburlent mixing in the upper plenum above the core outlet.

The important findings from these series of tests are the existence of the stagnant, thermally stratified region in the lower plenum with its associated thermal-stress concerns, lack of a stratified region in the upper plenum, and the existence of natural-convection heat transfer in the overflow gap, even without overflow.

\subsubsection{Natural Convection}

Four tests were conducted in which the immersion heater was set at a constant power to provide the sole driving force for natural-convection flow. The only heat sink was the stainless steel containment vessel walls which were cooled by ambient air. Tests JY1501, JY2401, JY1601, and JY2301, were run with $5,10,20$, and $30 \mathrm{~kW}$ of power, respectively $(27.5 \mathrm{~kW}$ corresponding to $10 \%$ power in the prototypic PRISM reactor). With the containment vessel initially filled with approximately $75^{\circ} \mathrm{F}$ water, the test was run until the temperature of the water in the upper plenum reached $105^{\circ} \mathrm{F}$ (dictated by concerns to protect the plastic model from damage), at which time 


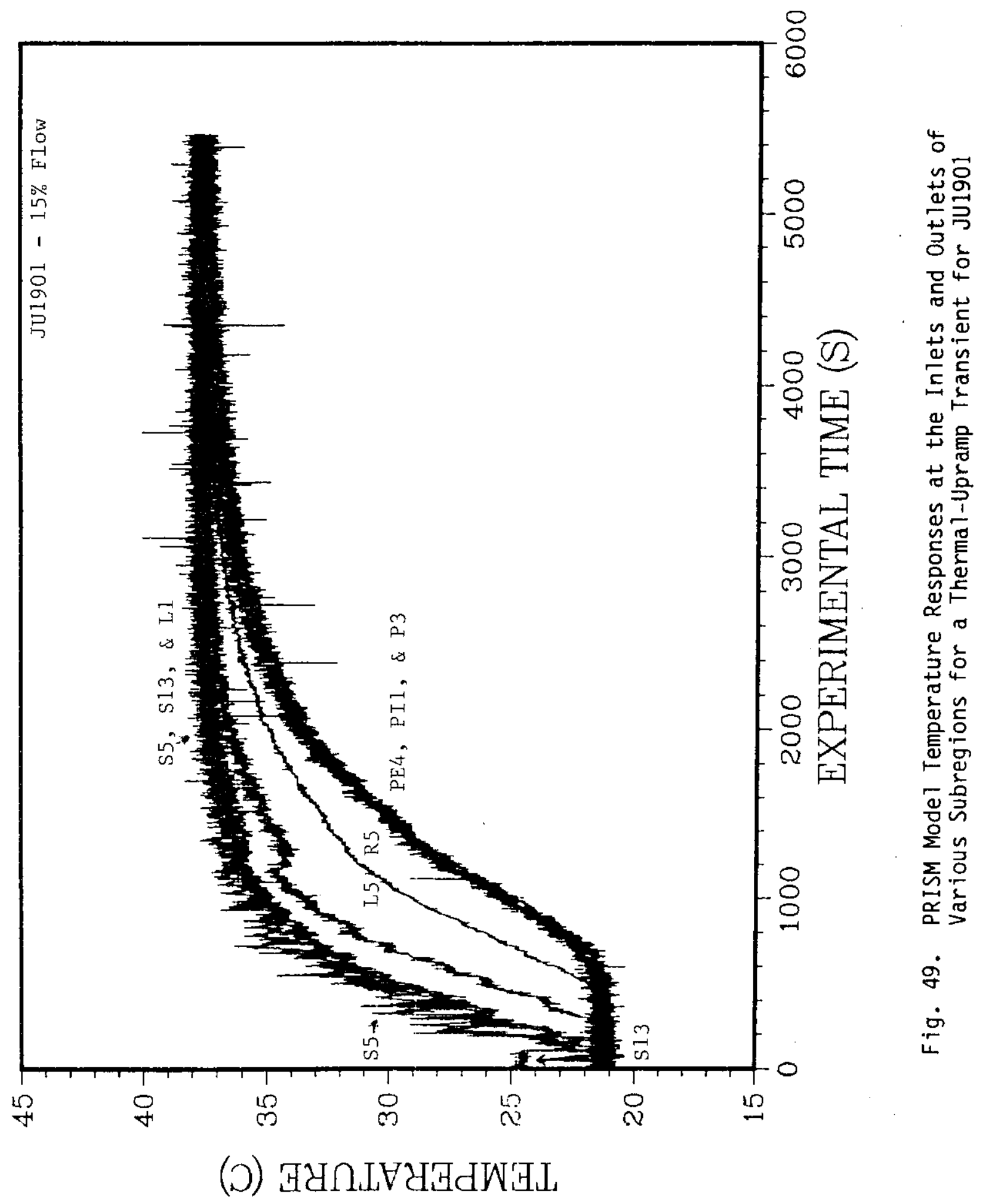




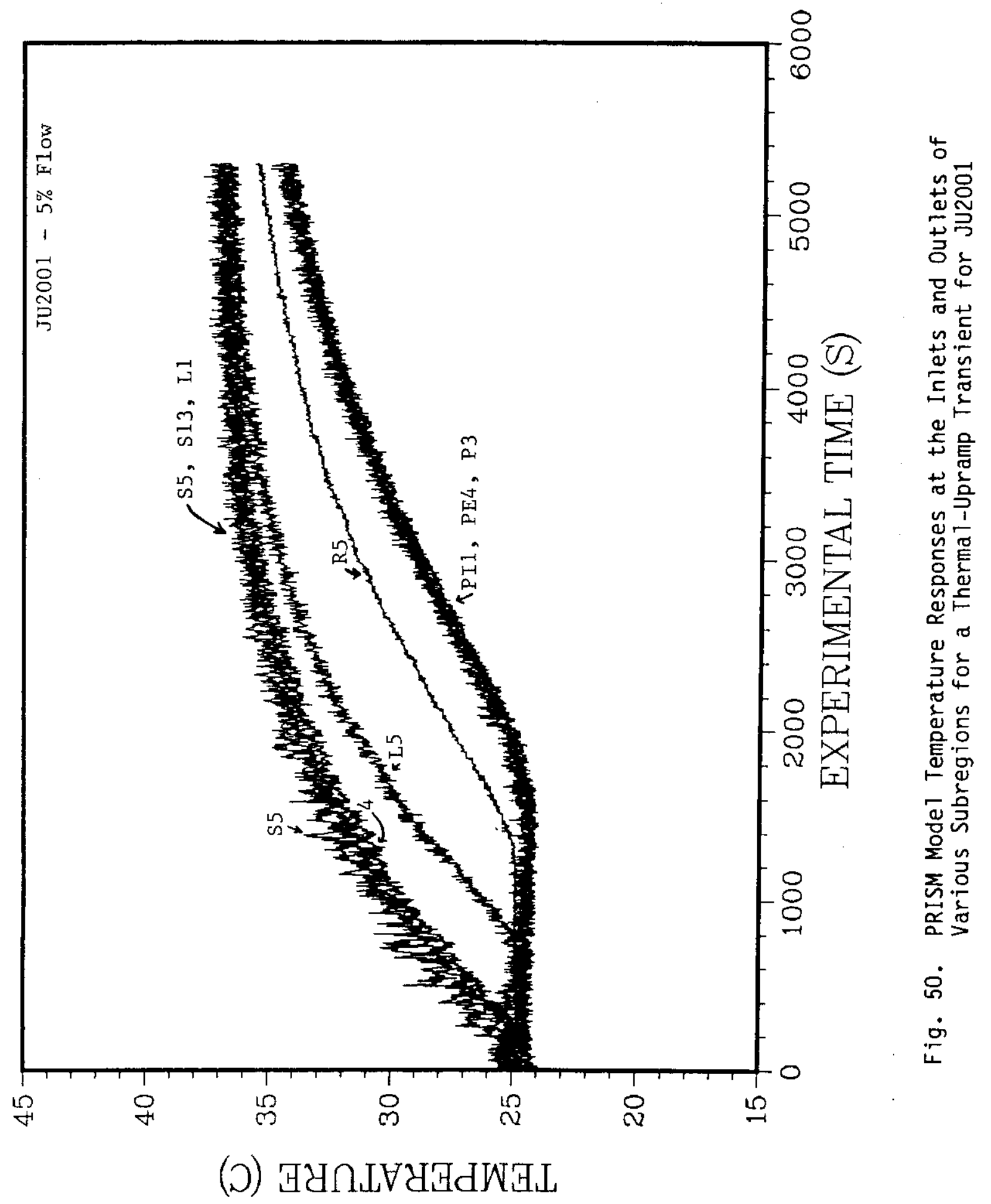




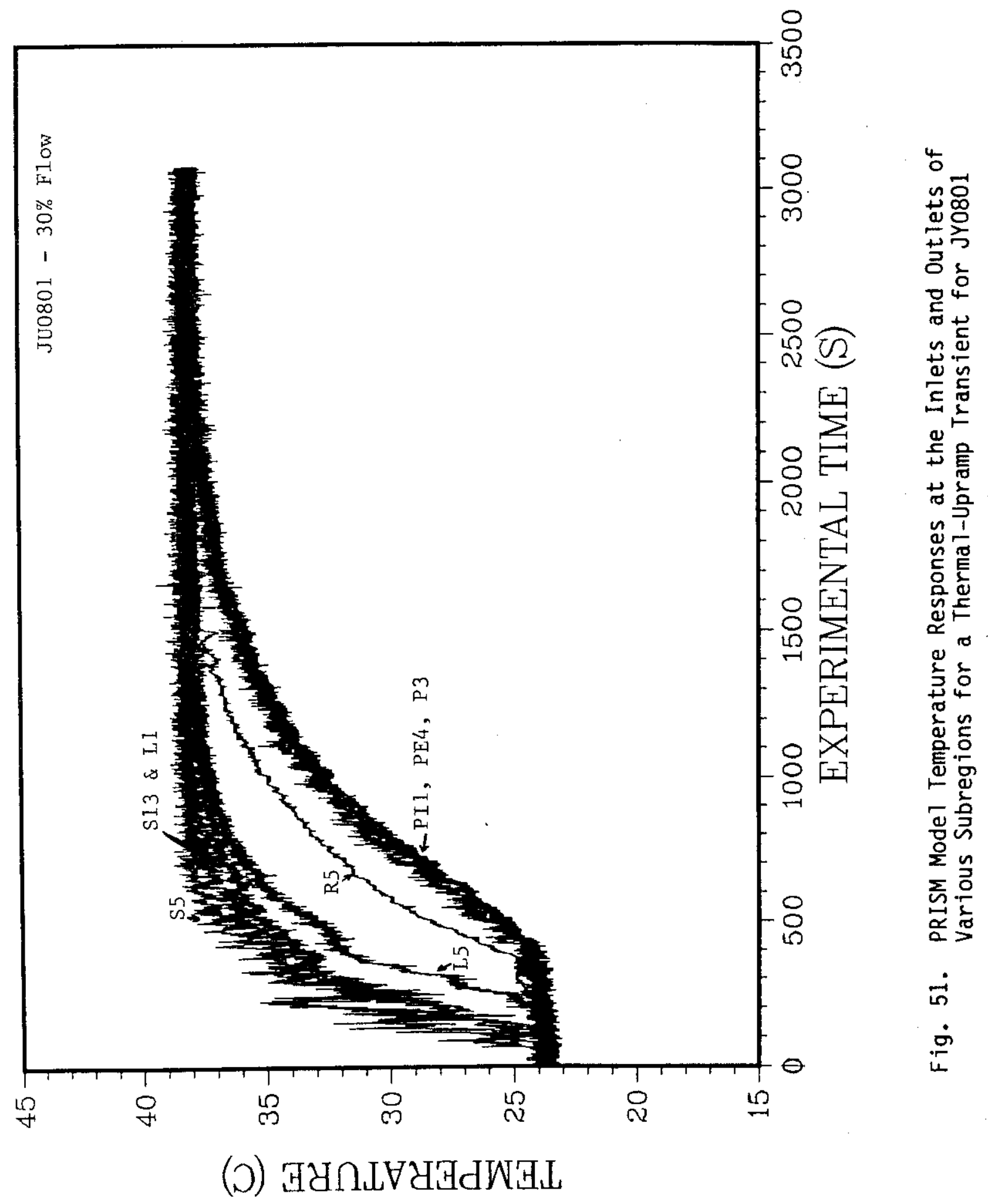




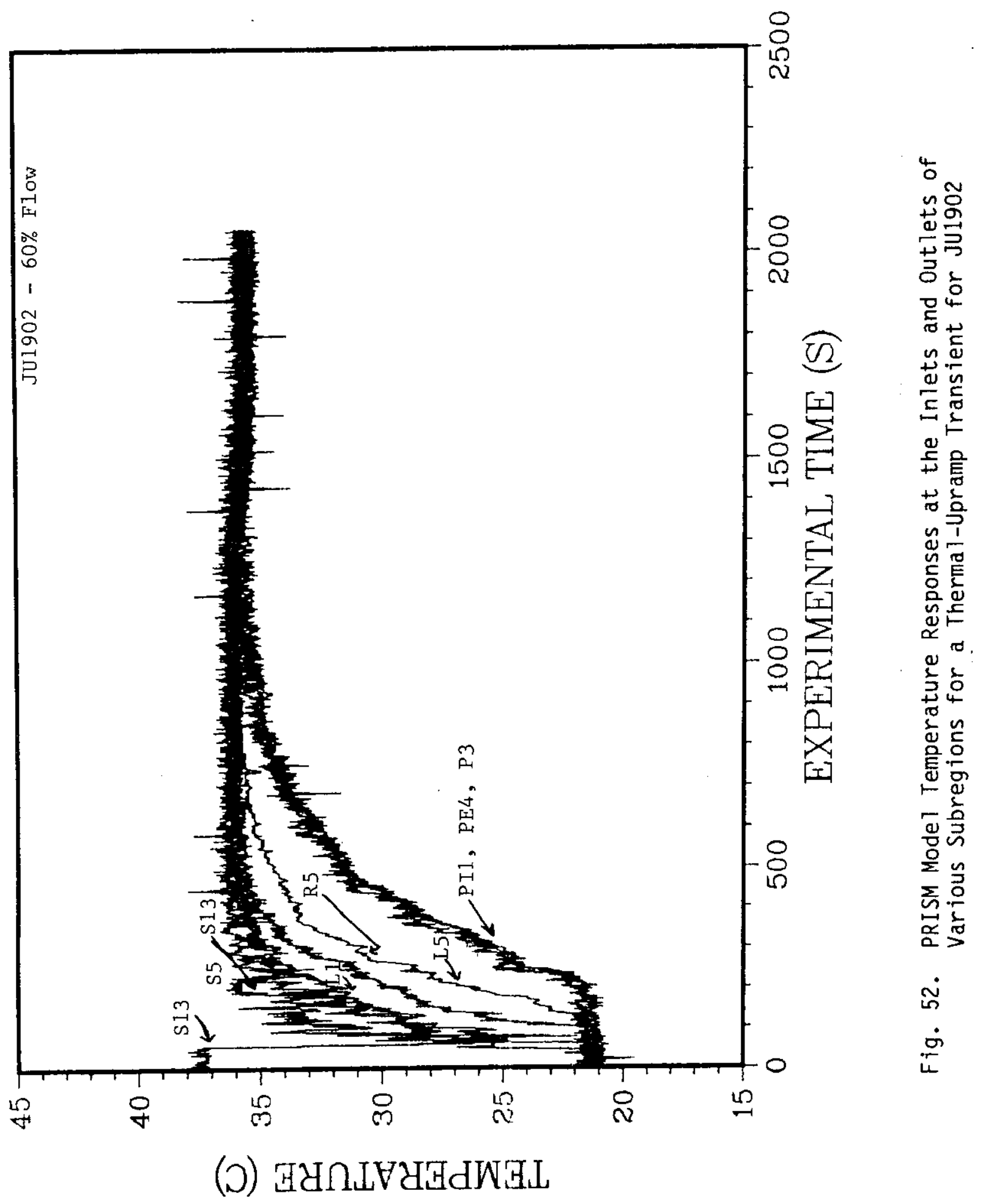


the immersion heater was turned off (i.e., at $t=4566 \mathrm{~s}$ for JY2301), but the thermocouples continued to be scanned and recorded by the DAS. These were transient tests; a steady-state was not reached. In Fig. 53, the thermocouple responses of 8 of the 11 thermocouples mounted on a vertical sting on the cold plenum floor about 2 in. inside the radial-shield liner (see Fig. 12) are presented for JY2301 with $30 \mathrm{~kW}$ power input. After a delay of approximately $1750 \mathrm{~s}$, the lower plenum was stratified, i.e., LP1 was at a higher elevation and temperature than LP11. Note the oscillation observed on LP3 near $t=$ $4500 \mathrm{~s}$ appears to be a thermal-hydraulic instability.

The corresponding thermocouple responses for the remaining naturalconvection tests (i.e., JY1501, JY2401, and JY1601) are presented in Figs. 5456. Stratification was observed in the lower plenum for all the tests except JY1501. The pertinent nondimensional parameters for each of these tests are presented in Table $V$. As the immersion heater power decreased, the strength of the flow (i.e., velocity) decreased and a longer time period was required for stratification to develop. Thus, in order for stratification to develop in the lower plenum under the thermal-hydraulic conditions of JY1501, a test duration longer than the $7500 \mathrm{~s}$ is required. Grashof numbers for these tests (i.e., the ratio of buoyancy to viscous forces) were all of the order of $10^{9}$, an indication that the flows were laminar. Reynolds numbers (based on the gap diameter outside the radial shield) are much smaller than 2300, also an indication that the flow was laminar in the lower plenum. Richardson numbers (based on the gap diameter outside the radial shield) were very large (i.e., greater than 1276), an indication that the buoyancy forces were much larger than the inertia forces.

The responses of three of the thermocouples on the center sting in the upper plenum (see Fig. 12) are shown in Fig. 57 for JY2301. S5 is located at a lower elevation than S13. The responses of these thermocouples fall on top of one another and reach a plateau at approximately $t=4800 \mathrm{~s}$, shortly after the immersion heater was turned off. Thus, there was no stratification in the upper plenum. Note these thermocouples were all on the centerline. Responses of thermocouples located off the centerline of the model, in the upper plenum, confirm that there was no stratification. In fact, stratification in the upper plenum was not found in any of these natural-convection tests. This is 
Table V. Nondimensional Parameters for the Natural-Convection Transients

\begin{tabular}{lcccccc}
\hline Test & Power (KW) & $u(\mathrm{~m} / \mathrm{s})^{\mathrm{a}}$ & $\Delta \mathrm{T}\left({ }^{\circ} \mathrm{C}\right)^{\mathrm{b}}$ & $\mathrm{Ri}_{\mathrm{gap}}{ }^{\mathrm{C}}$ & $\mathrm{Re}_{\mathrm{gap}}{ }^{\mathrm{C}}$ & $\mathrm{Gr}_{\mathrm{L}}{ }^{\mathrm{d}}$ \\
\hline JY2301 & 30 & 0.0165 & 4.75 & 1276 & 314 & $5.55 \times 10^{8}$ \\
JY1601 & 20 & 0.0156 & 7.29 & 2133 & 301 & $8.97 \times 10^{8}$ \\
JY2401 & 10 & 0.0100 & 5.82 & 5142 & 203 & $8.43 \times 10^{8}$ \\
JY1501 & 5 & 0.0072 & $\mathrm{e}$ & $\mathrm{e}$ & 120 & $\mathrm{e}$ \\
\hline
\end{tabular}

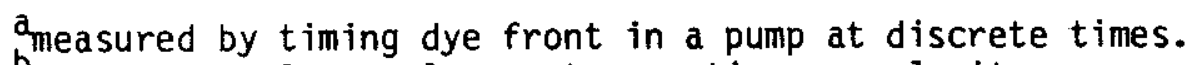

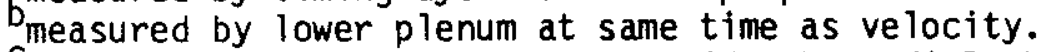

cbased on radial-gap diameter outside the radial shield.

based on height of radial-shield bottom above floor of lower plenum.

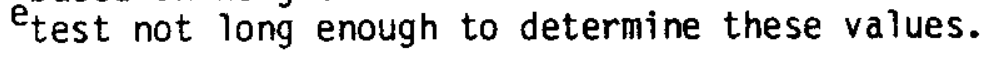




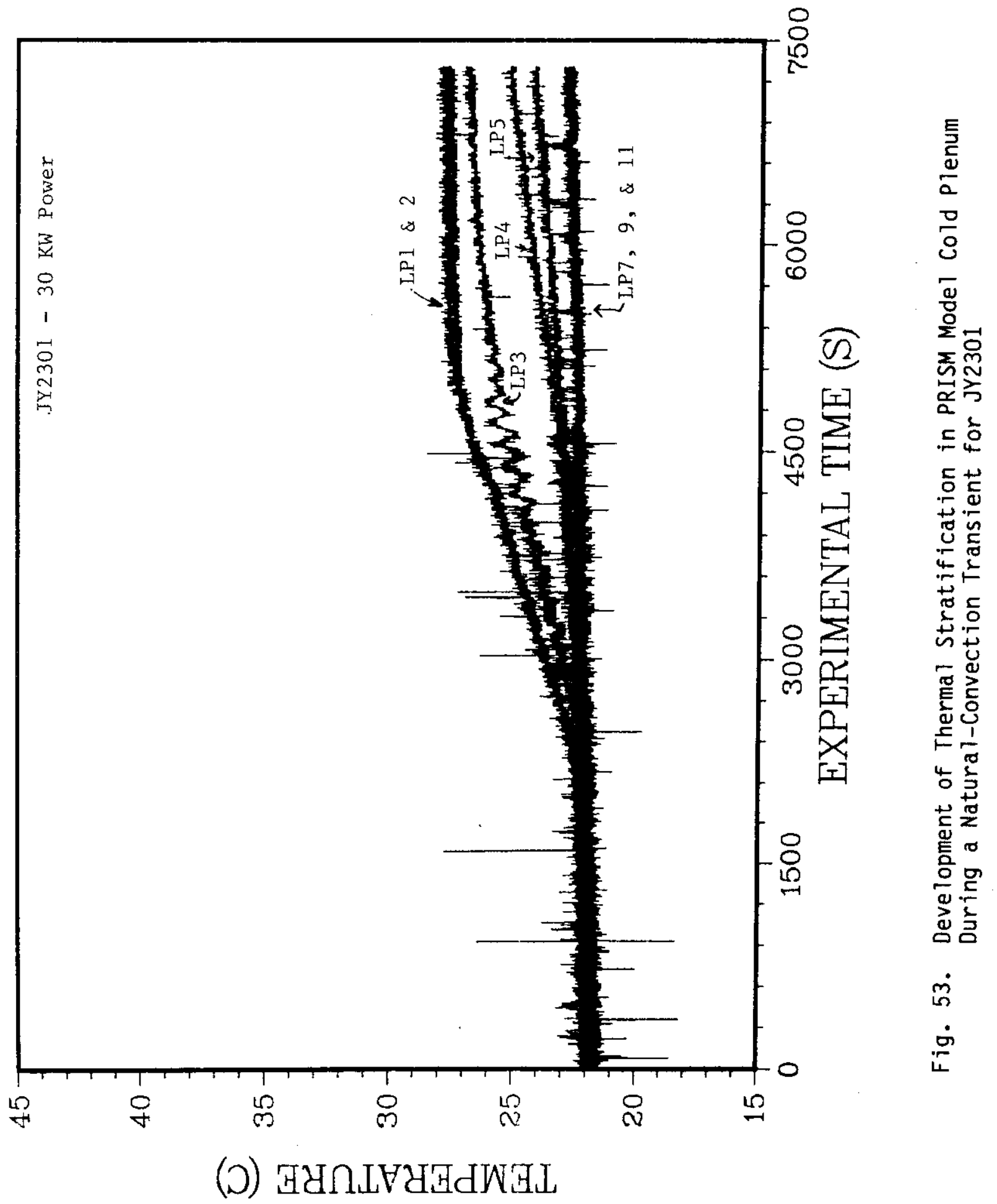




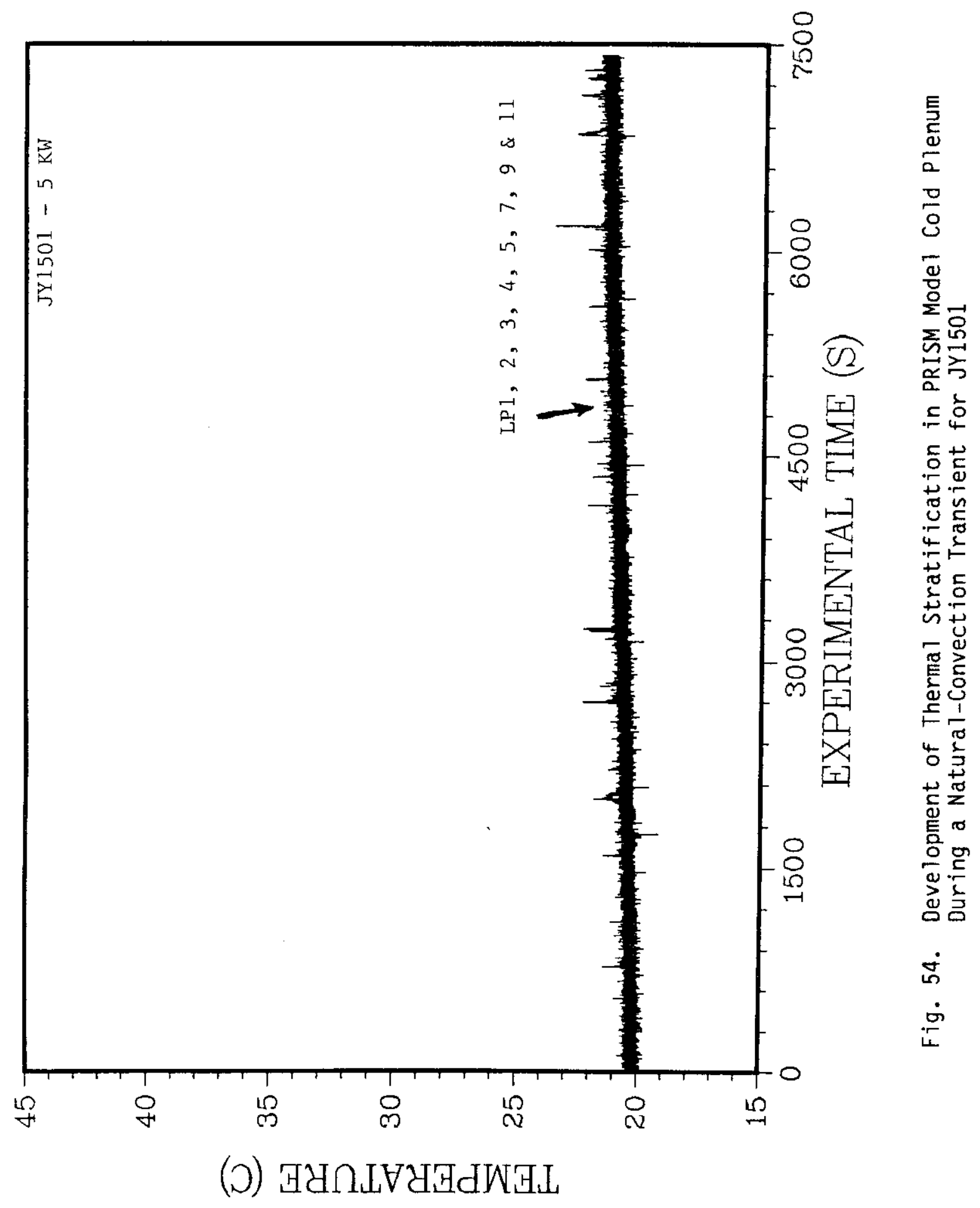




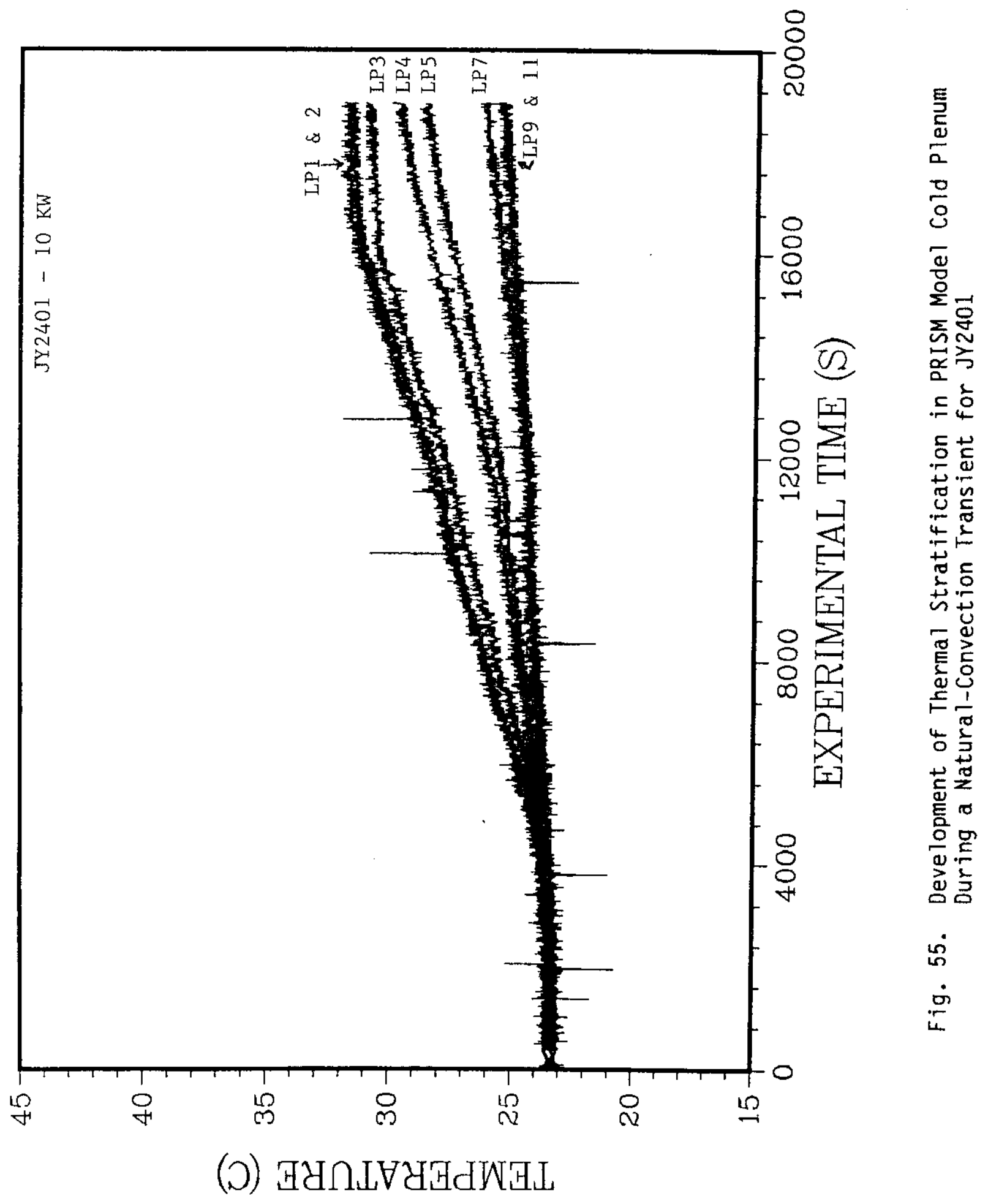




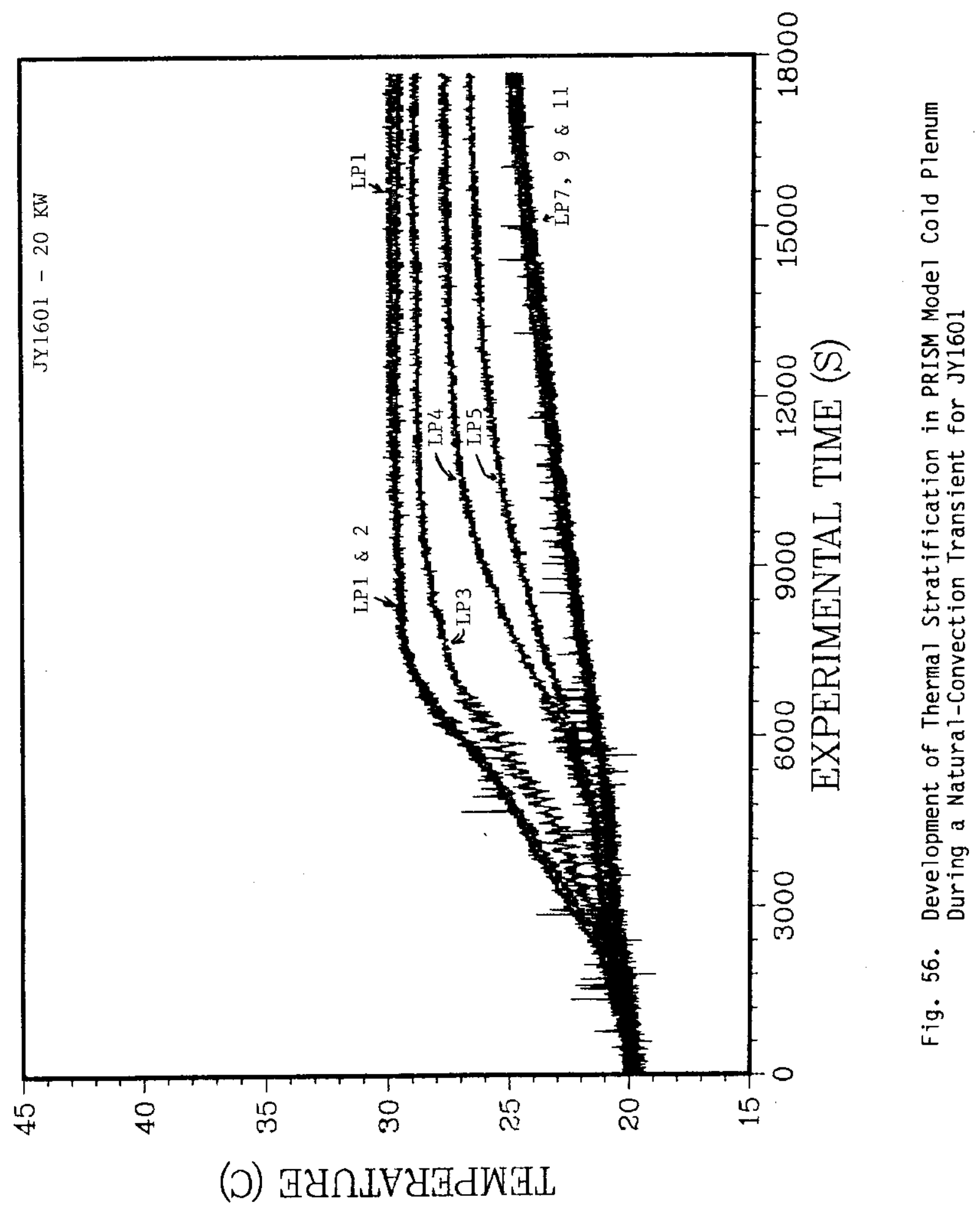




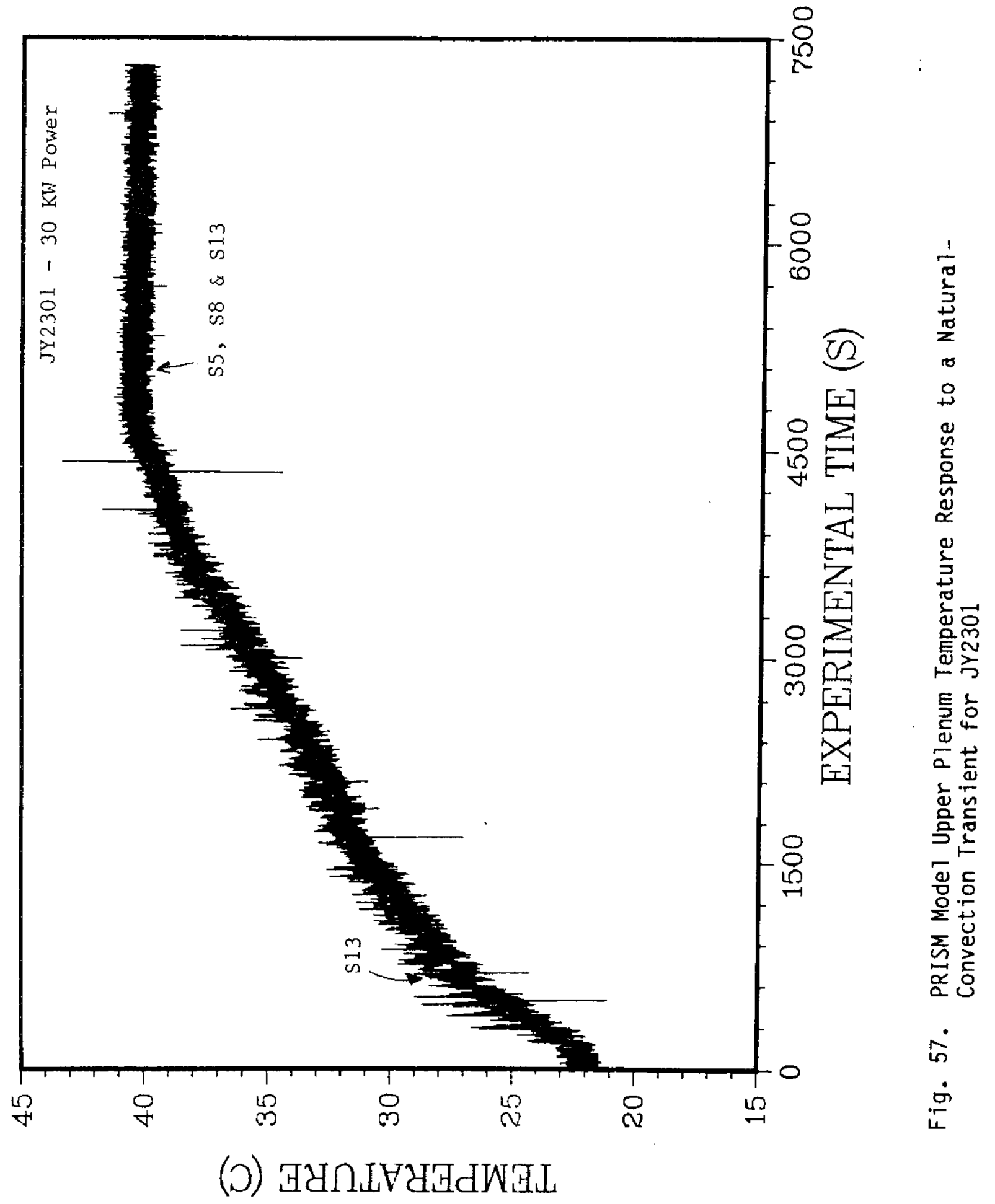


not surprising since the buoyancy forces act in the same direction as the inertia forces in the upper plenum.

The responses of thermocouples located at the entrances and exits of critical subregions (see Figs. 11 and 12) are presented in Fig. 58 for JY2301. The thermocouples were located in the upper plenum (S13), core exit (S5), IHX inlet (L1), IHX exit (L5), outside radial shield (R5), pump inlet (PI1), pump exit (PE4), and the core return pipe (P3). The average velocity in the pumps, determined by dye injection, was $1.08 \mathrm{in} . / \mathrm{s}$ at $t=600 \mathrm{~s}$, $0.87 \mathrm{in.} / \mathrm{s}$ at $t=1800 \mathrm{~s}$, and $0.65 \mathrm{in.} / \mathrm{s}$ at $t=3840 \mathrm{~s}$. Thus, while the water in the various regions of the model was heating up, the flowrate was decreasing because of the decreased thermal driving head. At $t=2820 \mathrm{~s}$, dye injected at the IHX exit rose upward toward the disc structure that was supporting the IHX. After the immersion heater was turned off (i.e., at $t=$ $4566 \mathrm{~s})$, there was no measurable flowrate in the pumps. The thermocouple responses of S5, S13, and L1 in Fig. $58 \mathrm{fall}$ on top of one another for most of the test, which indicates that there was very little stratification in the upper plenum. When the immersion heater was shut off at $t=4566 \mathrm{~s}$, the temperature in the upper plenum leveled off and then gradually decreased due to heat conduction through the containment vessel walls to the ambient air. During this same period of time, the temperature of the fluid at the IHX exit (L5) and at the bottom of the radial shield (R5) reached a maximum (allowing for transport time) and then decreased first due to redistribution of the cold dense fluid, initially in the region, from the radial shield to the core inlet after the thermal driving force disappeared (i.e., immersion heater was shut off); and later due to heat conduction from the IHX exit to the colder fluid near the floor of the cold plenum. Similarly, the temperatures in the pump region (i.e., PE4, P3, and PI1) rose until stratification of the whole PRISM model was stable (i.e., the temperature at each elevation was uniform). Each test was similar, with the only difference being the length of time that the immersion heater was turned on. The higher the power was, the shorter the length of time that the immersion heater was on (dictated by the temperature in the upper plenum reaching $105^{\circ} \mathrm{F}$ ).

The important findings from this series of tests are the existence of the thermally stratified region in the lower plenum and the lack of stratification 


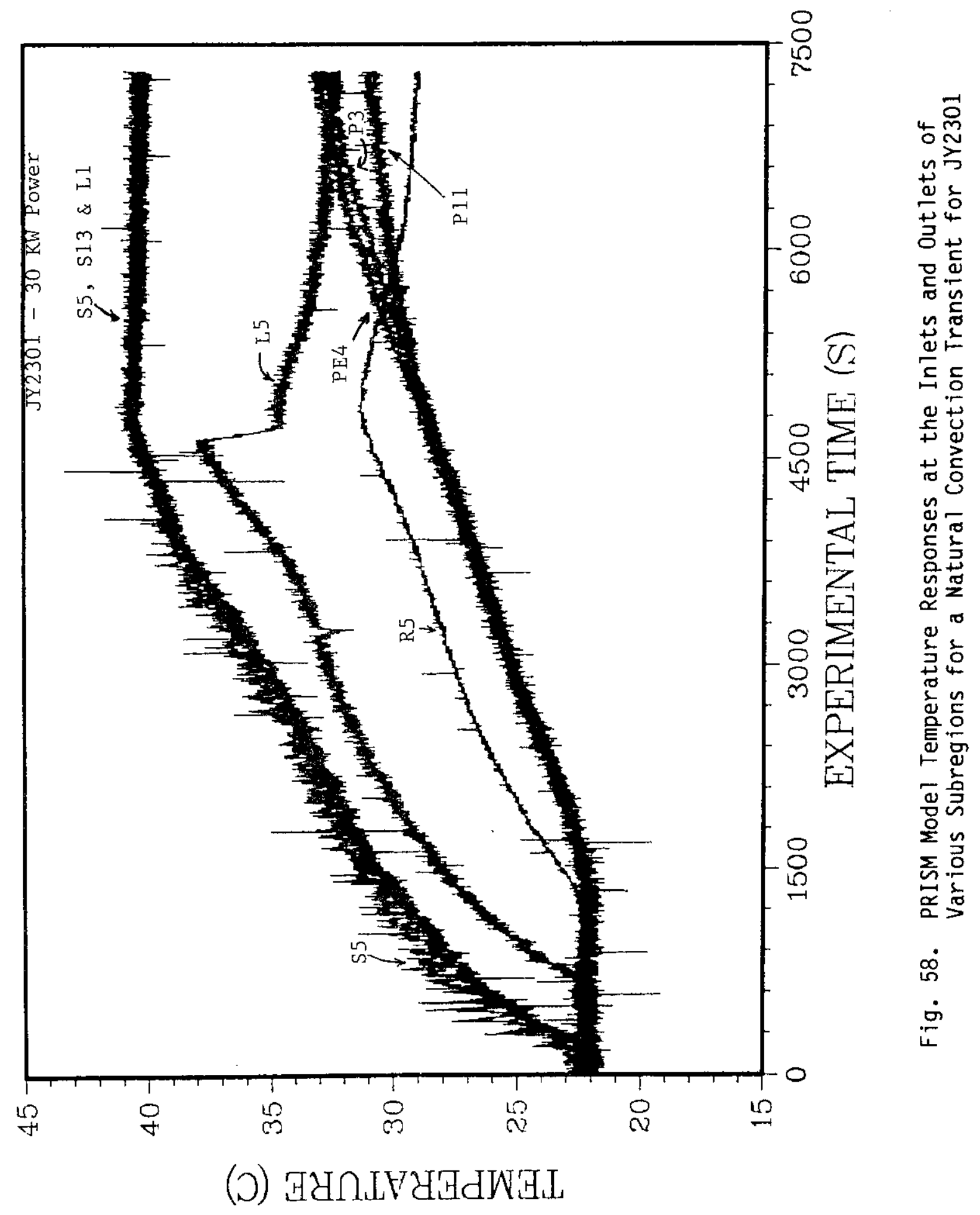


in the upper plenum under thermal-hydraulic conditions that were different from those in the tests described in Section 4.1.3.

\subsubsection{Mixed NaturaT-Forced Convection}

Three tests were conducted in which the immersion heater was set at a constant power and the internal pumps were set at a maximum of approximately $192 \mathrm{rpm}$. The only heat sink was the walls of the stainless steel containment vessel which were cooled by ambient air. Tests JY2401, JY2801, and JY2501 were run with 10,20 , and $30 \mathrm{~kW}$ of power, respectively, the same power levels that were used in the natural-convection tests described in Section 4.1.4. With the containment vessel initially filled with water at approximately $75^{\circ} \mathrm{F}$, the internal pumps set at the maximum $192 \mathrm{rpm}$ (corresponding to an average pump velocity of $2.24 \mathrm{in.} / \mathrm{s}$ ), the test was run until the temperature of the water reached $105^{\circ} \mathrm{F}$ (similar to the natural-convection tests) at which time the immersion heater was turned off (i.e., at $t=5240 \mathrm{~s}$ for JY2501) but the thermocouples continued to be scanned and recorded by the DAS. These tests, like the natural-convection tests, were transient; steady-state was not reached. The pertinent nondimensional parameters for each of these tests are presented in Table VI.

In Fig. 59 the thermocouple responses of 8 of the 11 thermocouples mounted on a vertical sting on the cold plenum floor about 2 in. inside the radial-shield liner (see Fig. 12) are presented for JY2501 with $30 \mathrm{~kW}$ power input, i.e., similar to JY2301 with internal pumps added. After a delay of $1600 \mathrm{~s}$, the lower plenum was stratified, i.e., LP1 was at a higher elevation and temperature than LP11. The corresponding thermocouple responses for the remaining mixed natural-forced-convection tests (i.e., JY2901 and JY2801) are presented in Figs. 60 and 61 . Stratification was observed in the lower plenum for all these tests, although JY2901 was not carried out long enough to reach a maximum temperature plateau. As the immersion-heater power decreased, a longer time period was required for stratification to develop, similar to the natural-convection tests discussed in Section 4.1.4. The Reynolds numbers (based on the gap diameter outside the radial shield) were significantly higher than those in the natural-convection tests, but they are still below 2300 , an indication that the flows were still laminar. The Richardson numbers that were based on the gap diameter outside the radial shield were 
Table VI. Nondimensional Parameters for the Mixed Natural-forcedConvection Transients

\begin{tabular}{lccccccc}
\hline Test & Power $(\mathrm{KW})$ & $\mathrm{u}(\mathrm{m} / \mathrm{s})^{\mathrm{a}}$ & $\Delta \mathrm{T}\left({ }^{\circ} \mathrm{C}\right)^{\mathrm{b}}$ & $\mathrm{Ri}_{\text {gap }}{ }^{\mathrm{C}}$ & $\mathrm{Re}_{\text {gap }}{ }^{\mathrm{C}}$ & $\mathrm{Ri}_{\text {core }}{ }^{\mathrm{d}}$ & $\mathrm{Re}_{\text {core }}{ }^{\mathrm{d}}$ \\
\hline $\mathrm{JY} 2501$ & 30 & 0.0579 & $7.08 / 8.97$ & 206 & 1275 & 99 & 5983 \\
$\mathrm{JY} 2801$ & 20 & 0.0618 & $4.10 / 9.33$ & 181 & 1307 & 56 & 6374 \\
$\mathrm{JY} 2901$ & 10 & 0.0560 & $\mathrm{e}$ & $\mathrm{e}$ & 999 & $\mathrm{e}$ & 4307 \\
\hline
\end{tabular}

ameasured by timing dye front in a pump.

$b_{\text {measured in upper plenum/lower plenum. }}$

Cbased on radial-gap diameter outside the radial shield.

dbased on core barrel ID.

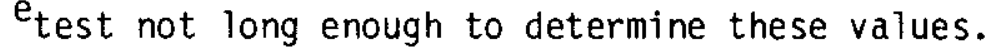




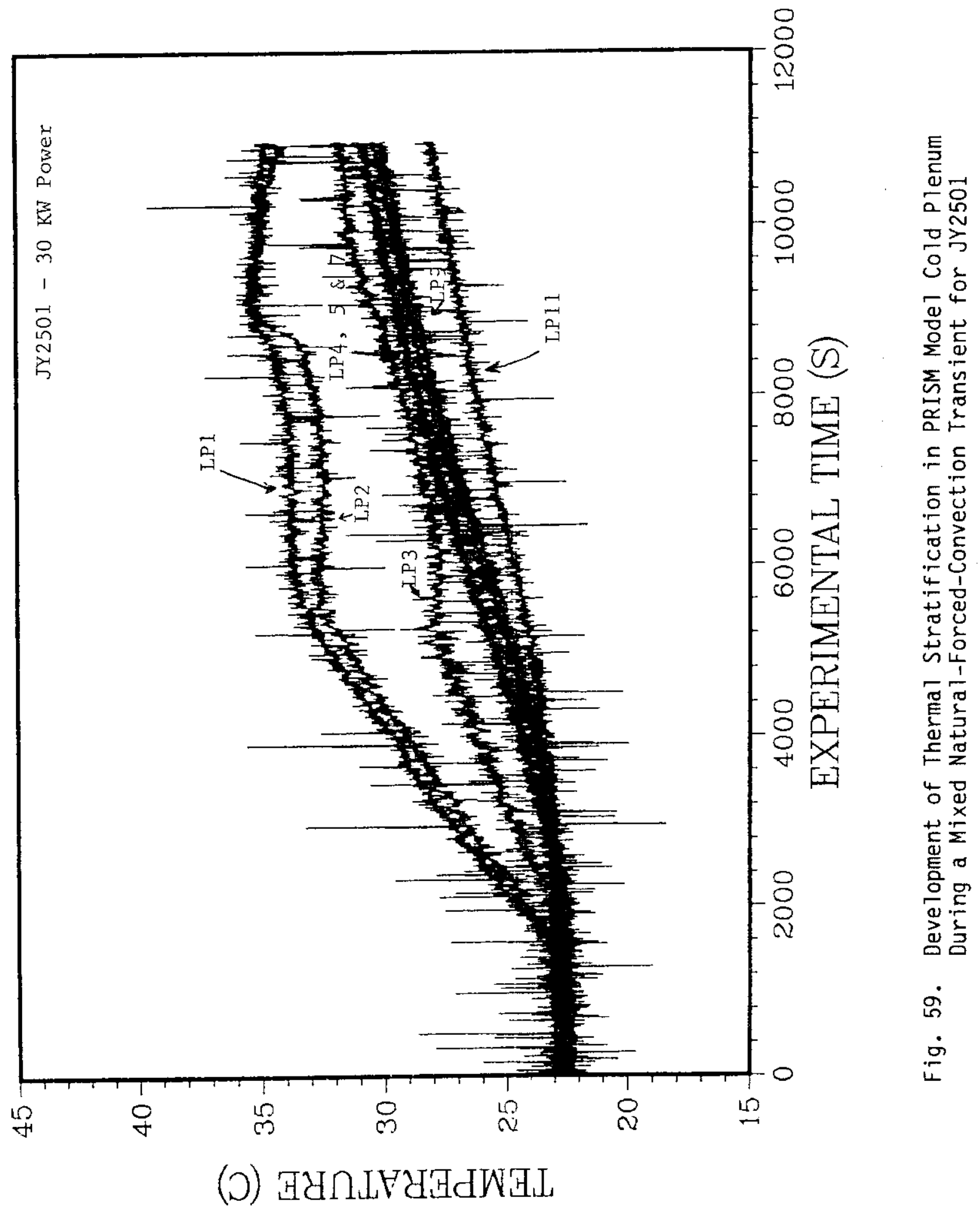




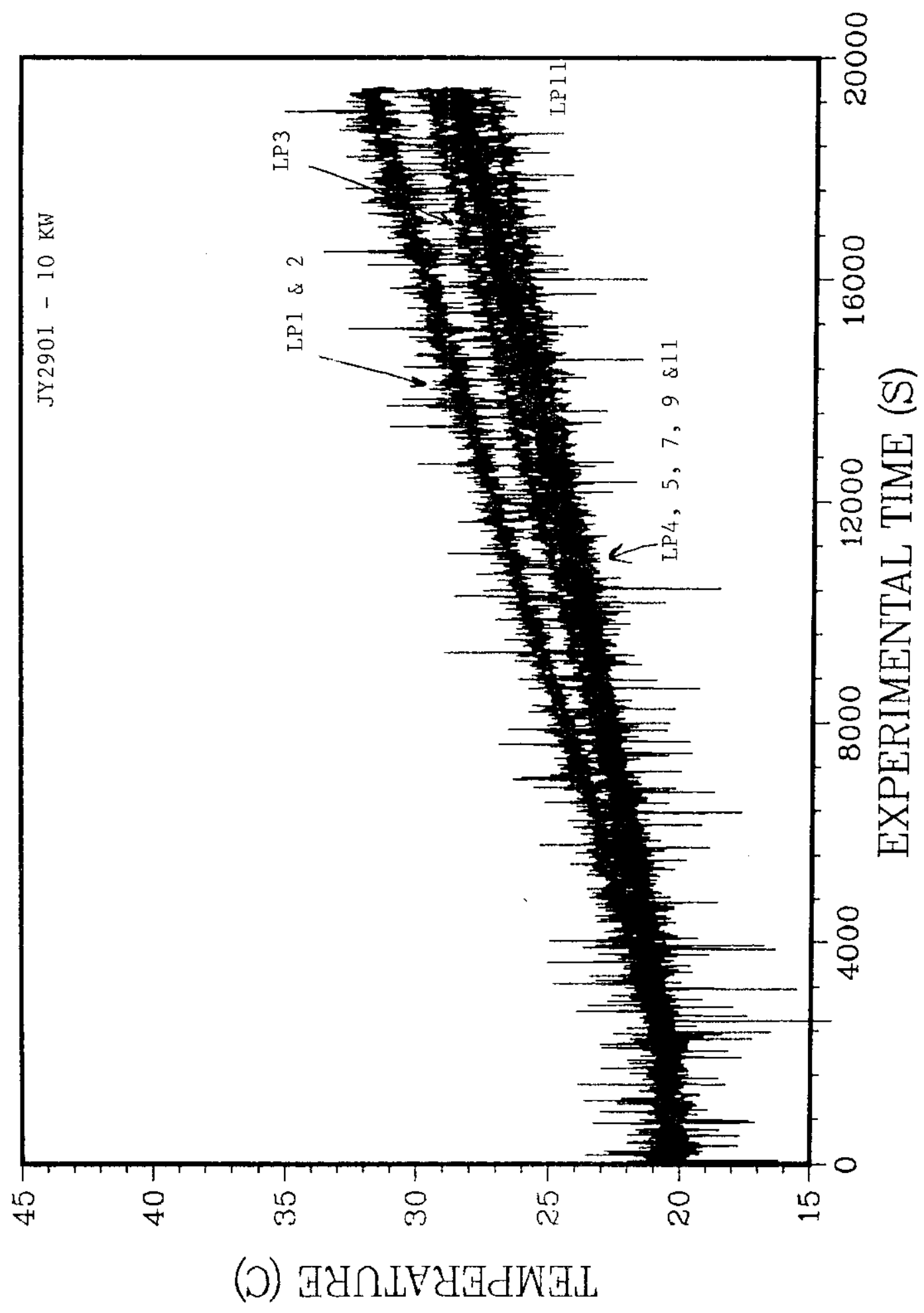

8ீ

它

(ว) AUกLVU A 


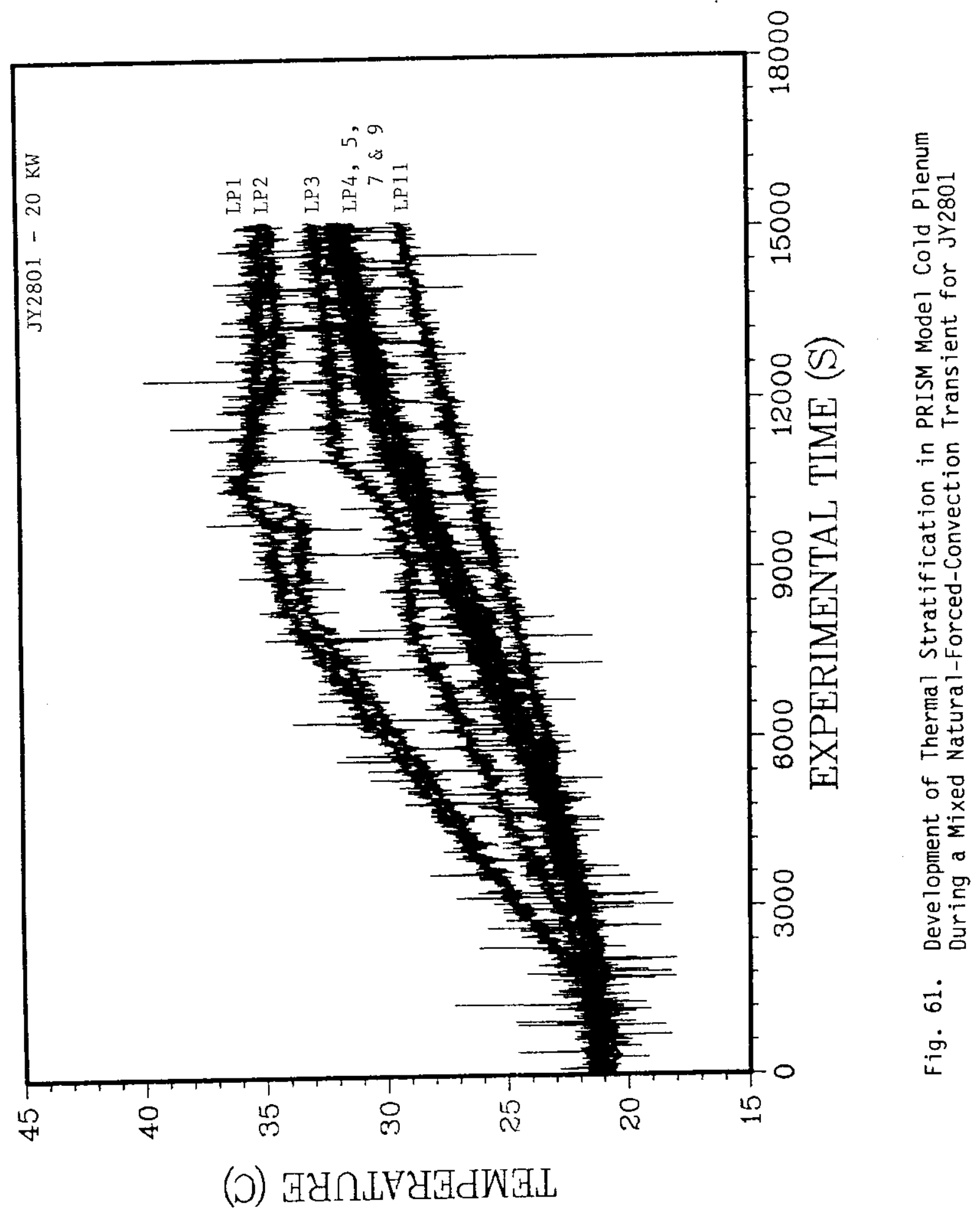


approximately 200, an indication that the buoyancy forces were still much stronger than the inertia forces.

Comparison of the thermocouple responses in Fig. 59 to those in Fig. 53 for JY2301 reveals that the time delay changed from $1750 \mathrm{~s}$ to $1600 \mathrm{~s}$, i.e., the forced convection provided by the pumps decreased the time for lower plenum stratification. The forced convection also increased the temperature level of each thermocouple at the corresponding time in each transient after the lower plenum was stratified. Generally, the lower plenum was warmer and the stratification was greater with forced convection than without, for the same power input for the level of forced flow tested. The forced convection, as expected, continued to force hot fluid into the lower plenum after the immersion heater was turned off (i.e., at $t=5280 \mathrm{~s}$ for JY2501). The forced convection, with its associated increased mixing (i.e., higher Reynolds numbers), which counteracted the thermal-buoyancy forces, accounts for the generally higher temperatures and the greater stratification (i.e., temperature difference) in the lower plenum. For high enough levels of forced flow (i.e., Richardson number of order of one or less), it is expected that there wi11 be no stratification in the lower plenum. The inertia forces are large enough for the incoming fluid to penetrate to the plenum floor and entrain the fluid, thus producing a lower plenum at an essentially uniform temperature. In the natural-convection test for the same power input (i.e., JY2301), the stratification of the model was essentially constant after the immersion heater was turned off, while, in the mixed natural-forced convection tests, the entrainment and/or transport continued until the end of the test.

The responses of four thermocouples on the center sting in the upper plenum are shown in Fig. 62. S5 was located at a lower elevation than S13. The responses of these thermocouples fall on top of one another during the first $5600 \mathrm{~s}$, reach a plateau at approximately $t=5280 \mathrm{~s}$ (i.e., when the immersion heater is turned off), and then, one by one, in ascending order of elevation, decrease from the plateau of $40.5^{\circ} \mathrm{C}$. Thus, after the first $5600 \mathrm{~s}$, the upper plenum was strongly stratified. However, the upper plenum in the corresponding natural-convection test, JY2301, was not stratified (see Fig. 57). Thus, after the immersion heater was turned of $f$, the forced convection provided by the internal pumps forced the cold fluid from the lower plenum 


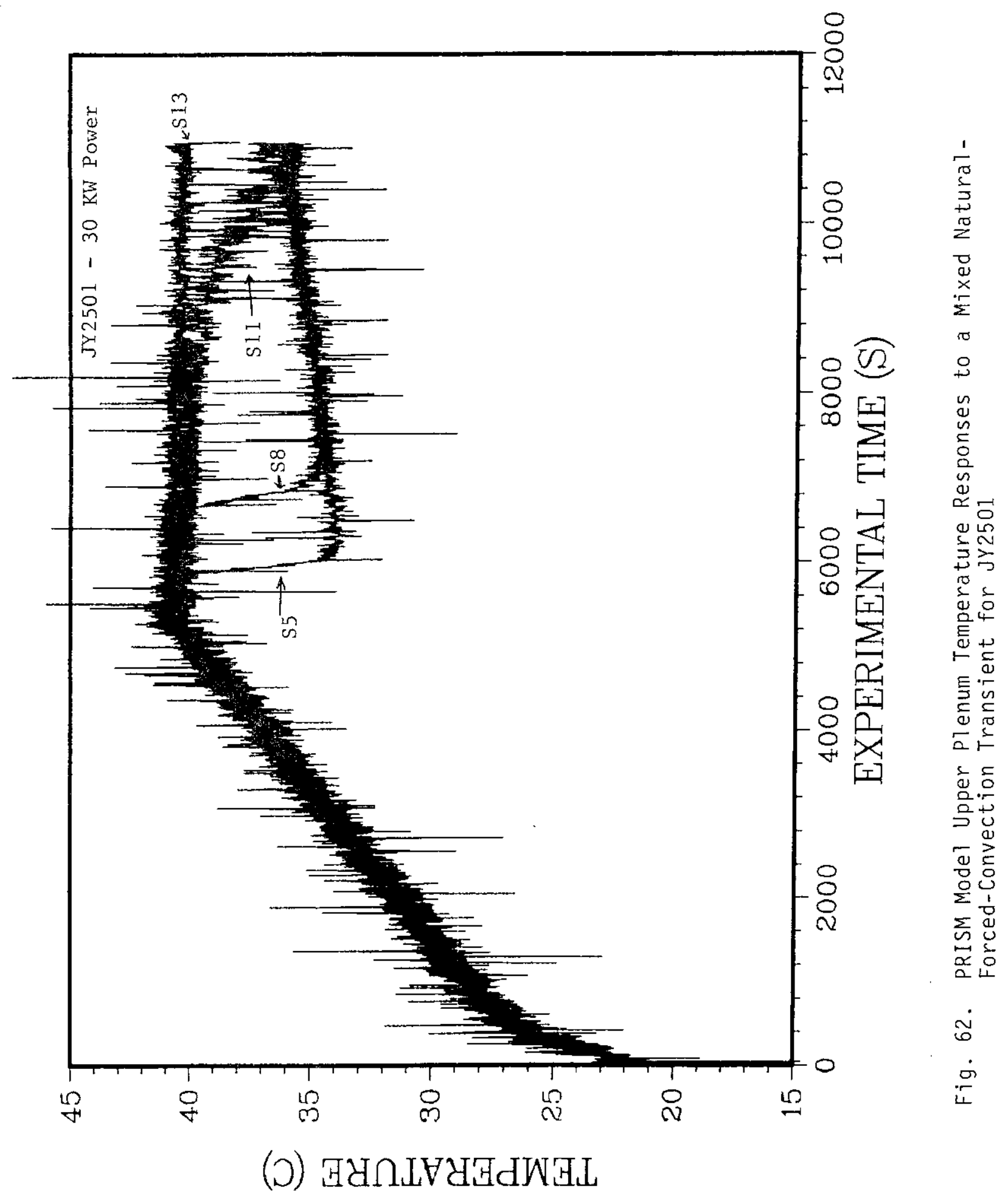


into the upper plenum where it mixed with the hot fluid already there to cause stratification. Because of the failure of a power supply to a number of thermocouple amplifiers, the corresponding curves for the remaining tests are not available. In their place, the responses of four thermocouples (NS1, NS2, NS3, and NS4) on the sting located midway between the IHXs in the upper plenum (see Fig. 11) are shown in Figs. 63-65. NSI is located at a lower elevation than NS4. Comparison of Figs. 62 and 65 indicates that the thermal stratification was uniform across the upper plenum for JY2501. As in the lower plenum, when the immersion heater power decreased, a longer time was required for the temperature in the upper plenum to reach $105^{\circ} \mathrm{F}$ (thus, turning off the immersion heater), and subsequently, for stratification to develop. Richardson numbers (based on the core ID) were 99 and 56 for JY2501 and JY2801, respectively, an indication that the thermal-buoyancy forces were large compared to the inertia forces. Test JY2901 was not carried out long enough for stratification to develop. The Reynolds numbers (based on the core barrel ID) for these tests (see Table VI) are all well above 2300, and thus indicate turbulence.

The responses of thermocouples located at the entrances and exits of critical subregions are presented in Fig. 66 for JY2501. The thermocouples are located in the upper plenum (S13), core exit (S5), IHX inlet (L1), IHX exit (L5), outside radial shield (R5), pump inlet (PI1), pump exit (PE4), and the core return pipe (P3). The noise on the thermocouple responses is not thermal-hydraulic, but is due to the heater and motor controllers that are used in the facility. As a part of the shakedown function of these tests, corrective action, i.e., isolation techniques, was taken prior to the start of Phase II testing to eliminate as much of this noise as possible. Velocities in the pumps, measured before the immersion heaters were turned on and $1080 \mathrm{~s}$ into the test, were $0.056 \mathrm{~m} / \mathrm{s}$ and $0.058 \mathrm{~m} / \mathrm{s}$, respectively. Thus, there was practically no change, i.e., the forced convection dominated. This is true for all three power levels tested (see Table VI). Dye injected at the IHX exit clearly defined a hot/cold interface in the lower plenum at $t=3600 \mathrm{~s}$. The interface was located 12-1/4 in. above the floor, just under the radial shield. The important findings from this series of tests are the existence of thermal stratification in both the upper and lower plena under thermalhydraulic conditions that were different from those in the tests described in 


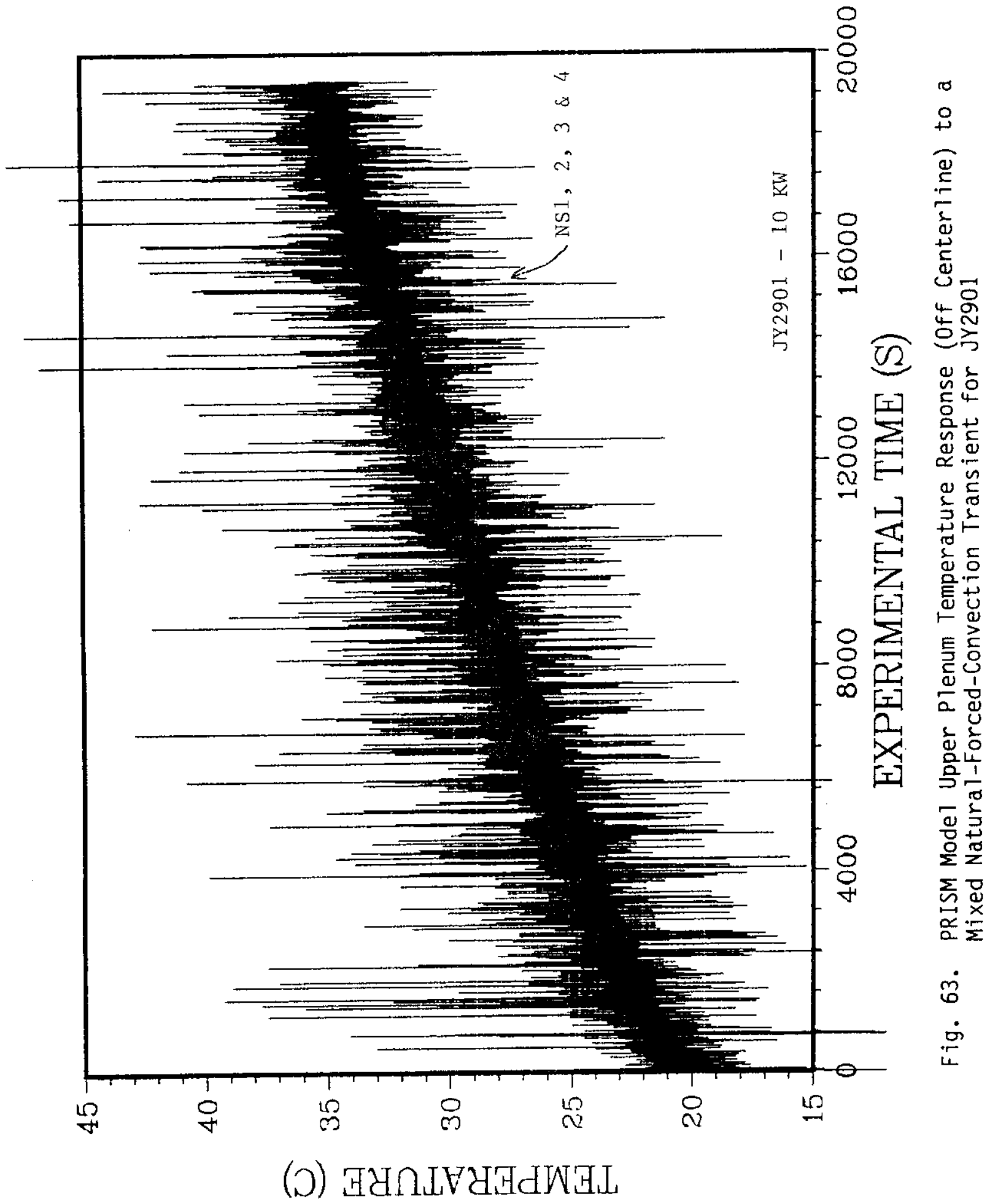




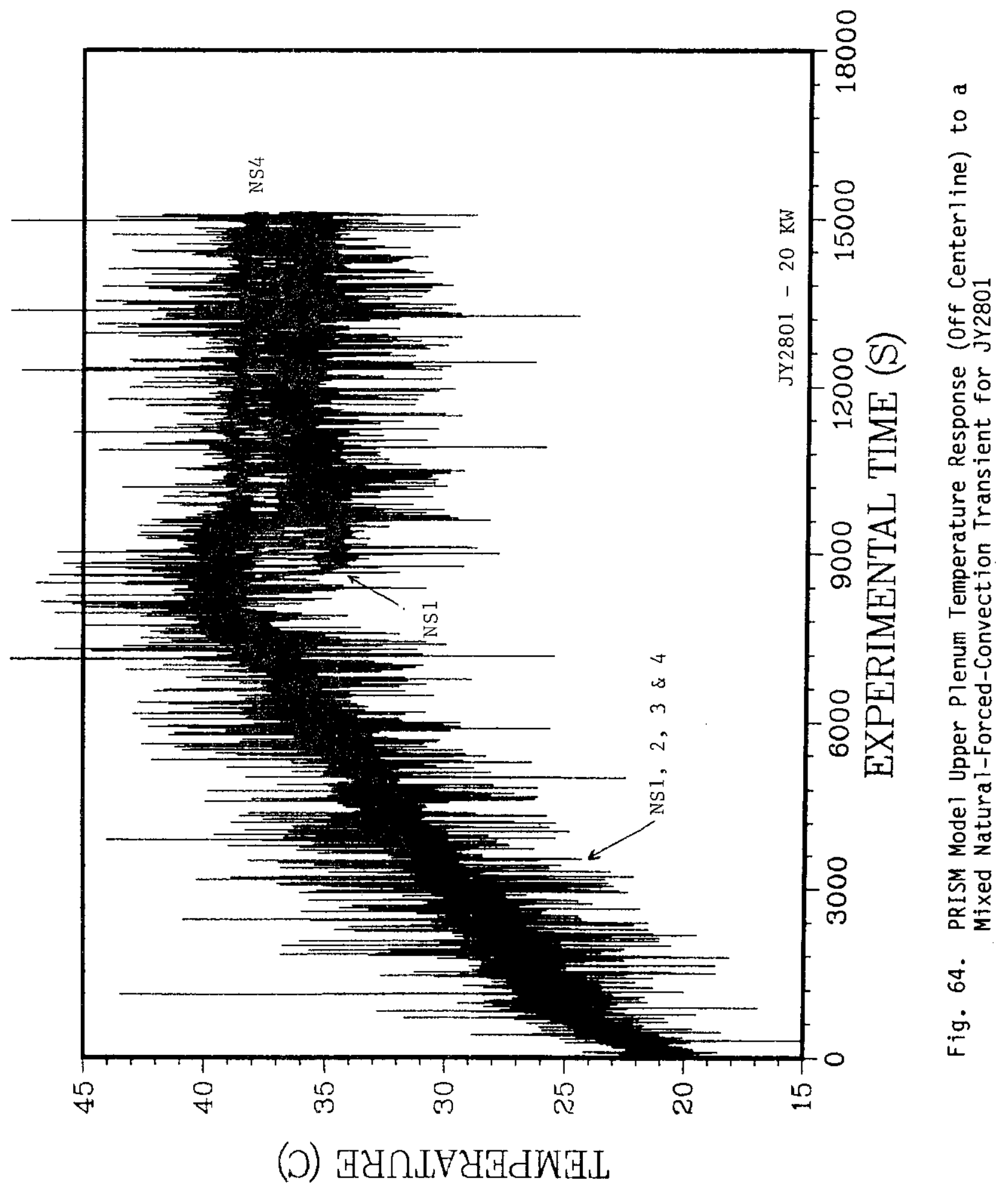




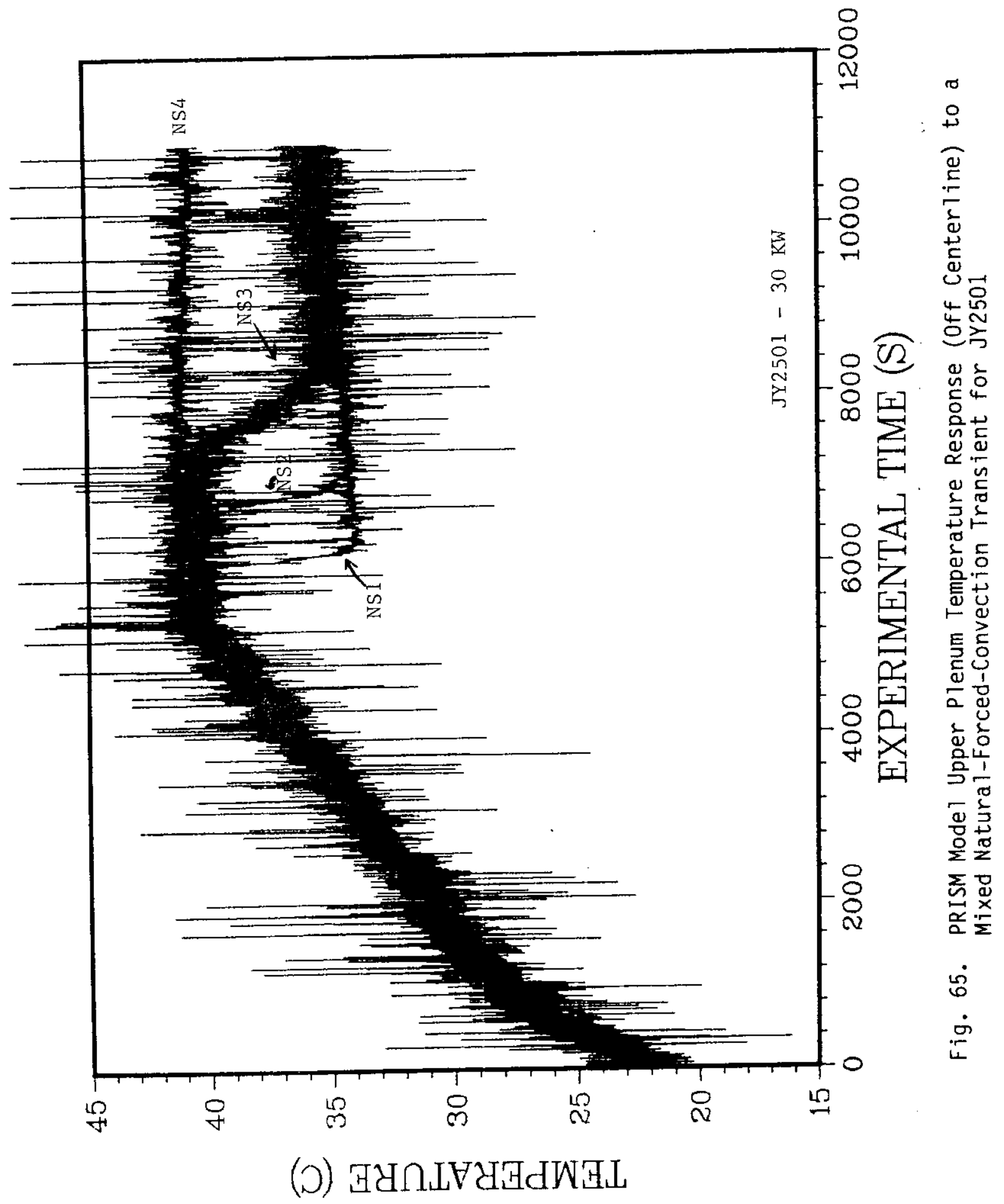




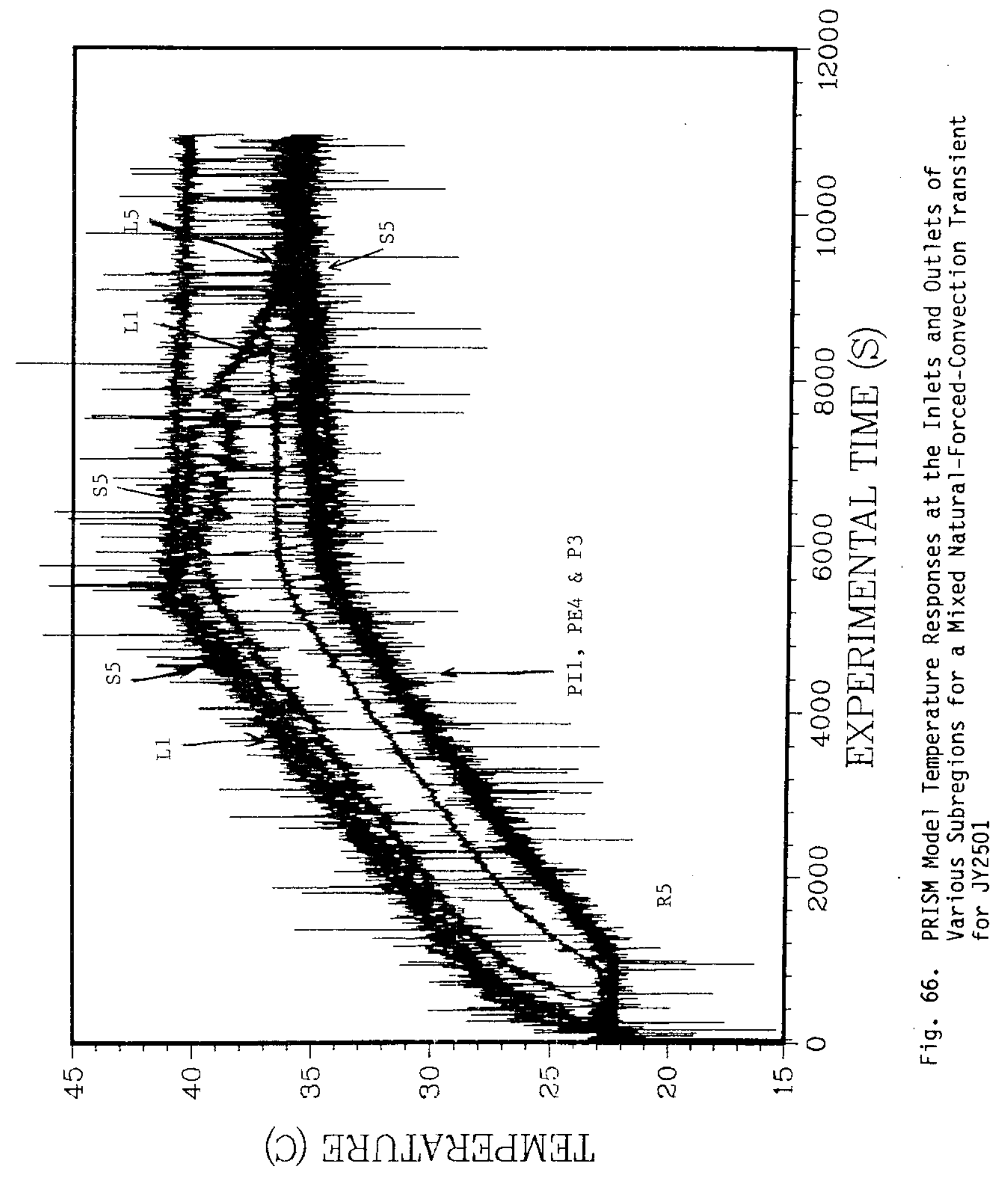


Sections 4.1.3 and 4.1.4. The stratification in the upper plenum was caused by the internal pump circulating colder fluid from the lower plenum into the upper plenum after the immersion heater was turned off. In the naturalconvection tests, discussed in Section 4.1 .4 no stratification was observed.

\subsubsection{Prototypic Transient A-4}

Two indentica1 tests, AU0601 and AU0701, were conducted in which a constant flow driven by the MCTF was forced through the PRISM model with a step change (downramp) in temperature to check on data reproducibility. These tests simulated the GE prototype transient A-4 (i.e., plant unloading at $3 \%$ per min from 100 to $25 \%$ power) and were conducted at the conclusion of Phase I PRISM water tests. In Phase II, tests of this nature involved a UIS model and IHX heat sinks. Tests AU0601 and AU0701 were run with $100 \%$ simulated full flow (corresponding to $128 \mathrm{gpm}$ in the model) with a nominal step change in temperature of $13.9^{\circ} \mathrm{F}$. Comparison of the data from tests AU0601 and AU0701 shows that the results were reproducible, and thus only the results of AU0701 will be presented here. The flowrate and temperature of the fluid entering the core from the MCTF are shown in Fig. 67 for test AU0701 as a function of time. The Reynolds and Richardson numbers (based on the core barrel ID) were 28114 and 4.0, respectively, whereas the Reynolds and Richardson numbers (based on the radial-gap diameter outside the radial shield) were 6494 and 6.4, respectively. The input thermal-hydraulic driving function (i.e., inlet temperature downramp as shown by IN1 in the inlet tee to the mode1) was supplied by the MCTF and moved by convection through the model with each thermocouple response closely following the input driving function, as expected, because the flowrate was high and an IHX heat sink was lacking.

The responses of 8 of the 11 thermocouples mounted on a vertical sting on the cold plenum floor about 2 in. inside the radial-shield liner are shown in Fig. 68. The responses generally fall on top of one another, indicating a we11-mixed lower plenum with no stratified regions which occurs with a Richardson number of 6.4 (based on radial-gap diameter outside the radial shield). A vertical sting of thermocouples located off the centerline on a radius midway between two IHX's (about 5-3/4 in. from the liner) in the upper plenum are shown in Fig. 69. The responses of thermocouple S8 (on the sting on the centerline of the model) and NS3 (on the sting off the centerline on a 


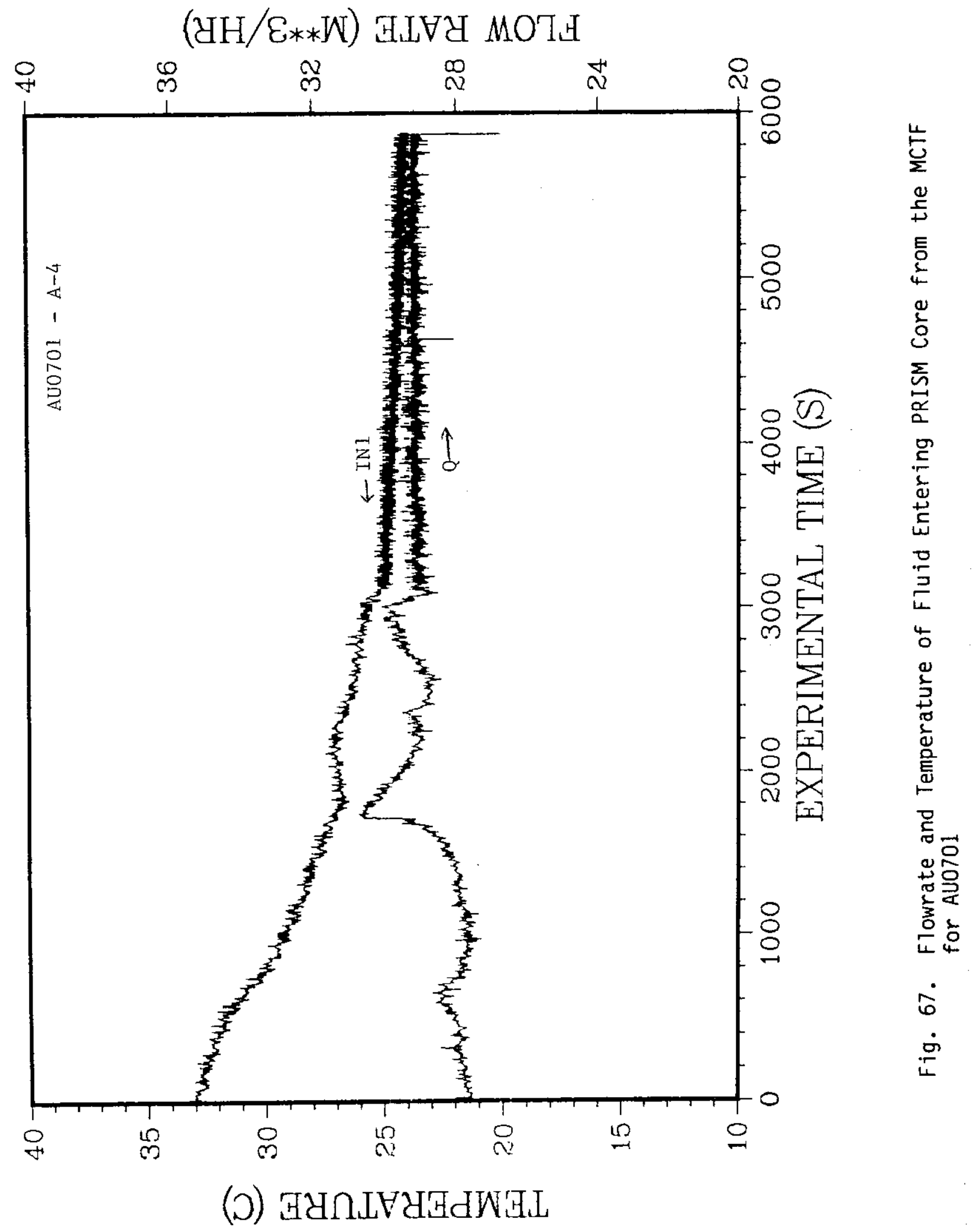




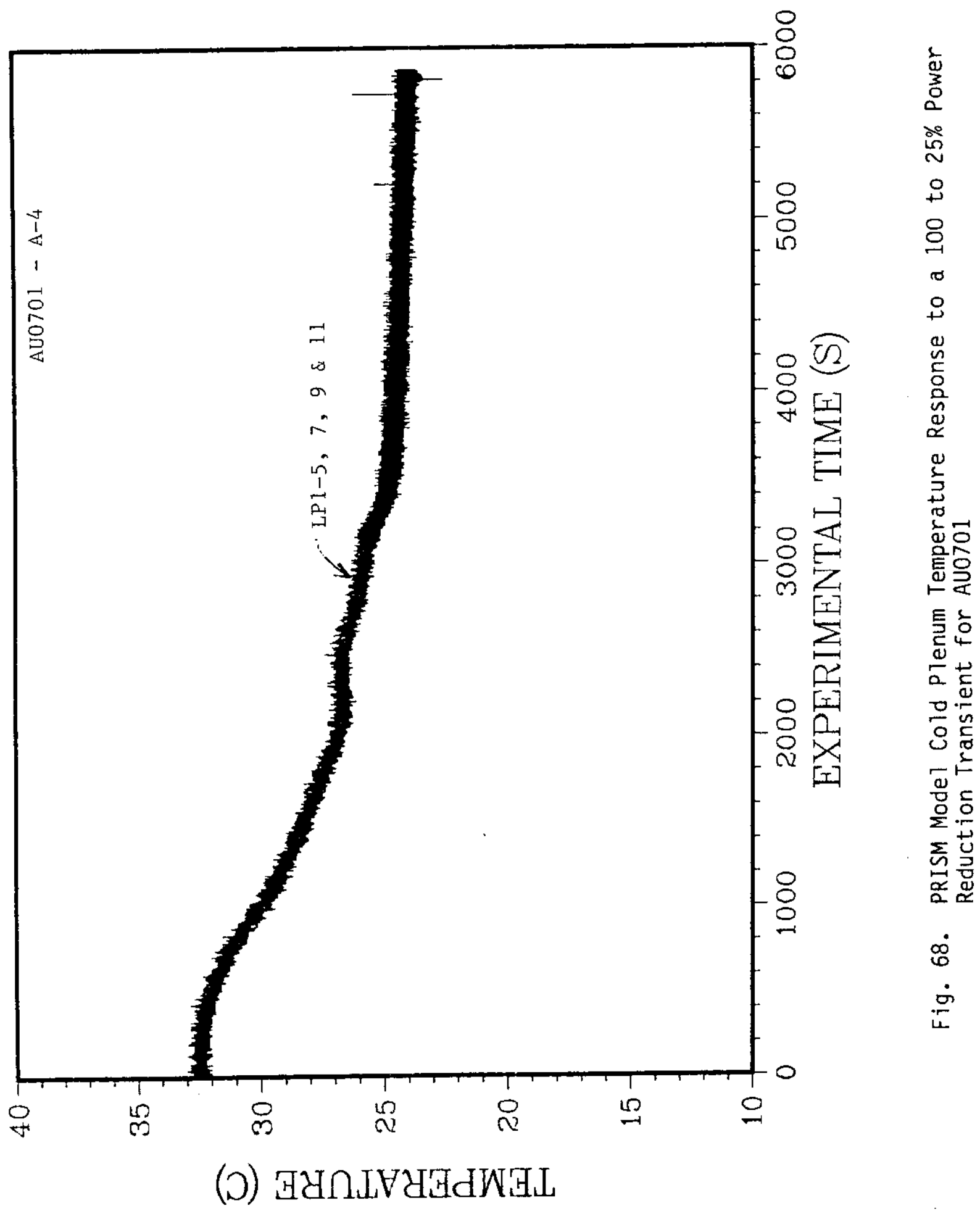




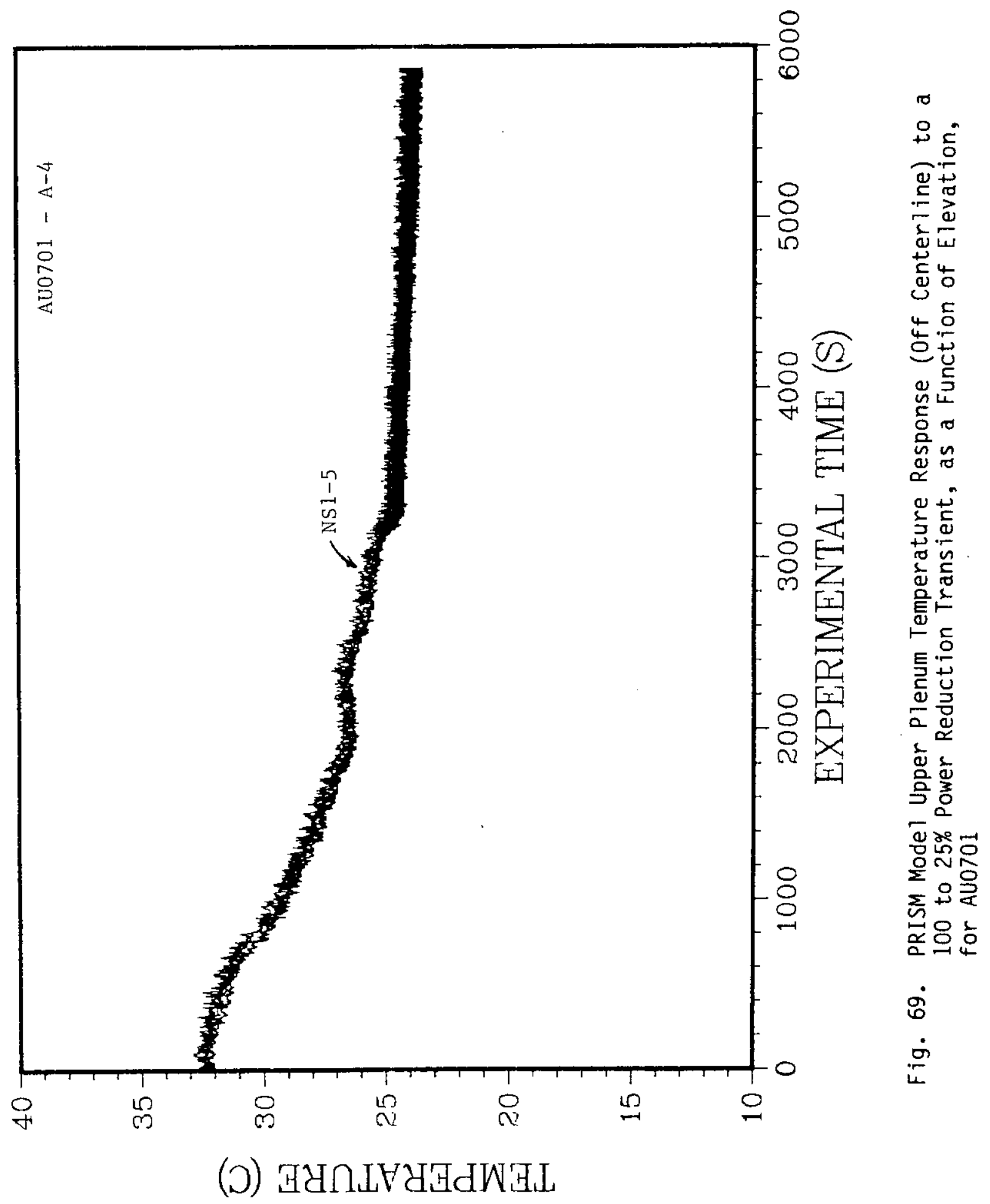


radius midway between IHXs) located near the elevation of the IHX inlets in the upper plenum are shown in Fig. 70. The responses in both figures fall on top of one another, indicating a uniformly mixed upper plenum with a Richardson number of 4.0 (based on the core barrel ID). Lastly, the responses of the thermocouples located at the entrances and exits of critical subregions are presented in Fig. 71. The thermocouple responses fall on top of one another (separated, by at most, the transport time delay between locations), indicating a well-mixed reactor in which each thermocouple response closely follows the input driving function, i.e., the thermal downramp. The slope of each of these thermocouple responses was determined in the 1000- to 1800-s time interval. The maximum value was $0.00363^{\circ} \mathrm{C} / \mathrm{s}$ in the model, corresponding to a maximum value of $0.0256^{\circ} \mathrm{C} / \mathrm{s}$ in the prototype. (The actual model core temperature difference of $17^{\circ} \mathrm{F}$ corresponds to a prototypic scale of $265.7^{\circ} \mathrm{F}$.) Thus, the maximum time rate of change of temperature is very small in PRISM during this transient and should not pose any thermal stress problems for structures in the flow field.

Generally, all thermocouple responses fall on top of one another, which is not surprising since the flowrate is so high (128 gpm corresponding to $100 \%$ flow) and there is no heat sink capability in the IHXs.

\subsection{Phase II}

\subsubsection{Simulated Prototypic Transients}

Twenty tests were conducted during the PRISM Phase II tests in which five prototypic transients, chosen by GE, were simulated. Each transient was repeated a minimum of three times in order to evaluate the experimental repeatability of the results. The experimental procedure used in setting up each of the five transients was described in Section 2.5 with values of parameters for the prototypic transient, reactor trip from full power with maximum decay heat $(B-1 A)$, as an illustrative example. Test ident ifiers for the PRISM Phase II tests are presented in Table VII together with transient type, simulated core temperature difference as dictated by modeling laws and IHX heat sink capacity of the IHXs. Note the actual heat rejection of the IHXs is very close to the nominal (desired) value. The value of the simulated core temperature difference is influenced by the overall temperature level 
Table VII. PRISM Phase II Tests: Transient Type, Simulated Core Temperature Difference, and Heat Sink Capacity of IHXs

\begin{tabular}{|c|c|c|c|c|}
\hline Transient & $\begin{array}{l}\text { Test } \\
\text { Number }\end{array}$ & $\begin{array}{l}\text { Nominal } \\
\text { Simulated Core } \\
\text { Temperature } \\
\text { Difference }\left({ }^{\circ} \mathrm{F}\right)\end{array}$ & $\begin{array}{l}\text { Simulated } \\
\text { Capacity of } \\
\text { Nominal }\end{array}$ & $\begin{array}{l}\text { Heat Sinks } \\
\frac{\text { IHXs [kW }(\%)]}{\text { Actua] }}\end{array}$ \\
\hline $\begin{array}{l}\text { Reduction of power } \\
\text { from } 100 \text { to } 25 \%(A-4)\end{array}$ & $\begin{array}{l}\text { AP2001 } \\
\text { AP2101 } \\
\text { AP2301 }\end{array}$ & $\begin{array}{l}10 \\
10 \\
10\end{array}$ & $\begin{array}{l}68.8(25) \\
68.8(25) \\
68.8(25)\end{array}$ & $\begin{array}{l}70.7(25.7) \\
68.8(25.0) \\
69.5(25.3)\end{array}$ \\
\hline $\begin{array}{l}\text { Reactor trip from full } \\
\text { power with maximum } \\
\text { decay heat }(B-1 A)\end{array}$ & $\begin{array}{l}\text { MY2001 } \\
\text { MY2101 } \\
\text { MY2201 }\end{array}$ & $\begin{array}{l}13 \\
13 \\
13\end{array}$ & $\begin{array}{ll}32.2 & (11.7) \\
32.2 & (11.7) \\
32.2 & (11.7)\end{array}$ & $\begin{array}{l}32.6(11.9) \\
31.8(11.6) \\
32.5(11.8)\end{array}$ \\
\hline $\begin{array}{l}\text { Loss of feedwater to } \\
\text { all modules supplying } \\
\text { one turbine, with } 30-5- \\
\text { delayed scram (B-5B) }\end{array}$ & $\begin{array}{l}\text { MY2801 } \\
\text { MY2901 } \\
300101\end{array}$ & $\begin{array}{l}12 \\
12 \\
12\end{array}$ & $\begin{array}{l}29.7(10.8) \\
29.7(10.8) \\
29.7(10.8)\end{array}$ & $\begin{array}{l}29.6(10.8) \\
29.6(10.8) \\
29.4(10.7)\end{array}$ \\
\hline $\begin{array}{l}\text { Loss of power to one } \\
\text { primary pump }(B-3 B)\end{array}$ & $\begin{array}{l}\text { JU0201 } \\
\text { JU0301 } \\
\text { JU0302 }\end{array}$ & $\begin{array}{l}12 \\
12 \\
12\end{array}$ & $\begin{array}{l}29.7(10.8) \\
29.7(10.8) \\
29.7(10.8)\end{array}$ & $\begin{array}{ll}29.9 & (10.9) \\
29.5 & (10.7) \\
29.5 & (10.7)\end{array}$ \\
\hline $\begin{array}{l}\text { Loss of feedwater to } \\
\text { all modules supplying } \\
\text { one turbine, with scram } \\
\text { after steam generator } \\
\text { dryout (B-5B) }\end{array}$ & $\begin{array}{l}J U 0801 \\
J U 0901 \\
J U 0902 \\
J U 1001\end{array}$ & $\begin{array}{l}12 \\
12 \\
12 \\
12\end{array}$ & $\begin{array}{ll}2.06 & (0.75) \\
2.06 & (0.75) \\
2.06 & (0.75) \\
2.06 & (0.75)\end{array}$ & $\begin{array}{ll}1.99 & (0.72) \\
2.29 & (0.83) \\
2.29 & (0.83) \\
2.21 & (0.80)\end{array}$ \\
\hline
\end{tabular}




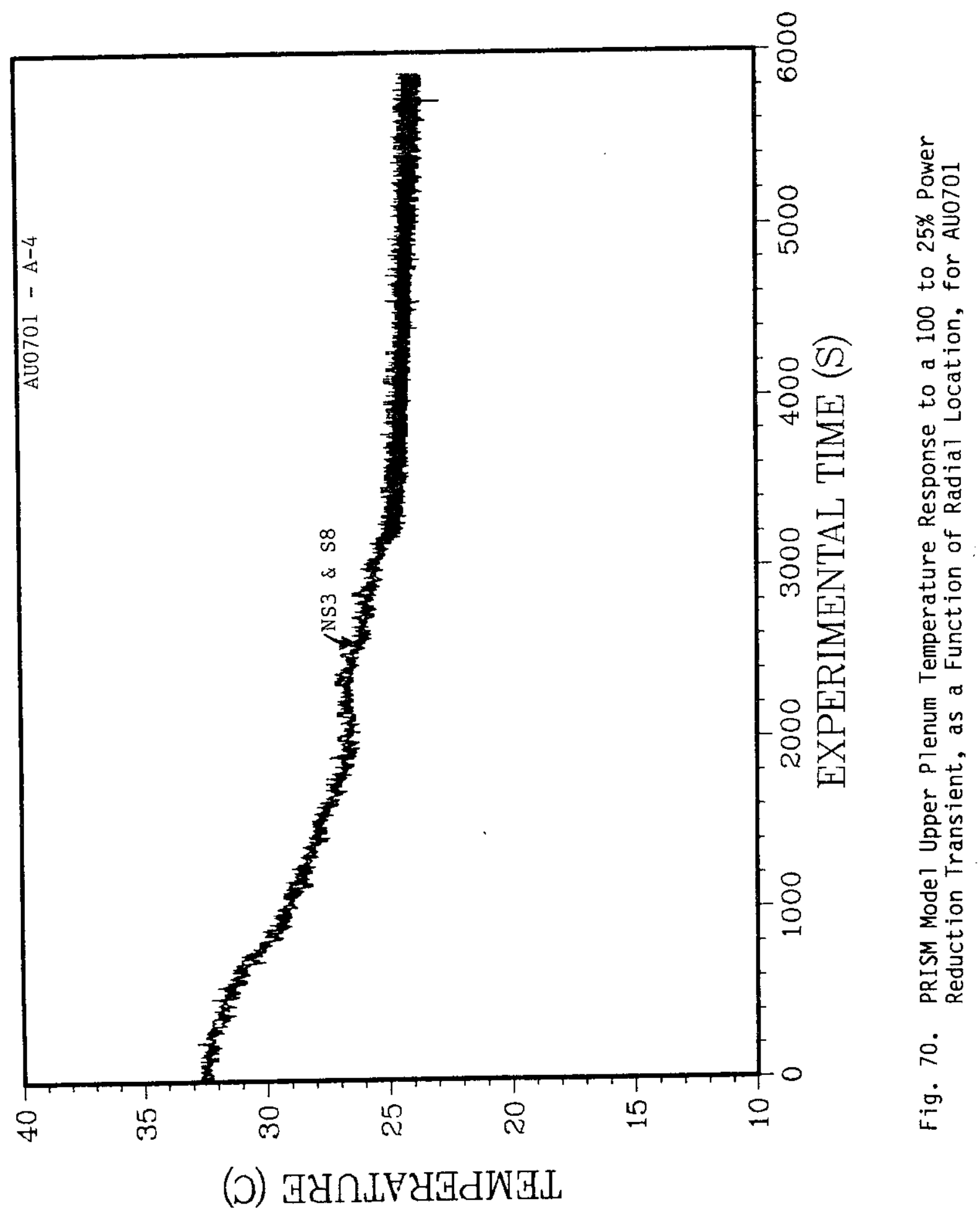




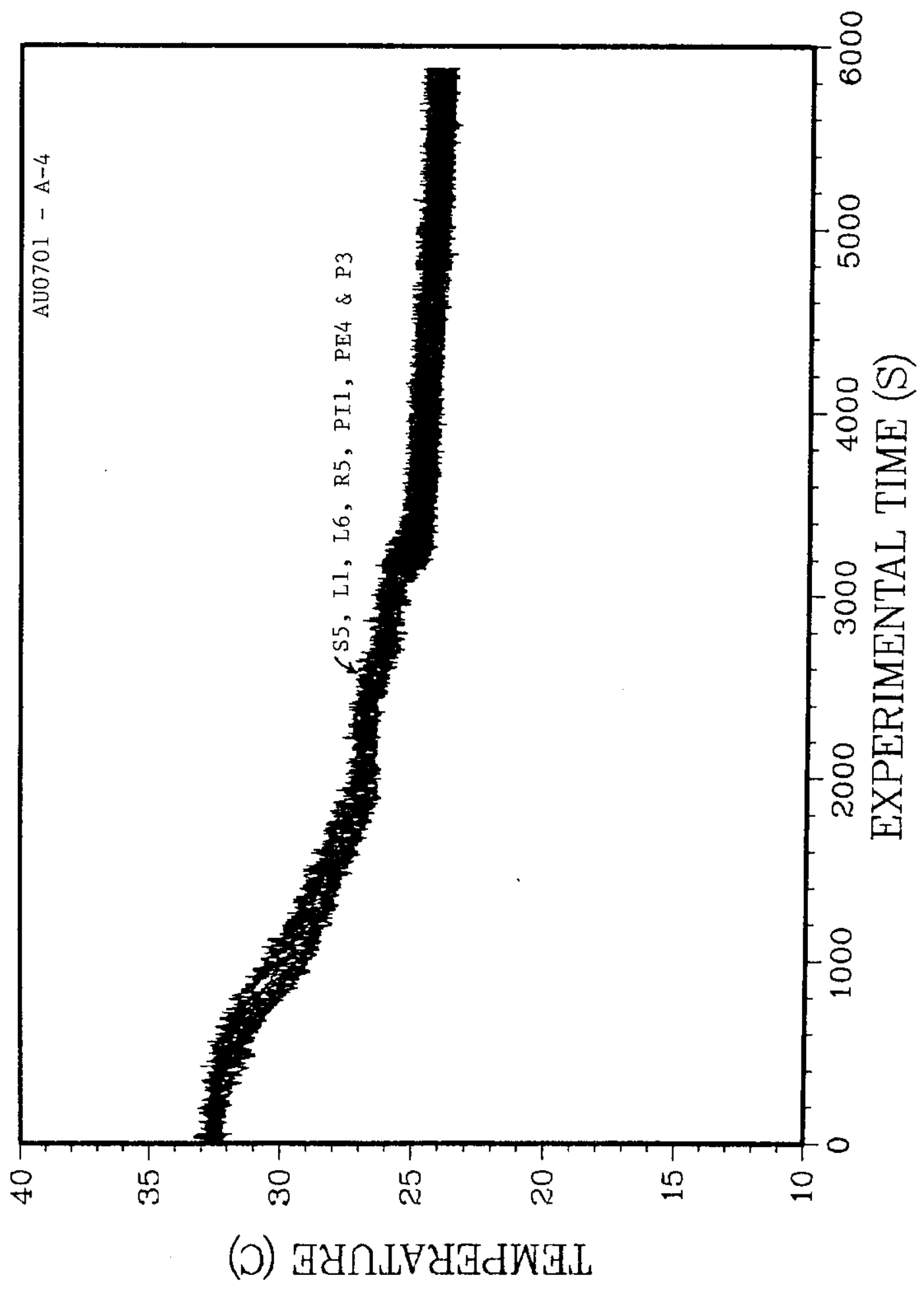

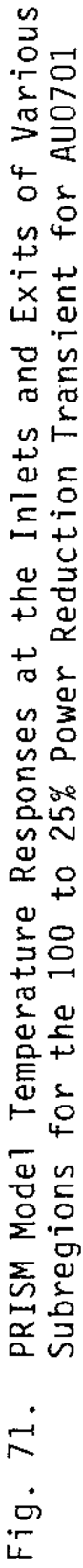


(i.e., the temperatures of the water in the MCTF hot and cold reservoirs). As the weather gets warmer, the canal water used for cooling the cold reservoir gradually rises in temperature and decreases the simulated core temperature difference that is necessary because of the change in water properties with temperature in Richardson number similarity. Similarly, the maximum heat sink capacity of the IHXs decreases with warmer weather for the same water temperature entering the PRISM model on the primary side. The integrity of the plastic PRISM model is the primary determinant of the water temperature level on the primary side. The preceding dye test reveals that it would not be possible to locate a fuel rod failure in the core by having fission product detectors located in the two IHXs exclusively.

The mode 7 core resistance was increased after Phase I testing by the addition of 15 perforated plates to make a total of 45 perforated plates in the simulated core. A series of constant flow, isothermal tests was conducted to measure the pressure drop across the simulated core as a function of flowrate. The resulting pressure drops across the core were: $1.2 \mathrm{in}$. of $\mathrm{H}_{2} \mathrm{O}$ at $38 \mathrm{gpm}, 0.6 \mathrm{in}$. of $\mathrm{H}_{2} \mathrm{O}$ at $26 \mathrm{gpm}, 0.3 \mathrm{in}$. of $\mathrm{H}_{2} \mathrm{O}$ at $13 \mathrm{gpm}$ (this value was used for similarity between model and prototype) and $0.1 \mathrm{in}$. of $\mathrm{H}_{2} \mathrm{O}$ at $6 \mathrm{gpm}$.

There is concern about the number and position of detectors necessary to determine the location in the core of a source of fission product release. In order to address this concern, dye was used to study flow patterns in the UIS/upper plenum region at full flow (i.e., $128 \mathrm{gpm}$ ). The UIS model was mounted on the center thermocouple sting (see Fig. 13) on which four dye injectors were also mounted, at different radial positions (i.e., in 2-in. increments) and at $90^{\circ}$ intervals circumferentially. The injector closest to the centerline was mounted directly upstream of the slot in the UIS, which was rotated to the center of the left IHX. Dye injected from either of the two injectors in the vertical plane midway between the IHXs flowed up through the gap between the UIS and the core barrel, and appeared to go toward both IHXs with no particular preference. The dye from the injector opposite the slot in the UIS went up the gap and preferentially towards the right IHX. The dye from the injector located directly upstream of the slot flowed in the UIS model up the side near the slot with some diffusion and entrainment. The dye diffused toward the UIS side opposite the slot, while flow in the gap between the UIS and the core barrel entrained some of the dyed flow from within the 
UIS starting at an elevation approximately 2 in. below the lower third of the UIS (i.e., puffs of dye observed in gap). The dye gradually filled the entire UIS by diffusion and a vertical rotational flow pattern. The dye from this injector showed a strong preference for the left IHX (i.e., closest to the slot). Finally, it took $75 \mathrm{~s}$ for the dye to clear out of the model once the dye injector was turned off.

\subsubsection{Reduction of Power from 100 to $25 \%(A-4)$}

In Phase II, tests simulating the GE prototype transient A-4 (i.e., Plant Unloading at $3 \%$ per minute from 100 to $25 \%$ power) were conducted in which a constant flow driven by the MCTF was forced through the PRISM model with a prescribed thermal downramp (see Section 3.2.1.1). This transient was repeated three times, tests AP2001, AP2101, and AP2301, to check reproducibility. These tests differed from the Phase I tests described in Section 4.1.6 in that a UIS model and operational IHX heat sinks had been added. These tests were run with $100 \%$ of simulated full flow (corresponding to $128 \mathrm{gpm}$ in the model) with a nominal simulated core temperature difference of $10.0^{\circ} \mathrm{F}$. Comparison of the data from these tests shows that the results are reproducible, and thus only the results of AP2001 with an actual core temperature difference of $11.2^{\circ} \mathrm{F}$ wi1l be presented here. The flowrate and temperature of the fluid entering the core from the MCTF are shown, as a function of time, in Fig. 72 for test AP2001. The Richardson and Reynolds numbers (based on the core barre1 ID) were 3.9 and 38662 respective1y, whereas the Richardson and Reynolds numbers (based on the radial gap outside the radial shield) were 6.4 and 8931 , respectively. The input thermal-hydraulic driving function (i.e., inlet temperature downramp as shown by IN1 in the inlet tee to the model) was supplied by the MCTF and moved by convection through the model with each thermocouple response closely following the input driving function, as expected, because of the high flowrate.

The responses of 8 of the 11 thermocouples mounted on a vertical sting on the cold plenum floor about 2 in. inside the radial-shield liner (see Fig. 12) are shown in Fig. 73 for AP2001. The responses generally fall on top of one another, indicating a well-mixed lower plenum with no stratified regions.

The responses of a vertical sting of thermocouples, NS1, NS2, NS3, and NS4, located off the centerline on a radius midway between the two IHXs (about 


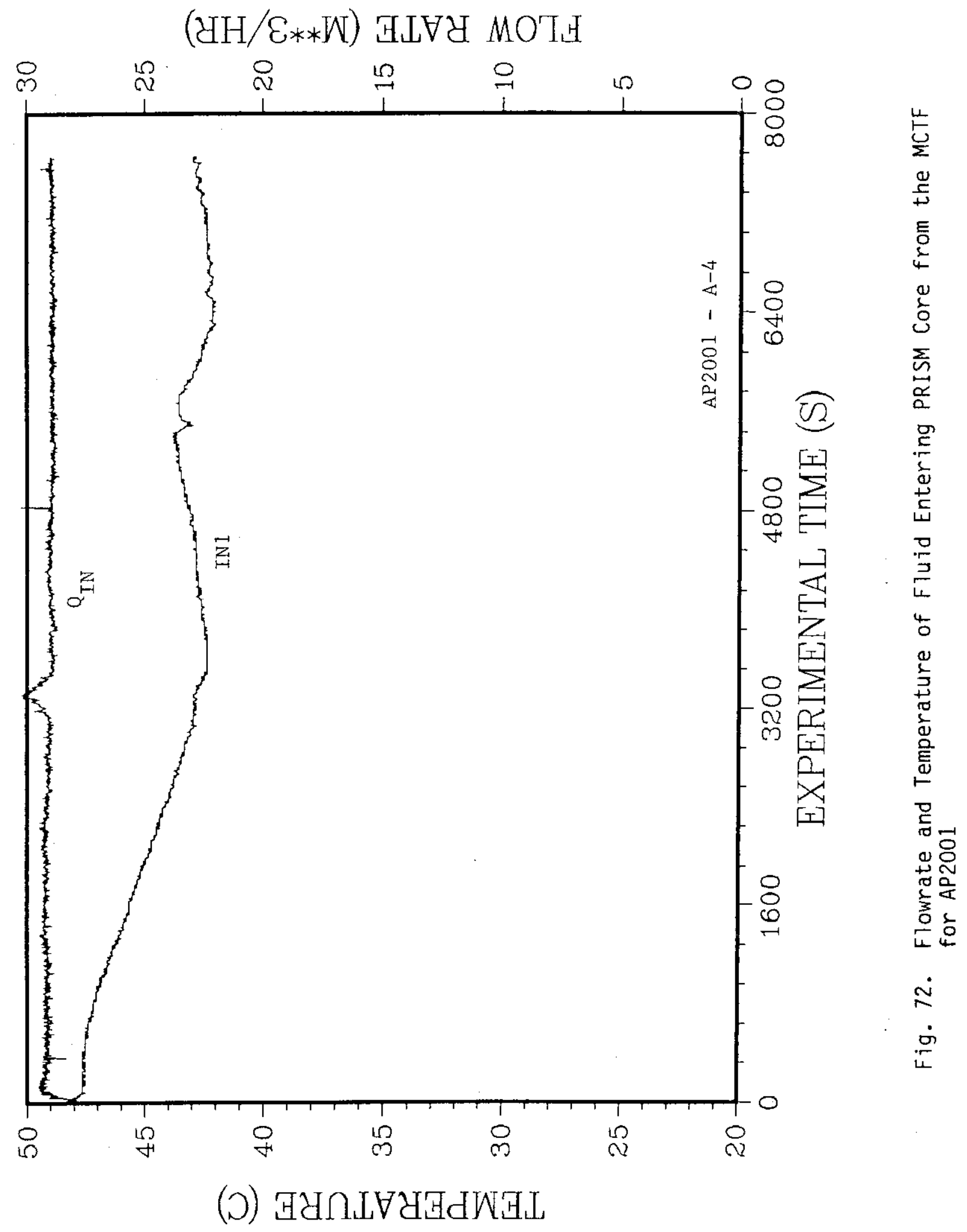




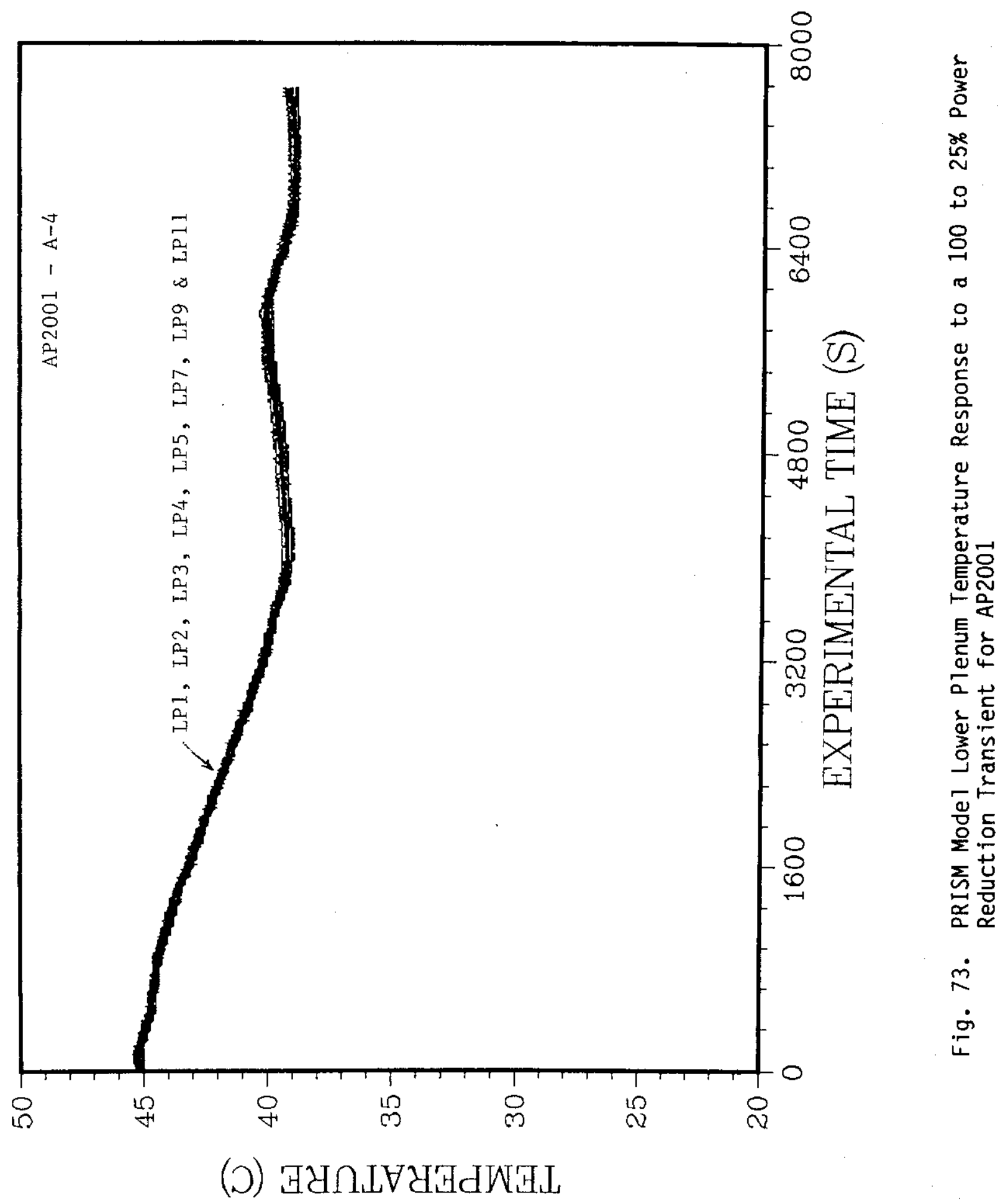


5-3/4 in. from the liner) in the upper plenum (see Fig. 11) are shown in Fig. 74 for AP2001. The responses of thermocouples S8 (on the sting on the centerline of the model) and NS3 (on the sting of $f$ the centerline on a radius midway between IHXs) located near the elevation of the IHX inlets in the upper plenum are shown in Fig. 75 for AP2001. And finally, the responses of thermocouples S5, S8, S11, and S13, located on the vertical sting on the centerline of the model in the upper plenum (see Fig. 12), are shown in Fig. 76 for AP2001. The thermocouple responses in each of the preceding figures fall on top of one another, indicating a uniformly mixed upper plenum with no stratification.

The thermocouple response of G3 for AP2001 (see Fig. 11), presented in Fig. 77, is very linear, indicating that heat is transferred mostly by conduction, not convection, in the overflow gap with no overflow in the present transient. The responses of the thermocouples located at the entrances and exits of critical subregions are presented in Fig. 78 for AP2001. The thermocouple responses generally fall on top of each other in one of two distinct groups. The higher temperature group consists of thermocouples $\$ 5, S 13$, and $L 1$, located in the hot upper plenum downstream of the core but upstream of the IHXs. The lower temperature group consists of thermocouples R5, PE4, P3, PI1, and L5, located downstream of the IHXs. The temperature difference between the two groups is primarify caused by the heat removed by the IHXs. L5, located at the IHX exit, is slightly colder than the other thermocouples in that group since it has not yet mixed with the fluid in the lower plenum. The slope of each of these thermocouple responses was determined in the 1600 - to $3200-s$ time interval. The maximum value was $0.00303^{\circ} \mathrm{C} / \mathrm{s}$ in the model corresponding to a maximum value of $0.0324^{\circ} \mathrm{C} / \mathrm{s}$ in the prototype. This value of $0.0324^{\circ} \mathrm{C} / \mathrm{s}$ compares favorably (i.e., same order of magnitude) with $0.0256^{\circ} \mathrm{C} / \mathrm{s}$ determined for AU0701 in Phase I without operational IHX heat sinks (see Section 4.1.6). Thus, the maximum time rate of change of temperature is very small in PRISM during this transient and should not pose any thermal stress problems for structures in the flow field.

The inlet and exit temperatures on the secondary side and the flowrate of the IHX heat sink, as a function of time, are presented in Fig. 79 for AP2001. The heat sink capacity, as a function of time, is shown in Fig. 80 for AP2001. Using the temperature difference between the two groups of 


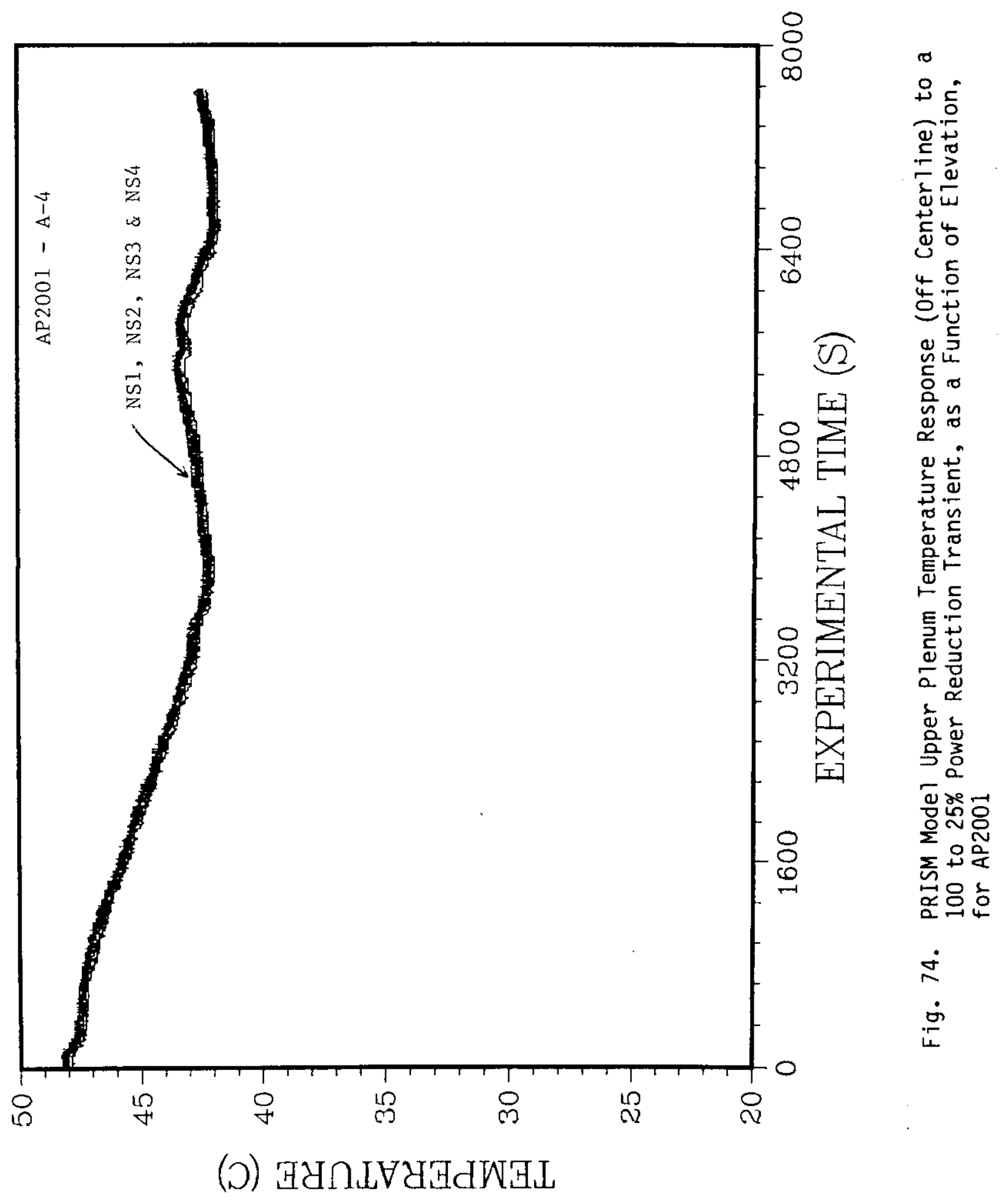




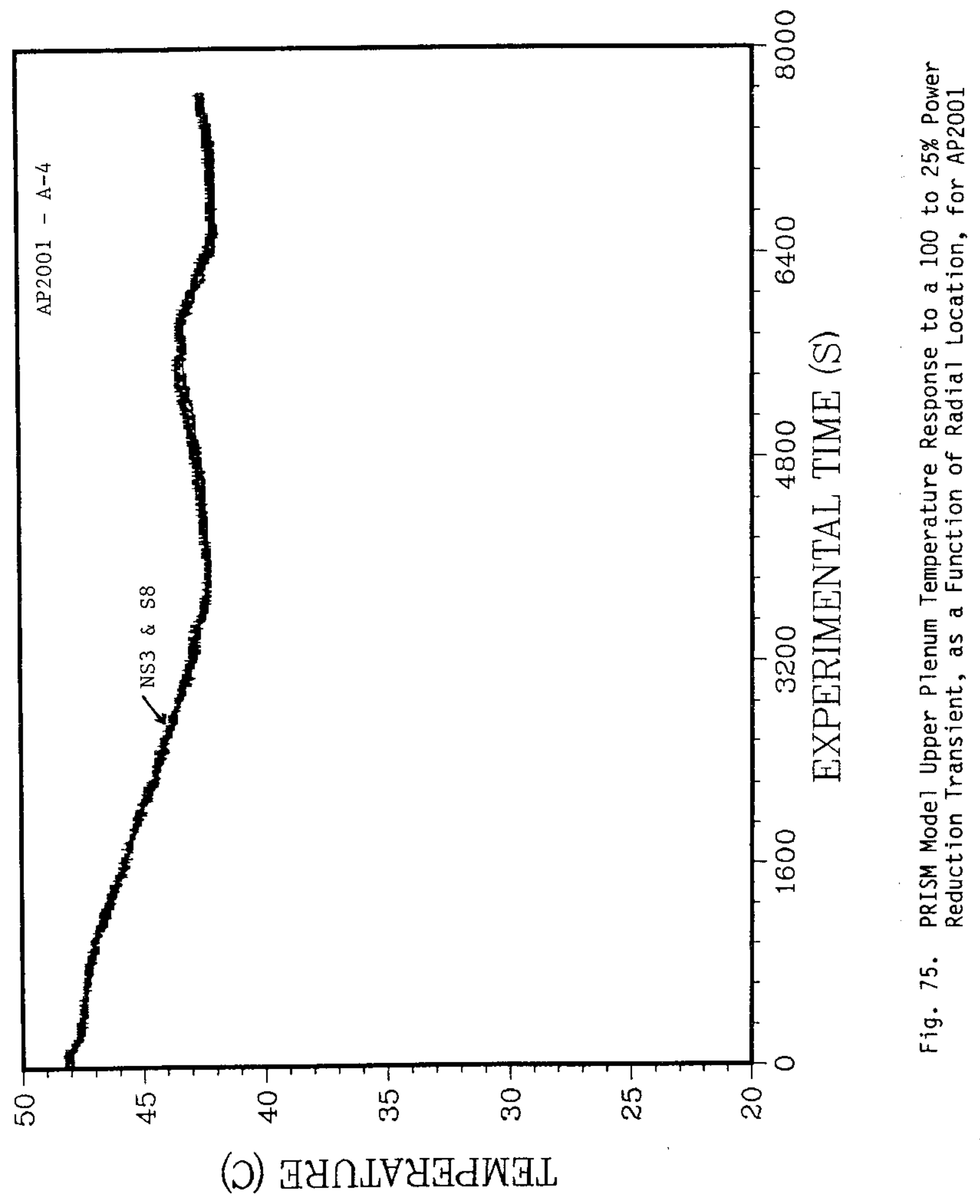




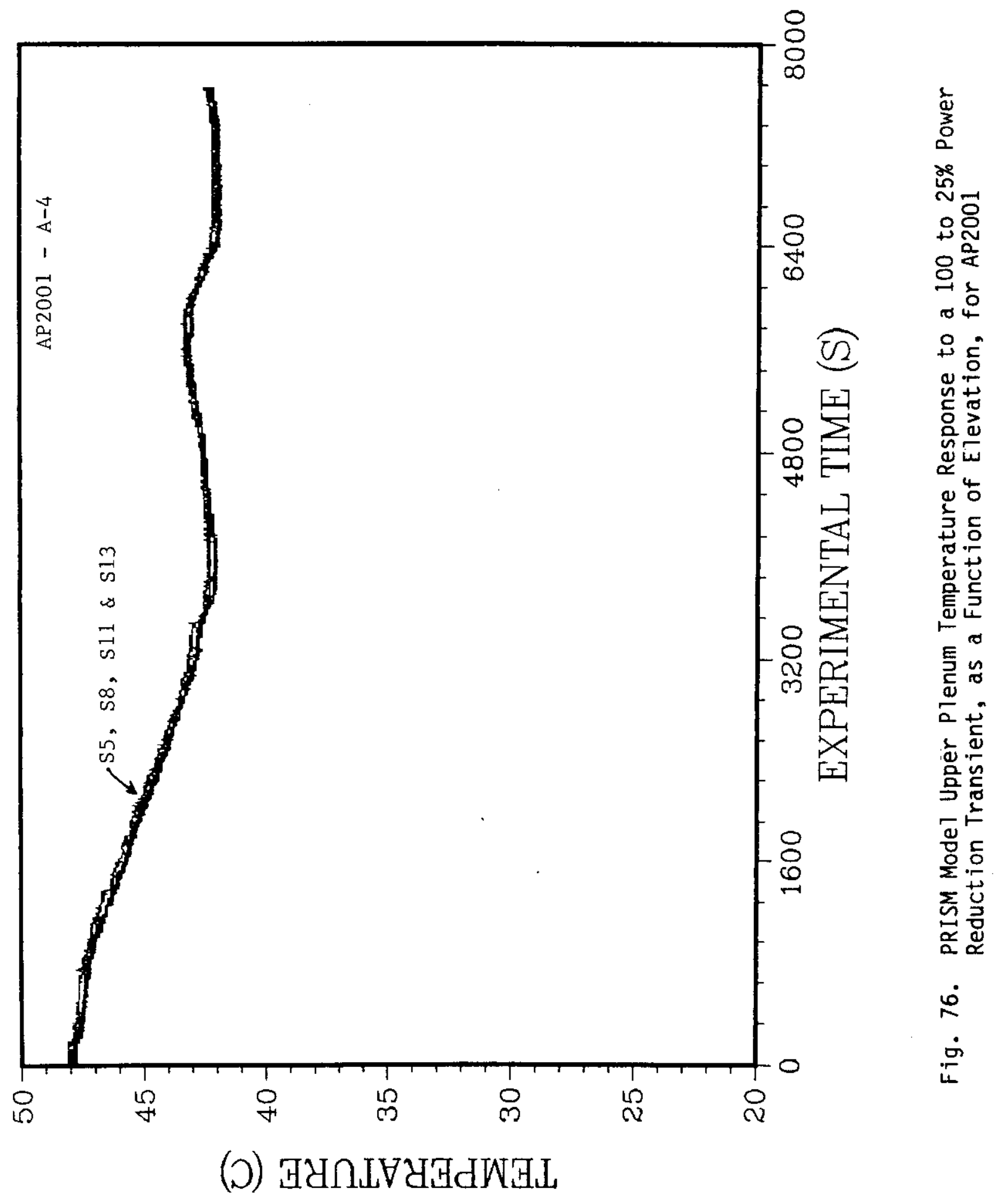




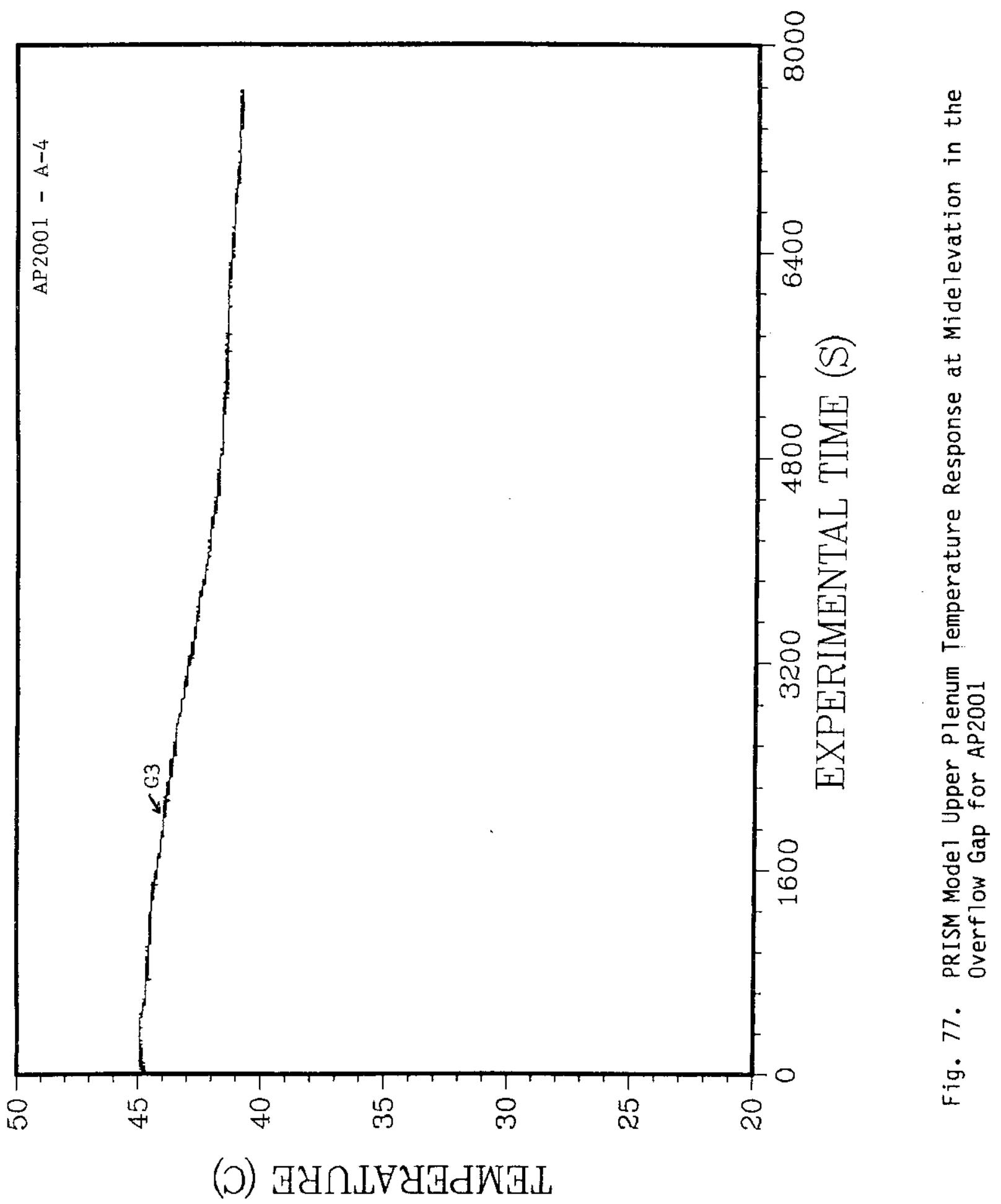




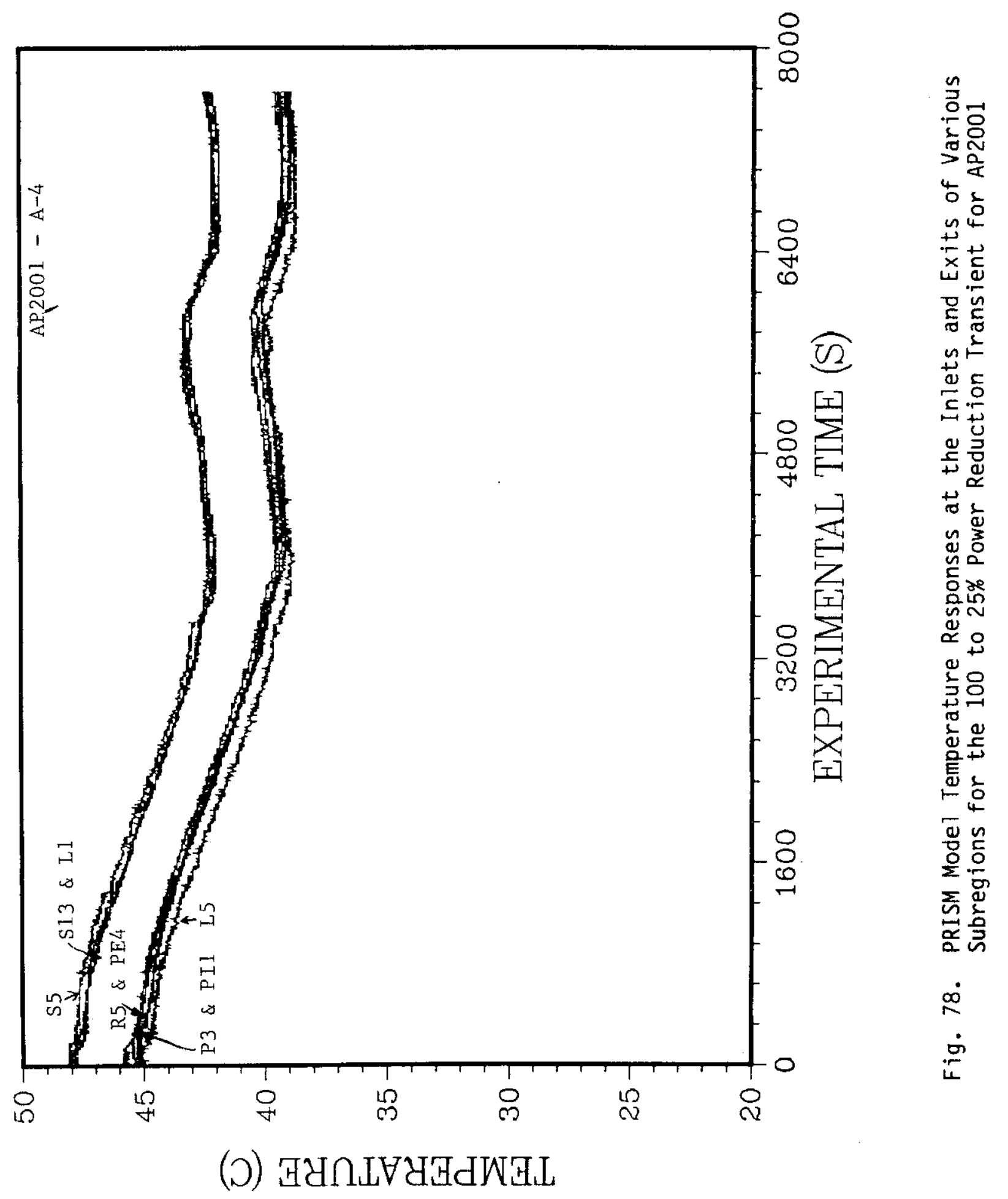




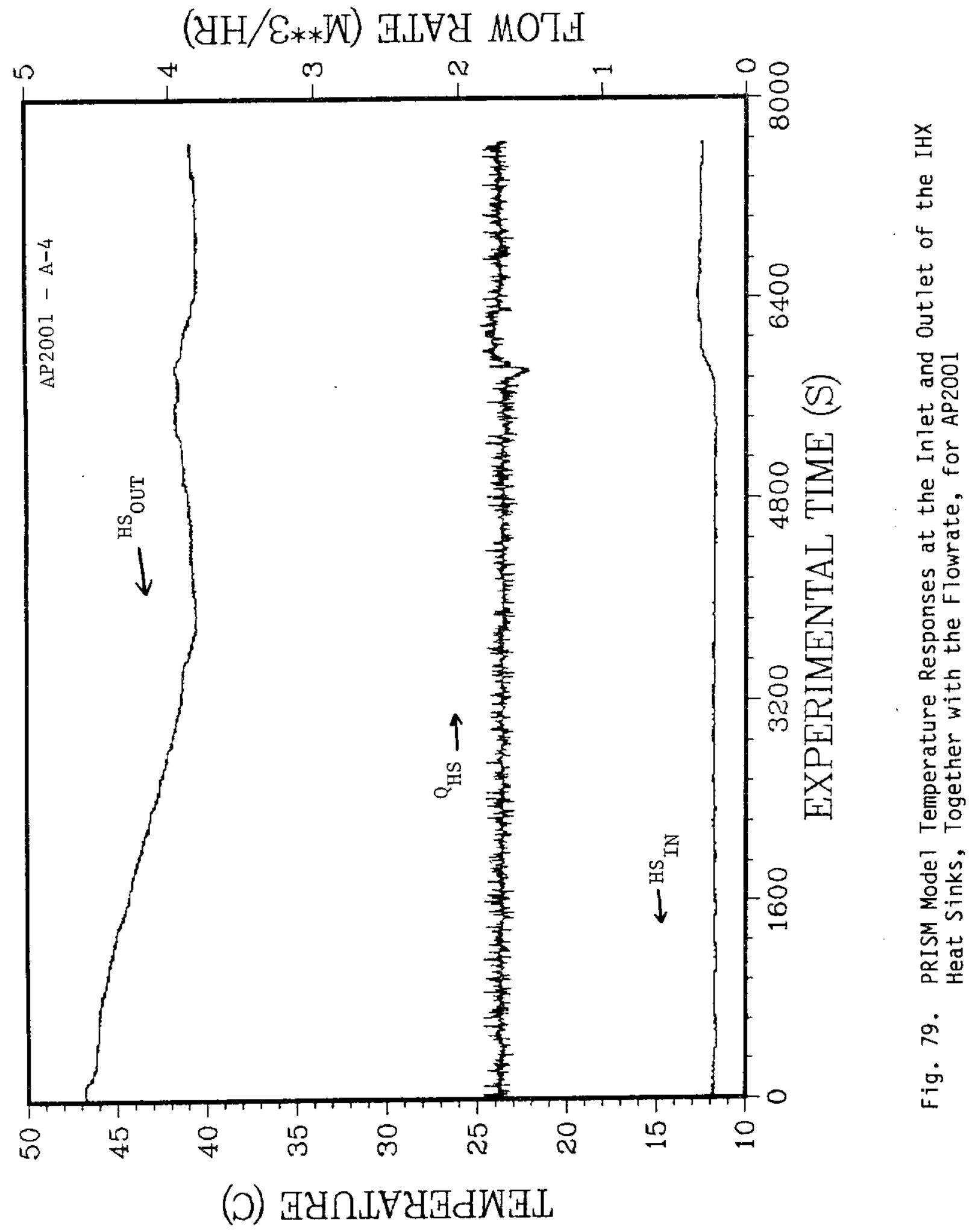




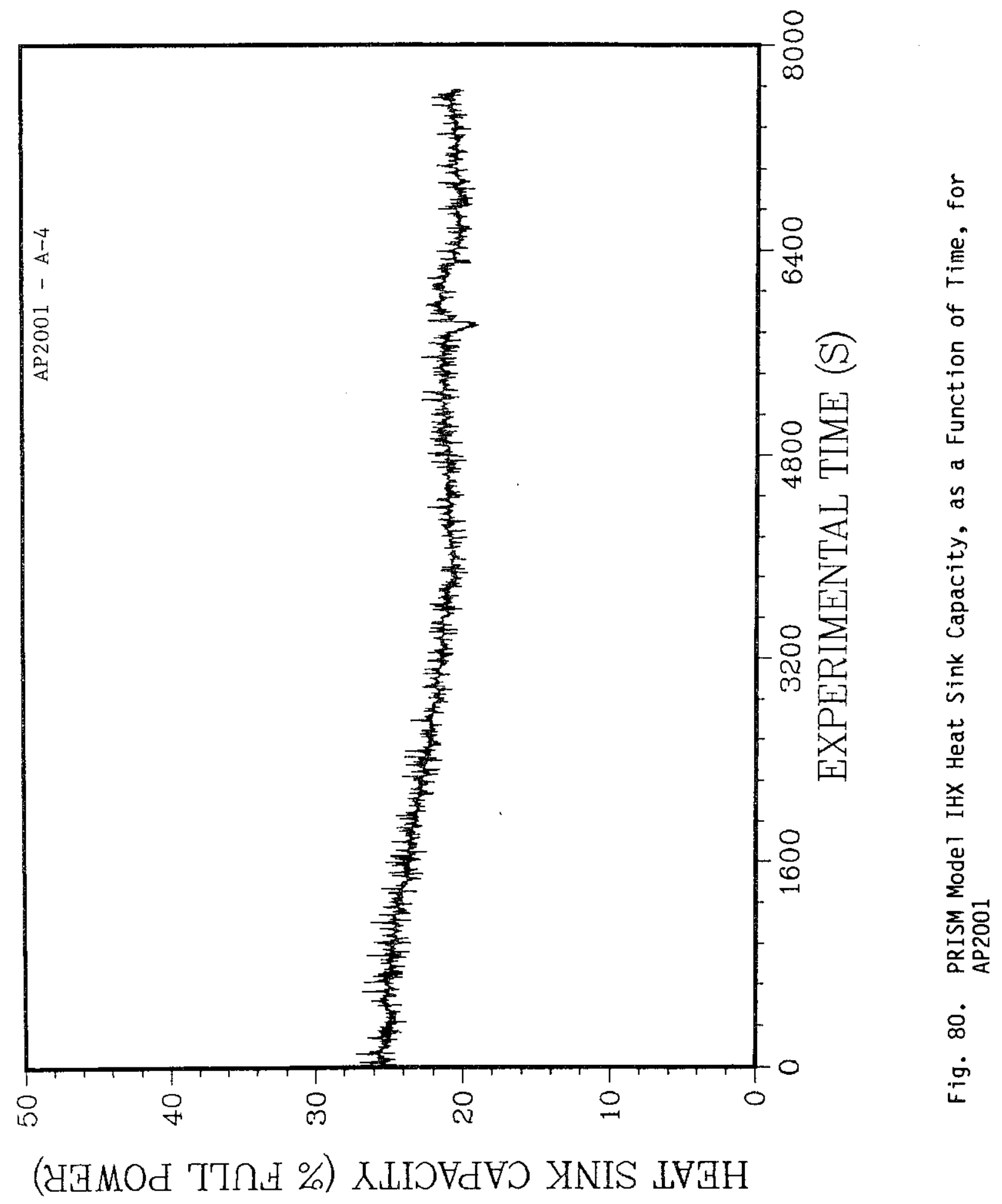


thermocouple responses on the primary side in Fig. 78 (i.e., $2.3^{\circ} \mathrm{C}$ ) and the primary flowrate (i.e., $28.8 \mathrm{~m}^{3} / \mathrm{hr}$ ), the heat removed was calculated to be $28.2 \%$ of full power, which compares favorably to the more accurately determined value presented in Fig. 80. Because of the model to ambient heat loss through the containment vessel walls, the energy loss on the primary side should be larger than the calculated heat removed by the IHXs shown in Fig. 80 .

The results of AU0701 of Phase. I and AP2001 of Phase II are generally in agreement. The addition of the heat sink capability in Phase II did not reveal any new concerns. In summary, there was no stratification in either the hot upper plenum or the cold lower plenum. This was expected since the conditions necessary for stratification are not created with a cold shock to a cold lower plenum, i.e., the buoyancy and inertia forces act in the same direction. The conditions for stratification do exist in the hot upper plenum with a cold shock since the buoyancy and inertia forces oppose one another. However, the buoyancy forces in this transient are not strong enough compared to the inertia forces to create a measurable effect. The absence of stratification in either plenum is important for the designer since the possibly large temperature gradients over small distances associated with stratification are not present to cause thermal stress problems in regions of the prototype in which these large gradients are unexpected. The Richardson number (based on the core barrel diameter), which is relevant for the upper plenum, was approximately 4.0; the Richardson number (based on the radial-gap diameter outside the radial shield), which is relevant for the lower plenum, was approximately 6.4. Both values are sma11, indicating that thermalbuoyancy forces are small compared to the inertia forces. The threshold Richardson number (based on core barrel diameter) below which stratification does not occur in the upper plenum, is now bracketed by 4.0 on the lower bound (from this test and AU0701 of Phase I, Section 4.1.6) and by 56.0 on the upper bound (from JY2801 of Phase I, Section 4.1.5).

\subsubsection{Reactor Trip from Full Power with Maximum Decay Heat (B-1A)}

Tests simulating the GE prototype transient $B-1 A$, reactor trip from full power with maximum decay heat, were also conducted in Phase II of PRISM testing. Temperature and flowrate were decreased in a prescribed manner, 
details of which were specified by GE (see Section 3.2.1.2). This transient was repeated three times (tests MY2001, MY2101, and MY2201), with a nominal core temperature difference of $13^{\circ} \mathrm{F}$ (see Table VII), to check reproducibility. Comparison of the data from these tests shows that the results are reproducible; thus, only the results of MY2001 with an actual core temperature difference of $14.6^{\circ} \mathrm{F}$ will be presented here. The temperature and flowrate as a function of time are shown in Fig. 81 for MY2001 during the initial portion of the transient when the flow was provided by the MCTF loop. At $68.7 \mathrm{~s}$, the immersion heater was turned on while the flow was still provided by the MCTF loop. At approximately $420 \mathrm{~s}$, the MCTF was completely isolated from the mode1, and the transients continued with only the immersion heater and internal pumps providing the power and flowrate, respectively. In Fig. 82, the responses of 8 of the 11 thermocouples that were mounted on a vertical sting on the cold plenum floor about 2 in. inside the radial-shield liner (see Fig. 12) are presented for MY2001. For the most part, the thermocouple responses fall on top of one another, indicating that there was no stratification in the lower plenum. This was expected since the conditions necessary for stratification are not created with a cold shock to a cold plenum, i.e., the buoyancy and inertia forces act in the same direction. Dye injected from the left exit of the left IHX immediately after transition to internal flow drifted predominantly downward and filled the lower plenum. However, a small portion swirled upward and filled the gap between the disc that was supporting the IHXs and the top of the radial-shield liner. These two distinct dye regions persisted for a long period of time, indicating that there was very little mixing owing to the very low flowrates.

The responses of four thermocouple located in the upper plenum on the center sting (see Fig. 12) are presented in Fig. 83 for MY2001. The plenum started out at a uniform temperature, stratified between $t=150$ and $800 \mathrm{~s}$, mixed to a slightly lower uniform temperature, and restratified after $t=1200 \mathrm{~s}$. This transient is a cold shock to a hot upper plenum, in which the buoyancy and inertia forces oppose each other. Under these conditions, stratification in the upper plenum can be expected if the buoyancy forces are large enough compared to the inertia forces. During the entire test, the flowrate and power were gradually decreasing, and thus the relative strengths of the inertia forces (velocity field) and buoyancy forces (thermal field) 


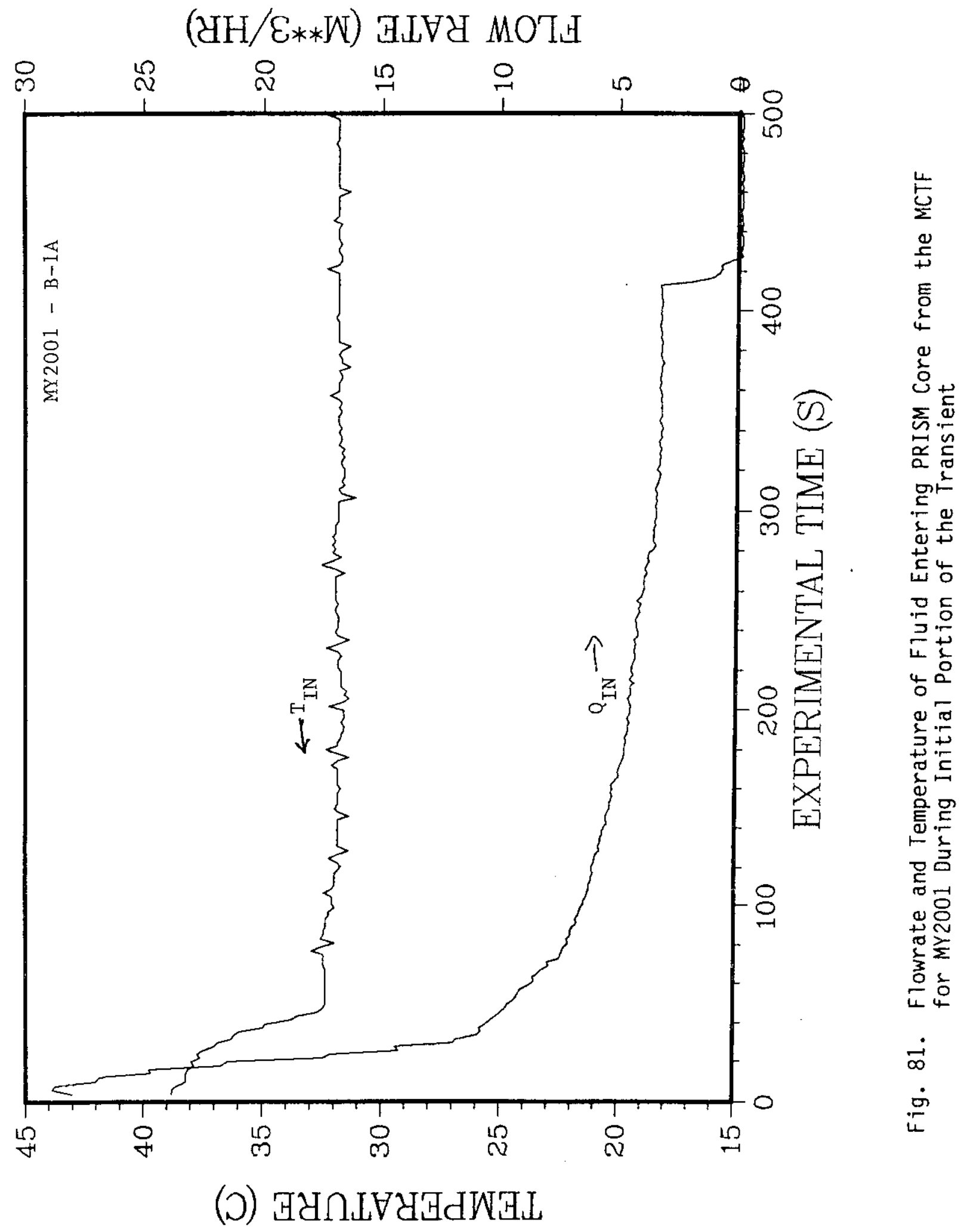




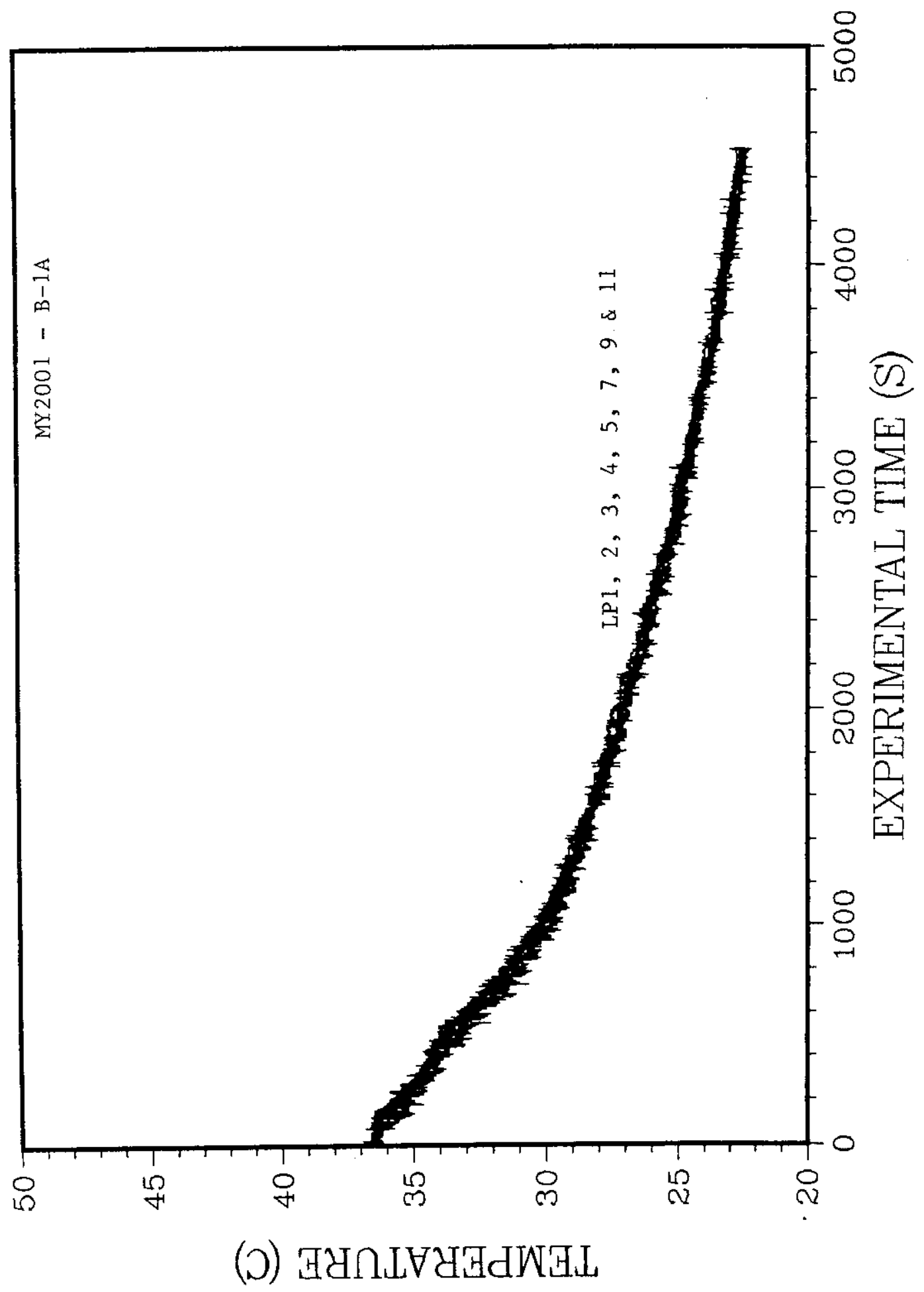

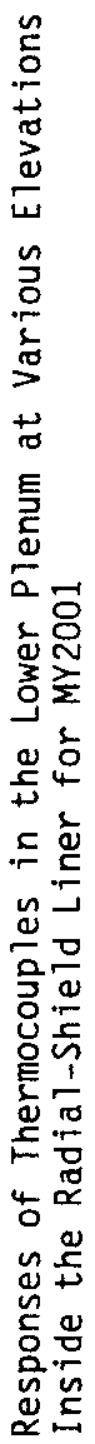

வ

훈 


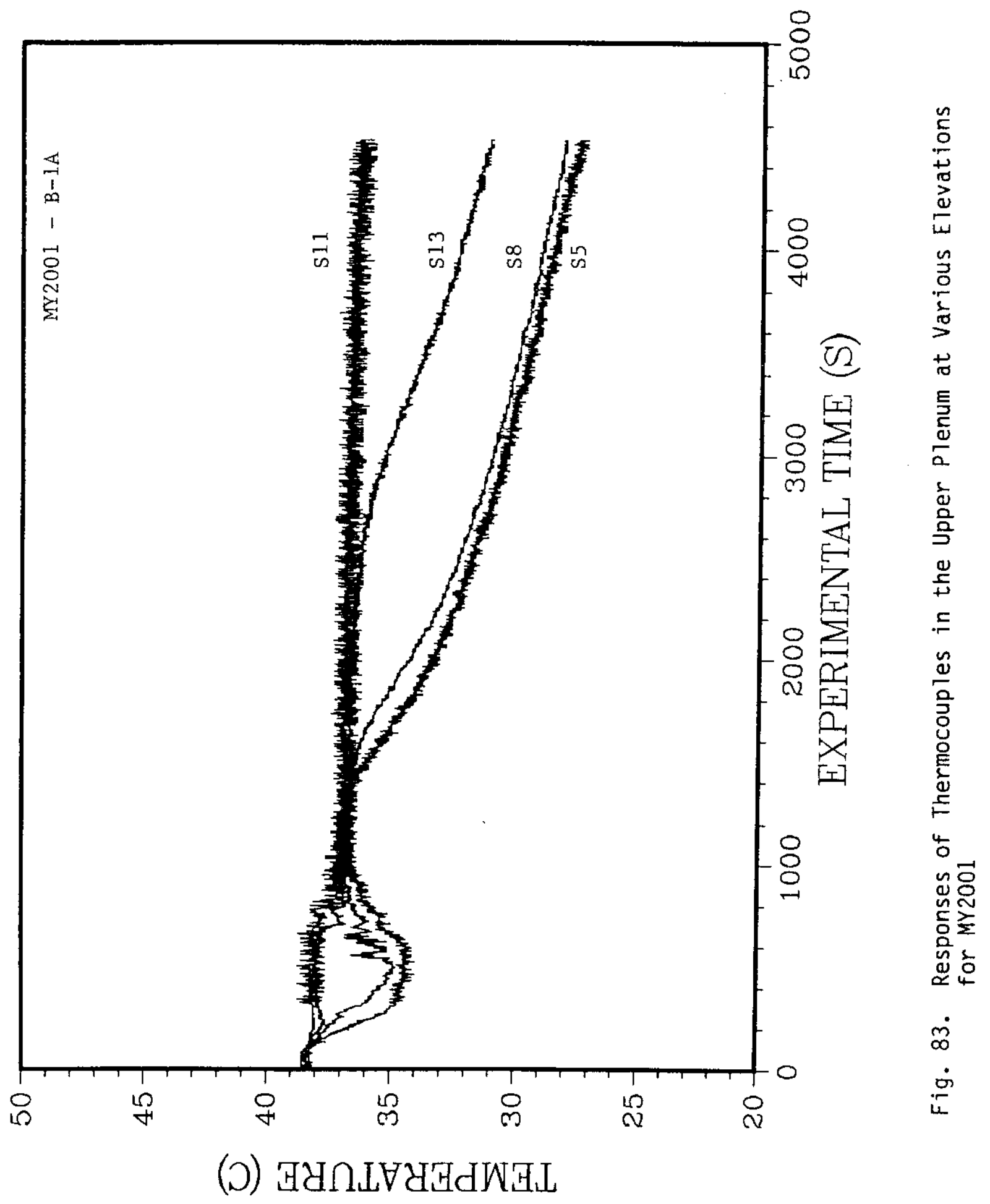


were varying. This variation accounts for the complex phenomenon observed in Fig. 83. Thermocouple S5 was located at a lower elevation than S13. As shown in Fig. 84, the IHX heat sink capacity, which was initially set at $11.7 \%$ of full power, varied during the test to a low of $6 \%$ while the power supplied by the immersion heater decreased to $1.5 \%$ of full power. Thus, a gradual cooling of the model, i.e., lower temperatures, was to be expected, and was observed after $t=1200 \mathrm{~s}$. The heat sink capacity in the prototype also did not remain constant, but decreased to below $6 \%$ during the transient. Thus, the cooling observed in Fig. 83 after $t=1200 \mathrm{~s}$ is exaggerated, i.e., the temperatures are lower than would be expected with a smaller, exactly simulated, IHX heat sink capacity. The inlet and exit temperatures of the IHX heat sinks, together with flowrate, are shown, as a function of time, in Fig. 85 . The initial upper plenum stratification observed between 150 and $800 \mathrm{~s}$ was analyzed in detail since it occurred during the time that the heat sink most closely simulated that of the prototype. The model was isolated from the MCTF at $416.8 \mathrm{~s}$. At approximately $450 \mathrm{~s}$, the flow was $8 \%$ of full flow (i.e., 10.24 $\mathrm{gpm})$ and the temperature difference measured in the upper plenum was $3.73^{\circ} \mathrm{C}$ $\left(76.2^{\circ} \mathrm{C}\right.$ in the prototype). On the basis of these values, the Reynolds and Richardson numbers (based on the core barrel ID) were 2615 and 3:13, respectively, at that instant. Such a large Richardson number indicates that the thermal-buoyancy forces are very much larger than the inertia forces.

The response of thermocouple G3, located at midelevation in the overflow gap that surrounded the hot plenum (see Fig. 11), is shown in Fig. 86 for MY2001. The response of thermocouple G3 is 1inear, an indication of heat transfer by conduction (i.e., no convection). This is important to the designer who is estimating RVAC capacity and vessel heat losses.

Responses of a vertical string of thermocouples mounted on the outer surface of the radial-shield liner (see Fig. 11) are presented in Fig. 87 for Mr2001. R1 is at the highest elevation, whereas R5 is at the lowest. The responses generaliy fall on top of one another if the initial thermocouple offsets are factored in, an indication that there was no stratification in the radial-shield region. Although slight stratification was exhibited in the thermocouple responses of $R 1$ and $R 5$ in the period between 300 and $900 \mathrm{~s}$, the degree of stratification present caused no loss of coolability to that region 


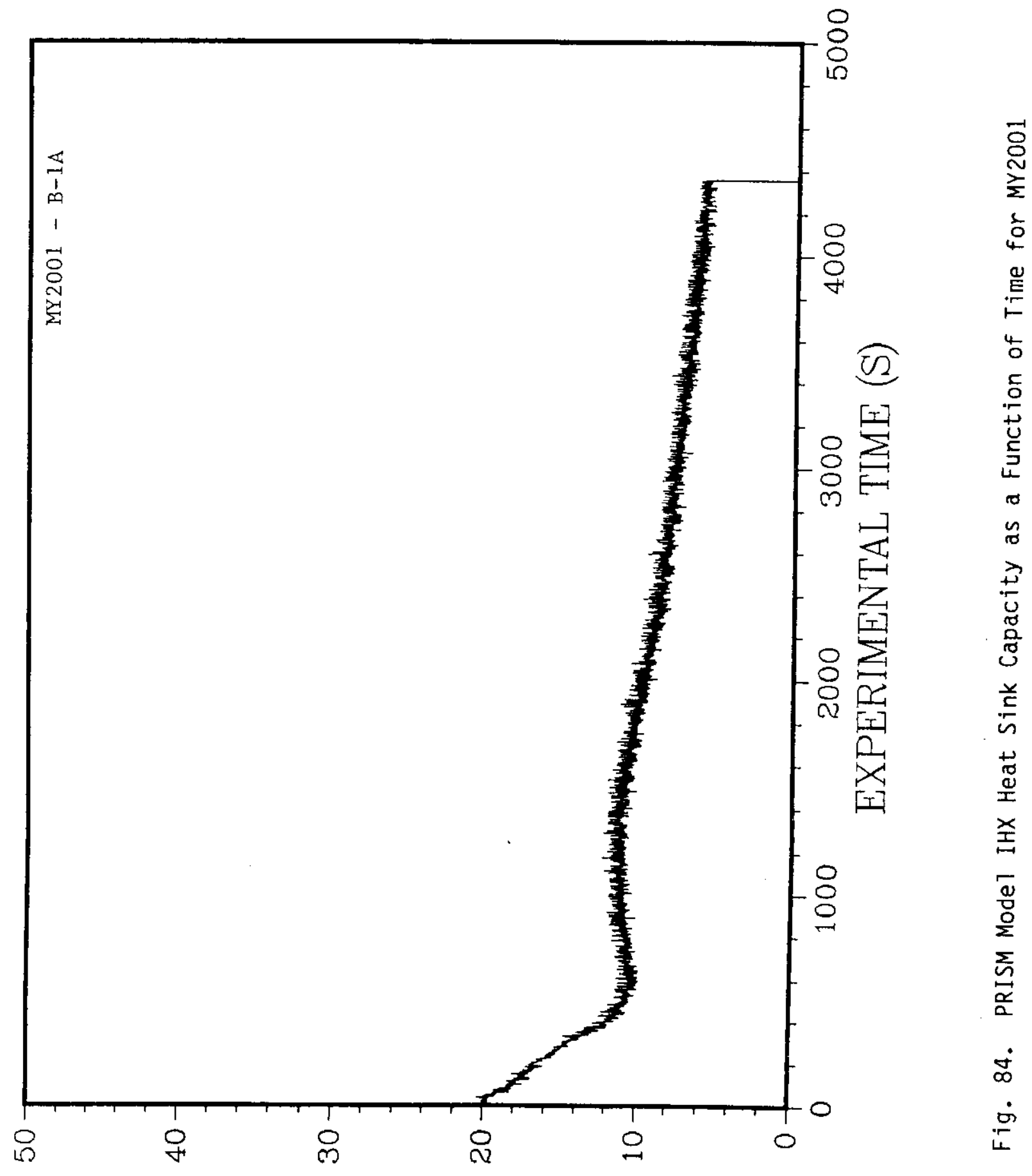

(YHMOd TTOH \%) XLIDVAVD YNIS LVHH 


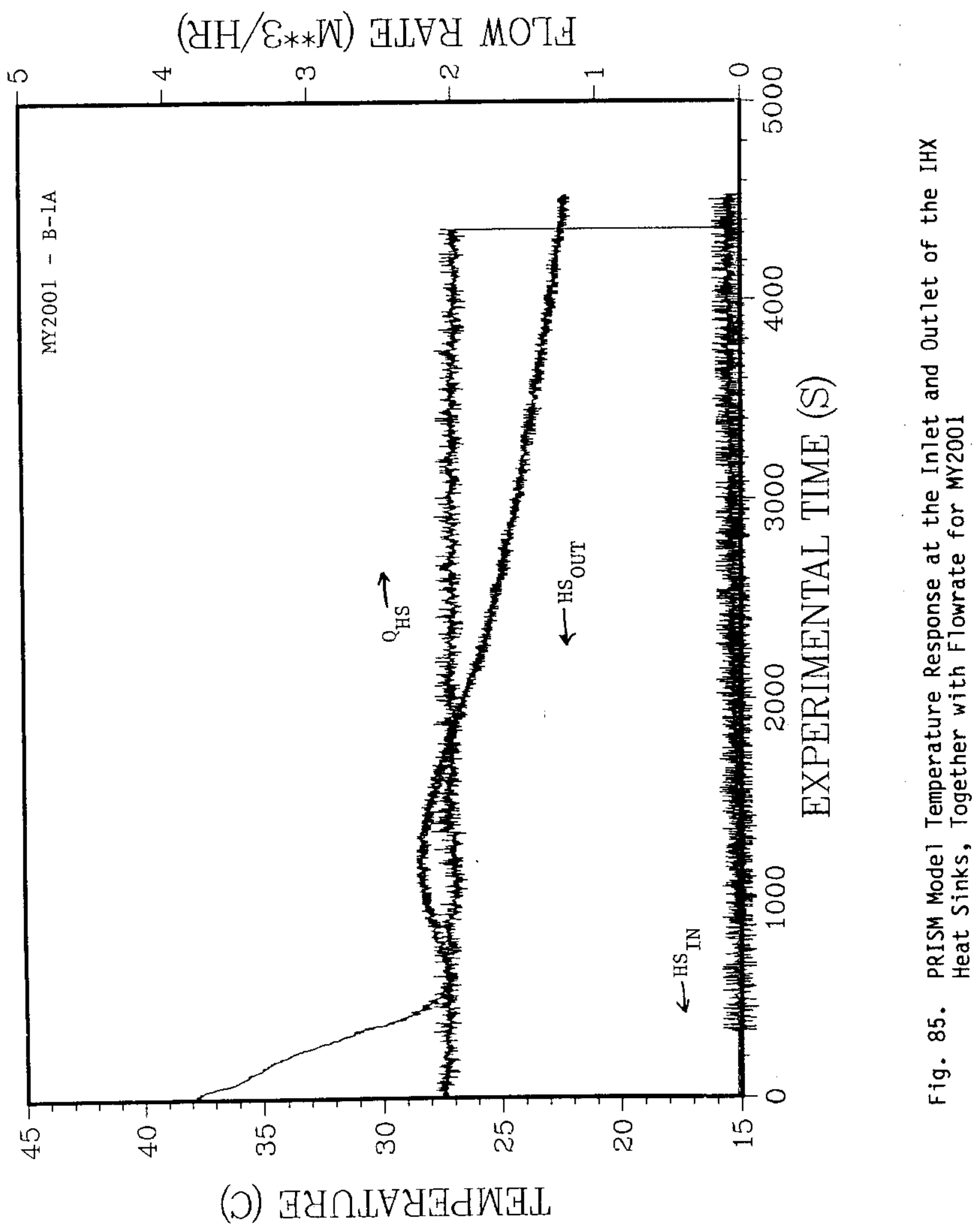




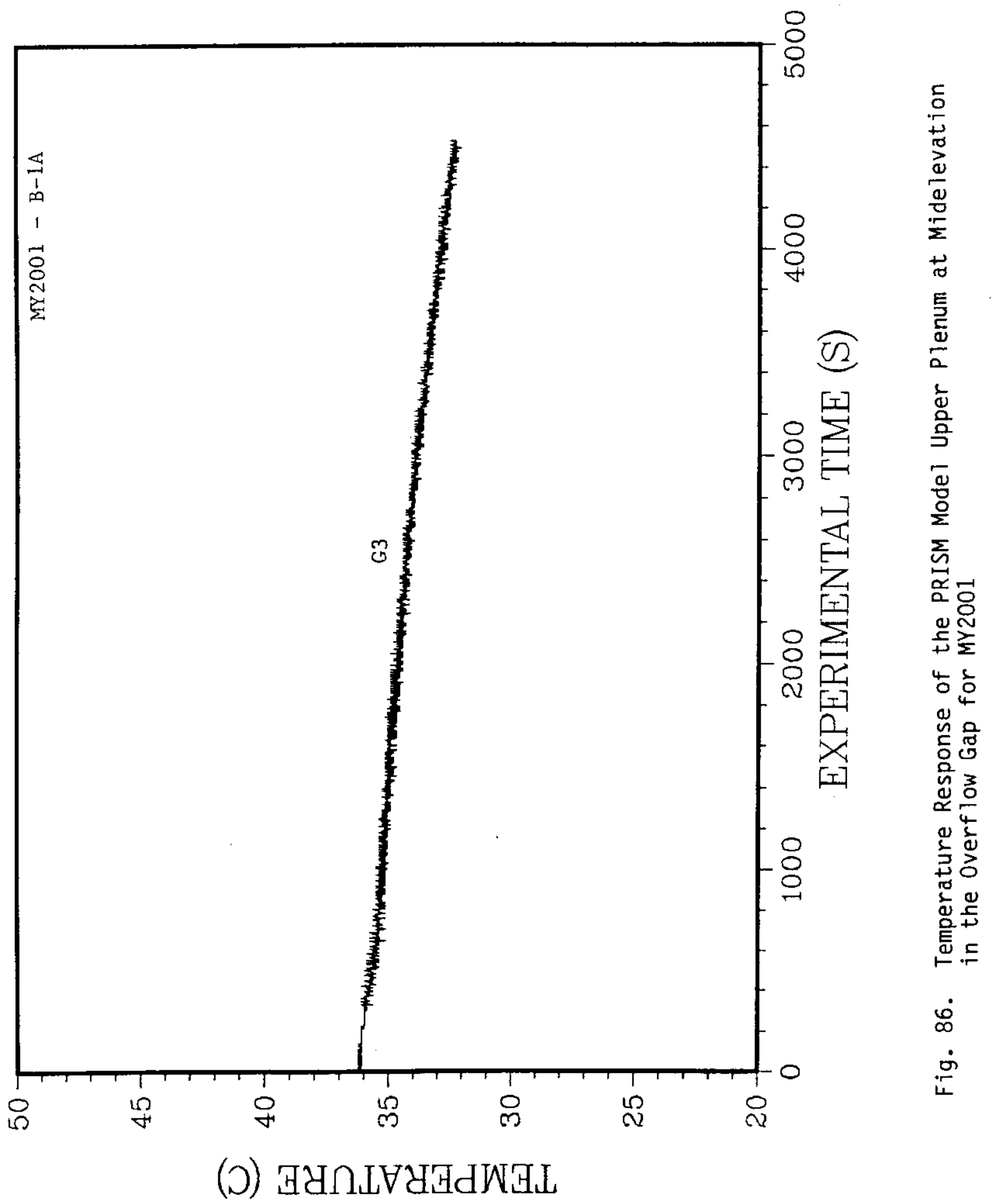




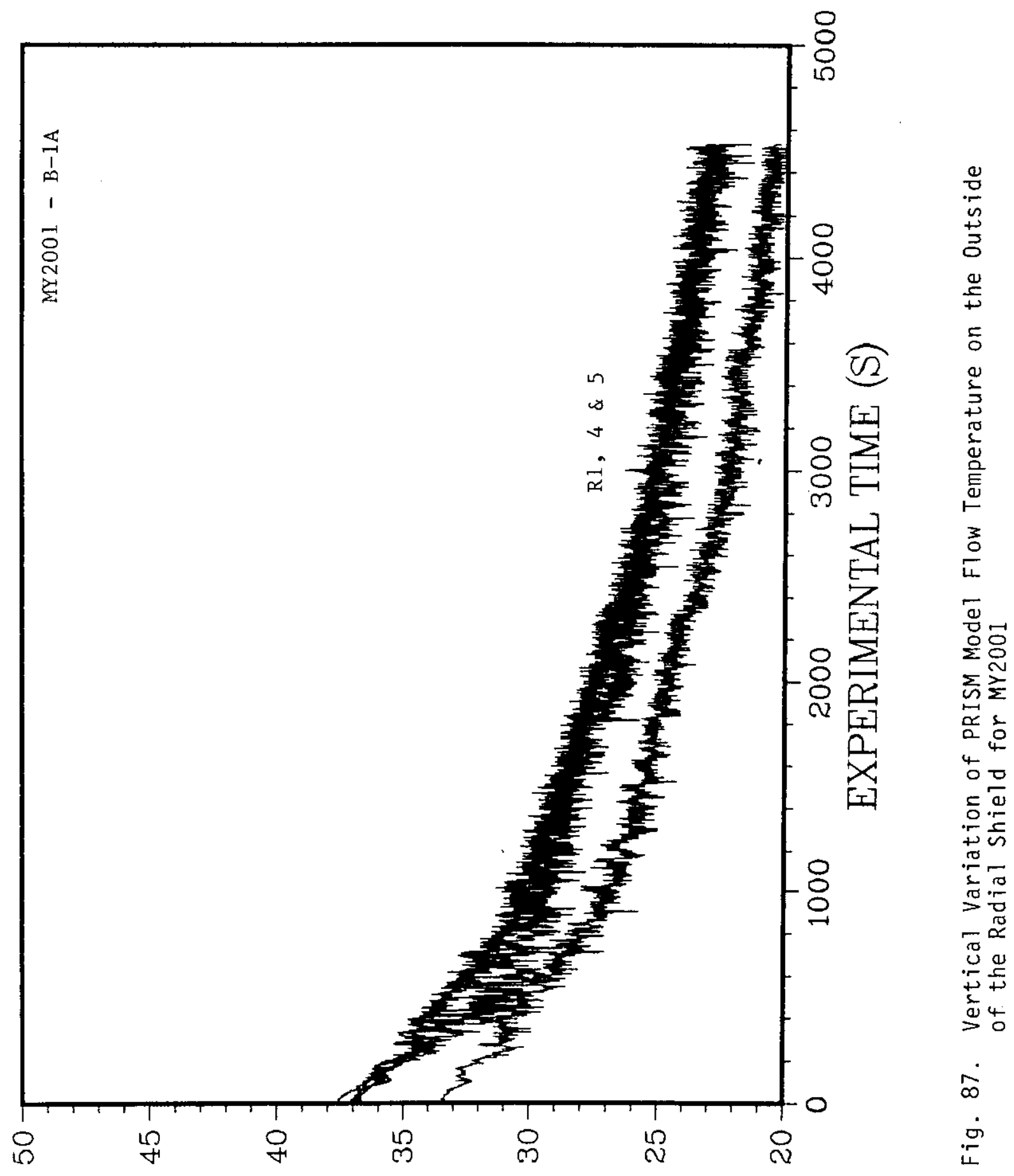

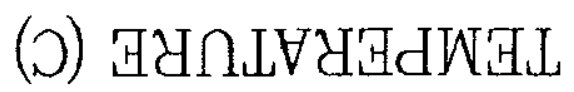


since the fluid exiting the IHXs was colder (thus more dense) and thus the buoyancy forces acted in the same direction as the inertia forces.

The responses of thermocouples located at the entrances and exits of critical subregions are presented in Fig. 88 for MY2001. The thermocouples are located in the upper plenum (S13), core exit (S5), IHX inlet (L1), IHX exit (L5), outside radial shield (R5), pump inlet (PI1), pump exit (PE4), and the core return pipe (P3) (see Figs. 11 and 12). Generally, after $t=1800 \mathrm{~s}$, the PRISM model was stratified (flowrate was less than $6 \%$ of full flow) and the cooling was due to the greater heat sink capacity of the IHXs compared to the power provided by the immersion heater, i.e., $11.7 \%$ versus $1.5 \%$ of ful1 power. Again, this behavior is exaggerated since the heat sink capacity in the prototype decreases to below $2.6 \%$ of full power as opposed to the decrease to $6 \%$ in the ANL model (see Fig. 84 ). The maximum rate of change of temperature with a meaningful duration of longer than $120 \mathrm{~s}$ was observed in the response of thermocouple L5, shown in Fig. 88. The maximum rate of change of temperature occurred during the period between approximately 50 and $250 \mathrm{~s}$. Its value in model units is $0.023^{\circ} \mathrm{C} / \mathrm{s}$, which corresponds to $0.196^{\circ} \mathrm{C} / \mathrm{s}$ in the prototype. These values are very small and present no problems to the designers of structures that experience these rates of change of temperature.

In summary, the simulation of transient B-1A indicates the existence of some stratification in the upper plenum for a short period of time, no stratification in the lower plenum, very small rates of change of temperature in internal structures, and a generally favorable coolability of the entire model after the scram. The absence of significant stratification in either plenum is important for the designers since the large temperature gradients over small distances associated with stratification are not present to cause thermal stress problems in regions in which these large gradients are unexpected.

\subsubsection{Loss of Power to One Primary Pump (B-3B)}

Tests that simulated the GE prototype transient B-3B, loss of power to one primary pump, were conducted during Phase II of PRISM testing. The transient was the transient described in Section 4.2.1.2 with the only deviation being that one of the four pumps was not operational. Temperature and flowrate were decreased in a prescribed manner, details of which were 


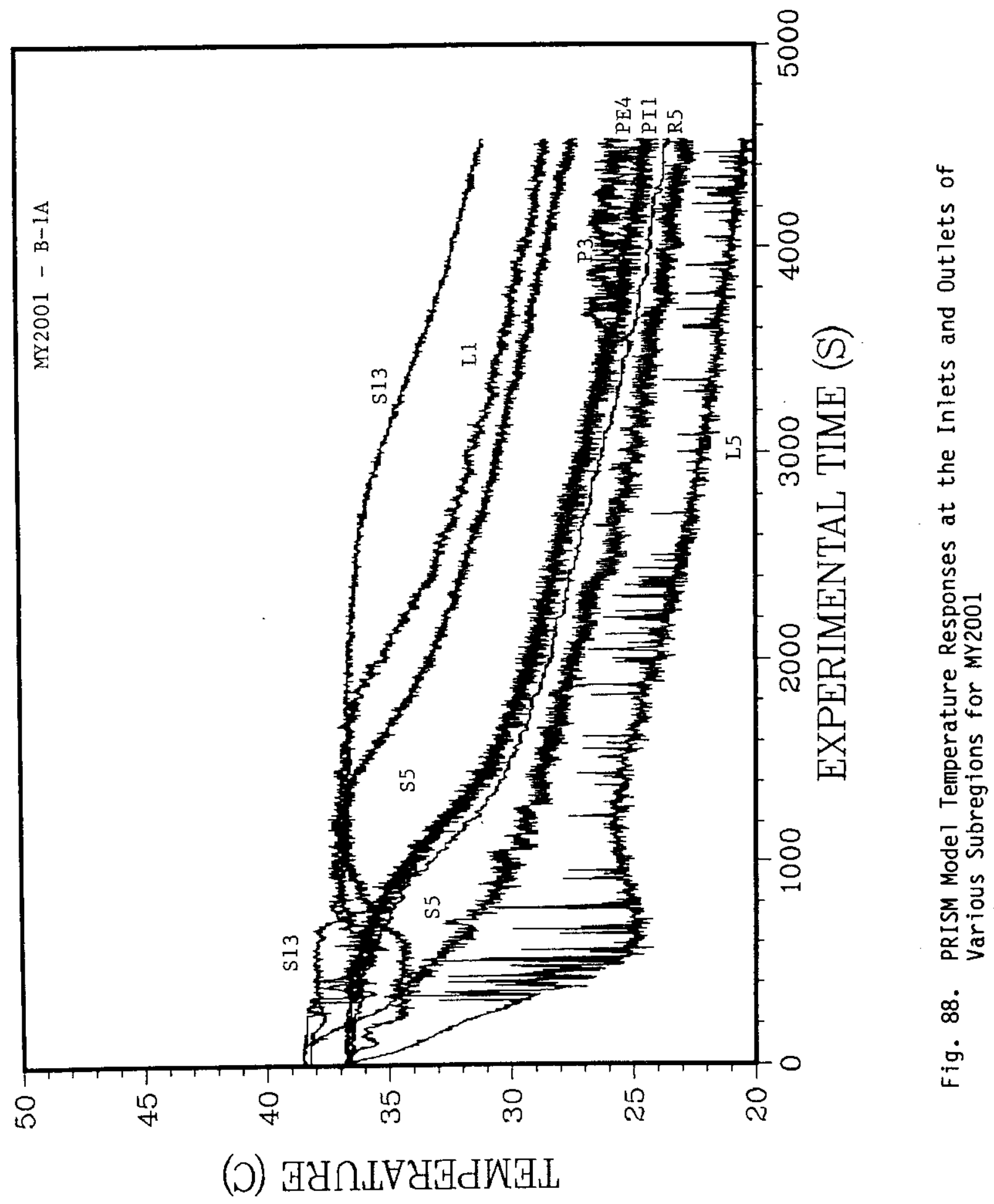


specified by GE (see Section 3.2.1.3). This transient was repeated three times (tests JU0201, JU0301, and JU0302), with a nominal core temperature difference of $12^{\circ} \mathrm{F}$ (see Table VIII), to check reproducibility. Comparison of the data from these tests indicates that the results are reproducible; thus only the results of JU0301 with an actual core temperature difference of $11.9^{\circ} \mathrm{F}$ will be presented here. The temperature and flowrate as a function of time are shown in Fig. 89 for Ju0301 during the initial portion of the transient when flow was provided by the MCTF loop. At $68.7 \mathrm{~s}$, the immersion heater was turned on while the flow was still provided by the MCTF loop. At approximately $450 \mathrm{~s}$, the MCTF was completely isolated from the model, and the transient was continued with only the immersion heater and three of the four internal pumps providing the power and flowrate, respectively. In Fig. 90 the thermocouple responses of 8 of the 11 thermocouples mounted on a vertical sting on the cold plenum floor about $2 \mathrm{in}$. inside the radial-shield liner (see Fig. 12) are presented for Ju0301. For the most part, the thermocouple responses fall on top of one another, indicating that there is no stratification in the lower plenum.

The responses of four thermocouple responses located in the upper plenum on the center sting (see Fig. 12) are presented in Fig. 91 for Ju0301. The plenum started out at a uniform temperature, stratified between $t=200$ and $900 \mathrm{~s}$, mixed to a slightly lower uniform temperature, and restratified after $t=1400 \mathrm{~s}$. During the entire test, the flowrate and power were gradually decreasing, and thus, the relative strengths of the inertia (velocity field) and buoyancy forces (thermal field) were varying. This variation accounts for the complex phenomenon observed in Fig. 91. Thermocouple $S 5$ is located at a lower elevation than S13. As shown in Fig. 92, the heat sink capacity, which was initially set at $10.8 \%$ of full power, varied during the test to a low of $6 \%$, while the power supplied by the immersion heater decreased to $1.5 \%$ of full power. Thus, a gradual cooling of the model, i.e., lower temperatures, was to be expected, and was observed after $t=1400 \mathrm{~s}$. The heat sink capacity in the prototype also did not remain constant, but decreased to below $2.6 \%$ during the transient (as in Section 4.2.1.2). Thus, the cooling observed in Fig. 91 after $t=1400 \mathrm{~s}$ is exaggerated, i.e., temperatures were lower than would be expected with a smaller, exactly simulated, model heat sink capacity. The inlet and exit temperatures of the IHX heat sinks, together with flowrate, are 


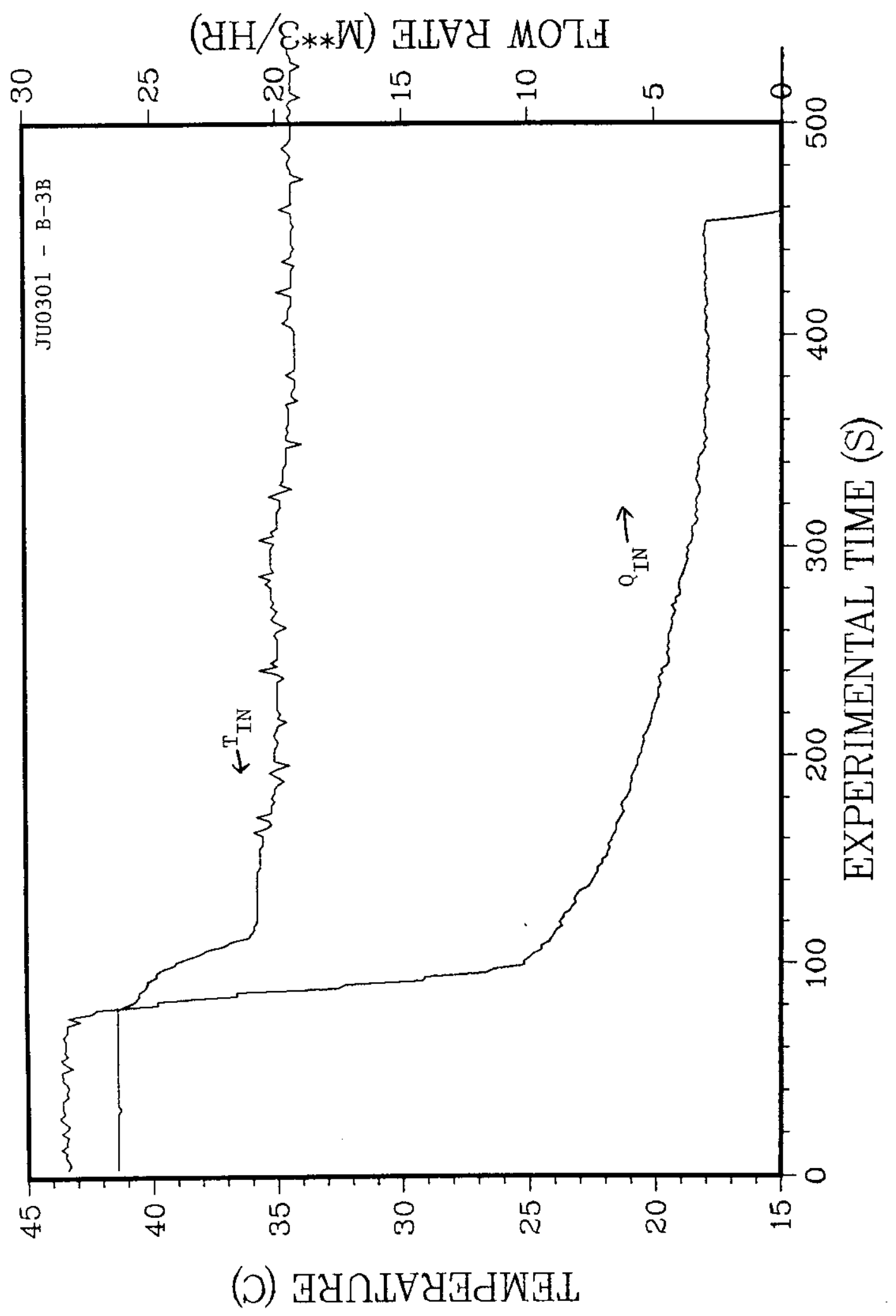

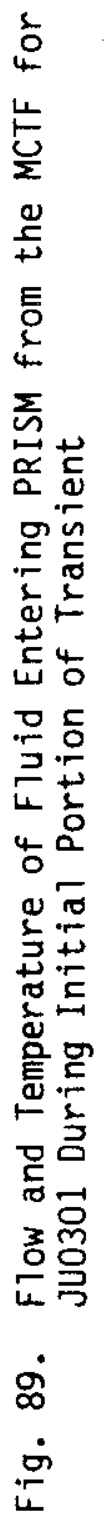




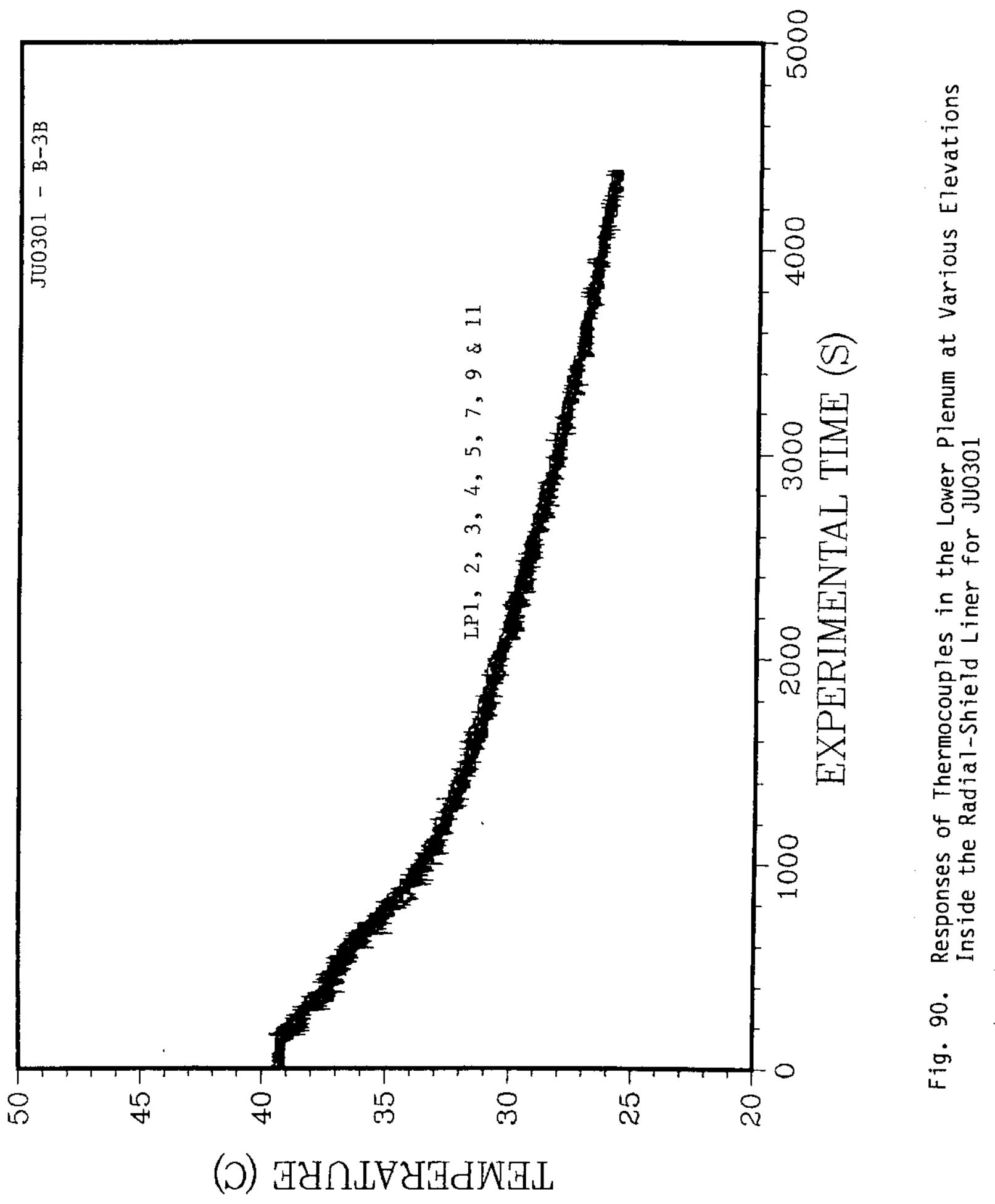




$$
\text { I }
$$




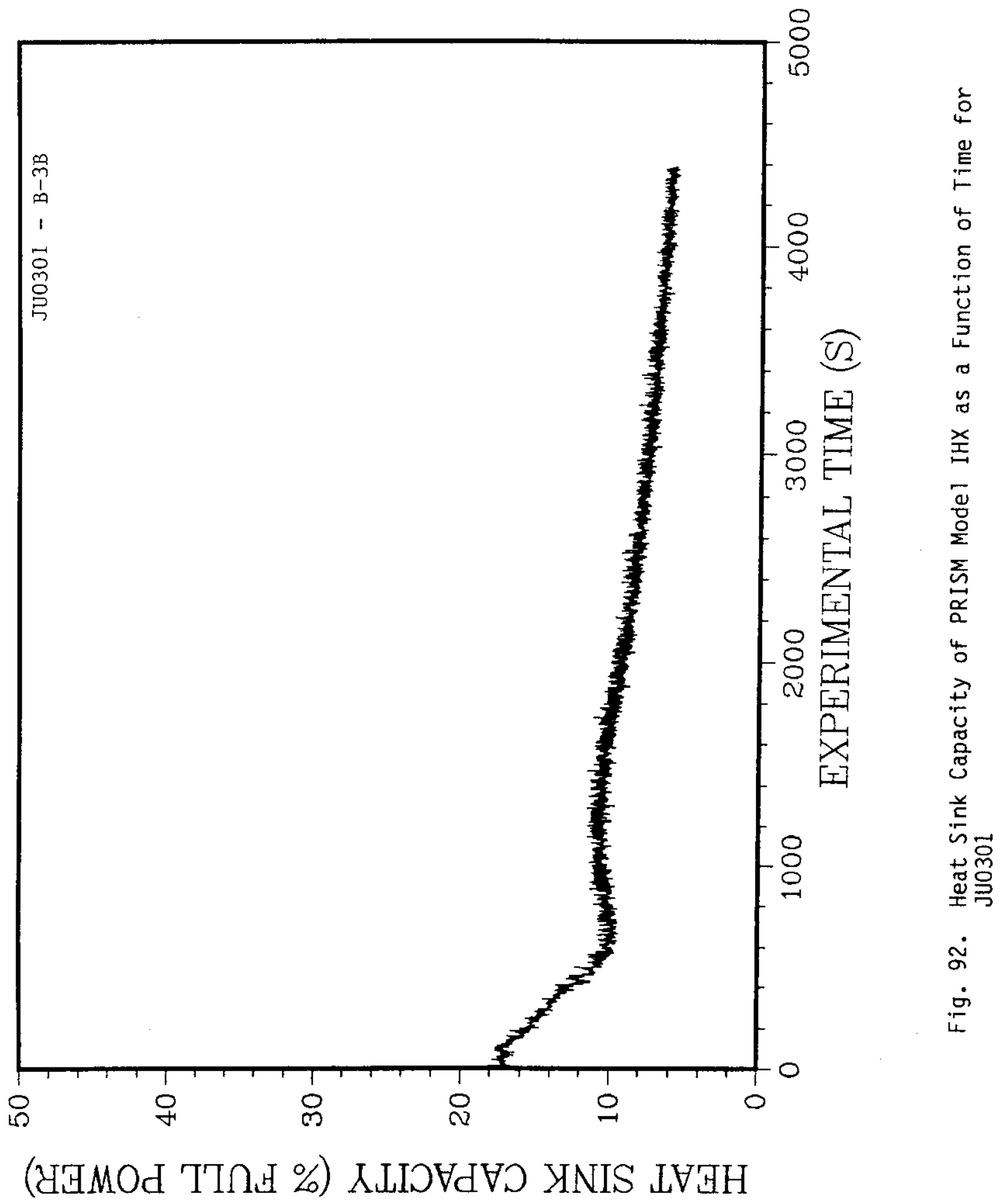


shown, as a function of time, in Fig. 93. The initial stratification observed between 200 and $900 \mathrm{~s}$ was analyzed in detail since it occurred during the time that the heat sink most closely simulated that of the prototype. The model was isolated at $456 \mathrm{~s}$ from the MCTF. At approximately $500 \mathrm{~s}$ the flow was $6 \%$ of full flow (i.e., $7.68 \mathrm{gpm}$ ) and the temperature difference measured in the upper plenum was $2.78^{\circ} \mathrm{C}\left(61.6^{\circ} \mathrm{C}\right.$ in the prototype). On the basis of these values, the Reynolds and Richardson numbers (based on the core barrel ID) were 2070 and 549, respectively, at that instant. Such a large Richardson number indicates that the thermal-buoyancy forces are very much larger than the inertia forces.

The response of thermocouple G3, located at midelevation in the overflow gap surrounding the hot plenum (see Fig. 11), is shown in Fig. 94 for MY2001. The response of thermocouple $G 3$ is linear, an indication of heat transfer by conduction (i.e., no convection). This is important to the designer who is estimating RVAC capacity and vessel heat losses.

Responses for a vertical string of thermocouples mounted on the outer surface of the radial-shield liner (see Fig. 11) are presented in Fig. 95 for Ju0301. R1 is at the highest elevation, whereas R5 is at the lowest. The responses generally fall on top of one another if the initial thermocouple offsets are factored in, an indication that there was no stratification in the radial-shield region. Although slight stratification was exhibited in the responses of thermocouples $R 1$ and R5 in the period between 400 and $1000 \mathrm{~s}$, the degree of stratification present caused no loss of coolability to that region since the fluid exiting the IHXs was colder (thus more dense) and thus the buoyancy forces acted in the same direction as the inertia forces.

The responses of thermocouples located at the entrances and exits of critical subregions are presented in Fig. 96 for JU0301. The thermocouples are located in the upper plenum (S13), core exit (S5), IHX inlet (L1), IHX exit (L5), outside radial shield (R5), pump inlet (PI1), pump exit (PE4), and the core return pipe (P3) (see Figs. 11 and 12). General1y, after $t=1800 \mathrm{~s}$, the PRISM model was stratified (flowrate was less than $4.5 \%$ of full flow) and the cooling was due to the greater heat sink capacity of the IHXs compared to the power provided by the immersion heater, i.e., $10.8 \%$ versus $1.5 \%$ of ful1 power. Again, this behavior is exaggerated since the heat sink capacity in 


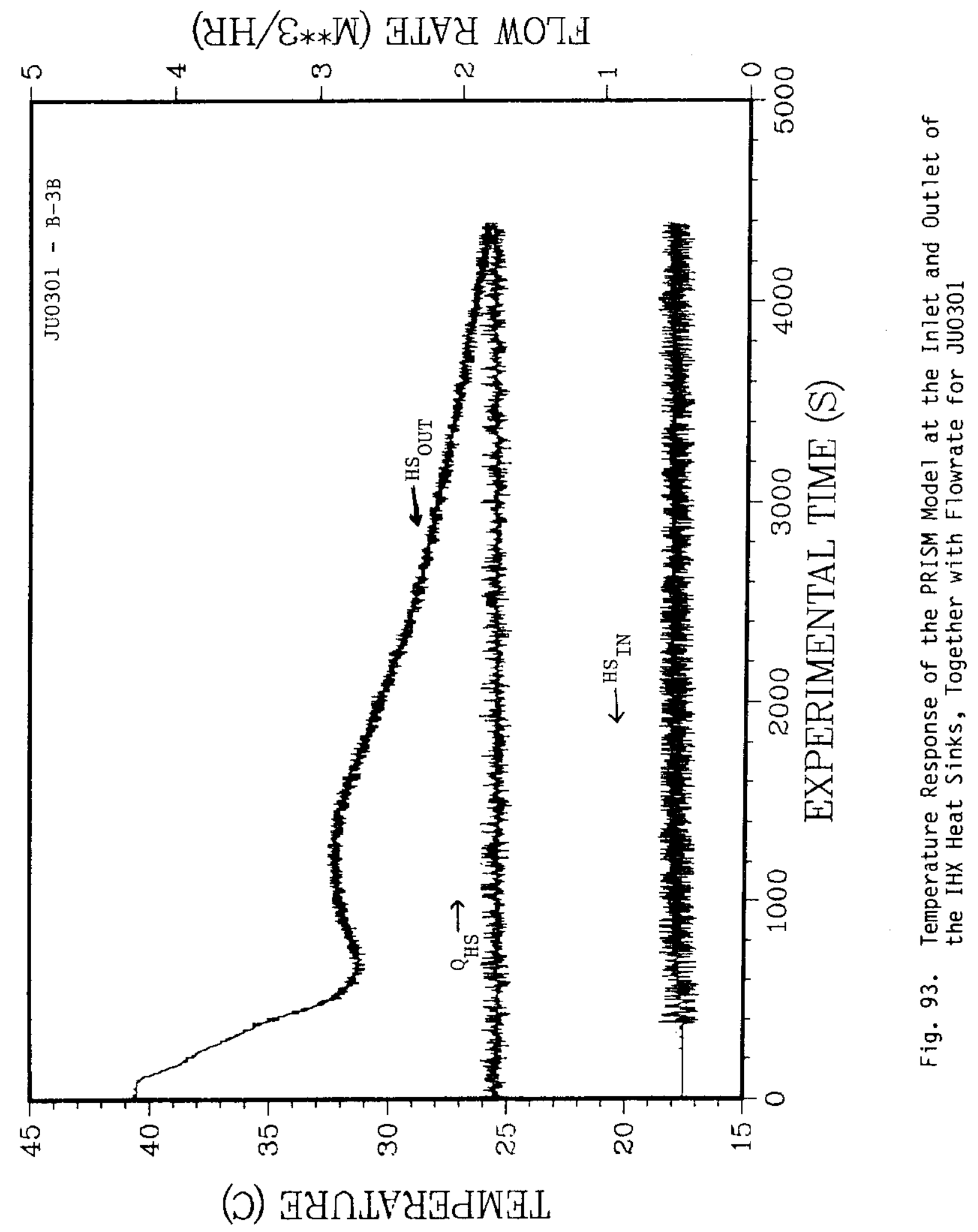




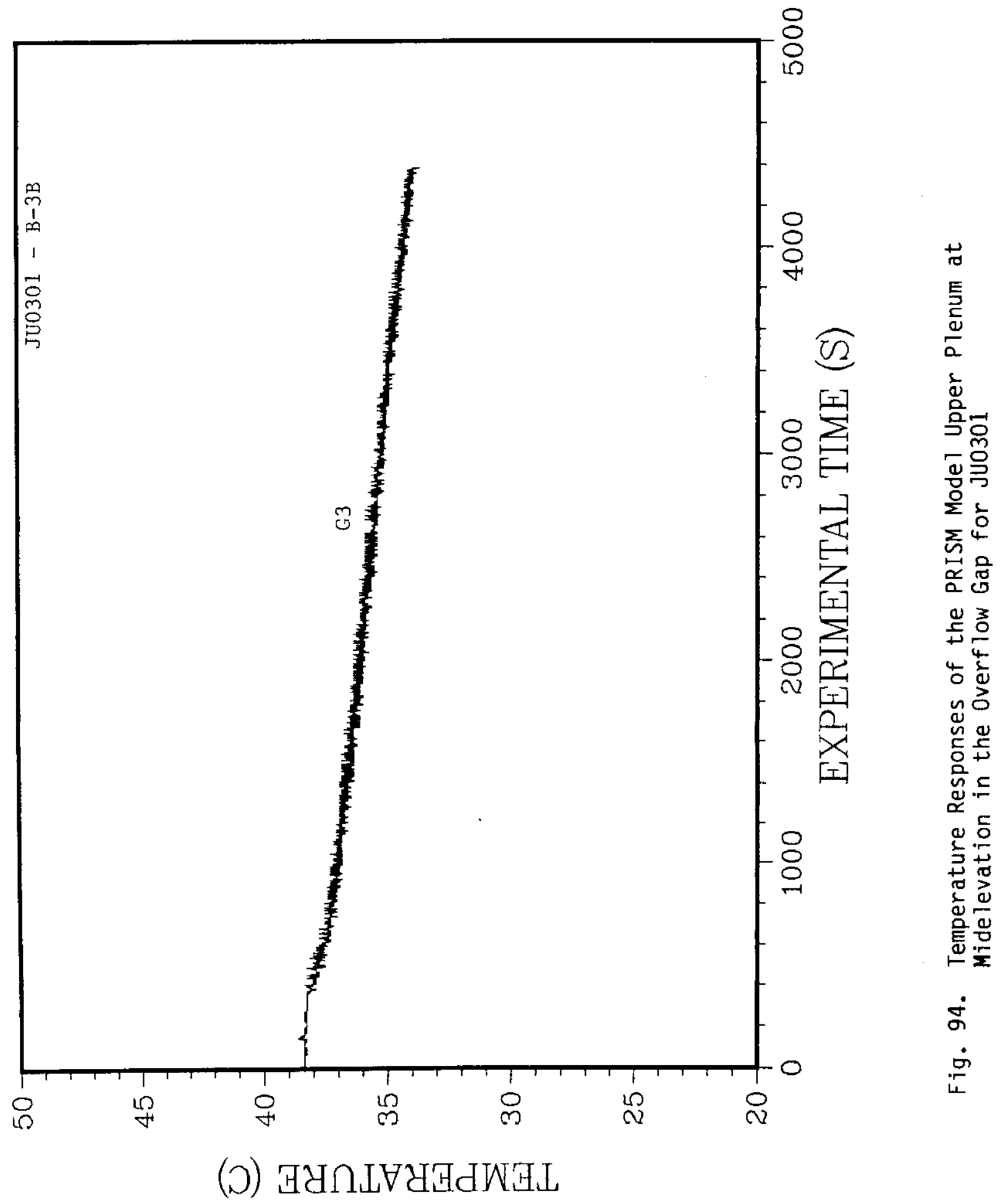




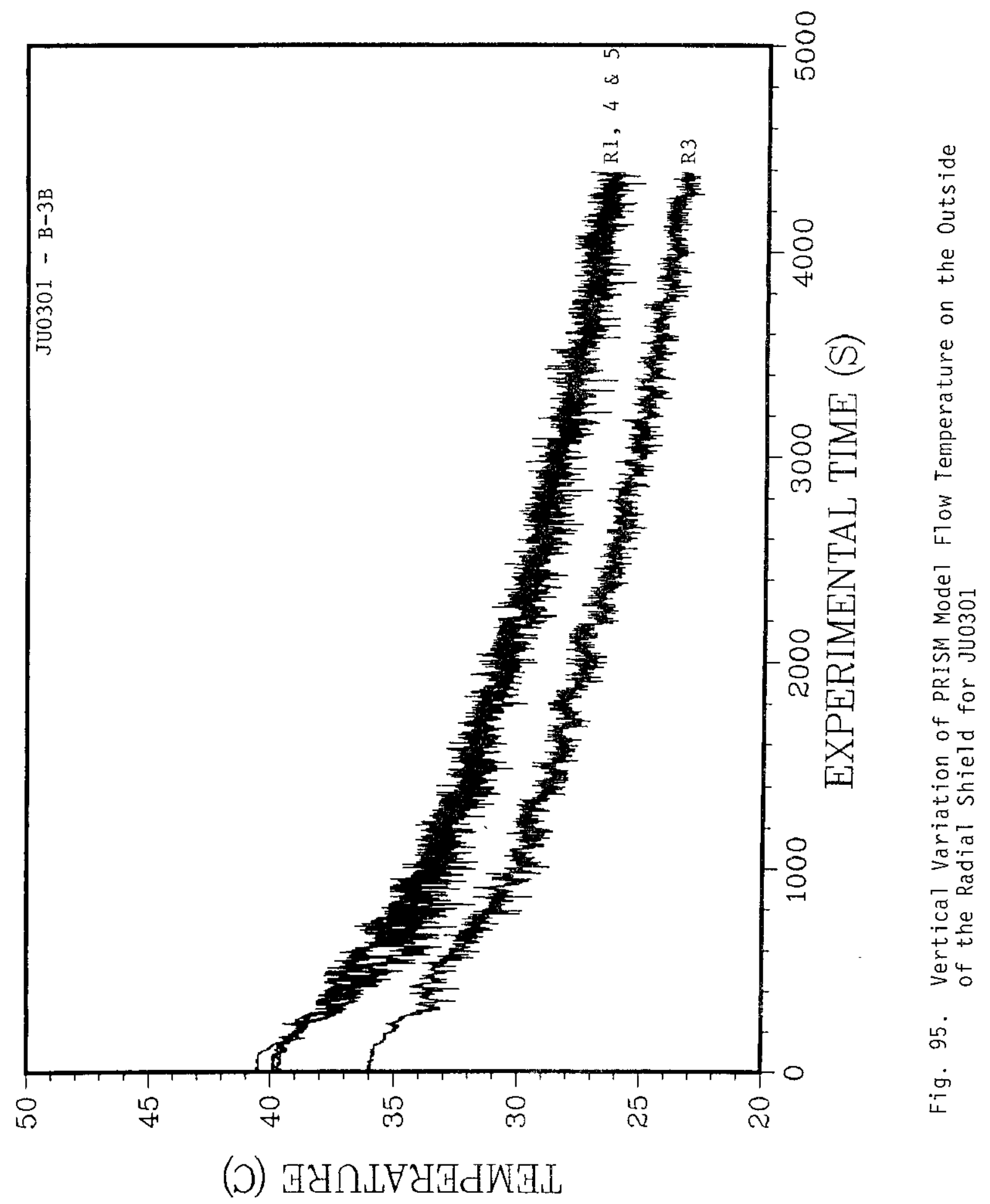




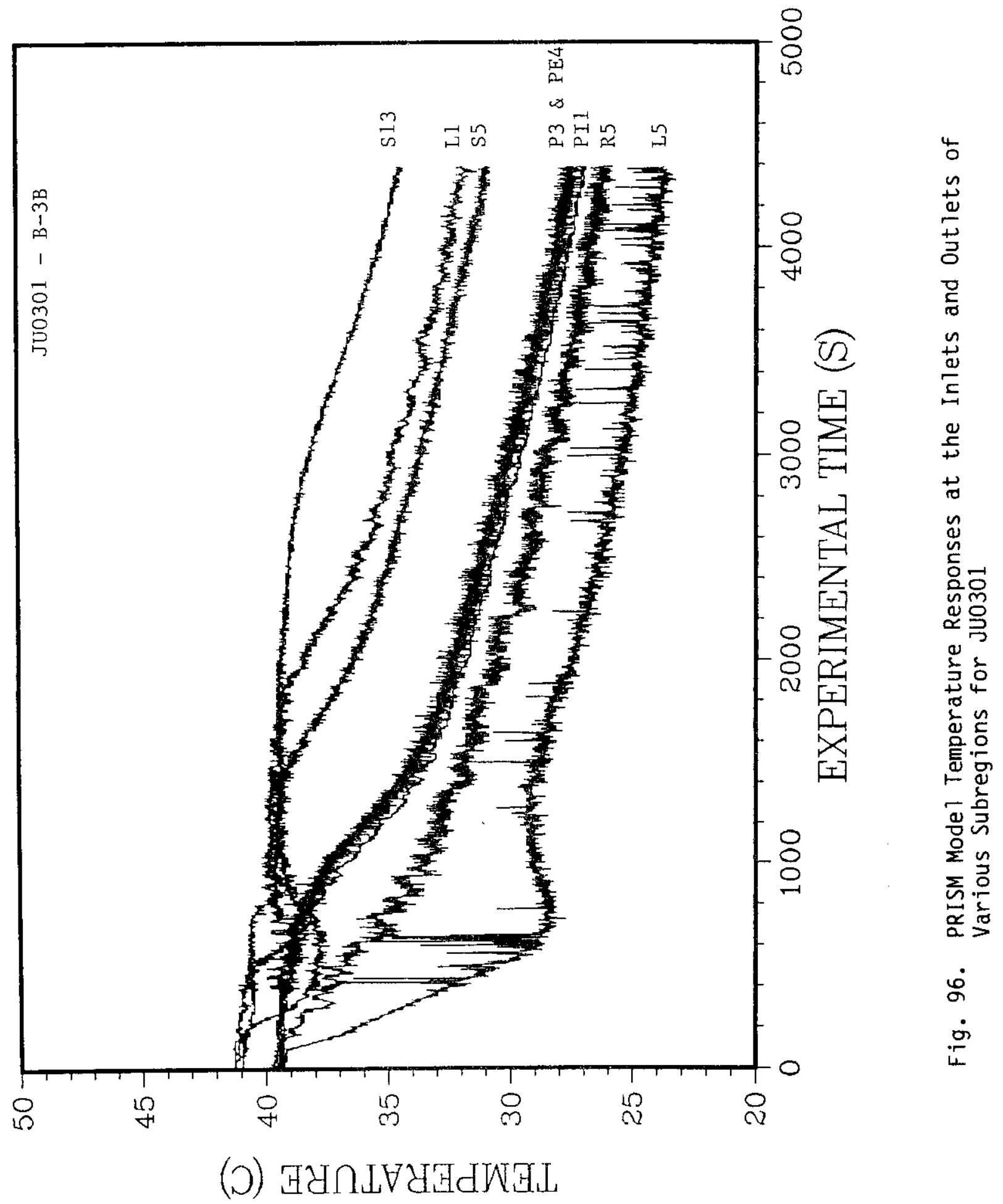


the prototype decreased to below $2.6 \%$ of full power as opposed to the decrease to $6 \%$ in the ANL mode1 (see Fig. 92). The maximum rate of change of temperature with a meaningful duration of longer than $120 \mathrm{~s}$ was observed in the response of thermocouple L5 shown in Fig. 96. The maximum rate of change of temperature occurred during the period between approximately 150 and $400 \mathrm{~s}$. Its value in model units is $0.019^{\circ} \mathrm{C} / \mathrm{s}$, which corresponds to $0.19^{\circ} \mathrm{C} / \mathrm{s}$ in the prototype. These values are very small and should present no structural problems.

Dye injected at the P4 pump exit, i.e., at PE4 (see Fig. 11), just after the transition to internal flow was swept into the exit of $P 4$, indicating the presence of reverse flow in the shut down pump. Dye injected into the transient at P4 pump exit at 6 min $24 \mathrm{~s}$ (and a 1 so at 8 min) drifted into the pump with a definite slow velocity and went out of view, an indication that the reverse flow was still present in the shut down pump. Dye was seen as a distinct filament. At 10.5 min (also $11.5 \mathrm{~min}$ ) into the transient, dye at the P4 pump exit flowed away from the exit and excess dye injected at inlet of P3, i.e., at PI3, went up the pump P4 inlet (at PI4), indicating the flow in the shut down pump has reversed again and was flowing in the normal direction. Near the end of the transient simulation (i.e., $1.25 \mathrm{~h}$ later), dye injected at the pump P4 exit, i.e., at PE4, remained sti11, while excess dye injected at the pump P3 inlet (at PI3) slowly drifted over to the pump P4 inlet (at PI4) and remained still in the inlet. This indicates that there was no flow in the shut down pump at this time. The presence of reverse flow in the shut down pump may cause design problems in that overall reactor coolability is affected and possible large temperature gradients which cause stress concerns as a result of the reverse flow of cold fluid from the lower plenum may exist.

Thermocouple PE4 was mounted on the exit of the shut down pump P4 (see Fig. 11). There was no observable difference in the thermal responses of PE4 for transient B-1A (Fig. 88) and for transient B-3B (Fig. 96). The observed reversed flow was not strong enough to influence the thermal behavior at the exit of the shut down pump. In fact, the response of thermocouples located in the various critical regions of the model were all very similar for the two transients. The main differences observed are the temperature difference in the initial stratified region of the upper plenum and the flowrate at that instant of transient $B-3 B$, which were both 0.75 of transient $B-1 A$, and the 
reversed flow observed in the shut down pump in B-3B. Reynolds and Richardson numbers (based on the core barrel ID) are very similar, i.e., 2615 and 313, respectively, for $B-1 A$, versus 2070 and 549 , respectively, for $B-3 B$, reflecting the previously mentioned differences.

In summary, the simulation of transient B-3B indicates the existence of some stratification in the upper plenum for a short period of time, no stratification in the lower plenum, very small rates of change of temperature of internal structures, reversed flow in the shut down pump for a short period of time, and a generally favorable coolability of the entire model after the scram. The absence of significant stratification in either plenum is important for the designers since the large temperature gradients over small distances associated with stratification are not present to cause thermal stress problems in regions in which these large gradients are unexpected. The reverse flow in the shut down pump can potentially cause thermal stress problems because of the potentially large temperature gradients which are not anticipated.

\subsubsection{Loss of Feedwater to All Modules Supply One Turbine, With Scram After Steam Generator Dryout (B-5B)}

Tests simulating the GE prototype transient B-5B, loss of feedwater to a11 modules supplying one turbine with scram after steam generator dryout, were conducted during Phase II of PRISM testing. Temperature and flowrate were decreased in a prescribed manner, details of which were specified by GE (see Section 3.2.1.4). This transient was repeated four times (tests JU0801, JU0901, JU0902, and JU1001), with a nominal core temperature difference of $12^{\circ} \mathrm{F}$ (see Table VII), to check reproducibility. Comparison of the data from these tests indicates that the results are reproducible; thus, only the results of $J u 0901$ with an actual core temperature difference of $12.2^{\circ} \mathrm{F}$ will be presented here. The temperature and flowrate, as a function of time, are shown in Fig. 97 for JU0901 during the initial portion of the transient when flow was provided by the MCTF 10op. At $610.3 \mathrm{~s}$, the immersion heater was turned on while the flow was still provided by the MCTF 1oop. At approximately $960 \mathrm{~s}$, the MCTF was completely isolated from the model, and the transient was continued with only the immersion heater and the four internal pumps providing the power and flow, respectively. In Fig. 98, the 


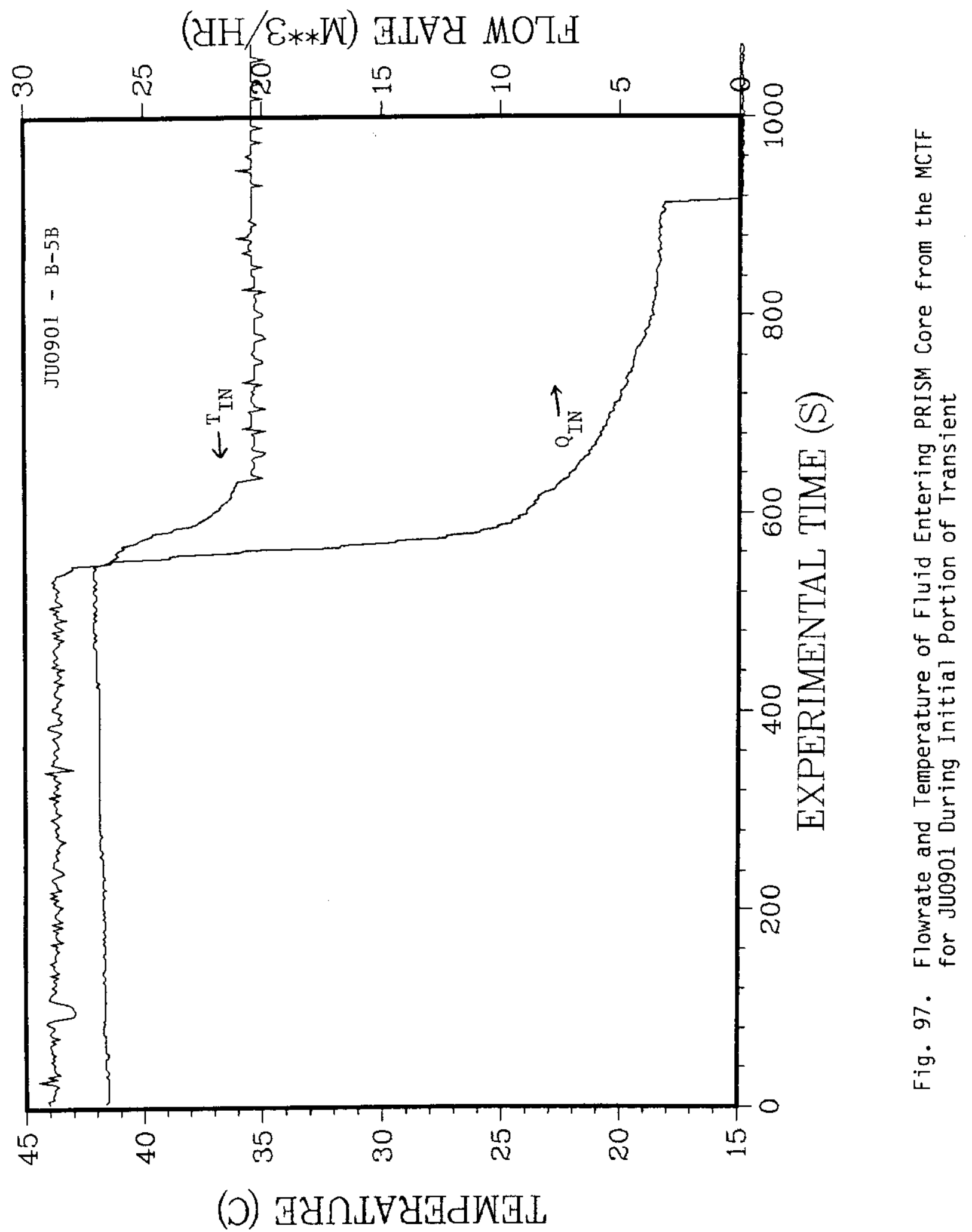




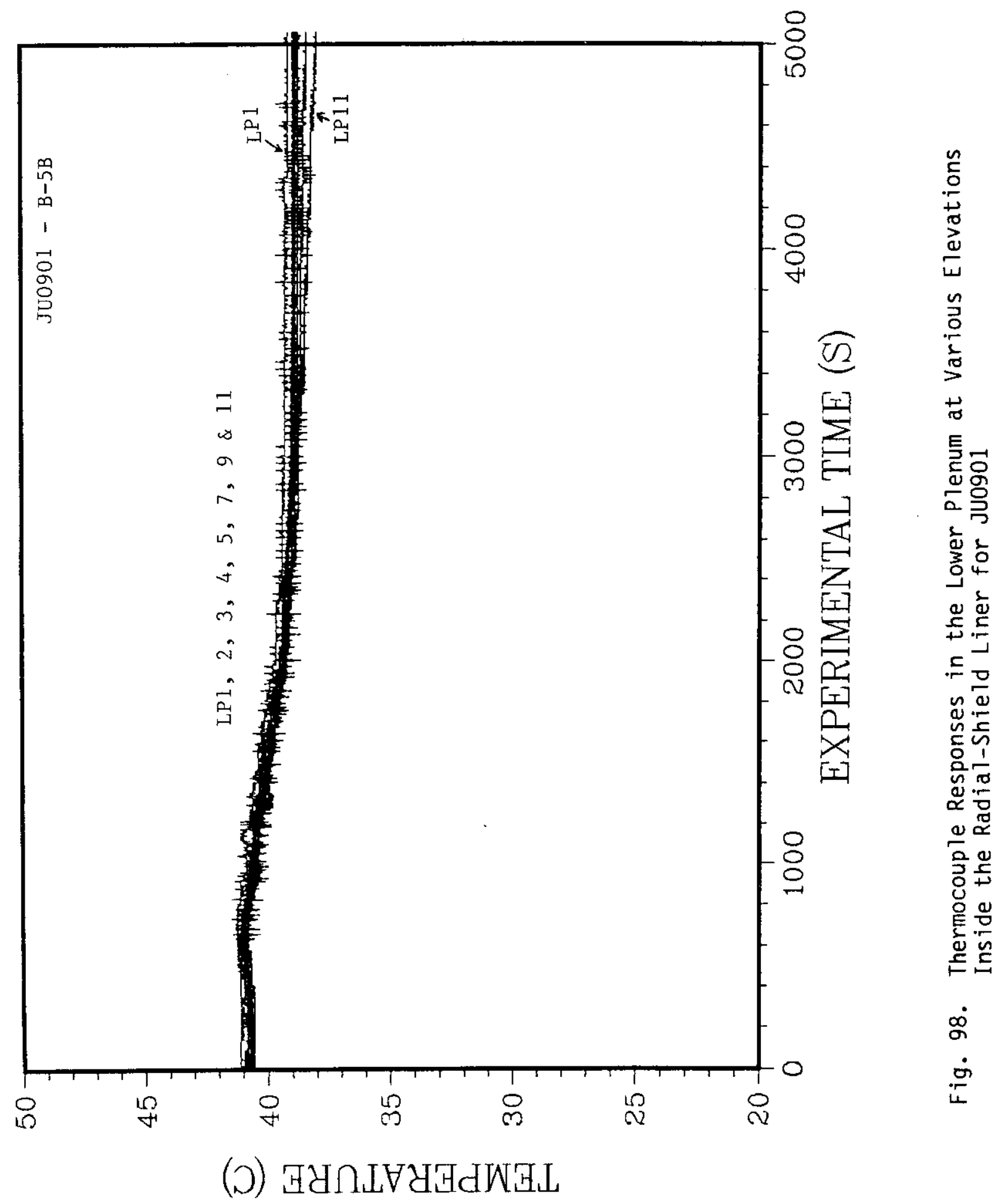


thermocouple responses of 8 of the 11 thermocouples mounted on a vertical sting on the cold plenum floor about 2 in. inside the radial-shield liner (see Fig. 12) are presented for Ju0901. For the most part, the thermocouple responses fall on top of one another with the response of LP1 being slightly higher than the rest, an indication of slight stratification. After $t=$ $2000 \mathrm{~s}$, the stratification grew stronger, but even at the end of the test there was only an approximately $1^{\circ} \mathrm{C}$ temperature difference between the top and bottom of the lower plenum.

The responses of four thermocouples located in the upper plenum on the center sting (see Fig. 12) are presented in Fig. 99 for Ju0901. The plenum started out at a uniform temperature, stratified between 700 and $1600 \mathrm{~s}$, mixed, and gradually the entire plenum increased slowly in temperature. During the entire test, the flowrate and power were gradually decreasing, and thus the relative strengths of the inertia (velocity field) and buoyancy forces (thermal field) were varying. This variation accounts for the complex phenomenon observed in Fig. 99. Thermocouple S5 is located at a lower elevation than $\$ 13$. The heat sink capacity, which was initially set at $0.83 \%$ of full power, remained practically uniform throughout the test at this extremely low value, as shown in Fig. 100, while the power supplied by the immersion heater decreased to $1.5 \%$ of full power. Thus, a gradual heating of the model, i.e., higher temperatures, was to be expected, and was observed after $t=1600 \mathrm{~s}$. The inlet and exit temperatures of the IHX heat sinks, together with flowrate, as a function of time, are shown in Fig. 101 for Ju0901. The initial stratification observed between 700 and $1600 \mathrm{~s}$ was analyzed in more detail. The model was isolated from the MCTF at $918 \mathrm{~s}$. At approximately $1000 \mathrm{~s}$ the flow was $6.9 \%$ of full flow (i.e., $8.8 \mathrm{gpm}$ ) and the temperature difference measured in the upper pienum was $3.02^{\circ} \mathrm{C}\left(66.9^{\circ} \mathrm{C}\right.$ in the prototype). On the basis of these values, the Reynolds and Richardson numbers (based on the the core barrel ID) were 2417 and 209, respectively, at that instant. Such a large Richardson number indicates that the thermal-buoyancy forces were very much larger than the inertia forces.

The response of thermocouple G3, located at midelevation in the overflow gap that surrounded the hot plenum (see Fig. 11), is shown in Fig. 102 for Ju0901. The respnse of thermocouple $G_{3}$ is linear and practically uniform, an indication of heat transfer by conduction (i.e., no convection). This is 


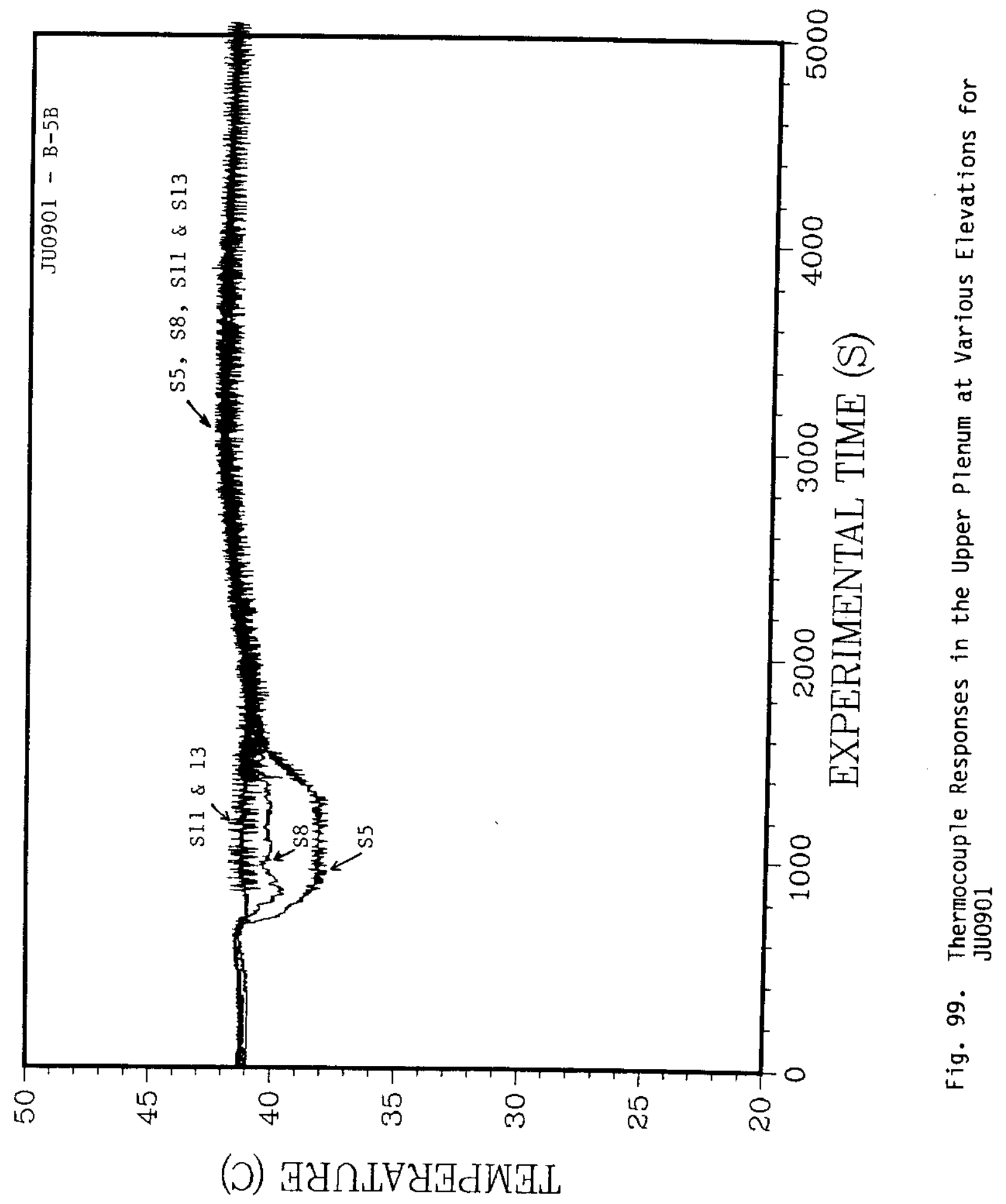




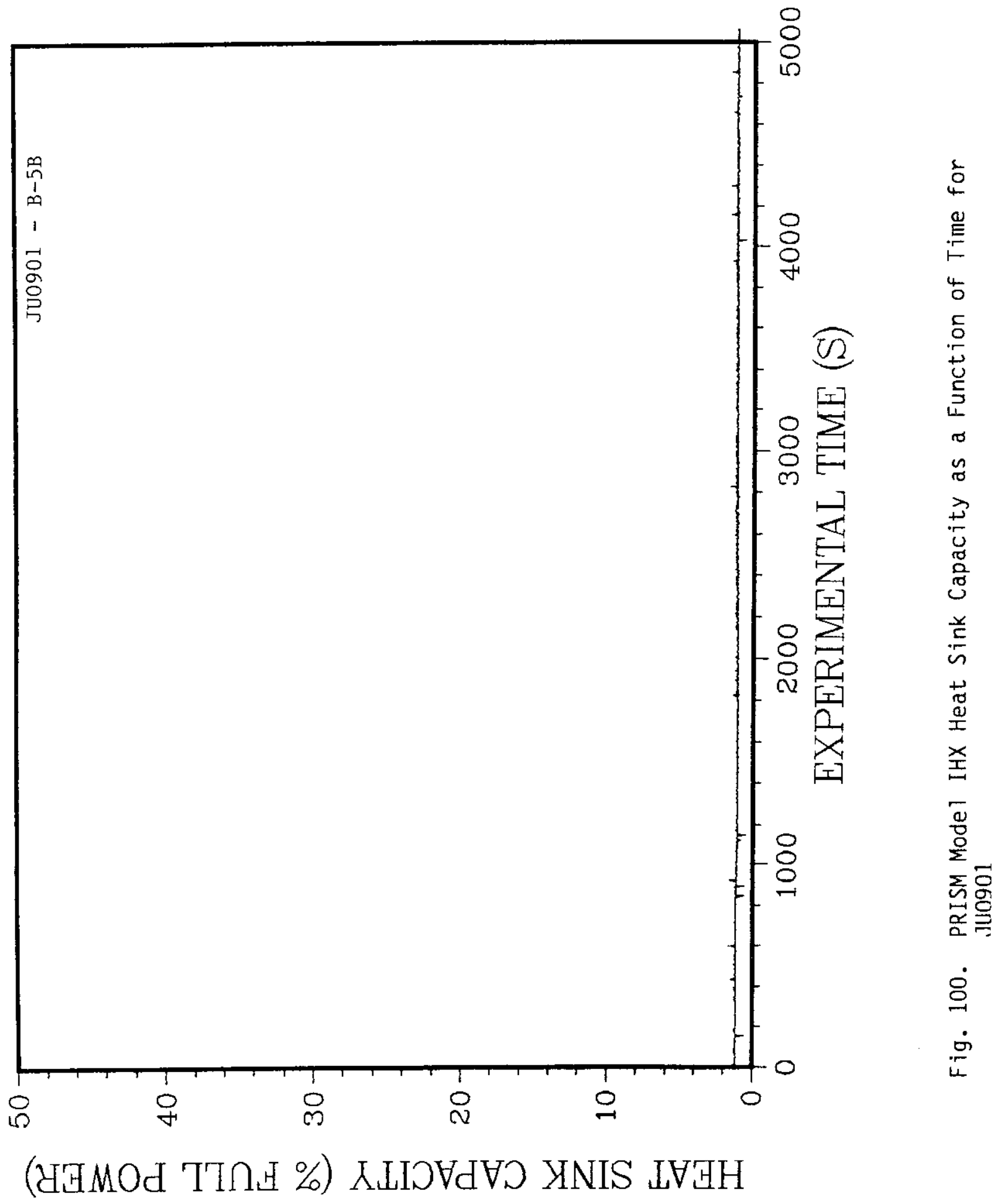




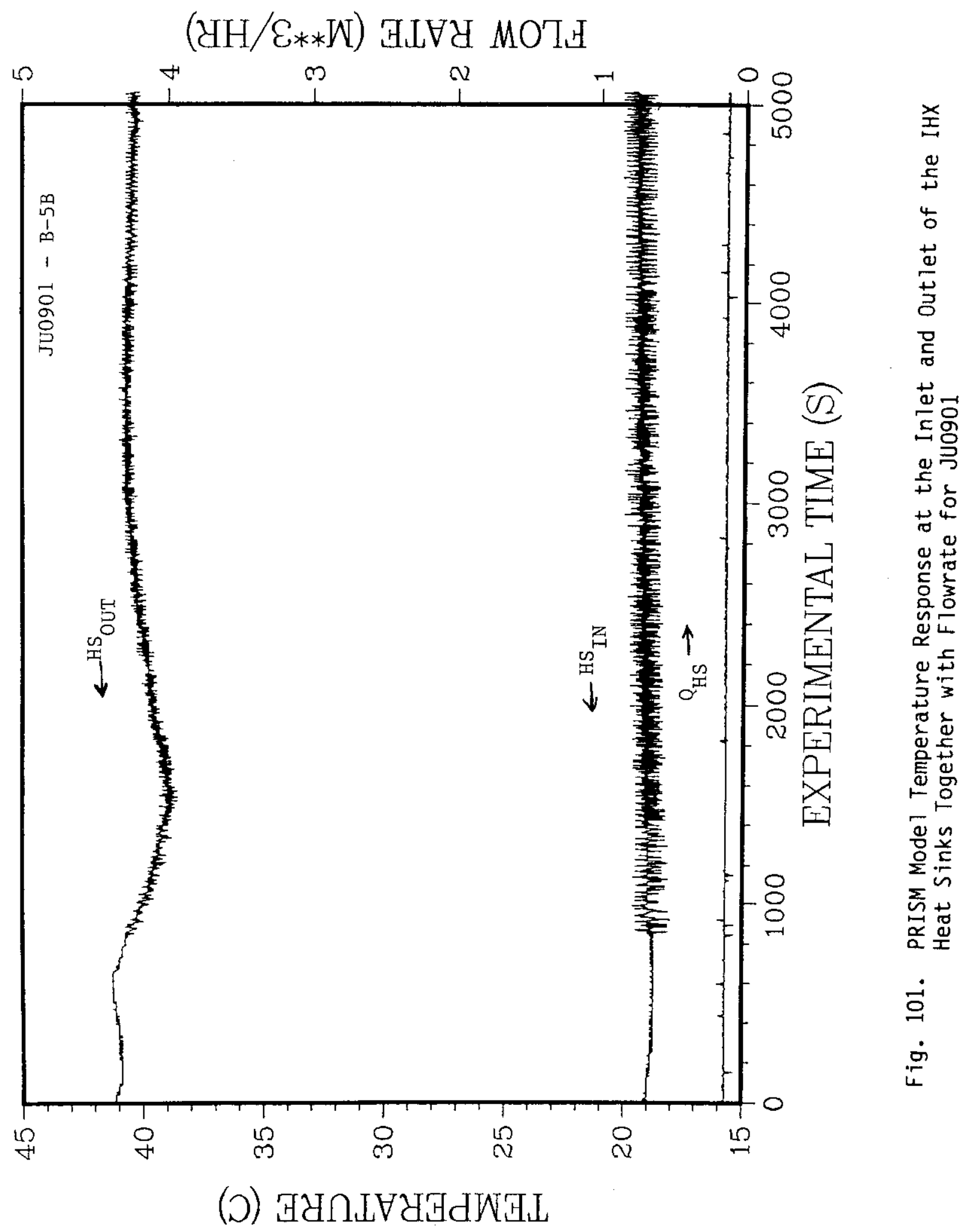




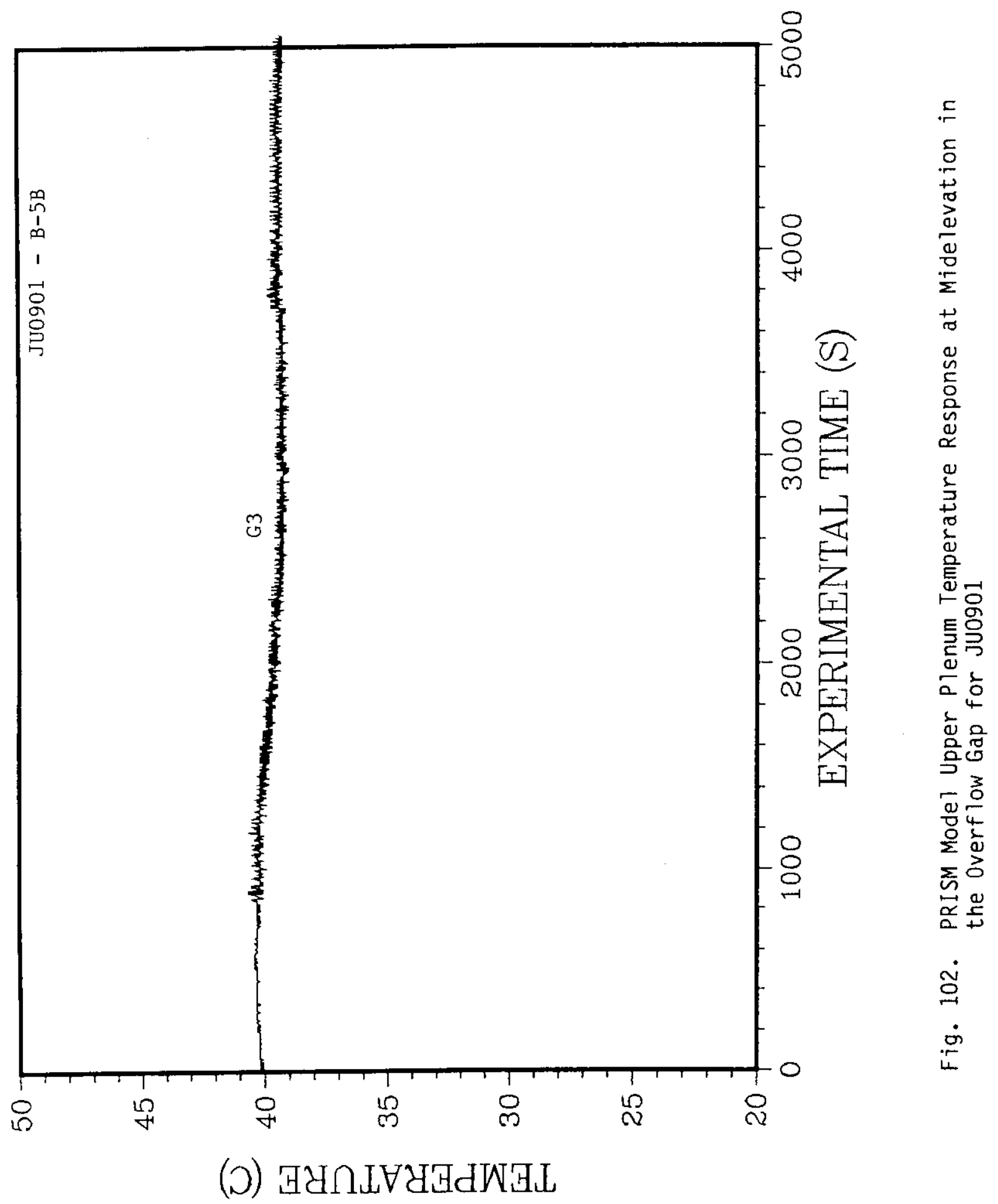


important to the designer who is estimating RVAC capacity and vesse 1 heat Tosses.

Responses for a vertical sting of thermocouples mounted on the outer surface of the radial-shield liner (see Fig. 11) are presented in Fig. 103 for Ju0901. R1 is at the highest elevation, whereas $R 5$ is at the lowest. The responses generally fall on top of one another if the initial thermocouple offsets are factored in, an indication that no stratification existed in the radial-shield region. Although slight stratification was exhibited in the responses of thermocouples R1 and R5 in the period between 1200 and $2600 \mathrm{~s}$, the degree of stratification present caused no loss of model coolability (see Fig. 104).

The responses of thermocouples located at the entrances and exits of critical subregions are presented in Fig. 104 for JU0901. The thermocouples are located in the upper plenum (S13), core exit (S5), IHX inlet (L1), IHX exit (L5), outside radial shield (R5), pump inlet (PI1), pump exit (PE4), and the core return pipe (P3) (see Figs. 11 and 12). General1y, after $t=2800 \mathrm{~s}$ the PRISM model exhibited (flowrate was less than $4.3 \%$ of full flow) two distinct temperature regions, the upper plenum and that part of the model that is donwstream of the IHX exits. Both regions remained at different, essentially uniform, constant temperatures, which indicates that a steady state condition had been reached. During this time, the temperature difference was $2.7^{\circ} \mathrm{C}$ and the flowrate was $5.5 \mathrm{gpm}$, which resulted in a calculated heat sink capacity of $1.43 \%$, which compares favorably to the $1.3 \%$ (see Fig. 100) calculated from the secondary flow conditions (the more accurate calculation). The maximum rate of change of temperature with a meaningful duration of longer than $120 \mathrm{~s}$ was observed in the response of thermocouple S5 (Fig. 104). The maximum rate of change of temperature occurred during the period between approximately 660 and $850 \mathrm{~s}$. Its value in model units is $0.015^{\circ} \mathrm{C} / \mathrm{s}$, which corresponds to $0.15^{\circ} \mathrm{C} / \mathrm{s}$ in the prototype. These values are very small and should present no structural problems.

Finally, dye injected at the right exit of the left IHX at 23 min into the transient flowed quickly to the lower plenum, started to turn radially inward under the radial-shield liner, and then spread circumferentially around the entire lower plenum. Thereafter, the dye moved very slowiy upward toward 


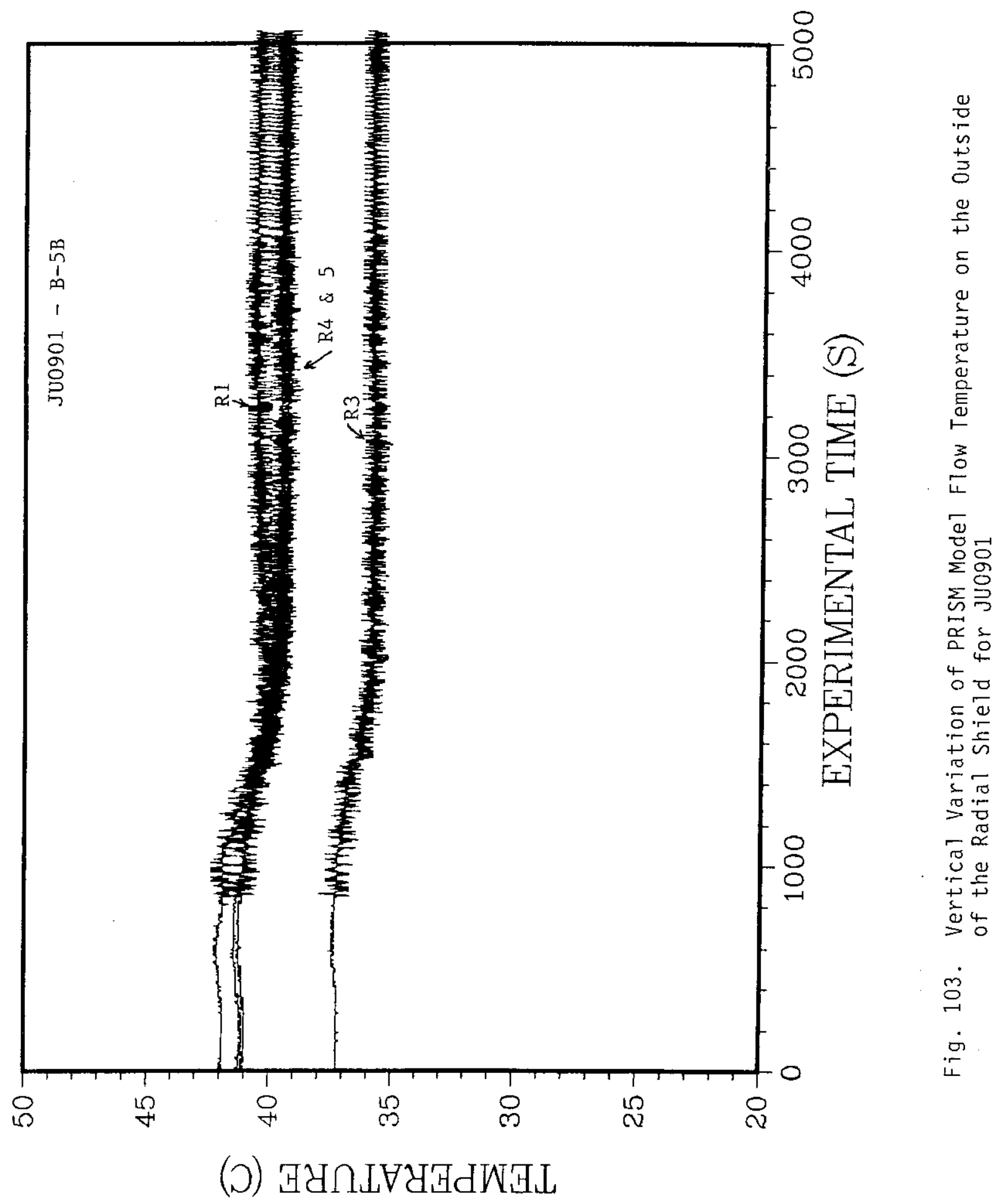




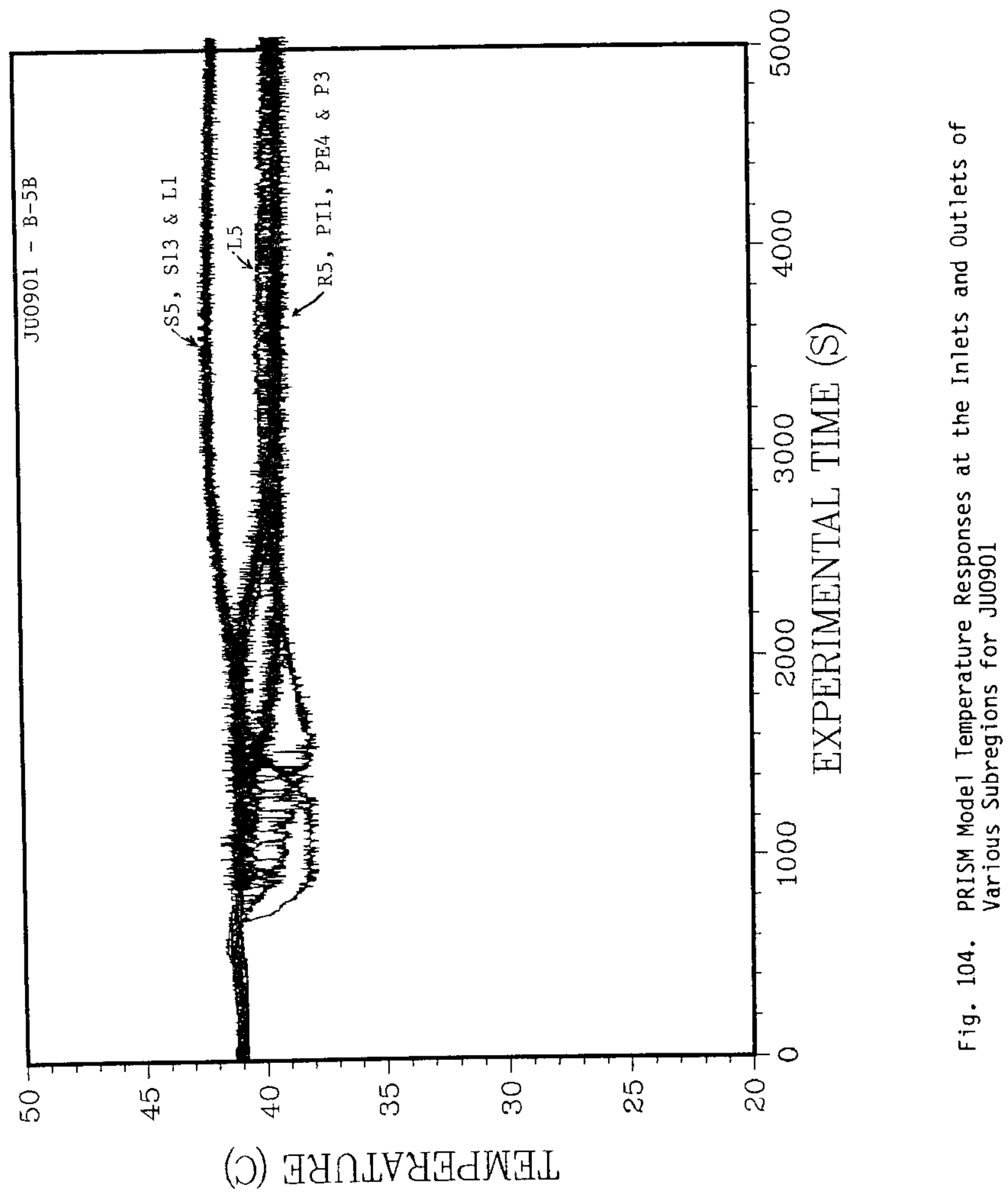


the pump inlets. The flowrate at that time was very sma11. At 46 min into the transient, the first trace of dye was visible in the P3 pump exit plenum and it started to flow down the core inlet tubes.

In summary, the simulation of transient B-5B indicates the existence of some stratification in the upper plenum for a short period of time, no stratification in the lower plenum, very small rates of change of temperature of internal structures, and a generally favorable coolability of the entire model after the scram. The absence of significant stratification in either plenum is important for the designers since the large temperature gradients over small distances associated with stratification are not present to cause thermal stress problems in regions in which these large gradients are unexpected.

\subsubsection{Loss of Feedwater to All Modules Supplying One Turbine, With Thirty- Second-Delayed Scram (B-5B)}

Tests simulating the GE prototype transient B-5B, loss of feedwater to al1 modules supplying one turbine, with 30-s-delayed scram, were conducted in Phase II of PRISM testing. Temperature and flowrate were decreased in a prescribed manner, details of which were specified by GE (see Section 3.7.5). This transient was repeated three times (tests MY2801, MY2901, and JU0101), with a nominal core temperature difference of $12^{\circ} \mathrm{F}$ (see Table VII) to check reproducibility. Comparison of the data from these tests indicates that the results are reproducible; thus, only the results of MY2801 with an actual core temperature difference of $12.2^{\circ} \mathrm{F}$ will be presented here. The temperature and flowrate as a function of time are shown in Fig. 105 for MY2801 during the initial portion of the transient when the flow was provided by the MCTF loop. At $144 \mathrm{~s}$, the immersion heater was turned on while the flow was still provided by the MCTF 1oop. At approximately $460 \mathrm{~s}$, the MCTF was completely isolated from the model, and the transient was continued with only the immersion heater and the four internal pumps providing the power and flow, respectively. In Fig. 106, the responses of 8 of the 11 thermocouples mounted on a vertical sting on the cold plenum floor about 2 in. inside the radialshield liner (see Fig. 12) are presented for MY2801. For the most part, the thermocouple responses fall on top of one another, indicating that no stratification is present in the lower plenum. 


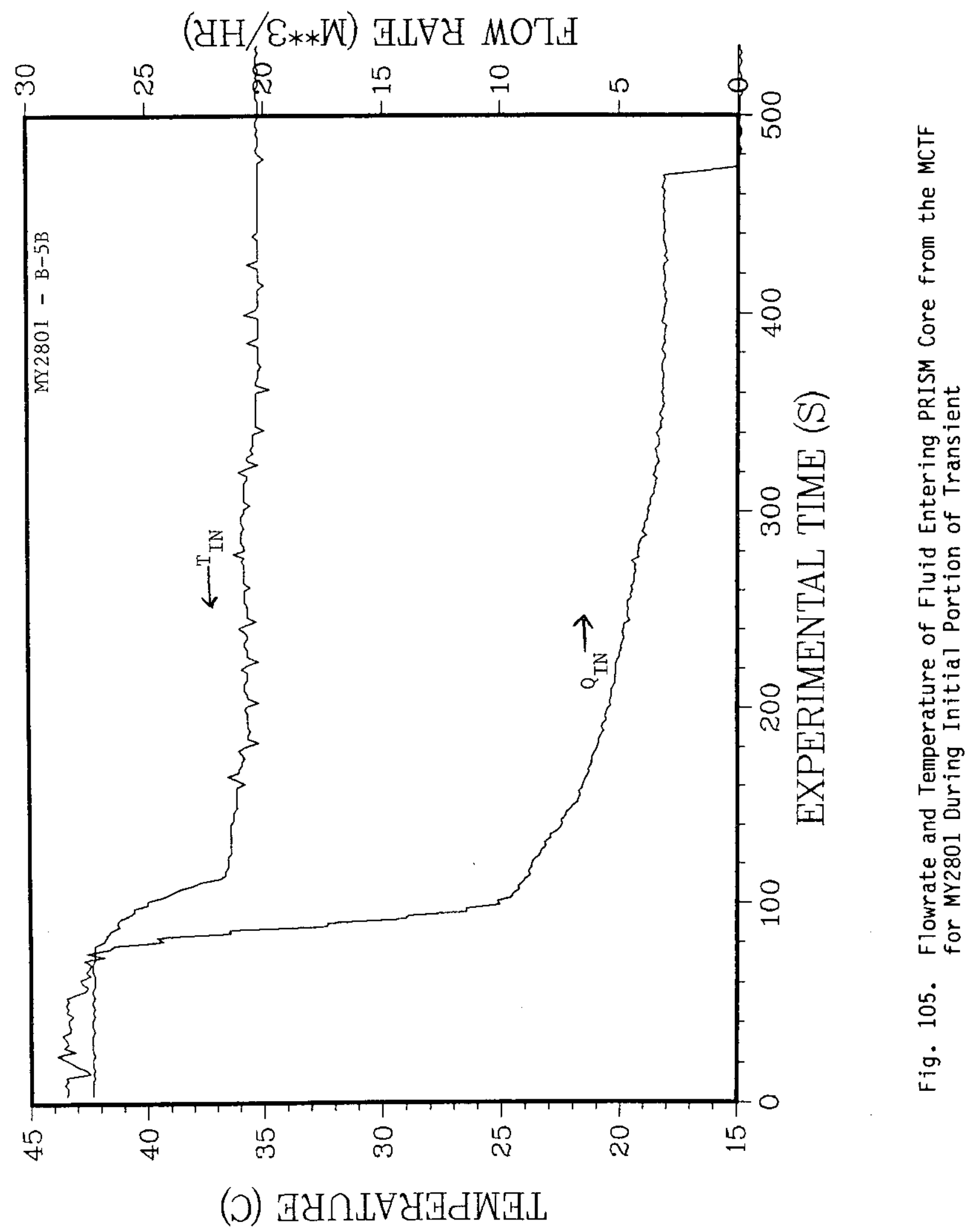




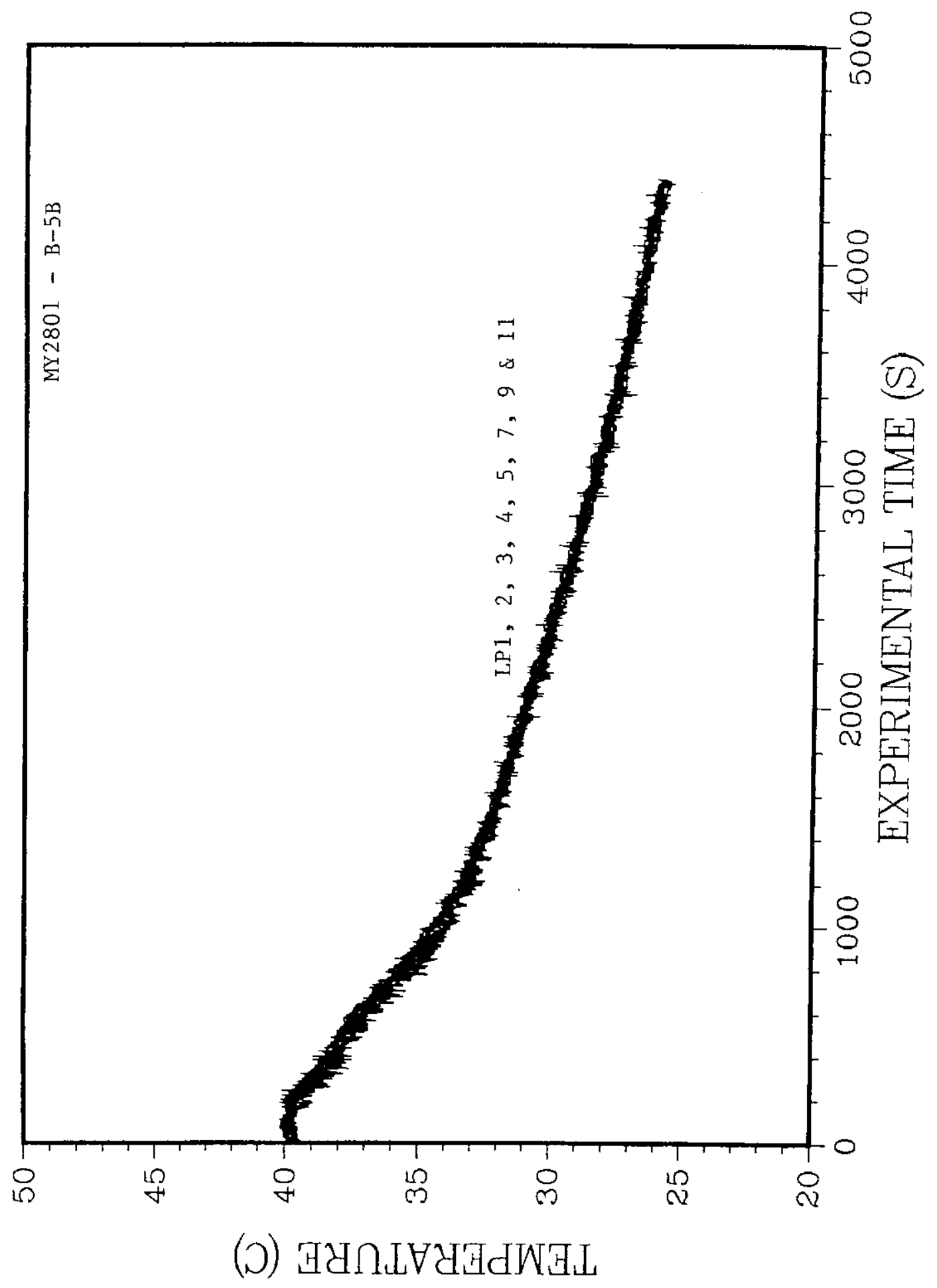

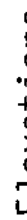


The responses of four thermocouples located in the upper plenum on the center sting (see Fig. 12) are presented in Fig. 107 for MY2801. The plenum started out at a uniform temperature, stratified between $t=200$ and $900 \mathrm{~s}$, mixed to a slightly lower uniform temperature, and restratified after $t=$ $1400 \mathrm{~s}$. During the entire test the flowrate and power were gradually decreasing, and thus the relative strengths of the inertia (velocity field) and buoyancy forces (thermal field) were varying. This variation accounted for the complex phenomenon observed in Fig. 107. Thermocouple S5 is located at a lower elevation than S13. The heat sink capacity, which was initially set at $10.8 \%$ of ful1 power, varied during the test, as shown in Fig. 108 , to a low of $6 \%$, while the power supplied by the immersion heater decreased to $1.5 \%$ of full power. Thus, a gradual cooling of the model, i.e., lower temperatures, was to be expected, and was observed after $t=1400 \mathrm{~s}$. The heat sink capacity in the prototype also did not remain constant, but decreased to below 2.6\% during the transient. Thus, the cooling observed in Fig. 107 after $t=1400 \mathrm{~s}$ is also exaggerated, i.e., temperatures were lower than would be expected with a smaller, exactly simulated, model heat sink capacity. The inlet and exit temperatures of the IHX heat sinks, together with flowrate, are shown in Fig. 109 as a function of time for MY2801. The initial stratification observed between 200 and $900 \mathrm{~s}$ was analyzed in detail since it occurred during the time that the heat sink most closely simulated that of the prototype. The model was isolated from the MCTF at $472 \mathrm{~s}$. At approximately $400 \mathrm{~s}$ the flow was $3.09 \mathrm{~m}^{3} / \mathrm{hr}$ and the temperature difference measured in the upper plenum was $3.04^{\circ} \mathrm{C}\left(67.3^{\circ} \mathrm{C}\right.$ in the prototype). On the basis of these values, the Reynolds and Richardson numbers (based on the core barrel ID) were 3759 and 87 , respectively, at that instant. Such a large Richardson number indicates that the thermal-buoyancy forces were very much larger than the inertia forces.

The response of thermocouple G3, located at midelevation in the overflow gap surrounding the hot plenum (see Fig. 11), is shown in Fig. 110 for MY2801. The response of thermocouple $G 3$ is linear, an indication of heat transfer by conduction (i.e., no convection). This is important to the designer who is estimating RVAC capacity and vessel heat losses.

Responses for a vertical string of thermocouples mounted on the outer surface of the radial-shield liner (see Fig. 11) are presented in Fig. 111 for 


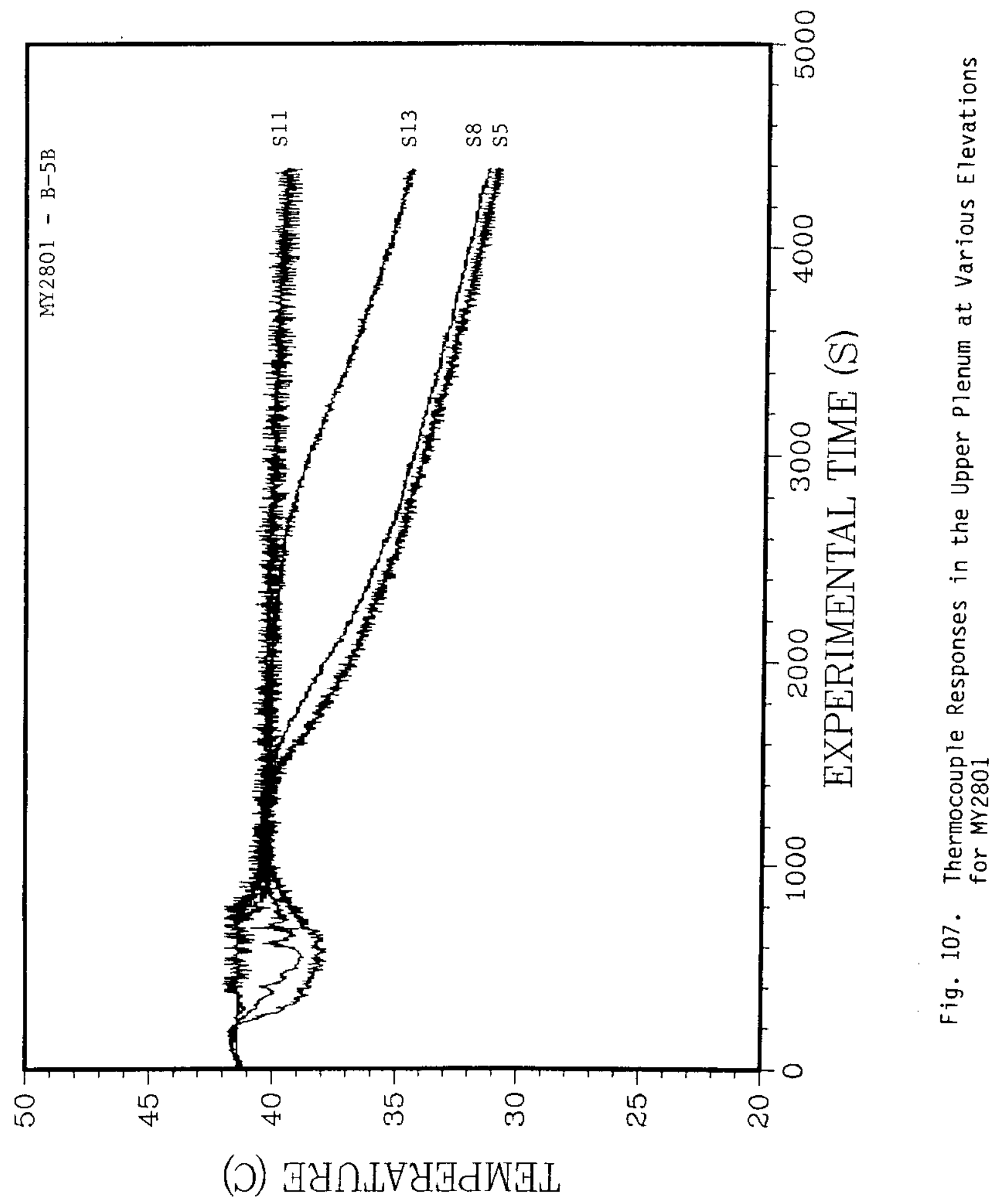




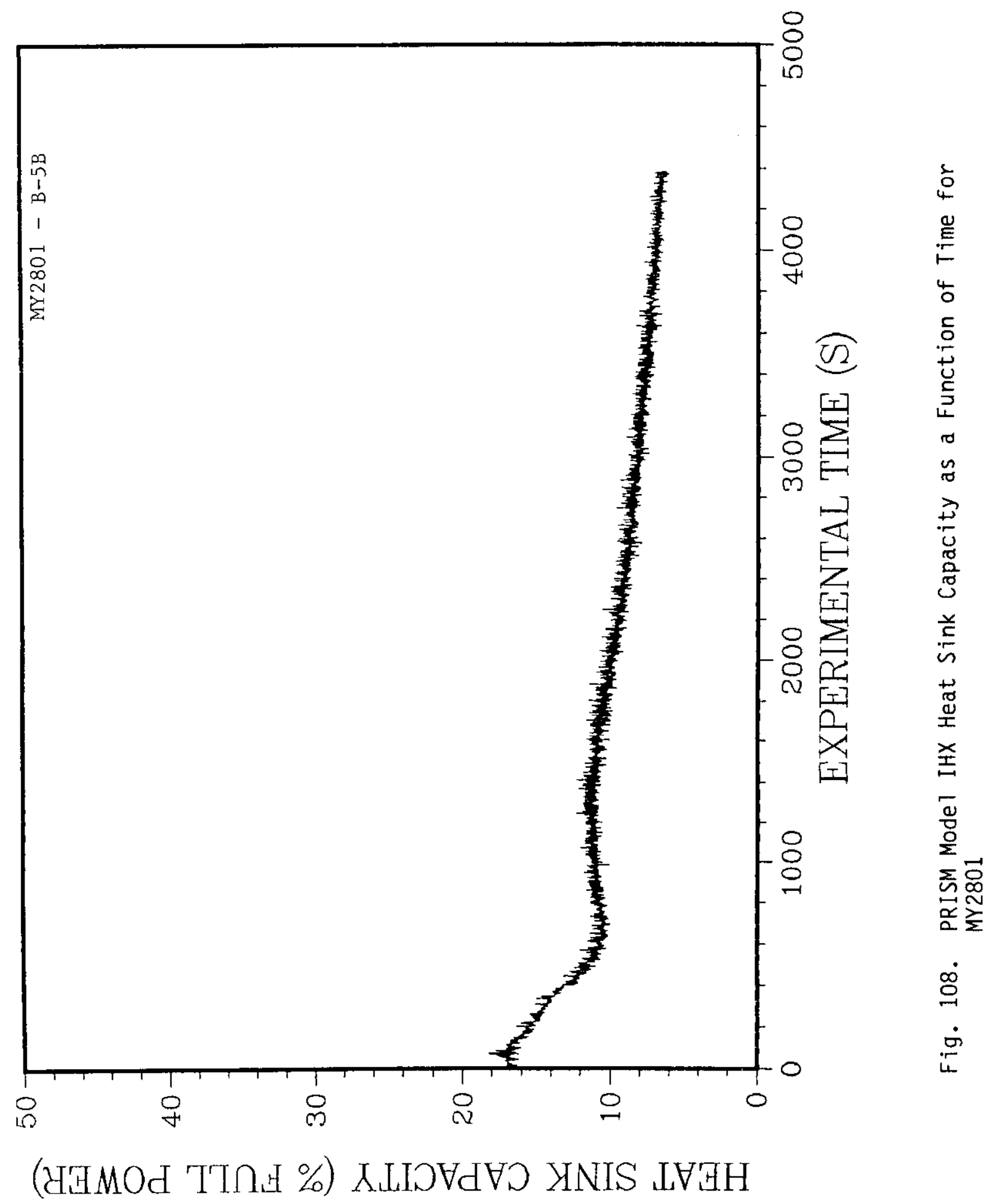




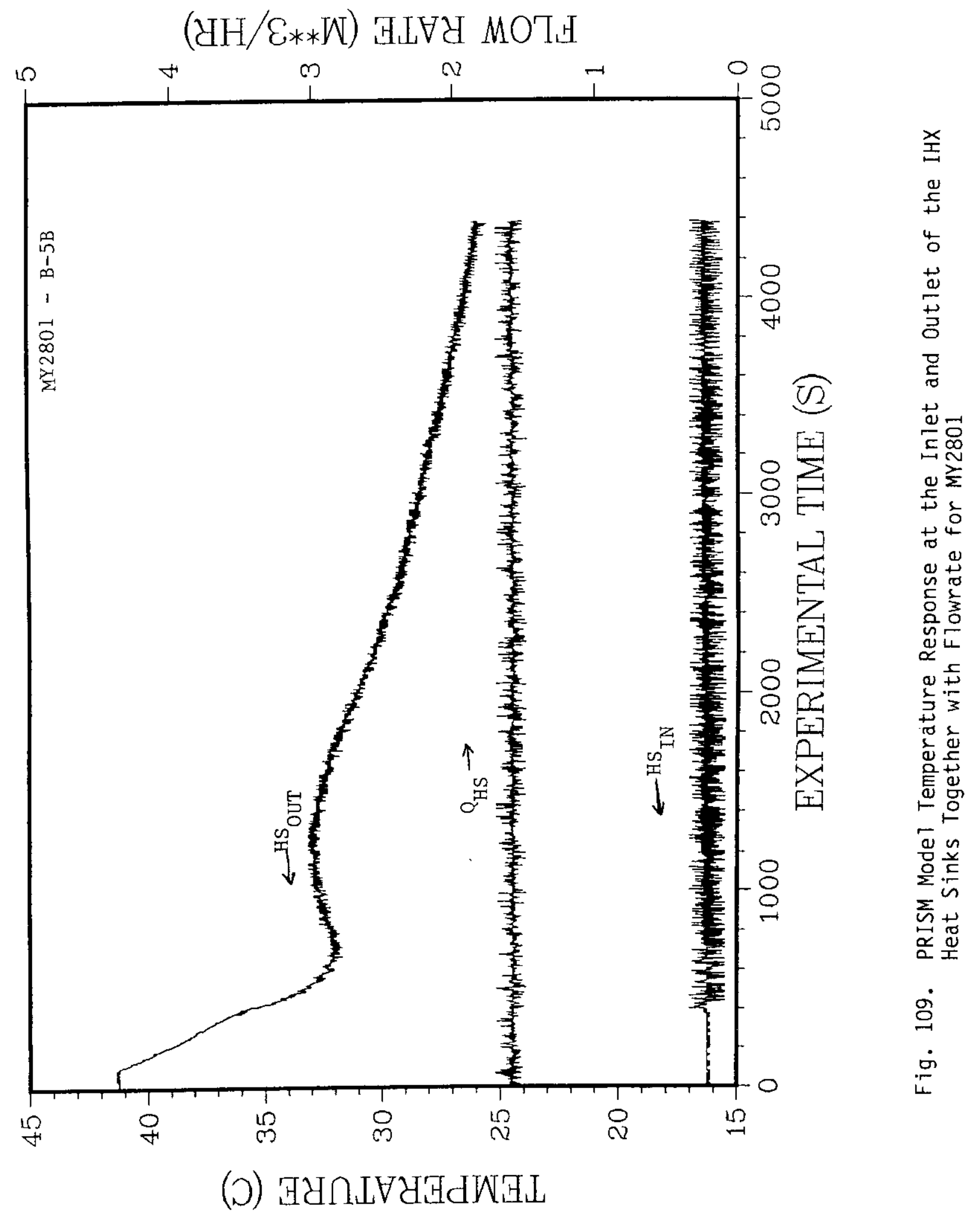




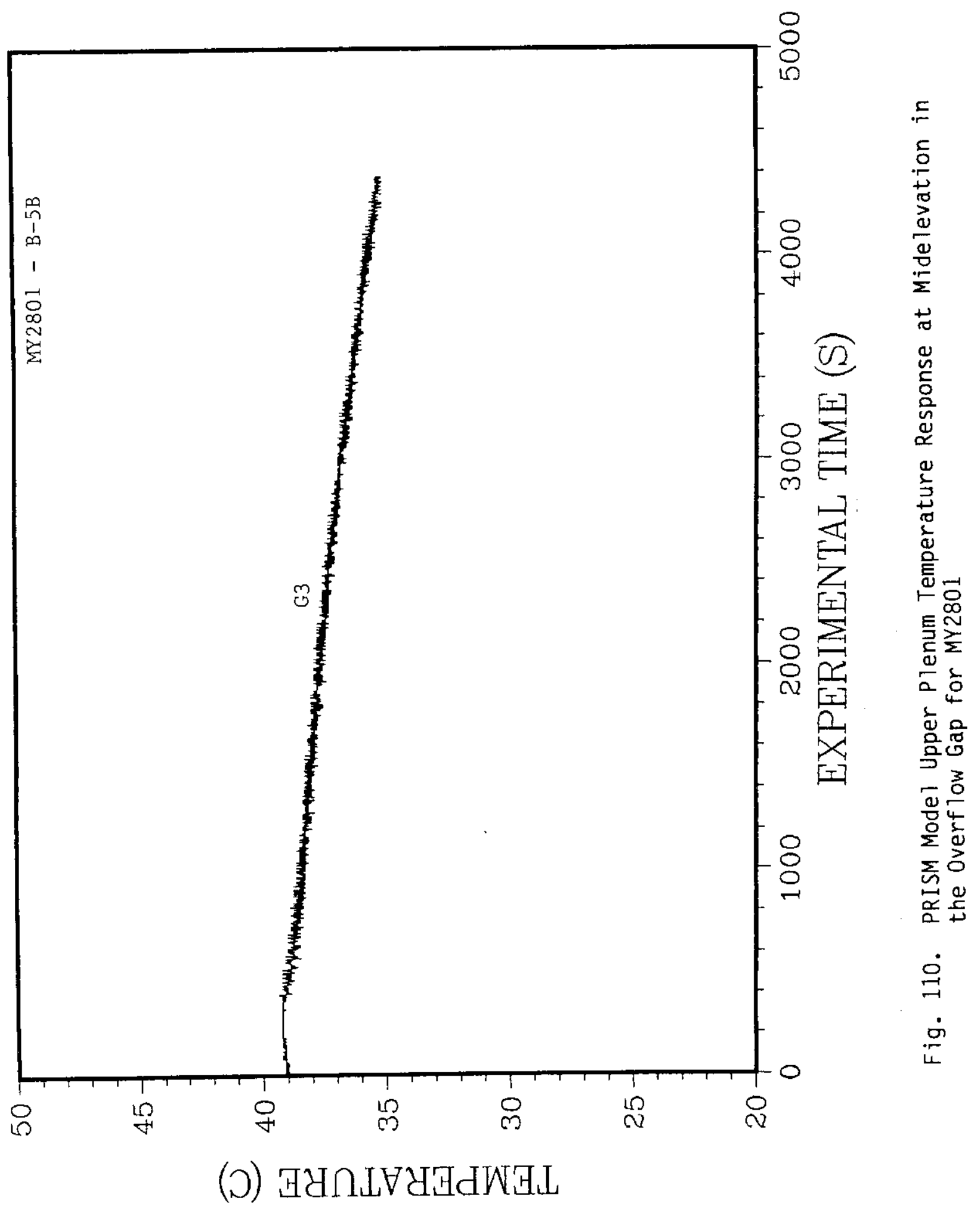




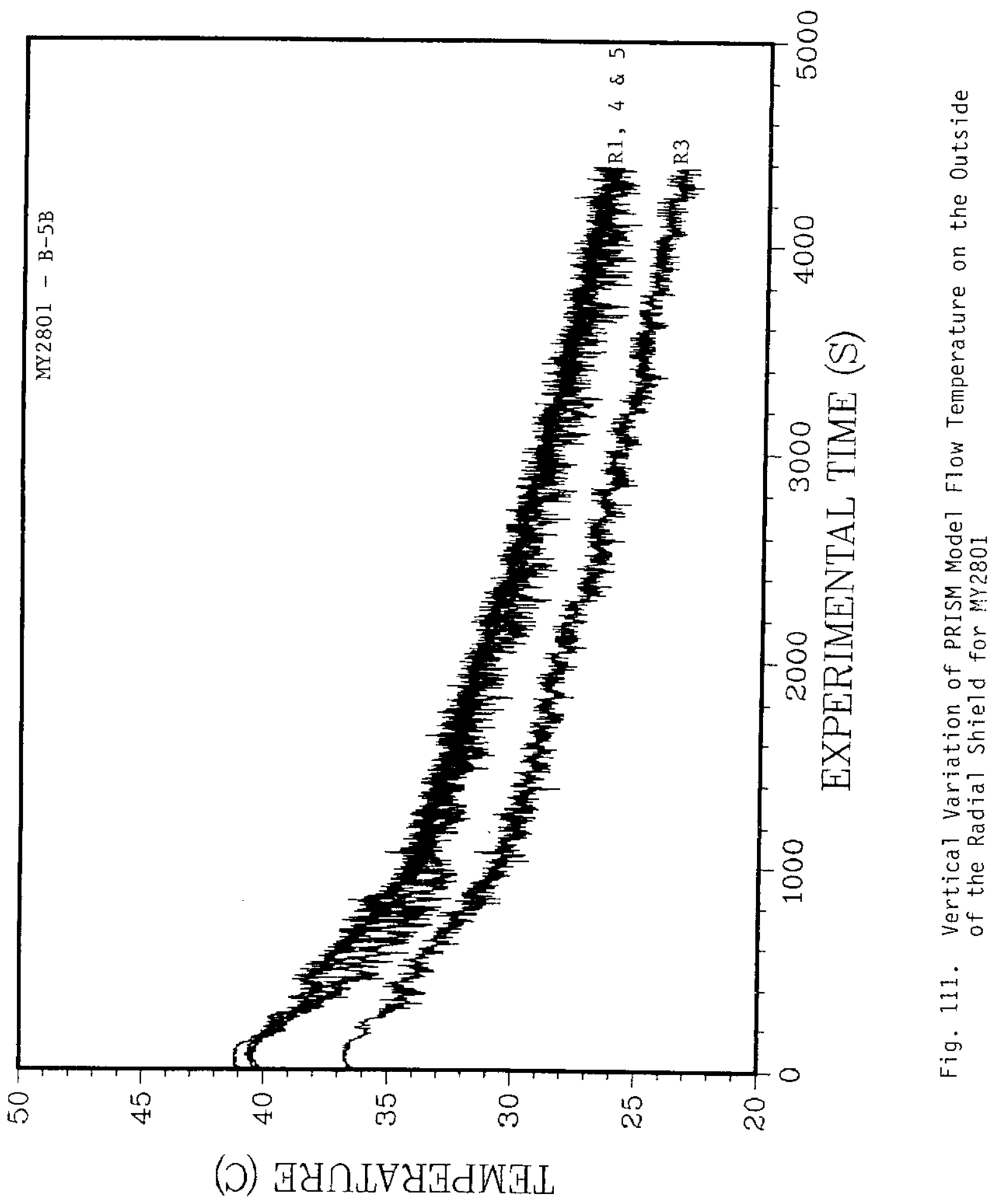


MY2801. R1 is at the highest elevation, whereas R5 is at the lowest. The responses generally fall on top of one another if the initial thermocouple offsets are factored in, an indication that no stratification exists in the radial-shield region. Although slight stratification is exhibited in the responses of thermocouples $R 1$ and $R 5$ in the period between 400 and $1000 \mathrm{~s}$, the degree of stratification present causes no loss of coolability to that region since the fluid exiting the IHX's is colder (thus more dense); thus, the buoyancy forces acted in the same direction as the inertia forces.

The responses of thermocouples located at the entrances and exits of critical subregions are presented in Fig. 112 for MY2801. The thermocouples are located in the upper plenum (S13), core exit (S5), IHX inlet (L1), IHX exit (L5), outside radial shield (R5), pump inlet (PI1), pump exit (PE4), and the core return pipe (P3) (see Figs. 11 and 12). Generally, after $t=1800 \mathrm{~s}$ (flowrate was less than $6 \%$ of full flow) the PRISM model was separated into two distinct temperature zones resulting from the $I H X$ heat rejection, each region being stratified. The cooling was due to the greater heat sink capacity of the IHXs compared to the power provided by the immersion heater, i.e., $10.8 \%$ versus $1.5 \%$ of full power. Again, this behavior is exaggerated since the heat sink capacity in the prototype decreases to below $2.6 \%$ of full power as opposed to a decrease of $6 \%$ in the ANL model (see Fig. 108). The maximum rate of change of temperature with a meaningful duration of longer than $120 \mathrm{~s}$ was observed in the response of thermocouple L5 (Figure 112). The maximum rate of change of temperature occurred during the period between approximately 90 and $350 \mathrm{~s}$. Its value in model units was $0.022^{\circ} \mathrm{C} / \mathrm{s}$, which corresponds to $0.22^{\circ} \mathrm{C} / \mathrm{s}$ in the prototype. These values are very small and should cause no structural problems.

In summary, the simulation of transient B-5B indicates the existence of some stratification in the upper plenum for a short period of time, no stratification in the lower plenum, very small rates of change of temperature of internal structures and a generally favorable coolability of the entire model after the scram. Essentially, the results indicate that this transient is very similar to transient B-1A discussed in Section 4.2.1.2 with a time delay. The absence of significant stratification in either plenum is important for the designers since the large temperature gradients over small 


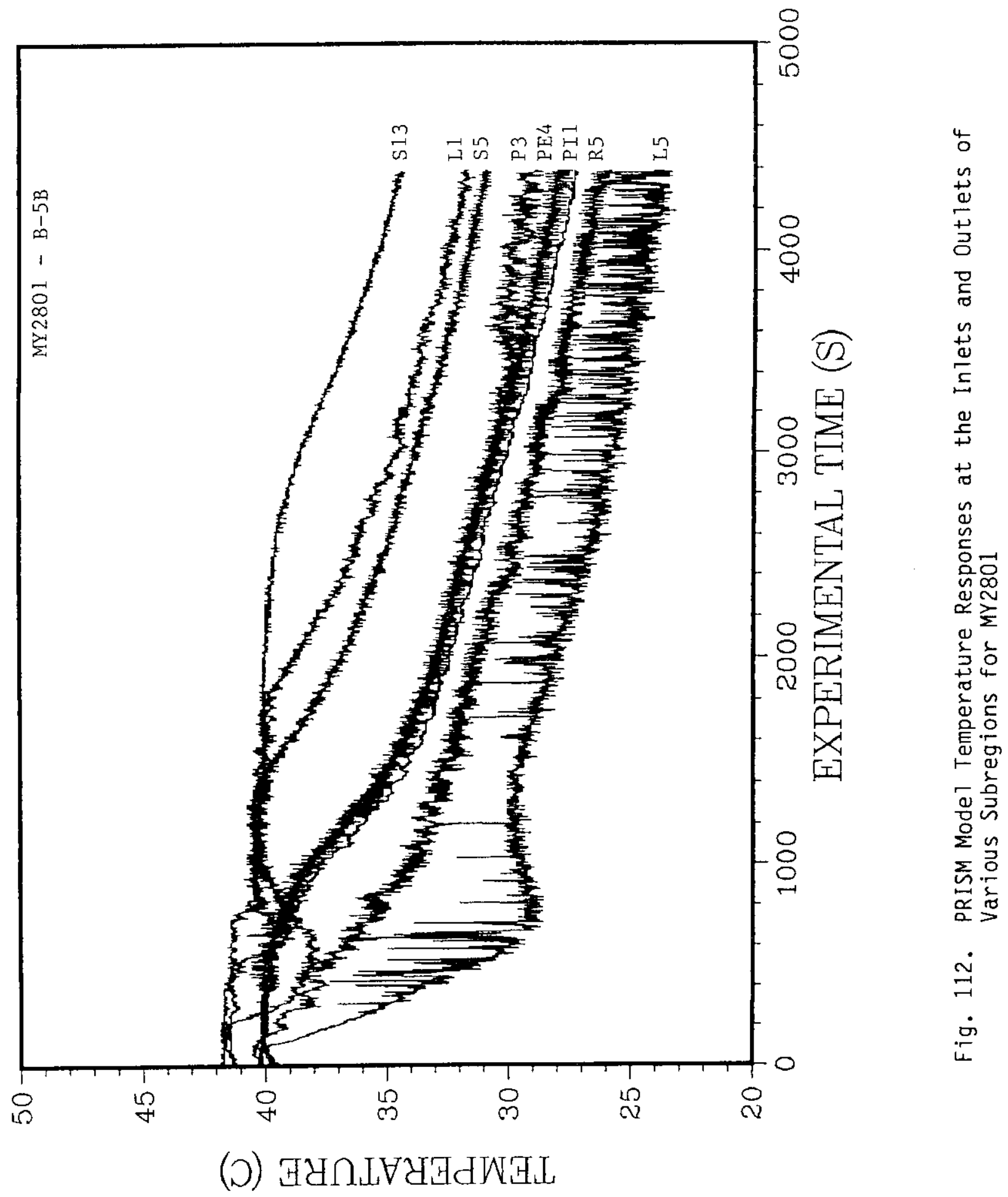


distances associated with stratification are not present to cause thermal stress problems in regions in which these large gradients are unexpected.

\subsection{SUMMARY AND CONCLUSION}

Both Phase I and Phase II testing of a multiphase program aimed at establishing the reliability and inherent safety of the PRISM advanced reactor design have been completed. An ANL/PRISM model, constructed of clear plastic for flow visualization, represents the most complete thermal-hydraulic water model built to date for a DOE LMR program. Phase I testing facilitated the shakedown process and the development of the many complex control features and subsystems which have been incorporated in the PRISM model. These tests also highlighted specific thermal-hydraulic phenomena of potential interest to designers. A series of 18 tests in Phase I have been conducted in the following general categories: isothermal flow distribution, hot plenum free surface behavior, constant-flow thermal transients, natural-convection flows, and mixed forced-natural-convection flows, together with, at the request of GE, the prototypic 100 to $25 \%$ power reduction transient A-4. During the period after Phase I testing, recent PRISM design changes were evaluated for their relative importance to the ANL model and were included when the change was thought to have a possible impact on the thermal-hydraulic tests. The following changes were incorporated in the ANL PRISM thermal-hydraulic model for Phase II tests: increased simulated core resistance, an upper internal structure (UIS), heat sinks in the two IHXs, and modifications of the inlets to the IHXs. Twenty tests were conducted during the PRISM Phase II testing. These represented five prototypic transients chosen by GE because their severity and frequency of occurrence could pose potential design concerns such as stress problems caused by rapid temperature changes, inadequate heat. rejection due to inadequate flow, etc.

The major results from these two program phases are as follows:

\subsection{Phase I}

- These tests confirmed that the new capabilities that were incorporated into the facility and required for Phase II simulations of prototypic transients are fully operational. 
- At flows yielding $20 \%$ of prototype Froude number, the free surface in the upper plenum was extremely quiescent; thus cover gas entrainment was not a problem. This is not conclusive for the prototype since $100 \%$ of prototype Froude number was unattainable in the present tests.

- Under isothermal conditions at about $10 \%$ of simulated prototype flow, the annular flow downstream of the IHX exits turned in radially just below the radial-shield bottom and then proceeded up through the radial shield, leaving a stagnant recirculation region in the lower plenum. For higher flowrates, there was no stagnant recirculation region in the lower plenum.

- In all the constant flow thermal upramp tests $(5,15,30$, and $60 \%$ of simulated full flow with a $16.7^{\circ} \mathrm{C}$ step change in temperature) a cold, thermally stratified stagnant region initially formed below the radial shield in the lower plenum, as in the isothermal tests. However, unlike the isothermal tests, the cold stagnant region also formed at flowrates greater than $10 \%$ of simulated prototype flow because of the strong thermal-buoyancy forces which oppose the downward-acting inertia forces of the fluid. This cold stagnant region is a potential thermal stress concern to the designers because of the large temperature gradients in a region with many welds (i.e., core inlet pipes etc.). There is also the potential for sodium freeze up in this region depending on the level of RVACS heat rejection.

- All four of the constant-flow thermal-upramp tests exhibited stratification in the lower plenum. Richardson numbers (based on the radial-gap diameter outside the radial shield) ranged from 34.6 to 4914. Thus, a threshold value of Richardson number below which stratification does not exist in the lower plenum could not be determined from these tests. Additional testing is needed to determine the Richardson number below which stratification would not occur.

- The persistence time of the cold stagnant region varies inversely with flowrate, i.e., the higher the flowrate, the shorter the persistence time. At higher flowrates the stagnant region is washed 
away owing to turbulent mixing (i.e., Reynolds numbers of these tests varied between 634.9 and 7258.2).

- Flow caused by natural-convection currents was found in the overflow gap during the Phase I constant-flow thermal-upramp tests. This is important to the designer who is estimating RVAC capacity and vessel heat losses, especially if it was previously assumed that heat transfer was only by conduction.

- In the natural-convection tests, the lower plenum stratified, whereas the upper plenum did not stratify. The Richardson numbers that were based on the radial gap diameter ranged between 1276 and 5142 for these tests. These large Richardson numbers indicate that the buoyancy forces are very much larger than the inertia forces in the lower plenum. The Reynolds numbers (based on the radial gap diameter) ranged between 203 and 314 for these tests. These small values indicate that the flows in the lower plenum are laminar.

- In the mixed natural-forced-convection tests, both the upper and lower plena stratified. As noted previously, this is a design concern because of the large temperature gradients which could cause stress problems. In the upper plenum, the Richardson number (based on the core barrel diameter) for those tests varied between 56 and 99, an indication that the thermal-buoyancy forces are much larger than the inertia forces in the upper plenum. The Reynolds number (based on the core barrel diameter) for these tests varied between 4307 and 6374, an indication that the flows are turbulent. In the lower plenum, the Richardson number (based on the radial-gap diameter outside the radial shield) varied between 181 and 206 for these tests, an indication that the thermal-buoyancy forces are also much larger than the inertia forces in the lower plenum. The Reynolds number (based on the radial-gap diameter outside the radial shield) varied between 999 and 1307, an indication that the flows in the lower plenum were laminar for these tests. Threshold values of the Richardson number below which stratification does not exist could not be determined from these tests for either the upper or lower plena. Additional testing is needed to determine these important threshold values. 


\subsection{Phase II}

- A series of five prototypic transients, as agreed upon with GE, was successfully completed on schedule. These tests utilized all the capabilities of the Advanced Reactor Test Facility checked out in Phase I.

- The results of AU0701 of Phase I and AP2001 of Phase II, the transient simulation of the reduction of power from 100 to $25 \%$ are generally in agreement. The addition of the heat sink capability in Phase II did not reveal any new concerns. There was no stratification in either the upper or lower plenum. The Richardson number that was based on the core barrel diameter, which is relevant for the upper plenum, was approximately 4.0. The Richardson number (based on the radial-gap diameter outside the radial shield), which is relevant for the lower plenum, was approximately 6.4. Both values are small, indicating that thermal-buoyancy forces are small compared to the inertia forces.

- The threshold Richardson number (based on the core barrel diameter) below which stratification does not occur in the upper plenum is now bracketed by 4.0 on the lower bound (from tests AU0701 and AP2001) and by 56.0 on the upper bound (from JY2801 of the mixed naturalforced convection Phase I tests).

- The maximum time rate of change of temperature was very smal1 in PRISM during each of the five transients of Phase II and should not pose any thermal stress concerns.

- The simulation of transient $B-1 A$, a reactor trip from full power with maximum decay heat, indicates the existence of some stratification in the upper plenum for a short period of time initial1y $\left(3.73^{\circ} \mathrm{C}\right.$ in the model corresponding to $76.2^{\circ} \mathrm{C}$ in the prototype), no stratification in the lower plenum, and a generally favorable coolability of the entire model after the scram.

- The simulation of transient B-3B, loss of power to one primary pump, indicates the existence of some stratification in the upper plenum for a short period of time initialiy $\left(2.78^{\circ} \mathrm{C}\right.$ in the model corresponding to $61.6^{\circ} \mathrm{C}$ in the prototype), no stratification in the 
lower plenum, and a generaliy favorable coolability of the entire model after the scram.

- Reverse flow in the shut down pump during transient B-3B, corresponding to the loss of power to one primary pump, was observed during portions of the transient as the relative strengths of the buoyancy and inertia forces changed. The presence of reverse flow in the shut down pump may cause design problems in that overall reactor coolability is affected and reverse flow of cold fluid from the lower plenum may create large temperature gradients, causing stress concerns. As a consequence, this transient is suggested as a potential candidate for simulation by COMMIX-1A as part of the code validation effort.

- The simulation of transient B-5B, loss of feedwater to all modules supplying one turbine, with scram after steam generator dryout, indicates existence of some stratification in the upper plenum for a short period of time initially $\left(3.02^{\circ} \mathrm{C}\right.$ in the model corresponding to $66.9^{\circ} \mathrm{C}$ in the prototype), no stratification in the lower plenum, and a generally favorable coolability of the entire model after the scram.

- The simulation of transient B-5B, loss of feedwater to all modules supplying one turbine, with 30-s-delayed scram, indicates that there is some stratification in the upper plenum for a short period of time initially $\left(3.04^{\circ} \mathrm{C}\right.$ in the model corresponding to $67.3^{\circ} \mathrm{C}$ in the prototype), no stratification in the lower plenum, and a generally favorable coolability of the entire model after the scram.

- Among each of the last four transients (see Table VII) the model Reynolds number that is based on the core diameter ranged between 2070 and 3759 (corresponding to 45000 and 81718 in the prototype), indicating that the flow in the upper plenum is in transition from laminar to turbulent. The much larger values of Reynolds numbers in the prototype compared to those in the model are a result of the choice of satisfying Richardson number similarity and of size scaling. Under these conditions Reynolds number similarity is very difficult to achieve. Since the Reynolds numbers in the model are not laminar, but are in the transition range, the present results are 
reasonable indications of what is occurring in the prototype. A computer code simulation of these transients (i.e., using COMMIX), validated with the data from these transients, would establish greater confidence. The Richardson number (based on the core diameter) ranged between 87 and 549 for these tests, an indication that the buoyancy forces are much larger than the inertia forces in the upper plenum. This, together with the buoyancy forces opposing the inertia forces, gives rise to stratification in the upper plenum.

- Steady-state flow patterns in the UIS region indicate a slowiy rotating body of fluid within the UIS, with some fluid near the slot being entrained by the flow in the annular gap around the UIS. There may not be enough flow through the UIS to locate the source of fission product release, i.e., additional flow holes in the top and bottom of the UIS may be necessary.

\subsection{Phase III}

Current1y, an updated UIS mode1, which is much more detailed, is being constructed for Phase III testing. Phase III testing, which will begin March 1, 1988, will consist of generic natural convection tests with operational heat sinks, generic mixed forced-natural convection tests with operational heat sinks, and RVAC tests. The generic natural-convection tests with operational heat sinks are important to establish the coolability of the PRISM design at various power levels during steady-state operation. The generic mixed forced-natural-convection tests with operational heat sinks are important to establish the coolability of the PRISM design at various power levels and low-flow during steady-state operation. And finally, the RVACS cooling tests are important to establish the inherent safety of PRISM with respect to its passive RVACS cooling. In order to conduct the RVACS cooling tests, the windows around one-half the circumference of the model will be removed and replaced with stainless steel inserts. Copper coils will be mounted on the half of the containment vessel with no plastic windows. The containment vessel will then be insulated from the ambient air. Thus, various known levels of cooling at the containment vessel wall can be applied and the internal flow and temperature fields can be monitored. The test details for Phase III will be determined in conjunction with GE. The results of Phase III 
will be reported by 0ctober 1988. If there is time during testing, lower priority tests will be conducted. Such lower priority tests are additional constant-flow thermal-upramp tests to determine the threshold value of Richardson number below which stratification does not occur in the lower plenum. Similarly, a new series of constant-flow thermal-downramp tests would be conducted to determine the threshold Richardson number for the upper plenum when the buoyancy forces oppose the inertia forces in the upper plenum. Determination of these theshold values of Richardson numbers for the upper and lower plena would al low the designers to determine under what kind of transients they would or would not have stratified plena.

\subsection{ACKNOWLEDGMENT}

We are thankful to T. M. Kuzay for his helpful collaboration, to A. Hunsbedt (GE) for his timely and helpful inputs, to F. J. Piotrowski, A. Mele, and W. Brewer for their efforts in the operation of the MCTF, development of instrumentation, and fabrication of the test section, and to C. A. Bertino for typing this manuscript.

\subsection{REFERENCES}

1. Kasza, K. E. and Colwe11, W. S., "Characterization of the Temperature Fluctuations Generated In a Thermal Mixing Tee (Sodium Versus Water Behavior)," ANL-CT-78-2 (November 1977).

2. Kasza, K. E., Chen, M. M., and Binder, M. J., "Initial Considerations on the Inf 7uence of Thermal Buoyancy on Heat Exchanger Performance," ANL-CT-78-47 (August 1978).

3. Kasza, K. E. and Chen, M. M., "Tube Bundle/Tube Side (Parallel Channel) Thermal Buoyancy Induced Flow Maldistribution and Instability During Thermal Transients," ANL-CT-80-9 (December 1979).

4. Kasza, K. E., Bobis, J. P., Lawrence, W. P., and Liljegren, J. C., "Thermal Transient Induced Pipe Flow Stratification: Phase I," ANL-CT-80-25 (June 1980). 
5. Kasza, K. E., Bobis, J. P., Lawrence, W. P., and Liljegren, J. C., "Thermal Transient Induced Pipe Flow Stratification Phenomena and Correlations: Phase II," ANL-CT-81-19 (February 1981).

6. Kasza, K. E., Bobis, J. P., Lawrence, W. P., and Kuzay, T. M., "HeatExchanger Therma1-Buoyancy Effects: Design and Performance Comments (Phase I)," ANL-CT-81-31 (Apri1 1982).

7. Kasza, K. E. and Kuzay, T. M., "Thermal Transient Induced Pipe and Elbow Flow Stratification Phenomena and Correlation (Phase-III), "ANL-82-85 (October 1982).

8. Oras, J. J. and Kasza, K. E., "Periodic Large-Amplitude Thermal Oscillations Occurring in a Buoyant Plume," Trans. Am. Nucl. Soc., Vol. 45 (1983).

9. Oras, J. J. and Kasza, K. E., "Thermal Buoyancy Phenomena at Reactor Pipe/Plenum Interfaces: Phase I - Overview and Pipe Backflow Correlation," ANL-83-106 (October 1983).

10. Oras, J. J. and Kasza, K. E., "Thermal Transient Induced Buoyant Flow Channeling in a Vertical Steam Generator Tube Bundle," ANL-83-109 (October 1983).

11. Kasza, K. E., Kuzay, T. M., and Oras, J. J., "Overview of Thermal Buoyancy Induced Phenomena in Reactor Plant Components," Third International Conference on Liquid Metal Engineering and Technology in Energy Production, Oxford, England (April 9-13, 1984).

12. Kasza, K. E., Kuzay, T. M., and Oras, J. J., "Overview of ThermalBuoyancy-Induced Phenomena in Reactor Plant Components, "Symposium on Fluid Dynamics, Univ. of 111. (April 26-27, 1984).

13. Oras, J. J. and Kasza, K. E., "Thermal Laminarization of a Stratified Pipe Flow," Trans. Am. Nucl. Soc., Vol. 46 (1984). 
14. Oras, J. J. and Kasza, K. E., "Mitigation of Thermal Transients by Tube Bundle Inlet Plenum Design," Trans. Am. Nuc1. Soc., Vol. 46 (1984).

15. Kasza, K. E., Oras, J. J., Kuzay, T. M., and Lin, H., "Thermal Buoyancy Effects in Reactor Plant Components: An Update on Recent ANL/MCTF Studies," 4th IAHR Specialists Meeting on Liquid Metals ThermalHydraulics, Westinghouse Hanford - Richland, Washington (July 31 August 3, 1984).

16. Oras, J. J. and Kasza, K. E., "The Use of Laser Flow Visualization Techniques in Reactor Component Thermal-Hydraulics Studies," Trans. Am. Nuc1. Soc., Vol. 47 (1984).

17. Oras, J. J., Kasza, K. E., and Lin, H. C., "Thermal Transient-Induced Buoyant Flow Channeling in a Vertical Steam Generator Tube Bundle: Effect of Inlet Plenum Design and Validity of 1-D Modeling," ANL-8-97 (October 1984).

18. Kasza, K. E., Oras, J. J., and Kolman, R., "Measurement of Velocity Profiles in a Stratified Pipe Flow Recirculatory Shear Zone Using Laser Flow Visualization," Trans. Am. Nucl. Soc., Vol. 48 (1985).

19. Kuzay, T. M., unpublished data (March 1986).

20. Halfen, F. J. and Baig, K., "PRISM Plant Transient Analys is," General Electric Company Report, GEFR-00755 (August 1985).

21. Halfen, F. J. and Switick, D. M., "PRISM Plant Transient Analysis," General ETectric Company Report, GEFR-00791 (September 1986).

22. Hunsbedt, A., personal communication, General Electric Company (19861987). 